Windmills and Landfills: Framing Controversial Environmental Policies as a Risk to Human Health and Conflict Expansion Strategies

\author{
by
}

Adam Thorn

M.A. Political Science, University of Western Ontario, 2008

B.A. (Honors) Political Science, University of Western Ontario, 2007

\author{
A Dissertation \\ presented to Ryerson University \\ in partial fulfillment of the \\ requirements for the degree of \\ Doctor of Philosophy \\ in the Program of \\ Policy Studies \\ Toronto, Ontario, Canada, 2016 \\ (C) Adam Thorn 2016
}




\begin{abstract}
AUTHOR'S DECLARATION
I hereby declare that I am the sole author of this dissertation. This is a true copy of the dissertation, including any required final revisions, as accepted by my examiners.

I authorize Ryerson University to lend this dissertation to other institutions or individuals for the purpose of scholarly research

I further authorize Ryerson University to reproduce this dissertation by photocopying or by other means, in total or in part, at the request of other institutions or individuals for the purpose of scholarly research.
\end{abstract}

I understand that my dissertation may be made electronically available to the public. 


\title{
Windmills and Landfills: Framing Controversial Environmental Policies as a Risk to Human Health and Conflict Expansion Strategies
}

\author{
Doctor of Philosophy, 2016 \\ Adam Thorn \\ Policy Studies \\ Ryerson University
}

\begin{abstract}
Conflicts about environmental policies are often focused on the risk to human health posed by a facility or technology. Genetically modified food, oil pipelines, and pesticides are examples of policy issues that have generated tremendous debate related to human health and safety. A key focus of scholarship on such contested policy debates places an emphasis on how these policies are framed, how framing alters the policy process and in turn alters policy outcomes. This research project asks how and why the framing of a policy as a threat to human health influences the policy process and policy outcomes? To answer this question, two case studies of environmental conflicts related to controversial facilities are examined and compared: a waste landfill conflict and a large wind energy conflict. This dissertation seeks to integrate an understanding of the role of risk into theories of public policy by building on the approach to analyzing policy conflicts developed by Sarah Pralle. By using a mix of qualitative, quantitative and process tracing methods in these two cases, this research seeks to understand the role of risk frames in conflict expansion strategies and how such frames are used to include new actors and institutions and thereby alter policy outcomes. The key finding in this study reveals the relationship between the framing of a policy as a threat to human health, the institutional venues in which that policy is contested, and the incentives for strategic venue-shopping these produce. When policy actors are able to successfully frame a facility as a threat to human health, they are able to shift the conflict over that facility to an institutional venue that does not privilege expert
\end{abstract}


understandings of risk. This venue shift opens the opportunity to defeat the facility in a venue more open to non-expert understandings of risk. This finding is not only theoretically important but should serve as warning that institutional venues such as environmental assessment processes that restrict the consideration of risk to expert based assessments will only incentivize opponents to seek out new venues in which to pursue their goals. 


\section{Acknowledgments}

Like raising a child, it takes a village to complete a dissertation.

My supervisor Carolyn Johns has been a mentor and advocate throughout my $\mathrm{PhD}$. Carolyn always manages to achieve the perfect blend of patience, encouragement, and gentle criticism always leavened with humor. She is a model scholar and mentor that I now have the intimidating responsibility of trying to emulate.

My committee members, Christopher Gore and Duncan MacLellan, were essential to my success. Chris always asks the tough questions I am trying to avoid but does so with good humor and encouragement. Duncan is unfailingly generous with his time and advice and was always cheerful about reading draft after draft (after draft). Selection of this committee was my one flash of brilliance during my doctoral studies.

Thank you also to Sarah Pralle, the external examiner, for her detailed comments and thoughtful questions and Corey Searcy, the Ryerson internal examiner for challenging my assumptions.

This work would not have been possible without the support of my wife Erin. Her sense of humor, wisdom, and ever-supportive patience, has made this project not only possible, but also somehow enjoyable. We are partners in every sense of the word and this work belongs as much to her as to myself. My daughters Abigail (never Abbey) and Elly (sometimes Eleanor) never let me forgot where my real priorities lie and are daily reminders of why environmental research is important.

My family has always been my biggest boosters. My parents, Ted and Sharon Thorn, always made learning a priority and this may have finally paid off. My brother and sister-in-law, Tyler and Eileen Thorn, and their children Rebecca and Jacob, always proved a welcome antidote to academic drudgery. Dave and Nola Harvey were unfailingly generous in their support and understanding of their son-in-law's strange decision to return to graduate school. My brother and sister in law, Brad and Shauna Boitson, nephews Nolan and Jared, and niece Sarah were always a welcome distraction during visits from the west.

My fellow students in the Policy Studies program at Ryerson have made my time in the program a rich and intellectually stimulating time. I would especially like to thank Frederica Gomes for her support throughout our time together. Shared pain always seems easier to bear.

The Policy Studies program faculty and Politics department faculty at Ryerson University have always been generous with their time, support, and encouragement. I would like to thank Tracey Raney in particular for her mentorship. The departmental staff, especially Mary Beth Kraay was always supportive, even when asked endless, probably nonsensical questions. 
I also wish to acknowledge all those that agreed to participate in my research as interview subjects, survey respondents, or informal sources. Many people generously shared their time and knowledge and this project would not have been possible, or at least as interesting, without them.

Finally, to my students at Ryerson University who unfailingly remind me I have more to learn. 


\section{Table of Contents}

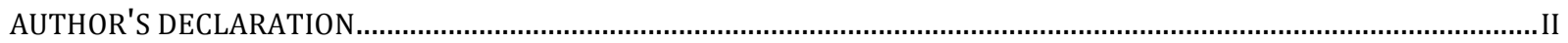

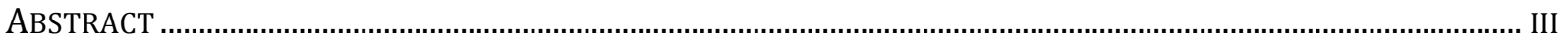

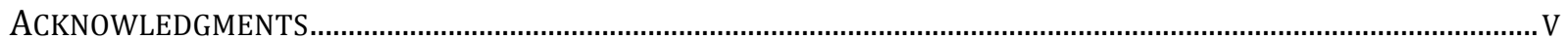

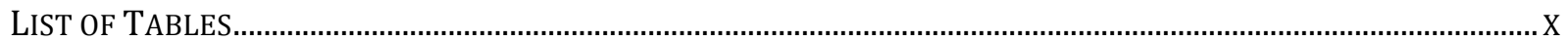

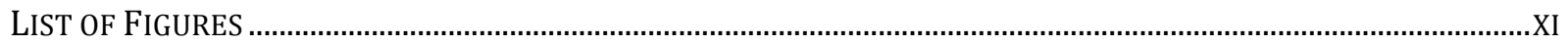

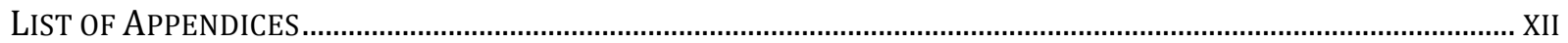

CHAPTER 1 - INTRODUCTION

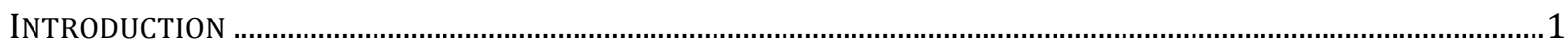

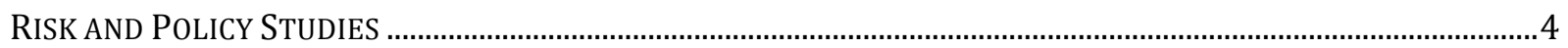

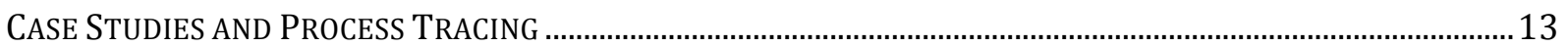

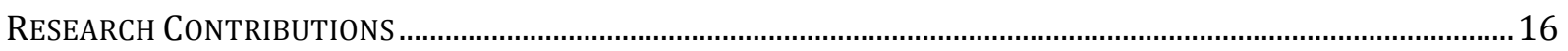

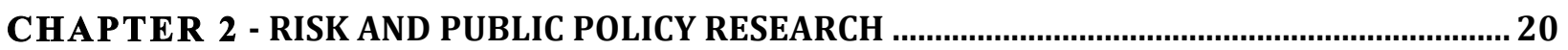

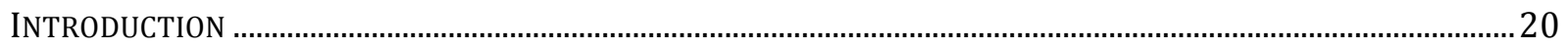

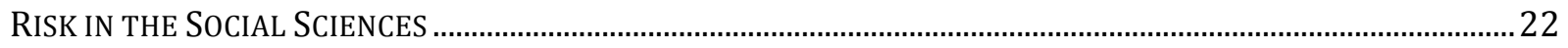

Risk Communication, Social Amplification of Risk, and Land-use Conflicts .........................................24

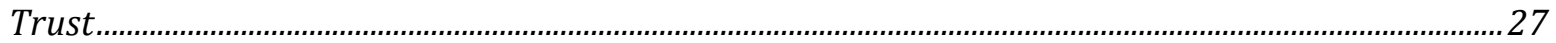

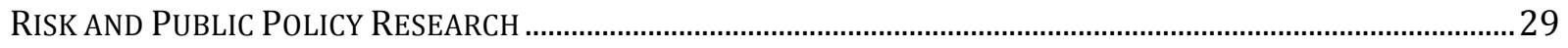

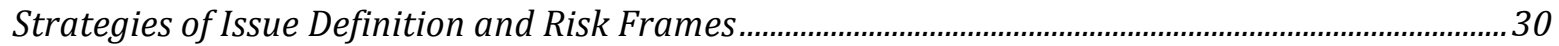

Strategies of Actor Participation and the Role of Actors in Policy Conflicts........................................38

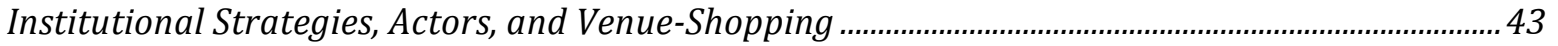

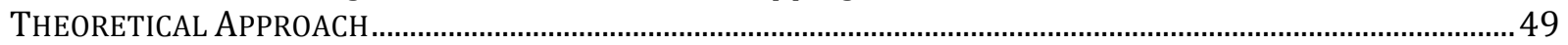

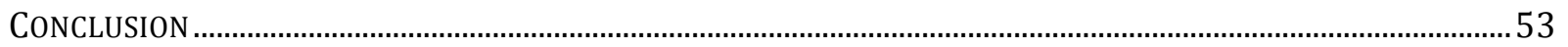

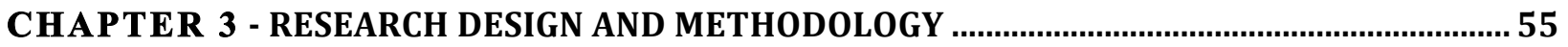

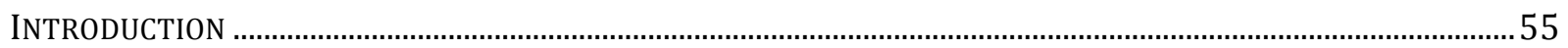

RESEARCH DESIGN: CASE STUDIES AND PROCESS TRACING................................................................................5

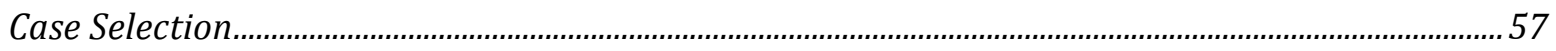

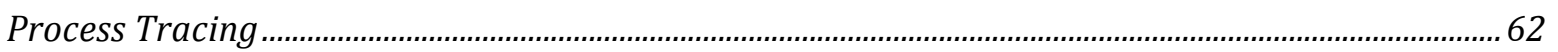

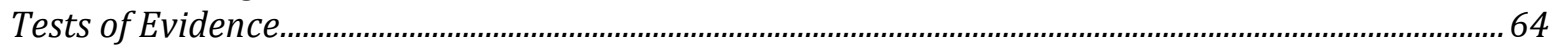

CONFLICT EXPANSION: TRACING CAUSES TO OUTCOMES ................................................................................. 65

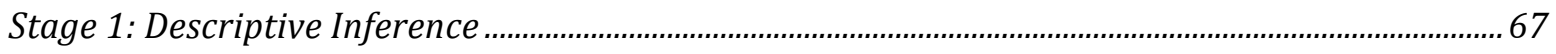

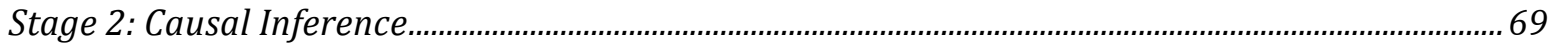

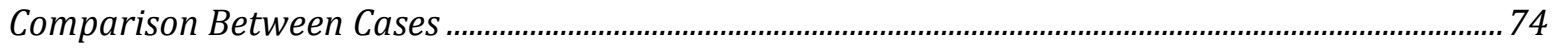

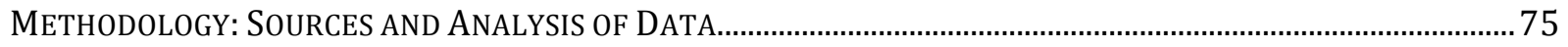

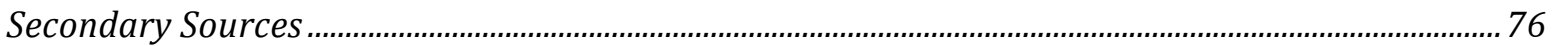

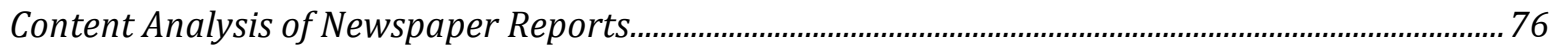

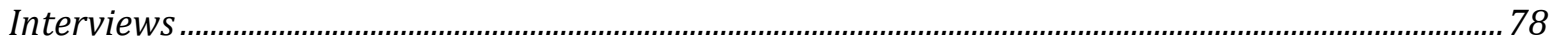

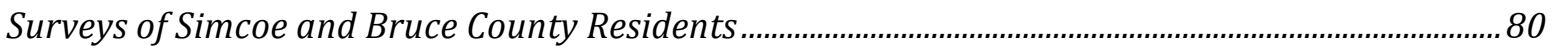

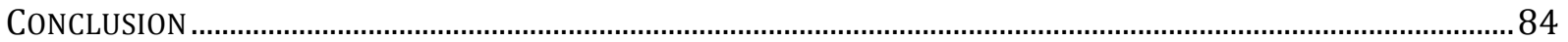

\section{CHAPTER 4 - POLICY CONFLICTS AND THE FRAMING OF RISK: EVIDENCE FROM A LAND}

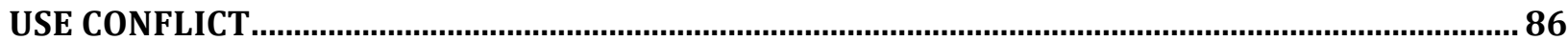

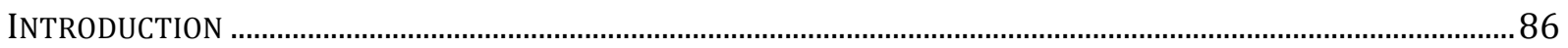

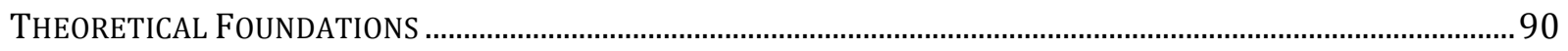

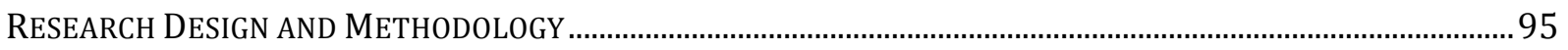

The CASE STUdY: SitE 41 In Simcoe CounTY, ONTARIO, CANADA.................................................................... 98

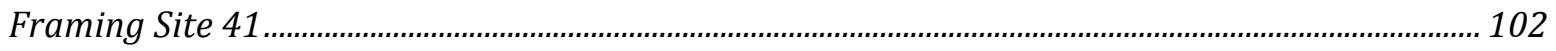


Expanding the Conflict: Actor Strategies, Site 41 and Participation................................................... 107

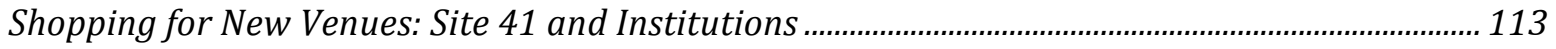

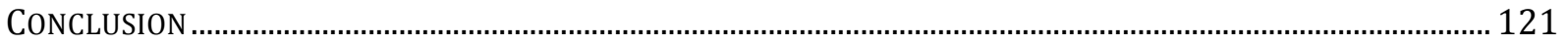

\section{CHAPTER 5 - WIND POWER IN ONTARIO: RISK, TRUST, AND THE ROLE OF INSTITUTIONS}

\begin{tabular}{|c|}
\hline INTRODUCTION \\
\hline THEORETICAL APPROACH \\
\hline Social Acceptance.......... \\
\hline 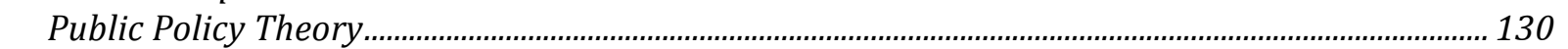 \\
\hline 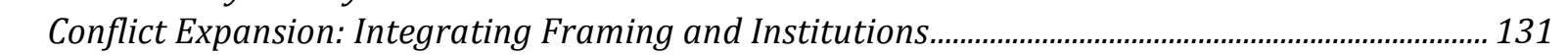 \\
\hline METHODOLOGY \\
\hline CASE STUDY: THE KINCARDINE WIND FARM \\
\hline 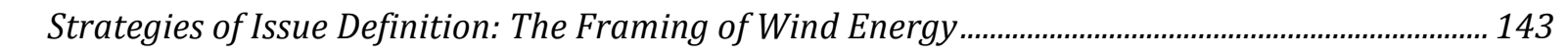 \\
\hline Strategies of Actor Participation \\
\hline 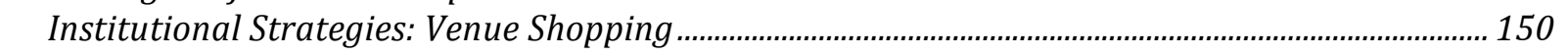 \\
\hline PostScript: The Green Energy Act, 2009 and Framing Wind Energy \\
\hline ONCLUSION \\
\hline
\end{tabular}

\section{CHAPTER 6 - THE STRATEGIC USE OF RISK IN PUBLIC POLICY CONFLICTS: EXPANDING}

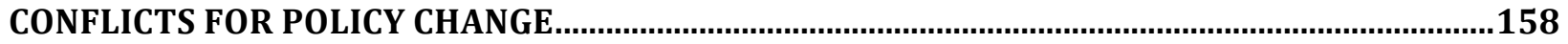

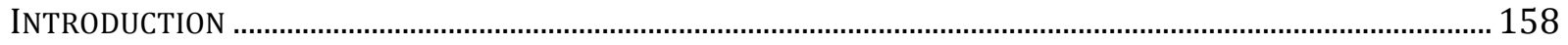

THEORETICAL APPROACH: RISK AND PUBLIC POLICY THEORY …….................................................................... 161

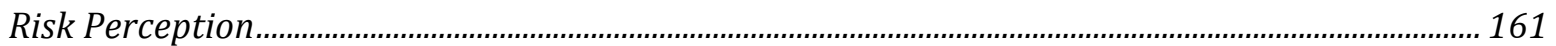

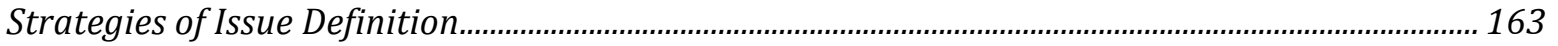

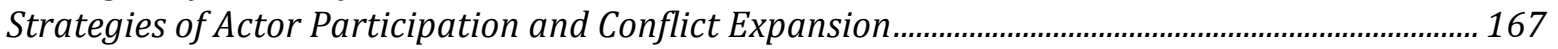

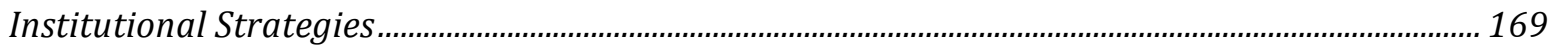

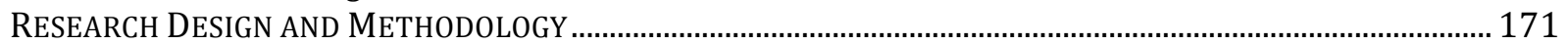

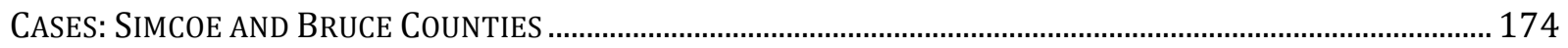

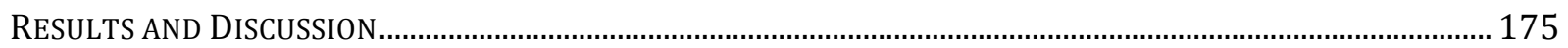

Issue Definition: Risk to Human Health ............................................................................................. 175

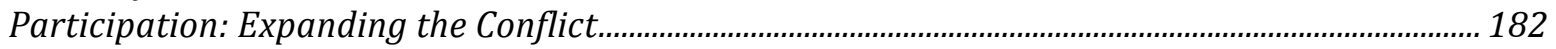

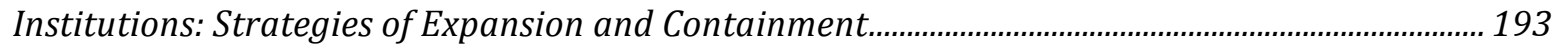

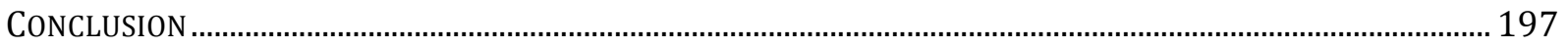

CHAPTER 7 - RISK, VENUE SHOPPING AND INSTITUTIONS: EXPLORING THE RELATIONSHIP BETWEEN PROBLEM DEFINITION AND VENUE SHOPPING IN TWO LAND USE CONFLICTS ...200

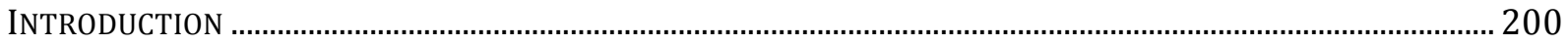

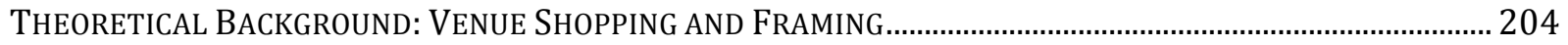

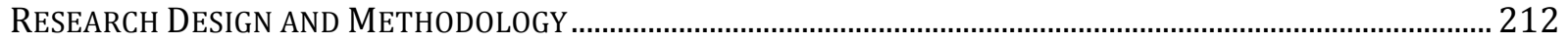

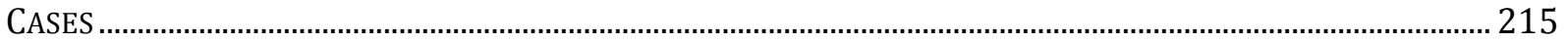

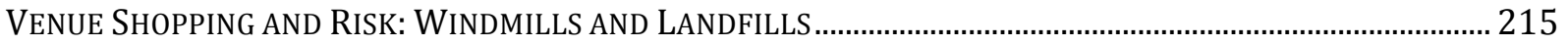

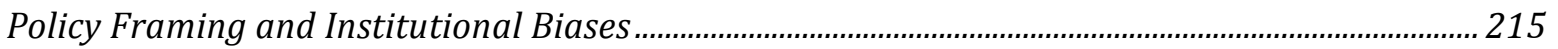

Shopping for New Venues: From EA Processes to Municipal Politics................................................. 224

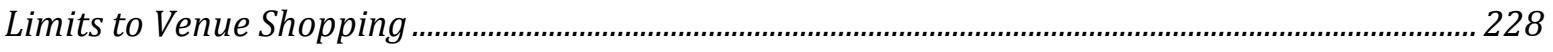

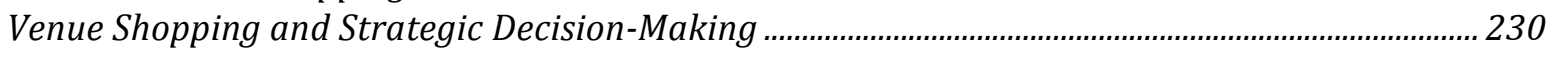

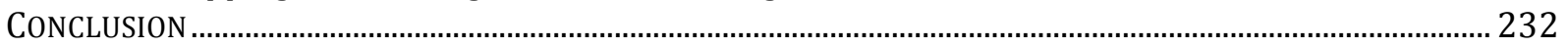

CHAPTER 8 - CONCLUSION

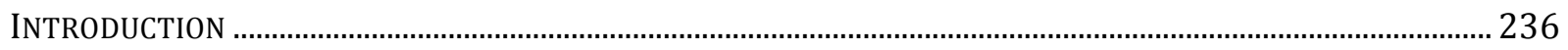

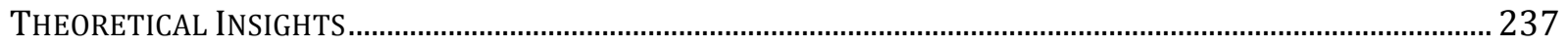

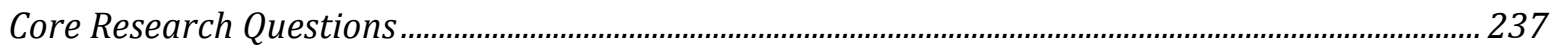




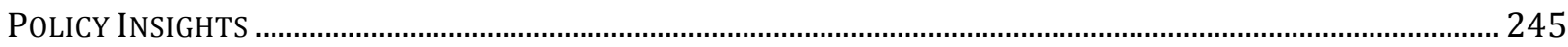

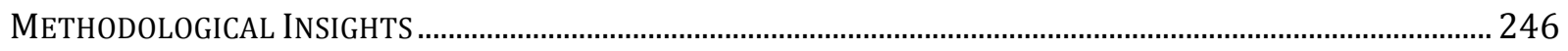

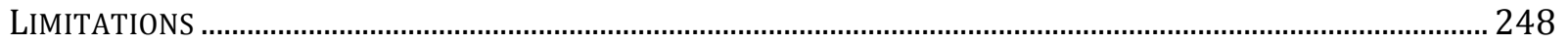

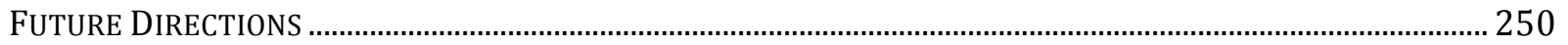

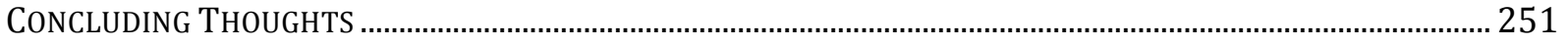

APPENDICES

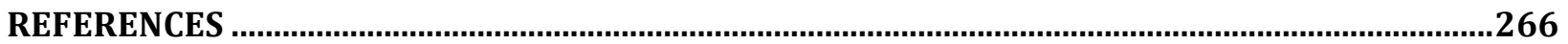




\section{List of Tables}

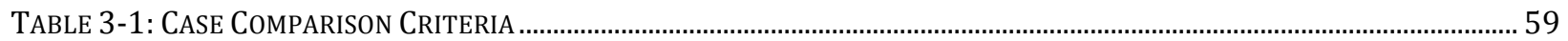

TABLE 3-2 TESTS OF OBSERVABLE IMPLICATIONS OF THEORY IN PROCESS TrACING (VAN EVRA, P. 31 )................................. 65

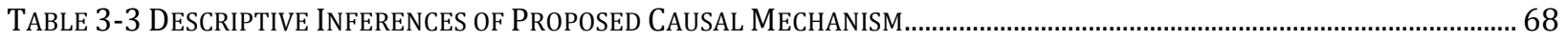

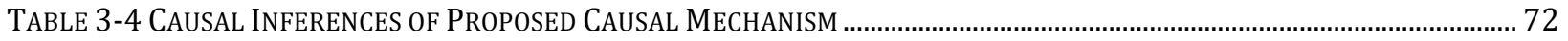

TABLE 3-5: NUMBER OF INTERVIEW SUBJECTS BY POSITION .................................................................................................... 80

TABle 4-1 Percentage of Media Reports that InClude at LEAST Single OF Supportive OR Oppositional Frames

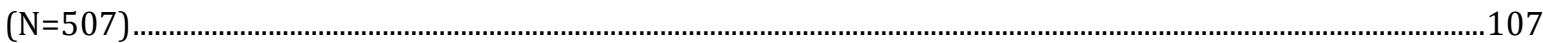

TABLE 4-2 RELATIONSHIP BETWEEN PROXIMITY TO SITE 41 AND OPPOSITION.........................................................................111

TABLE 4-3 RELATIONSHIP BETWEEN RISK, OPPOSITION, AND INFLUENCE ON VOTING PREFERENCES....................................113

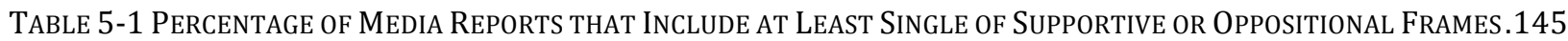

TABle 5-2 Comparison Between 2006 and 2010 Surveys Reporting Support For Wind FARMS In BRuCE County 148

TABLE 5-3 EFFECTS OF RISK ON OPPOSITION TO WIND FARMS, PARTICIPATION, AND VotING .................................................149

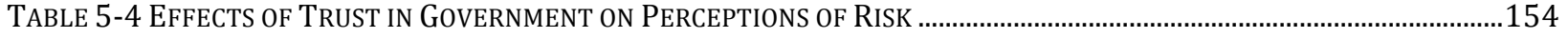

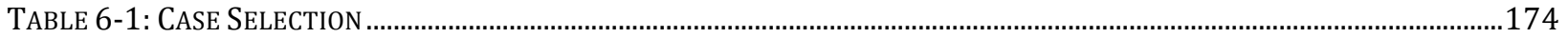

TABle 6-2 Change OVER Time of MEdia Reports that InClude AT LEAST Single MENTION OF HEALTH RiSK Frame....178

TABLE 6-7: COMPARISON OF THE HEALTH RISK FRAMES .................................................................................................186

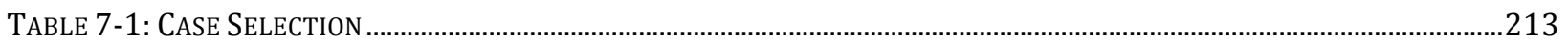

Table 7-2 Percentage of Media Reports that InClude at Least Single Mention of Oppositional Frames............218 


\section{List of Figures}

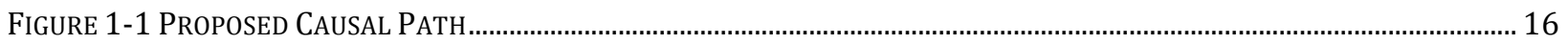

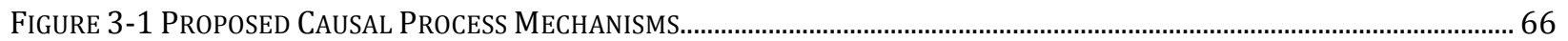

FiguRE 4-1 MAP OF SiMCOE CounTY (SIMCOE CoUnTY, N.D.) ………………………................................................................ 99

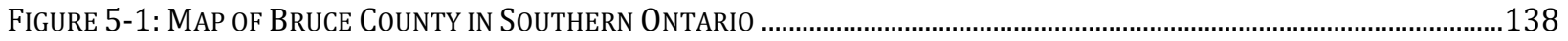

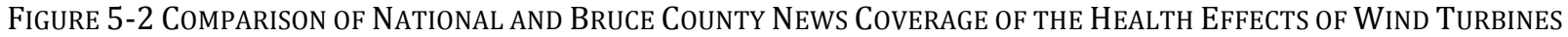

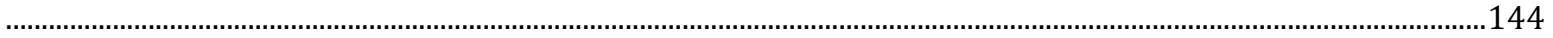

FIGURE 8-1: FRAMEWORK FOR ANALYZING HEALTH RISK POLICY CONFLICTS .............................................................................24 


\section{List of Appendices}

APPENDIX A: INTERVIEW DOCUMENTS ........................................................................................... 252

APPENDIX B: SURVEY DOCUMENTS ............................................................................................... 254 


\section{Chapter 1 - Introduction}

\section{Introduction}

From the early 1980s to 2010, an intense conflict in Simcoe County, Ontario divided the community. Simcoe County is a largely rural area of about 440,000 residents north of Toronto, Ontario. The County of Simcoe borders over 500 kilometers of shoreline on the Great Lakes, which leads to relatively high levels of tourists and seasonal residents. The conflict focused on the potential contamination of local water by a proposed solid municipal waste landfill called Site 41. Simcoe County, which was the proponent, characterized the risk of contamination as low and approved the project as a low cost means of meeting the need for local waste disposal. Opponents of the project characterized the risk of water contamination as high and organized a campaign of opposition to the project. The conflict continued even after construction had begun and it saw protests, sit-ins, and the arrest of protestors. It garnered the attention of activists from outside the region and generated intense animosity. In 2010, after significant expenditure of resources, the project was halted and the Simcoe County council withdrew approval.

In 2003, a large wind turbine facility was proposed by a private energy company for the municipality of Kincardine in Bruce County, Ontario. Bruce County is a largely rural region of Ontario, Northwest of Toronto and on the shores of Lake Huron and Georgian Bay with a population of just over 66,000 people. Once the project was proposed, opponents of the facility engaged in advocacy against the project that focused on the possible negative health effects of wind turbines. There was significant local media attention and opponents attempted to stop the facility through protests and legal 
challenges. However, unlike Site 41 these opponents to the project were ultimately unsuccessful and the Kincardine wind farm was completed in 2009.

The proposed projects in Simcoe and Bruce Counties both became divisive conflicts within their regions. These conflicts focused on land use decisions but more importantly, both conflicts hinged on different perception of risks posed by each facility. In Simcoe County, proponents of the landfill argued it was a relatively low risk and cost effective way to manage municipal solid waste. Opponents of the proposal suggested that the facility was a fundamental and unacceptable risk to local drinking water. In Bruce County, proponents of the wind turbine facility argued it was a low risk and clean energy technology that would benefit the local and provincial economies. Opponents suggested it was a threat to the health of those living near turbines because of the sound and vibration caused by the spinning turbine blades. Opponents and proponents of these facilities presented different understandings of the risk to human health posed by each of these facilities.

In both of these conflicts, opponents focused their opposition on the potential threat to human health. While there is no doubt that for many there was a genuine belief that these facilities posed a risk, it was also a strategic decision made by groups opposing these facilities to focus on the potential threat to human health in their opposition campaigns. Most public policies can be contested across a wide array of potential issues. Economic concerns such as the efficiency of a given policy choice are often central. That opponents would choose to focus on the health concerns is not surprising given the potential strategic value of these frames. But why was it successful in one conflict and not the other? This question can be broadened to ask how do issues framed as risks to 
human health influence the outcome of a policy process? In both of these cases, the decision to focus on the potential risk to human health posed by these facilities prolonged the conflicts and drew in a much wider constellation of actors than would have been the case if the focus of the conflict had been focused on property values or aesthetic concerns.

While interesting cases of conflict in their own right, these cases are examples of a broader trend. Conflicts over risk are, in fact, becoming ubiquitous. Genetically modified food, vaccinations, oil pipelines, and pesticides are examples of policy issues that have generated tremendous debate around their relative safety to humans. What is common to these conflicts is that expert assessments of the risk posed by these technologies are unlikely to satisfy opponents. While a panel of experts or an environmental assessment tribunal might approve a technology or specific facility as safe, there are still significant groups of actors that dispute these findings on the grounds that the technology or facility poses an unacceptable threat to human safety. In the conflict over Site 41, opposition actors were able to overcome the initial approval of Site 41 through a long political conflict. In the conflict over the Kincardine Wind Farm this was not the case. This dissertation focuses on the central question of why the opposition strategy of framing these facilities as a threat to human health was successful in one case but not the other. The central focus is therefore on the competing understandings of the risk posed by each facility advocated by proponents and opponents and therefore understanding the role that risk might play in the policy process is essential. 


\section{Risk and Policy Studies}

The recognition that policies that threaten basic values often lead to conflict is certainly not new (Booth and Harrison 2009; Leiss, 2001; Stone, 1989). Risk has been a central issue in many public policy studies, particularly environmental policy studies (Caduff and Bernauer, 2006; Harrison, 1991; Harrison and Hoberg, 1991; Legge and Durant, 2010; Montpetit, 2011; Montpetit and Rouillard, 2008; Zerbe, 2007). Risk to human health touches perhaps the most basic of human values and it is no surprise that conflicts over risk should generate intense emotions. While risk has been a component of policy research, less attention has been paid to systematically integrating risk into theories of the policy process. This is primarily due to the disciplinary boundaries that separate much of the literature about risk (psychology, sociology, risk assessment) and policy studies as well as the often issue specific analysis of many policy studies that include risk as a component. Given the seemingly inevitable growth of risk conflicts, this lacuna is unfortunate. This dissertation proposes a framework for integrating the role of risk into theories of the policy process. It focuses on the role that competing definitions of the policy problem - the degree of risk of a given undertaking - plays in the agendasetting phase.

Conflict is a central concept in political studies generally and policy studies specifically. However, it is rarely explicitly defined. The definition of conflict used here is "a perceived divergence of interest, or a belief that the parties current aspirations

cannot be achieved simultaneously" (Rubin et al., 1994). Risk conflicts (like most policy 
conflicts) require at least two individuals or parties who have divergent interests, and that these actors or groups of actors must take actions to advance their interests. Actors or parties who perceive divergent interests but take no actions are not involved in a conflict. This is how we make the distinction between direct participants in a conflict and the attentive public. Actors with divergent interests may be organized into groups, which will be institutionalized to different degrees.

What separates a risk conflict from other forms of policy conflict is the centrality of divergent understandings of risk posed by the policy. While different perceptions of risk may not be the only focus of the conflict, for example economic considerations will almost always play some role, risk will be the central problem definition advanced by at least one (most often the opponent) group of actors. In response, another group of actors (most often the proponent) will at least deny the perception of risk presented and will present an alternative conception. In these conflicts, risk cannot be understood as only a technical concept but is also socially constructed, so resolution of these conflicts will not be simply based solely on expert assessment of these risks. Divergent perceptions of risk therefore become an important way of understanding the arguments advanced by the proponents and opponents of a particular policy. The goal of this dissertation is to understand the degree to which framing a policy as a threat to human health changes the nature of the conflict in which it is deployed.

Risk conflicts are the unit of analysis of this dissertation and define the boundaries of the cases selected. Risk conflicts are the focus of the project, but to aid in analysis, a sub-set of these conflicts was selected. Land use conflicts, as a sub-type of risk conflict, offer a relatively bounded unit for study. They have a clear geographic center, a 
relatively identifiable set of participants, and the outcome, the completion of the facility, is easy to identify. The specific types of policy conflict that are of interest here are therefore conflicts over land use which are defined as a perceived divergence of understanding of the risk posed by an activity on a particular piece of property by two or more parties who engage in activities to further those divergent interests (Rubin et al., 1994). Each case selected for this study (land use for waste management and land use for wind energy) represents a conflict in which risk to human health became the central frame advocated by opponents.

The land use conflicts selected here form the basic unit of analysis of this dissertation. Defining the boundary of any case study can often be complex, as elements that may affect the outcome may not be contained within any easily identifiable spatial or temporal boundaries. Both cases are bounded geographically within the counties in which they occurred although in both cases, actors attempted to expand these conflicts beyond these boundaries. They also occurred at different scales as these conflicts were contested in both local and provincial institutions. The time span for both case studies began once the original project was proposed and ended when a facility was either completed or the proposal was defeated.

Within the study of public policy, there is no one dominant theoretical approach. While the policy stages approach has been critiqued as atheoretical, it is accepted by many as a useful heuristic for describing the process of policy formulation, implementation, and evaluation (Smith and Larimer, 2013). The stages heuristic is particularly useful for recognizing the fragmentation of public policy research. The fragmentation of the discipline is essentially based on the stages of the policy process, 
from problem recognition approaches such as agenda setting, through studies of how policy actually unfolds in implementation studies, to the evaluation of policy through program evaluation research. Any attempt to integrate conceptions of risk into public policy theory must contend with this fragmentation.

One consistent element studied in public policy decision-making are the role of institutions. Institutionalism has always been important in Canadian political science generally and policy research specifically, and the most dominant form has arguably been historical institutionalism (Smith, 2005). Institutionalism has become important enough to policy research that it has been credibly suggested "that policy studies can hardly produce convincing explanations without accounting for the role of institutions" (Montpetit, 2005, 226).

This research accepts the centrality of institutions but recognizes they are not sufficient for a full explanation of the role that competing conceptions of risk can play in exacerbating policy conflicts. The nature of the issues at the center of these conflicts risk to human health - will be demonstrated in this dissertation to be different than other types of policy issues. Any theoretical approach to understanding these conflicts needs to be capable of accounting for the distinct character of conflicts over risk. Approaches to policy studies that fall under the broad category of agenda setting recognize the importance of the interplay between a policy issue and the institutional structure within which that issue is decided.

Approaches for studying public policy that focus on the agenda-setting phase include the Advocacy Coalition Framework (ACF) developed by Sabatier and JenkinsSmith to understand the role of ideas and policy sub-systems (1988; 1993), the Multiple 
Streams approach developed by Kingdon (1995), and the theory of Punctuated Equilibrium developed by Baumgartner and Jones (1993). Each approach recognizes the centrality of ideas and the framing of a policy to the process of agenda setting. While all of the agenda-setting approaches offer valuable insights, this project adopts the conflict expansion approach developed by Sarah Pralle (2006) that builds on the conflict expansion literature (Cobb and Ross, 1997; Rochefort and Cobb, 1994; Schattschneider, 1960) and the theory of punctuated equilibrium originally developed by Baumgartner and Jones (1993).

The theory of punctuated equilibrium focuses on the agenda-setting phase of public policy. Baumgartner and Jones sought to develop a theory of policy change that could explain long-term stability, while also accounting for instances of abrupt and significant policy change (1993). They identified two concepts as essential: policy images and institutional venues. In order to explain policy stability, Baumgartner and Jones identify policy monopolies as groups of policy actors who are able to control a particular policy area for long periods of time. They do so by maintaining a dominant policy image, which is the political understanding of that policy, and through control of the relevant institutional venues that are crucial to that policy area (1993). Because of apathy or a lack of awareness of those not directly involved in the policy, monopolies are able to control these policy areas for long periods of time. This accounts for the long periods of policy stability observed in many policy areas.

Policy change can occur abruptly however, when policy monopolies are challenged. When policy actors become interested in that policy area, they will seek to challenge the dominant policy in order to capture the institutions crucial to decision- 
making in that policy area or move the decision-making to an institutional venue more receptive to their preferred policy image (Baumgartner and Jones, 1993). Which policy image will be the dominant one is therefore crucial to the outcomes of these policy conflicts. This project suggests that risk to human health can be a powerful contending policy image for overturning a policy monopoly. A policy monopoly occurs when a group of policy actors is able to maintain control of a decision-making around a policy or policy sector for long periods of time. They do so by controlling how that policy is framed, what Baumgartner and Jones call "a monopoly on the political understandings concerning the policy of interest", and through control of the relevant political institutions (Baumgartner and Jones, 1993, p. 4). If actors attempting to overcome a policy monopoly can create a perception of significant risk, they can overcome the consensus that helps maintain a policy monopoly.

Baumgartner and Jones have primarily focused their research on agenda setting and punctuated equilibrium on explaining long-term change in congressional behavior in the United States (1993). However, his research has now been applied in a number of contexts including comparative research (Baumgartner and Green-Pedersen, 2006; Boothe and Harrison, 2009). Sarah Pralle has developed an approach for understanding policy conflicts that builds on the agenda-setting and conflict expansion literatures and has been primarily applied to case studies (2006a). This approach recognizes that actors participating in a policy conflict have numerous strategies they can deploy to achieve their preferred outcome. To clarify analysis, Pralle has organized these strategies into three categories: strategies of issue definition, strategies of the expansion or contraction of participation, and institutional strategies (2006a). 
The first set of strategies focuses on issue definition. These are the strategies that can be deployed in order to raise or lower the salience of an issue to the public, policy actors and decision makers. By raising the salience of an issue, advocates of policy change hope to place the issue on the public agenda thereby providing the opportunity to overturn the existing policy monopoly. Controlling the way in which a policy issue is defined can provide significant advantages by controlling the scope of the issue, by claiming ownership of an issue, or by linking a previously low salience issue to a more salient one (Pralle, 2006a). This dissertation focuses on issue definition as the key to explaining the conflicts outlined above. As will be made clear, issues that can be framed as a risk to human health are particularly strong forms of issue definition that can significantly alter the nature of a conflict in which they are deployed. How and why this occurs is the central focus of this dissertation.

The second set of strategies focuses on the participation of actors around the policy (Pralle, 2006). When a policy is controlled by a policy monopoly, actors within that monopoly will seek to limit the participation of new actors in order to preserve their monopoly of the policy. Advocates of change will seek to draw in new actors in order to tip the balance and undermine the monopoly. In both cases analyzed in this dissertation, the reframing of the facility as a threat to human heath is the key to explaining the success of the strategies of actor participation deployed by the opponents of each facility.

The final set of strategies focuses on the role of institutions. Groups seeking policy change will often attempt to shift to institutional venues they believe will provide them with advantages relative to their opposition (Baumgartner and Jones, 1993; Boothe and Harrison, 2009). All institutions contain within them biases that advantage or 
disadvantage different actors operating within those institutions (Baumgartner and Jones, 1993, Boothe and Harrison, 2009). Actors will therefore seek to access or control the institutions that provide them with advantages relative to their opponents. As the analysis of the two cases presented in this dissertation will make clear, venue shopping is the key institutional strategy of the groups opposing each facility and is made possible by the framing of the two facilities as a threat to human health.

Advocates or opponents of policy change will therefore seek to deploy these strategies in order to expand or contain a policy conflict. Opponents of policy change will most often seek to maintain control of a policy by advocating an issue definition that does not attract new participants and by restricting decision-making to venues in which they have greater advantages. Proponents of policy change will seek to redefine a policy in a way that attracts more attention and will attempt to shift decision-making to venues that provide them with greater advantages (Baumgartner and Jones, 1993; Pralle, 2006; Rochefort and Cobb, 1994). This approach to understanding policy conflicts provides a strong analytical framework for understanding the deployment of risk in the conflicts described above because it focuses on the interrelationship between issue definition and the other strategies of conflict expansion (Pralle, 2006). This dissertation seeks to build on this approach by identifying how one form of issue definition - the risk to human health - can drive the success of the other strategies.

The above approach to understanding conflict expansion strategies in agendasetting conflicts provides both a specific set of testable propositions for understanding the role risk played in these specific conflicts as well as an opportunity to integrate risk into this theory of the policy process. The central unifying research question of this 
dissertation is how do issues framed as risks to human health influence the outcome of a policy process?

By applying Pralle's approach to this analysis, the above research question can be further specified by focusing on the strategies of actors involved in these conflicts. Because the framing of a policy as a threat to human health is a strategy of issue definition used by opponents of the facility, the question then becomes how does the use of that strategy influence the choice and success of strategies of participation and institutional strategies deployed by opponents within these conflicts? Given this approach, three hypotheses can be tested:

1. That the greater the acceptance of a risk frame (by the public or elite actors), the greater degree to which a conflict will expand to include new actors (public and elite).

2. That the more actors that are drawn into the conflict, the more opportunity there will be to pursue venue shopping strategies.

3. That the more opponents are able to engage in venue shopping, the greater the likelihood of altering the outcome of the conflict.

If these hypotheses are confirmed, it strongly suggests that risk to human health is a distinct form of issue definition that is more likely to lead to conflict expansion. This occurs through the expansion of the conflict to include new actors, which can create opportunities for opponents to engage in new institutional strategies and the potential for altering policy outcomes. If this is the case, then evidence exists that risk, and particularly human health risk, should be integrated into theories of agenda setting and conflict expansion. If framing a policy as a potential threat to human health is more effective at conflict expansion, then successfully deploying this frame is more likely to lead to policy 
change. Testing these hypotheses requires a methodology capable of revealing the causal links between each of these strategies of conflict expansion.

\section{Case Studies and Process Tracing}

The approach to studying conflict expansion proposed by Pralle (2006) is based on in-depth case studies of specific conflicts over public policy. This thesis adopts this approach. Case study research is used extensively in policy studies because they often provide in-depth understanding of historical events, which can aid in disentangling the complex causality of these events. The research design of this study receives extensive treatment in Chapter 3 but below is a brief discussion of the case selection criteria and introduction to the type of within-case analysis used in this dissertation.

Case selection in this study was based on the decision to include cases that varied on the independent and dependent variables. Selection on the dependent variable was necessary to ensure that both possible values on that variable, a proposed facility that was eventually defeated and one that was completed were included. Site 41 ended in defeat of the proposed facility and the Kincardine wind turbine farm was completed.

The cases also varied on the key independent variable of the health risk frame. In each case opponents opposed each facility based on a number of initial opposition frames but eventually coalesced around the health risk frame. The different health risks posed by each facility creates variation on the type of health risk frame which allows for the testing how these different frames influenced the outcome of each conflict (the dependent variable). The key difference in the frames was the type and scale of risk posed by each facility. The crucial question is whether the risk frame contributed to the different 
outcomes observed in each case? A comparison of why the risk frame contributed to the defeat of the facility in one case and not the other can help answer this question.

Any given policy conflict is a complex case being observed in a dynamic context with many variables at play, some which are difficult to isolate and control. However, indepth case study analysis can utilize a variety of methodologies and data sources to examine policy ideas, actors and institutions. This research project utilizes a form of case study analysis most commonly referred to as process tracing.

Process tracing has only recently begun to receive attention from policy scholars (Kay and Baker, 2014) but offers two advantages that make it particularly appropriate for policy studies. First, process tracing focuses on the causes of events by trying to reveal the mechanisms that transmit causality from independent to dependent variable. While causation is a central interest to many social researchers, policy scholars have a particular interest. Anytime we create public policy we are, at least implicitly, making a causal statement about the world. To create a carbon tax to reduce greenhouse gases is to assume a causal relationship between that tax and the hoped for reduction of greenhouse gas emissions. A form of analysis that focuses on causality should be a part of the policy studies toolkit.

Second, process tracing is a form of analysis that makes explicit the logic of descriptive and causal inference used. Good process tracing requires researchers to specify their theoretical assumptions and the data and evidence used to test those assumptions. Each step of a proposed causal explanation is specified and then tested using evidence that is specific to the expected relationship. In short, process tracing is inherently concerned with the openness of the research process. Openness of data and 
research design have become important issues in political science and analytic transparency is an important part of this new imperative (Moravcsik, 2014). Process tracing is well suited to transparency because each step of the research process is explicit. While the focus of this study is on explaining the cases selected using the theoretical framework of agenda setting and conflict expansion, this study is also a demonstration of the strengths and potential weaknesses of process tracing as a method for the study of public policy and the policy process.

Applying a process tracing method to the conflict expansion framework outlined by Pralle (2006) presents a challenge by making explicit the need to understand the causal path underlying the expansion of these conflicts. Each of the hypotheses detailed above must be understood as a step in a causal process from the framing of a facility as a threat to human health to the outcome of that conflict. If policy conflicts centered on risk to human health are distinctly different than conflicts over other types of policy issues than this is clearly a strategy focused on issue definition. If this is the case, then an observable causal linkage between strategies of issue definition and the other two sets of strategies outlined by Pralle (2006) is necessary. If risk to human health is the key issue strategy that changes the character of these conflicts, then that choice must also drive subsequent strategies and opportunities for drawing in new actors and institutional venues. Risk to human health as a policy frame helps opponents draw in new participants that might never have participated if the issue had remained about economic or aesthetic arguments. The participation of new actors opens the possibility of opponents shifting the conflicts to new venues in which they perceive they have some advantage. This opens the possibility of defeating the facility. This causal path is illustrated in Figure 1 below. 
Chapter 3 outlines the methodology and evidence used to test for this causal mechanism in each case.

Figure 1-1 Proposed Causal Path

Adoption
of a Risk
Frame $\longrightarrow \begin{gathered}\text { Expansion } \\ \text { to New } \\ \text { Actors }\end{gathered} \longrightarrow \begin{gathered}\text { Venue } \\ \text { Shift }\end{gathered} \longrightarrow \begin{gathered}\text { Defeat of } \\ \text { Facility }\end{gathered}$

\section{Research Contributions}

The cases and research questions examined in this thesis lead to a number of key findings. Chapter 2 presents a literature review and discussion of the key concepts that are analyzed in each of the case studies. Chapter 3 presents the research design, details on the case selection, and methodologies used to collect data related to the in-depth comparative case analysis. The empirical results of this dissertation are presented as independent chapters ready for submission to journals. Chapters 4-7 each offer a discrete set of findings. Because the empirical chapters are designed as standalone papers that will be submitted as journal articles (Chapters 4-7), some of the material in each chapter will inevitably be repetitive.

Chapter 4 presents the results of the first case study, Site 41 . The chapter begins by asking: did the framing of Site 41 as a threat to human health significantly alter the outcome of this conflict? This chapter's key contributions are to specify the 
interrelationship between one type of framing/issue definition strategy (the framing of a policy as a threat to human health), and the subsequent opportunities available to both opponents and proponents of that policy. Chapter 4 advances this understanding by identifying the relationship between a specific frame - policies understood as a risk to human health - and specific institutional biases. These findings deepen our understanding of the linkage between institutional structures and the issues that are contested within these structures.

Chapter 5 presents the findings of the second case study focused on wind turbines in Bruce County. This case asks a similar set of questions to the first case but finds that initially opponents of the wind turbine facility in Bruce County were unsuccessful at redefining the conflict as a threat to public health. However, after the facility was completed, the opposition to wind turbine projects in Ontario has become more successful (Ferguson-Martin and Hill, 2011). This chapter makes a substantive contribution through the integration of the research on social responses to wind energy development that focus on concerns to human health (Deignan, Harvey, and HoffmanGoetz , 2013; Hill and Knot. 2010; Songspore and Buzzelli, 2014) and the institutional context of that development (Agterbosch, Meertens, Vermeulen, 2009; Jobert, Laborgne, and Milmer, 2007; Wolsink, 2000). The integration of the literatures about social acceptance and institutions in the deployment of renewable energy utilizes the conflict expansion framework developed Pralle (2006a) to reveal the linkage between the problem definition and the institutional biases important to this conflict.

Chapter 6 offers a comparison of the two cases and focuses on the success of the health risk frame at drawing in new actors to each conflict. This chapter explores the first 
stage of the causal path described above in order to test the first hypothesis: the strategy of redefining the facility as a threat to human health and its effect on the participation of new actors in each case. The relative strength of the health risk frame in each case is compared and linked to the participation of actors who would have never participated if these conflicts were simply about local property values. The findings contribute to the agenda-setting literature by identifying the relative strengths and weaknesses of risk, and specifically human health risk, as a particular form of policy frame.

Chapter 7 is the final empirical chapter and it focuses on the second stage of the causal path and the relationship between risk to human health and the strategy of venue shopping across both cases. In particular, the relationship between a specific form of policy frame, that of risk to human health, and the institutional biases of specific venues is tested to understand the incentives for venue shopping produced by that relationship. The chapter contributes to the literature on agenda setting and venue-shopping through the identification of the specific institutional characteristics that influence or shape venue shopping strategies and how and why opposition groups make strategic decisions. In addition this chapter identifies the characteristics of the groups engaged in these conflicts that contribute to their ability to engage in venue shopping.

The final chapter is not intended as a stand-alone paper for subsequent submission as a journal article but as a conclusion to the dissertation as a whole. This chapter integrates the findings from each empirical chapter into a final conclusion aimed at incorporating risk into agenda-setting theories and reflecting on process tracing. The broadest contribution this research project makes is to the integration of risk into theories of policy process and policy change. With the increasing frequency and challenge of 
resolving these types of conflicts, integrating them into our current explanations of policy conflict is essential. It is clear that risk to human health is a powerful political frame but an understanding of how this actually drives the outcomes we observe are important. It is the interplay between this type of policy issue and the institutional structures within which these policies are fought over that is important to understand. The cases provide a clear opportunity for understanding how decisions to focus on the risk to human health by opponents of these facilities were structured by the available institutions of decisionmaking. This ultimately contributed to the outcome of these conflicts. Additional methodological insights about the potential strengths and weaknesses of process tracing as an approach to policy studies are also explored. Finally, some broad observations are made about how these types of conflicts actually occur and might ultimately be resolved and directions for future research on policy conflicts where risk is involved. 


\section{Chapter 2 - Risk and Public Policy Research}

\section{Introduction}

Chapter 1 introduced the topic, research questions, and key hypotheses of this dissertation. Chapter 2 builds on this by first briefly reviewing the literature on risk in the social sciences to identify some of the key findings important to this study. The most important of these is that the evaluation of risk by experts and the perception of risk by the public will often be distinctly different. This disconnect often contributes to conflicts over public policies that involve potential risks to humans. While the literature on risk perception is impressive, this study is focused less on how individuals come to form perceptions of risk and instead focuses on how those perceptions inform their political actions. It is the very different perceptions of risk advanced by actors within the conflicts studied here, and the effects of these understandings of risk on the outcome of these conflicts that is of interest.

Next, the chapter introduces the theoretical approach of conflict expansion developed by Sarah Pralle (2006a) and adapted in this dissertation. Pralle focuses on the strategies that groups involved in a policy conflict will deploy to advance their interests. Pralle has organized these strategies into three groups: strategies of issue definition, strategies of participation, and institutional strategies. These are the strategies that actors will select to expand (generally those seeking policy change) or contain (generally those seeking policy stability) a policy conflict. This framework is well suited to the study of risk and public policy because in this context, the decision to focus on the potential threat 
to human health posed by a technology or facility is a strategic decision (although many actors may genuinely believe in that risk). That framing of a facility as a threat to human health is a strategy of issue definition and the decision to use that strategy will then structure the other strategic opportunities available to those actors. While Pralle (2006a) recognizes the interdependence of the three groups of strategies, this dissertation seeks to further specify the conflict expansion approach by identifying a causal link between the decision to frame a policy as a threat to human health and its effect on the outcome of a conflict over that policy. In this chapter I argue that the more successful actors are at framing an issue as a threat to human health, the more likely they are to draw in new participants to the conflict, the more successful they will be at shifting to institutions they believe will provide them with advantages relative to their opponents, and therefore the more opportunity there is to affect the outcome of the policy conflict. The focus is therefore on the strategic opportunities opponents had available once their preferred framing of each facility was accepted and not the organizational capacity and resources available to each group. Capacity and resources are considered in the empirical chapters but they are secondary considerations to the success of the framing strategy of opponents.

The next section of the chapter examines the role of institutions more closely. Agenda setting research has always highlighted the linkage between issue definition and institutions because it is this linkage that drives policy change. By reframing a policy problem, actors can shift a policy to a new venue thereby potentially achieving policy change. In both cases studies in this dissertation the defeat of the facility was only possible after opponents successfully shifted to a new venue but it should not be assumed that shifting venues always leads to policy change. Policy actors hope a new venue will 
provide them with advantages but as only boundedly rational actors they cannot know this until they successfully shift to that venue.

The final section of the chapter outlines the theoretical approach adopted in this dissertation by adapting Pralle's approach to focus on the role that the framing of public policy as a threat to human health has on the strategies available to actors participating in a policy conflict. This thesis applies the concept of a policy frame to understand the precise role that the definition of a policy as a threat to human health plays in a conflict about that policy. The concept of a risk frame is also developed as a form of issue definition that focuses on a policy's perceived threat to human health through some form of hazard. A definition of strategy is presented as well as some approaches to identifying and analyzing actor strategies are offered. Finally, the hypotheses introduced in Chapter 1 are linked to the theoretical approach.

The purpose of this chapter is to integrate the literatures on risk perception, agenda-setting and conflict expansion, and institutionalism in order to build a framework for answering the central question of this dissertation: how does the framing of a policy as a threat to human health influence the outcome of that conflict? The three hypotheses introduced in Chapter 1 and repeated below are derived from these literatures to answer this question in the two cases examined in the following chapters.

\section{Risk in the Social Sciences}

Risk is a broad concept and is studied within a variety of social science disciplines including psychology, sociology, risk communication and assessment, economics, and 
political science. Early work on risk within psychology, often termed the psychometric paradigm, studied the expressed perceptions of risk by individuals, often through questionnaires, to reveal their subjective understanding of risk (Zinn and Taylor-Gooby, 2006). This research suggests that how risk is framed is important to risk assessment (Slovic, Fischhoff, \& Lichentstein, 1984), that social, political, and psychological factors play a role in risk assessments (Slovic, Fischhoff, and Lichentstein, 1982), and that there is often a disconnect between our emotive response to risk and a more balanced analysis of the same risk (Slovic, Peters, Finucane, \& MacGregor, 2005). The psychometric research informs much of the research about risk perception in the social sciences.

A second influential approach to explaining risk perception in the social sciences is the anthropological approach called cultural theory. Initially developed by Mary Douglas and Aaron Wildavsky (1982), the cultural approach suggests that the values or worldviews, called cultural biases, of individuals fundamentally affect how they perceive risk (Rippl, 2002). Douglas and Wildavsky developed a grid typology of cultural biases consisting of four broad categories: fatalism, hierarchy, individualism, and egalitarianism. Each place on the grid is aligned on two dimensions of social relations: control, and social commitment. For example, egalitarians reject social relations based on control but have high commitments to social relations. Fatalists are the opposite; they accept social control but reject close social relations. These cultural biases shape how individuals understand and accept risk. Like the psychometric paradigm, the cultural theory approach has undergone extensive empirical testing and has become central to much of the study of risk perception in the social sciences. 
The psychometric and cultural theories of risk offer important but oftencompeting explanations of how individuals understand risk. While the formation of risk perception is obviously important, this study is focused less on how individuals come to form perceptions of risk and instead focuses on how those perceptions inform political action. The non-rational process of risk formation, particularly the fear of the new or less understood, is important to the study of risk conflicts. The cultural theory of risk recognizes the importance of underlying cultural characteristics to how people perceive risk. Perhaps the most important lesson from both approaches is that perception of risk will inevitably be individual. No technology or facility will generate the same perception of risk in everyone. Varying understandings of risk posed by different technologies will therefore be the center of conflicts over risk as individuals form collectives in order to advocate for their understanding of the risk. These two approaches to understanding how perceptions of risk are formed are central to social science research on risk perception and create the basis of several approaches that focus on how conflicts over different perceptions of risk can be understood. These are the foundations of risk studies and have been applied to a growing field of inter-disciplinary work on risk.

\section{Risk Communication, Social Amplification of Risk, and Land-use Conflicts}

Three related bodies of literature build on studies of risk perception and are aimed directly at investigating the role risk plays in social conflict: the risk communication and management literature, the social amplification of risk literature, and particularly relevant to this study is the literature about risk and land use conflicts. These are more directly related to the focus of this dissertation; the role risk plays in expanding policy conflicts. Risk communication and management literature focuses on the disagreements between 
actors about the most appropriate way to evaluate and manage risk (Leiss, 1996). This research assumes as given, the different perceptions of risk held by varying actors and seeks to bridge that gap through productive dialogue (Leiss, 1996). Closely related to the risk communication literature is the social amplification approach that attempts to merge psychological and risk communication approaches (Zinn and Taylor-Gooby, 2006). Both provide a number of crucial insights into the study of risk conflicts and perhaps the most important is the recognition that the public's perception of risk is socially constructed.

Conflicts over risk are almost always rooted in the very different assessment of risk by experts, generally scientific experts, and the public. Expert assessment of the risk of a technology or facility is almost always determined through a quantitative scientific risk assessment. Risk in this context is defined in terms of two related dimensions: probability and effect (Breakwell, 2007). Probability refers to the likelihood of an event occurring, while effect is the magnitude of the damage of that event (Breakwell, 2007). Technical risk assessment is generally the multiplication of these two in order to quantitatively assess the relative risk of some technology or activity (Kasperson et al., 2005). Risk assessment is therefore a technical, science-based quantification of a particular hazard.

The perception of risk by the lay public is very different. The perception of risk by members of the public is dependent on a host of personal and cultural characteristics but is rarely purely rational (Slovic, 1987). The public's perception of risk is often contrary to the beliefs of risk management professionals who quantify the risk as minimal without recognizing that the perception of risk by the public is often rooted in "non- 
quantifiable factors" (Johnson, 2007; Kasperson, 2005; Siegrist and Cvetkovich, 2000; McAvoy, 1998). In particular, the involuntary and unknown nature of a risk contributes to an individual's perception of risk and the unwillingness of an individual to accept that risk (Hunter \& Leyden, 1995; Kasperson, 2005; Leiss, 2001). In some cases, the public's opposition to the imposition of risk is not based on a technical evaluation of risk but on a perception of risk that is socially constructed.

Risk perception is also not just the product of individual beliefs but can be amplified or attenuated by social, institutional, and cultural perspectives. The social amplification of risk paradigm seeks to make this process explicit using communication theory (Kasperson et al., 2005). Social amplification or attenuation occurs as signals about risk pass through social amplification stations such as experts, the news media, cultural groups, and even interpersonal networks (Kasperson et al., 2005). The amplified or attenuated risk signals then influence individual risk perception, which subsequently informs behavior. Risk in this context is not understood in absolute terms, the risk perceptions of individuals is as relevant as the assessment of experts (though may not be as influential) as they are all part of a social and political process.

The disconnect between the public assessment of risk and expert assessments of the same risk often gives rise to conflict. This is not to say that all experts will agree on a particular risk assessment. Opponents will often deploy different expert risk assessments to support their preferred understanding of risk. However, conflicts over risk will never be resolved by some definitive expert assessment as the public assessment of risk is socially, and not scientifically constructed. The public may trust the assessment of risk 
made by experts but this cannot be assumed. In addition, while a host of demographic, attitudinal, and institutional factors contribute to the social construction of risk, the literature shows that trust is a central to the public's consideration of risk.

\section{Trust}

Trust has long been recognized as important to the perception of risk. When people assess the risk of a technology or facility, part of that assessment rests on the trust they feel in those responsible for managing that risk (Slovic, 1993). For example, Slovic points to the high level of trust accorded physicians and the corresponding acceptance of risky medical technology, compared with the lack of trust in governments that oversee nuclear facilities and the corresponding lack of trust in those facilities (1993). This is particularly important when people have little personal knowledge about the risk in question, which is often the case with new technologies (Siegrist and Cvetkovich, 2000). Lack of trust in those responsible for managing and evaluating risks is therefore often at the center of the conflicts that arise over these risks.

Trust affects the perception of risk because actors will evaluate the institutions, organizations, and individuals that are responsible for overseeing risks. When they trust those actors, they believe that those risks will be managed well (Baxter, Eyles, and Elliott, 1999; Jenkins-Smith and Kumreuther, 2001; Sjoberg and Drottz-Sjoberg, 2009; Slovic, 1993; Whitfield, Rosa, Dan, and Dietz, 2009). Many risk researchers have identified trust as especially important in the public's assessment of the risk of a given facility or technology (Breakwell, 2007; Fischhoff, 1995; Hunter \& Leyden, 1995; Kasperson, 2005; McAvoy, 1998; Sjoberg and Drottz- Sjoberg, 2009; Siegrist and 
Cvetkovich, 2000). Kasperson, Golding, and Tuler (2005) explain that trust is often described as a component of social capital and suggest that social trust of institutions generally has been falling in the United States (US) and that this is particularly true surrounding health and the environmental issues. Trust in institutions is difficult to regain, especially in the limited time surrounding a land use proposal, which is why the creation of a participatory process for decision-making power is often advocated (Kasperson, Golding \& Tuler, 2005). Two factors are particularly important for building trust in institutions: participation and equity.

Much of the research on land use conflicts suggests that public opposition is largely due to the imposition of siting decisions on communities which have been given little to no input in the process (Aitken, 2010; Breukers and Wolsink, 2007; Gross, 2007; Kuhn and Ballard, 1998; McAvoy, 1998; Puschak \& Rocha, 1998; Hunter \& Leyden, 1995; Gerrard, 1994; Rabe, 1994). Communities are most often informed after siting decisions have been made which immediately leads to local opposition (Rabe, 1994). Researchers identify this as the primary cause of siting gridlock and point to the need for voluntary siting processes where the ultimate decision of whether to host a site lies with the host communities (Kuhn and Ballard, 1998; Gerrard, 1994; Rabe, 1994). Several studies have identified two cases of waste facility siting in Alberta and Manitoba that were entirely voluntary and are subsequently two of the best examples of successful hazardous waste disposal siting processes (Kuhn and Ballard, 1998; Rabe, 1994). In both these cases, the provincial governments solicited volunteer communities that would be willing to participate in a process to site hazardous waste facilities. No community was required to participate and the final decision to build the facility was ultimately at the 
discretion of the selected community. Participation of the communities selected to host these facilities is essential for success.

Much of the risk communication and management research supports and explains the findings of research on land use conflict. The importance of public participation in the process of facility siting is emphasized in this literature, and many siting failures are attributed to the imposition of decisions on a community by an external decision maker (Kasperson, 2005). These types of processes, characterized as "decide, announce, defend", ignore the reality that the public's perception of risk is increased when confronting a problem that is perceived to have been imposed (Breakwell, 2007; Kasperson, 2005; Fischhoff, 1995). Siting processes that focus only on the technical merits of a proposal are often unsuccessful because they proceed on the belief that experts and traditional political institutions possess sufficient legitimacy to make decisions (Kasperson, 2005; Fischhoff, 1995). If citizens are excluded from a decisionmaking process, or judge that process to be unfair, perceptions of risk will be higher.

\section{Risk and Public Policy Research}

As the above discussion demonstrates, risk has been an important concept of study in a number of disciplines. Risk has also been an important concept in many studies of public policy including topics as diverse as terrorism (Li, Fuhrman, Early, and Vedlitz, 2012) and food safety (Caduff and Bernauer, 2006). Risk has played a particularly important role in research about environmental policies. Environmental policy research where risk has figured as an important concept includes food safety (Caduff and Bernauer, 2006; Maney and Plutzer, 1996), radon and asbestos (Scheberle, 1994), lead 
and public health (Kraft and Scberle, 1995), biotechnology (Legge and Durant, 2010; Montpetit, 2011; Montpetit and Rouillard, 2008; Zerbe, 2007), and dioxins and toxic substances (Harrison, 1991; Harrison and Hoberg, 1991). Many studies of public policy include elements of risk without making risk a central part of the analysis.

Approaches to these problems have utilized a range of theoretical frameworks mirroring the theoretical fragmentation in policy studies. Some have focused on the role of institutions (Caduff and Bernauer, 2006; Harrison, 1991; Harrison and Hoburg, 1991). Others have focused on attitudinal research around public and elite perceptions of risk (Gerber and Neeley, 2005; Palfreman, 2006; Legge and Durant; Maney and Plutzer, 1996; Stewart and McLean, 2008). Some have also applied the problem definition and agenda setting approaches (Scheberle, 1994). Many studies have focused on the role of science in policy making around risk (Harrison and Hoberg, 1991; Montpetit, 2008, 2011). While all of these studies have successfully applied a theoretical approach to understanding risk, less attention has been paid to integrating risk into the theoretical approach itself. This research project seeks to remedy this by recognizing that public policy that involves, or can be understood to involve a risk to human health is a specific form of policy frame.

\section{Strategies of Issue Definition and Risk Frames}

While many approaches to studying the role of risk in policy conflicts are possible, the conflict expansion approach developed by Sarah Pralle is particularly appropriate because it focuses on the strategies of those participating in these policy conflicts (2006a). Building on the theories of conflict expansion proposed by 
Schattscheider (1975) and further developed by Rochefort and Cobb (1993), and the agenda setting literature, especially the theory of punctuated equilibrium developed by Baumgartner and Jones (1993), Pralle has developed an approach that recognizes that groups engaged in policy conflict deploy numerous strategies to advance their interests (2006). Groups seeking policy change will deploy strategies that seek to expand conflicts to overturn the policy monopolies that seek to prevent policy change (Baumgartner and Jones, 1993; Pralle, 2006a). Groups seeking to maintain a policy monopoly will deploy strategies to contain a conflict to a small group of actors. Pralle organizes the strategies deployed by those seeking to overturn or maintain a policy monopoly into three groups: strategies of issue definition, strategies of the expansion or contraction of participation, and institutional strategies (2006a). Pralle (2006a) recognizes the inter-dependency of these strategies but this study seeks to build on the approach by hypothesizing a causal relationship between strategies of issue definition and the other forms of conflict expansion strategies.

Issue definition is the first set of strategies identified by Pralle (2006) and the most critical for this case study as it is hypothesized here to be the strategy that opens opportunity for the other strategies. Building on research by Stone (1988), Cobb and Ross (1997), Kingdon (1995), Rochefort and Cobb (1993), and others, Pralle focuses on the conflict to define a policy issue and how that drives strategies of expansion and containment. A policy issue definition is the accepted understanding of the causes and consequences of a public policy. Issue definition is about how groups are "interpreting events and constructing them in such a way that makes sense to potential participants and decision-makers" (Pralle, 2006a, p. 17). Those interested in expansion will seek to 
advance an understanding of that issue as a significant problem that affects large groups of people and threatens important values (Pralle, 2006a, p. 17). Probably the most fundamental value, and the one that we might expect can contribute to the successful expanding of a conflict by advocates of that issue understanding, is the sanctity of life. Strategies of issue expansion will seek to increase the salience of the issue at the center of a conflict. This is the key battle in conflicts over risk.

Conflicts over risk are essentially what Stone calls conflicts over causal stories (1988). Causal stories explain who has been affected by a problem and who is responsible for the problem; it is about identifying who are the oppressors and who are the victims (Stone, 1988, p. 207). Conflicts over causal stories are about the struggle to control which story will become the prevailing narrative and therefore which story will inform policy decisions. Conflicts over risk are very much about conflicts over the 'correct' causal story of that risk. Depending on one's values or preferences, a wind turbine facility can be a low impact method for generating clean electricity or an industrial blight that poses substantial health risks to those living near them. In the former case, those supportive of wind technology will seek to characterize those opposing wind turbines are resisting a safe technology for their own selfish purposes. In the latter, opponents of wind energy will claim that wind turbines are being imposed on communities regardless of the real risk they pose to members of those communities. Creating the most compelling causal story can provide the opportunity to shape public opinion around a particular policy even if scientific evidence runs counter to opinion. 
Research focusing on the role of problem definitions recognizes the importance of causal definitions to how conflict over that policy develops (Rochefort and Cobb, 1993). Public policies are almost always proposed as solutions to some problem. A carbon tax is a 'solution' to the problem of climate change. How we define a problem is of course crucial to the solutions that will be deemed acceptable. Problem definition includes elements such as the cause and severity of the problem, who is affected by that problem, and what is the preferred solution to that problem (Rochefort and Cobb, 1993). Conflicts over public policy therefore often involve competing understandings of the problem at the heart of a given public policy.

Many of the approaches to public policy conflicts outlined above recognize that how a policy is framed is essential to how conflicts about that policy are fought. However, each use different terms to describe how a policy is understood: 'problem definition' (Rochefort and Cobb, 1994), 'issue definition' (Pralle, 2006), 'policy image' (Baumgartner and Jones, 1993), and 'causal story' (Stone, 1988). This list is certainly not exhaustive. While there are differences in how these terms are used within the given theoretical approach, each of these terms essentially seeks to capture how a policy is understood by those advocating or opposing that policy. While these terms can be (and often are) used interchangeably, this thesis applies the concept of a policy frame to understand the precise role that the definition of a policy as a threat to human health plays in a conflict about that policy. Framing can defined as "the process by which people develop a particular conceptualization of an issue or reorient their thinking about an issue" (Chong and Druckman, 2007). For instance, framing wind turbines as a boon to agricultural economies suggests to individuals exposed to that frame that economic 
considerations are important when evaluating that issue. Frames generally contain three important elements: "a problem, a protagonist, and a solution (Levin, 2005, p. 84). Frames affect an individual's opinion of an issue by focusing attention on a particular aspect of that issue (Druckman, 2001). Frames can be thought of as the different, often competing conceptualizations of the issue definition at the heart of a policy conflict.

Policy research to date indicates there are different policy frames at play in the policy process and some policy frames are more 'powerful', 'compelling' or 'contested' than others (Boothe and Harrison, 2009; Stone, 1989). Health risk frames as a particular form of issue definition are essentially a causal story about risk. These causal stories include who exactly is at risk from a particular policy (children, residents, communities, etc.), what is the danger (radiation, contaminated water, etc.), and who is the cause of the risk (corporations, governments, etc.). As Stone outlines, causal stories can challenge existing social relations or conditions and legitimate some group of actors as a cause of the problem, thereby requiring they change their behavior (1989). Homelessness can be understood as a refusal to work as productive members of society requiring criminal prosecution or as a symptom of mental health or addiction problems requiring medical intervention. Other groups are potential fixers of the problem thereby legitimating that group, and causal stories can aid in creating new linkages between victims of this problem (2012, p. 224). A health risk frame contains a danger, victims, and villains.

In political conflicts, framing occurs in what Chong and Druckman refer to as a competitive framing environment (2007a, 2007b). This occurs when actors are exposed to multiple, competing frames about a single issue. Frames in this context are the 
weapons used by competing sides to advance support for their preferred policy. This of course leads to questions about why some frames are more effective than others. Chong and Druckman identify the relative strength of a frame as an important element in explaining its success in shaping public opinion. A strong frame can "strike opinion leaders and audiences as being more compelling than alternative arguments" (Chong and Druckman, 2007b, p. 116). They do so by connecting to an idea or value that is widely shared. A strong frame is therefore one that that better connects to an audience and is more likely to influence their behavior. This dissertation is focused on the degree to which health risk frames are more likely to influence political behavior (ie. through increasing participation) and the characteristics of specific health risk frames (harm from contaminated water versus harm from wind turbines) that make them more or less likely to exert that influence. Chong and Druckman identify the relative paucity of research about what makes a frame stronger but research has suggested some characteristics such as a credible source and that a frame does not contradict existing beliefs (Chong and Druckman, 2007a). Two key characteristics introduced in Chapter 7

There are any number of frames that can be advanced to support or oppose a particular policy and conflicts over facility siting are no different. Both cases in this thesis began with opponents identifying a variety of potential opposition frames. For example, wind turbines were often presented as a threat to local tourism. However, in both cases opponents shifted to frames that focused on the threat to human health posed by the facility they opposed. In both cases opponents had little success at opposing each facility until the health frame was accepted. Opposition based on aesthetic or economic concerns had little success at drawing in the public to each conflict. Once they focused on 
the health risk frame and once the public began to accept that frame, opposition actors were able to expand each conflict. This is hypothesized to occur because a risk frame is more effective at conflict expansion than alternative frames. A risk frame will most likely be deployed by opponents of a policy or facility to overcome an existing policy monopoly, (groups of policy actors who are able to control a particular policy area for long periods of time) based on another definition of the underlying problem. Opponents deploy this image as a strategy of conflict expansion (as well as through genuine belief in the risk) to draw in new actors and shift the conflict to a more advantageous institutional venue. A risk frame is therefore a form of issue definition that focuses on a policy's perceived threat to human health through some form of hazard.

The success of a risk frame in expanding a conflict is dependent on who accepts that frame and the decision rules of the relevant institution. In an environmental assessment process or a bureaucracy it may only require a small of number of people to accept the frame in order to affect the outcome of the policy process. However, in an electoral based institution such as a County Council, a frame that is only accepted by a small number of actors is unlikely to aid in conflict expansion. Enough people must accept the frame that public pressure is applied to the Council in order to influence their voting behavior.

This dissertation contends that the health risk frame is often more effective than other frames at expanding a conflict but not all health risk frames are the same. The above research around framing provides some insight into why people may or may not 
accept a frame but additionally health risk frames differ in the degree to which they can aid conflict expansion. Two key characteristics can be

The more an issue is believed by an individual to affect them seriously, the more likely they are to mobilize: "just as they are more likely to organize and fight hard about something they perceive as a loss, they are more likely to organize and fight hard about something that affects them in a big way than about something that affects them only minimally" (Stone, 2012, p. 238). Very few issues are likely to mobilize opposition as much as policies believed to pose a risk to the health and wellbeing of oneself or one's family.

Acceptance of the causal story contained within a risk frame can depend on a number of factors including the role of the media and the strategies of those actors advocating (and opposing) that frame (individuals and groups). The role of the media in drawing and sustaining attention to issues of risk is clear; media attention to an issue increases opposition (Baumgartner and Jones, 1993). However, the media is no more likely to systematically understand risk than the public or policy actors. Media attention shifts for many reasons beyond objective ones including a tendency to focus on controversy or conflict (Baumgartner and Jones, 1993). The identification of the dominant frame can be identified through the analysis of media stories about the issue, which has always been an important method in agenda-setting research (Baumgartner and Jones, 1993; Jones and Baumgartner, 2005; Pralle, 2006a). Analysis of media reports is used extensively in framing research and can identify what policy frames were deployed, 
how often each frame was referenced, and how they changed over time (Chong and Druckman, 2007a).

The relative strength of a policy frame can additionally be affected by how the groups at the center of the policy are perceived. Building from Stone's work, Schneider and Ingram use a typology of deservedness to understand how the groups affected by a policy can be constructed (1999). The deservedness of a group refers to the perceptions that different people are more or deserving of protection or punishment than others and it can provide insights into why policies aimed at them might succeed. Groups that are the focus of a particular policy can be categorized by the degree to which they are perceived as deserving of public attention and the amount of power held by those groups (1993). While groups that have both political power and are perceived to be deserving of public attention are the most able to mobilize attention; environmental policies that may disadvantage powerful groups often choose to focus on less powerful but particularly deserving groups such as children (Boothe and Harrison, 2009). Policies that can be framed as a risk to a deserving group can provide a particularly strong causal story requiring political action to protect the deserving group. In the case of risk conflicts, risk that threatens deserving groups, such as farmers or children, can be a powerful frame for gaining public support.

\section{Strategies of Actor Participation and the Role of Actors in Policy Conflicts}

The second set of strategies identified by Pralle focuses on the participation of actors in the conflict. Policymaking that is contained within a small group of policy actors (whether state or societal) constitutes a policy monopoly (Baumgartner and Jones, 
1994). Efforts to overturn these monopolies are often aimed at expanding the number of actors who participate, or who seek to participate in policy-making decisions. The expansion of actors can upset the existing power balance. This is often accomplished by challenging the dominant policy frame thereby drawing new actors to the arena.

The framing of a policy as a threat to human health is proposed in this dissertation to be the key strategy that opens the opportunity for strategies of actor participation and institutional strategies. Strategies of actor participation are aimed at drawing in new actors to a conflict to change the relative balance of power in that conflict. The relationship between risk frames and strategies of actor participation will be further expanded on in the empirical chapters that follow but before that is possible a discussion of how actors are conceptualized in this thesis is required. The approach developed by Pralle (2006a) and adopted in this thesis was initially applied to an analysis of environmental advocacy organizations in two conflicts over forest policy. The three categories of strategies were therefore developed and applied to explain the action of advocacy groups. However, many policy conflicts involve a range of actors including groups that are not highly organized and well-resourced advocacy groups but instead are loosely organized collections of actors and/or key individuals. Applying the approach to these types of policy conflicts can therefore be more challenging and raises an important theoretical and empirical question about whether these actors can in fact be treated as a single coherent policy actor or constellation of actors capable of strategic action.

The proponents and opponents of the facilities at the center of the policy conflicts in this study, for the most part, loosely organized networks of individual actors who 
shared a common set of goals, either the completion or cancellation of each facility. The policy conflicts in this study are made up of actors that can loosely be grouped into proponents and opponents of each facility. These include actors such as elected municipal government councilors, municipal bureaucrats, local and national environmental groups, and First Nations activists. Both proponents and opponents included state and non-state actors. Given this, one important question is whether loose collections of actors that comprise proponents and opponents in policy conflicts can be considered as a collective of actors to which strategic intent can be attributed? Fritz Scharpf draws an important distinction between collective and corporate actors and the degree to which they can be treated as single actors in evaluations of strategic behavior in policy research (1997). Corporate actors, such as corporations or highly institutionalized advocacy groups are hierarchical organizations that are insulated from the preferences of their members and can be treated as singular actors when considering strategic actions. Collective actors, such as social movements or organizations with collective decision-making processes such as the OECD, are assumed to be aggregates of their members and determining if these collections should be treated for the purpose of analysis as single actors capable of making strategic decisions is more complex (Scharpf, 1997).

Scharpf identifies two dimensions essential to considering where a group, whether a collective or corporate actor can behave strategically: the cognitive and evaluative. The cognitive dimension refers to the degree to which members share a "cognitive map" and can "converge on common interpretations of a given situation" (1997, p. 58). The more members agree on this map, the more effectively they can agree on appropriate strategies. The evaluative dimension refers to the integration of 
preferences in regards to strategic actions. The more actors within a collective are able to agree on the relative merits of various strategies, the more able they are to decide on and implement strategies. These two dimensions therefore are the key to evaluating whether a group can be treated as a single actor when participating in a policy conflict (Scharpf, 1997).

Each of the two conflicts studied here had one set of actors that initially proposed and supported the facility. In both cases these actors were a loose network of individual actors who shared a common goal and not formally organized groups. These networks of proponents can be understood as policy monopolies within this context because they initially controlled both the policy image and the relevant institutional venues in each case. The policy images were the initial frames describing each facility when they were first proposed: cost effective and responsible waste management in the Site 41 case and environmentally and economically advantageous source of power in the Kincardine Wind Farm case. These actors controlled the most important institutional venues because they had were able to present scientific, expert based evidence in the EA processes in both cases and in both cases the majority of County Councilors supported the projects. Each case also contained a set of actors opposed to the proposed facilities and who engaged in activities aimed at overturning these monopolies in order to stop their construction. The initial opponents to both facilities were primarily loosely organized groups of citizens who lived nearest these facilities. In order to overturn the policy monopolies that sought to complete these projects, opponents needed to challenge the framing of the facility or shift to a more advantageous institutional venue. The question asked in this dissertation is 
did the health risk frame aid these opponents in challenging the respective policy monopolies.

The two groups of actors labeled for convenience as proponents and opponents were not corporate and hierarchical groups. However, it is the consensus within these groups of actors around the framing of the facility (the cognitive map) and their general agreement around their goals and strategies (completing or stopping each facility) that makes analyzing them as a collective in the policy process as though they were organized groups appropriate. As will be presented in the analysis of these conflicts, these groups may have been loosely organized but they were clearly capable of acting strategically.

The public in each case under study is also important to consider. In each case, the public was not initially interested in the facilities and conflicts around them. It was this relative apathy that opponents in each case hoped to overcome by deploying strategies to draw the public in to each conflict. The framing of each facility as a threat to human health, protests and media events, and the public relations campaign each set of opponents engaged in are examples of strategies designed to draw in the public as well as influence local decision-makers. The measure of the success of these strategies is the evidence gathered for this dissertation and introduced in the following chapter. The media, both local and provincial/national, played a role in both cases as the most significant transmitter of frames advocated by each side. While there is a vast literature about the role of the media in framing, the focus of this study is not why or how the media adopted or focused on a particular frame, only that they did so and that its attention influenced the outcome of the policy conflict. If opponents advocated for the health risk 
frame and the media reported on that frame then that was treated as 'success' at framing the issue. Why exactly the media chose one frame or another is not something investigated beyond the assumption that some frames are more likely to attract media attention (health risk frames for example). Evidence of the adoption of the frames is gathered from analysis of the media reports of each conflict presented in Chapter 3.

\section{Institutional Strategies, Actors, and Venue-Shopping}

The third set of strategies of conflict expansion identified by Pralle focuses on institutions (2006a). The above discussion asserts that actors who participated in the policy conflicts studied here are capable of engaging in strategic action and one of the key strategies is venue shopping. Venue shopping can be defined as "the activities of advocacy groups who seek out a decision setting where they can air their grievances with current policy and present alternative policy proposals" (Pralle, 2006a, p. 26). They do so because they are prevented from accessing the current decision setting or that setting's rules are biased against them (Pralle, 2006a). A basic assumption of the agenda-setting framework is that some institutional venues are more receptive to some frames than others (Baumgartner and Jones, 1994; Boothe and Harrison, 2009; Pralle, 2006a, b). Policy change often occurs because actors are able to change to a venue more receptive to their preferred frame (Pralle, 2006b). For example, a group that is unsuccessful at achieving their goals through a legislative change may seek to advance their interests through the court system. They may believe the court provides more access to a group advocating a rights based frame. However, for other groups the legal costs of that strategy may be prohibitive. This strategy is generally referred to as venue shopping. Because of the centrality of institutions to the explanation of why framing a policy as a health risk is 
effective, a more detailed discussion of institutionalism and institutional biases is required. Drawing on various strands of institutionalism, the goal is to understand what institutional characteristics can lead to the success or failure of a health risk frame at driving policy change.

Institutions must be part of any analysis of policy conflicts over risk when that conflict will involve formal decision-making. Institutions will be the focus of strategies of groups that are seeking to advance their preferred understanding of risk. While institutionalism has become essential to many explanations of public policy, there is a diversity of forms of institutionalism that makes defining a single approach difficult (Peters, 1999). In all likelihood, no two researchers apply precisely the same form of institutionalism. This makes defining the approach problematic, but it also creates a richness of possible research strategies. This project draws from two institutional traditions: the institutional rational choice of Elinor Ostrom (2005) and the broad literature of historical institutionalism (Hall and Taylor, 1996; Peters, 1999; Pierson, 2000; Thelen, 1999). The thesis adopts the definition of institutions as formal or informal rules.

All institutions, as sets of rules, contain biases that advantage or disadvantage the various actors operating within them (Boothe and Harrison, 2009; Ostrom, 2005). Biases occur because the rules of an institution can provide advantages and disadvantages to the actors that interact within those institutions. They are never neutral fields in which all actors are equal. Policy conflicts about risk are predominantly the result of the varying conceptions of risk held by different actors. The different institutions that structure these 
conflicts will generally privilege one form of risk conception over the other. Institutions such as the Environmental Assessment panels analyzed in this dissertation restrict participation to approved actors (generally stakeholders) and have formalized or even quasi-judicial proceedings that privilege expert and technical understandings of risk. This is not to say that they are more likely to approve facilities or technologies as other consideration such as the social or environmental ramifications of the facility are considered in these institutions. However, when considering the risk to human health posed by a facility, these institutions require technical, expert based confirmations of any claims. Effectively opposing a proposed facility in these institutions therefore requires significant technical evaluations confirming any claims of risk.

Conversely, some institutions have few or no restrictions on who may participate. Electoral institutions are probably the most important example of these types of institutions. These institutions are characterized by more open participation where participants have actual, if diffused impact on decision making, and where considerations of risk are social instead of technocratic. Because these relatively open institutional venues will almost always privilege lay conceptions of risk, we can predict that actors seeking to prevent risk facilities or technologies will seek to shift conflicts to these types of institutions. That is not to say that opposition actors will not also try to compete within institutional venues such as EAs, but because they must present expert evidence in these institutions, with little regard to public (non-technical) understandings of risk, they will not necessarily have any advantage in that venue. Actors seeking to advance non-expert understandings of risk will seek to shift institutional venues that privilege their preferred understanding of risk. 
A second key characteristic of institutions in these conflicts is scale. Any understanding of the risk from a given technology contains within it an understanding of the potential geographic scale of that potential risk. The potential harm might be localized to only those closest to that technology such as potential stray voltage from high-tension electricity transmission towers. The potential harm might threaten a much larger area such as potential radioactive contamination from a serious event at a nuclear power facility. The perceived scale of the potential harm from any risk is part of the problem definition around that technology and may be very different in lay and expert conceptions of that risk.

Scale is also a crucial characteristic of institutions (Hall, 1992; Ostrom, 2005; Sproule-Jones, 1993). The geographic scope of an institution's decision-making power is always limited. In federal systems, there will be a hierarchy of scale where institutions of municipal decision-making will have the smallest geographic scope and national institutions the broadest. What is important in risk conflicts is the match between the scale of risk and the institutions of decision-making that have authority over that risk. If the scale of the risk is believed to be localized but the institutions that make decisions over that risk are national, the mismatch between scales will most often favor those supportive of the technology. For example, the potential threat to human health from wind turbines are localized to those living close to those turbines. Those actors will have the most influence over local decision-making institutions such as municipal councils. However, if approval authority is the provincial government, those local actors may have little influence over decision-making. This would be particularly true if wind energy is popular provincially. Because a localized risk is likely to mobilize only those nearest the 
technology, this may prevent them from having a significant impact on national decisionmaking and therefore allow supporters to contain the conflict. However, if the scale of the crucial decision-making institution and the perceived scale of the risk are matched, opponents of the technology, if able to gain wide acceptance of their conception of risk, will be able to capture the institution of decision-making. In the conflict over Site 41, opponents were able to exert significant influence over the County Council by the end of the conflict but had little success at influencing provincial decision-making. Because the County Council was capable of making key decisions over Site 41, influencing that Council was sufficient to influence the outcome of the conflict. Actors in these conflicts will therefore seek to move the conflict to an institutional venue that provides the best advantage, relative to their understanding of risk. This is a key factor for explaining the outcomes of the cases studied in this project.

A third crucial set of institutional characteristics important to risk conflicts is the effects of the institutions themselves on the risk perception of actors that interact within these institutions. The first two characteristics described above, take the risk perceptions of different actors as given and suggest how they interact with the institutional structure within which these conflicts occur. However, as the discussion on risk above makes clear, institutions can also influence the degree of risk perceived by actors. Distrust of the institutions of decision-making in a conflict can amplify perceptions of risk (Baxter, Eyles, and Elliott, 1999; Jenkins-Smith and Kumreuther, 2001; Sjoberg and DrottzSjoberg, 2009; Slovic, 1993; Whitfield, Rosa, Dan, and Dietz, 2009). 
Related back to the centrality of trust to the risk literature, trust in the institutions of decision-making is important in these conflicts as it contributes to the perception of risk posed by the technology at the center of the conflict. Literature on institutional trust identifies institutional trust as a key independent variable in explanations of when and why individuals might consent to policies that are contrary to their own interest (Levi, 1997; Levi \& Sacks, 2009; Scholz, 1998; Scholz \& Lubell, 1998). This is referred to as 'institutional trust'. Higher levels of institutional trust are theorized to increase the likelihood that actors will consent to policies. Institutional trust, like interpersonal trust, has three elements: $a$ trusts $b$ to do $x$ (Hardin, 2006, p. 19). There is a truster, a trustee, and the object of that trust. I may trust my neighbor to return the shovel she borrowed but not to invest my life savings. Trust is specific to a context. In the case of land use conflicts, trust is placed in specific institutions in relation to a specific role of that institution.

The above review of some of the literature on risk, the conflict expansion theories developed by Pralle (2006a), and the insights from institutionalism, together, contribute to a novel approach to the study of risk in the public policy process used in this thesis. This approach builds on Pralle's approach to policy conflicts by specifying the difference that a specific type of policy frame, the health risk frame, can play in influencing the outcome of a policy conflict in a way that other frames cannot. This approach, while rooted in classic approaches to policy studies that focus on ideas, actors, and institutions, focuses on the interaction of these three to explain the outcome. The following section outlines this approach. 


\section{Theoretical Approach}

This thesis seeks to answer the question: how does the framing of a policy as a threat and risk to human health influence the policy process? To answer this question the approach to conflict expansion developed by Pralle is adapted. The goal is to build on this approach by specifying the relationships between a specific form of issue definition strategy, the framing of a policy as a threat to human health, and the other categories of conflict expansion strategies. Adapting Pralle's approach to analyzing policy conflicts can focus attention on how the framing of a policy can influence the opportunities available to actors contesting that policy.

Simply identifying when the framing of a policy as a risk to human health occurs is not sufficient to establish the effect of that framing on the outcome of a conflict. The effects of that frame on who chooses to participate in the conflict and what institutional venues are available to those actors need to be traced in order to establish a causal link between that frame and the subsequent strategies utilized by actors in that conflict. This can be done by examining the strategies deployed by these actors and the interrelationship between the categories of these strategies identified by Pralle (2006). Does the strategy of framing the facilities as a threat to human health in each conflict contribute to the expansion of actor participation and institutional strategies deployed by the actors that opposed these facilities? From this question three interrelated hypotheses, introduced in Chapter 1, can be derived to test the influence of the framing of a policy as a threat to human health on the outcome of a conflict over that policy: 
H1: That the greater the acceptance of a risk frame (by the public or elite actors), the greater degree to which a conflict will expand to new actors (public and elite).

$\mathrm{H} 2$ : That the more actors that are drawn into the conflict, the more opportunity there will be to pursue venue shopping strategies.

H3: That the more opponents are able to engage in venue shopping, the greater the likelihood of altering the outcome of the conflict.

The three hypotheses are interrelated in that they represent steps in a causal chain. The second hypothesis can only be true if the first was also found to be true and the third can only be true if the second was also true. This is the case because it is hypothesized here that framing a policy as a threat to human health will not aid actors in pursuing venue shopping opportunities if they do not first have sufficient support to influence actors within the institutional venues that they are seeking to access. These three hypotheses are tested using the two conflicts descripted in Chapter 1. The unit of analysis in this study is the totality of the conflict - from the initial proposal of the action to a decision about its completion or termination. The hypotheses above are about the actions of both proponents and opponents to achieve their preferred policy outcome: either the completion or cancelation of each facility.

The activities engaged in by proponents and opponents are conceived of here as strategies. The definition of strategy is not always well defined in the conflict expansion literature. ${ }^{1}$ In this thesis, strategy is defined as any action that is an attempt by the actors involved to advance the realization of a goal or preference. When an opponent of one of

\footnotetext{
${ }^{1}$ See for example Cobb and Ross's extensive discussion of the relative costs of strategies without a clear definition of strategy.
} 
the facilities decides to protest they are engaging in a strategic activity whether they recognize it or not. When actors perceive an opportunity (correctly or not) to advance their goals and then engage in that activity, this is a strategic action. Strategies need not be recognized as such by those engaging in them but they are observable as actions and individual and/or group behaviors. Actors that are experienced political operators will often explicitly recognize and consciously engage in strategies to advance their goals. Citizens engaging in political activity for the first time however may not think specifically in strategic ways. Nonetheless, when they decide to engage in purposeful activity to advance their goals they are acting strategically. Whether that strategy is wise is of course another matter. Because actors formulate strategies in a boundedly rational way (Ostrom, 2005; Scharpf, 1997), actors will not always make the most effective choices but whether or not strategies are effective or well chosen does not reduce their strategic intent.

One important element in this thesis is the strategies of opponents and proponents of the facilities as policy actors in each case and therefore the focus on how their strategies can be recognized is of central importance. The researcher can best recognize strategies by reviewing documents, media statements and interviews with those who engage in strategic action to gain insights into what was their goal and how they sought to realize their goals (more on this is next chapter). Asking actors about their goals and the actions they take to reach their goals is therefore revealing of their strategies. Strategies can also be revealed through secondary sources that reveal what actors publicly state are their goals and through the actions of actors. If an actor organizes a protest we can 
assume that was a strategic action. What may be less clear is what was the intention of that strategy but this can often be revealed or inferred.

In summary, the hypotheses above are designed to test the relationship between the three categories of strategies identified by Pralle (2006a). The first suggests that the more the risk frame is accepted by the elite actors and the public, the more successful will be the strategies of actor participation deployed by those seeking to defeat those facilities. The more people (public or elite) that accept the risk frame, the more success opponents will be at drawing new participants to the conflict. The second hypothesis suggests that the more successful opponents are at drawing in new participants, the more likely opponents are to be at shifting these conflicts to institutional venues (a strategy of institutions) in which the risk frame will be successful. The final hypothesis captures the impact of these strategies on the outcome of the conflict. In both cases studied here, the relevant political actors had approved the facility in question. The goal of opponents was to overturn these decisions. The final hypothesis is an attempt to measure their success. If these hypotheses are correct then we can conclude that the framing of each facility as a threat to human health had a significant impact on the outcomes of these conflicts. This impact is felt through the strategies that proponents and opponents chose to deploy to advance their goals. If these hypotheses are correct in a case, then the framing of the facility as a threat to human health altered the strategies available to these actors and the relative success of those strategies in effecting the outcome of the conflict. This begins the process of integrating risk into a theoretical approach to the study of public policy. 


\section{Conclusion}

This chapter began with a brief review of the substantial literature around risk in the social sciences. While this literature is too vast to summarize here, for purposes of this study, the key finding from this literature is that the risk perception of individuals is both highly personal and at least partially socially constructed. This is central to understanding conflicts over risk and public policy. Technical assessments of risk, while often an important component of that social construction, are often insufficient for resolving disputes around risk. Disputes about risk are therefore essentially clashes between the different understandings of the risk held by different actors.

Theories of the policy process have long recognized that different understandings of a public policy, whether termed the problem definition, frames, causal stories, or policy images, drive conflicts over those policies. The conflict expansion approach developed by Pralle (2006), which builds on theories of problem definition and agendasetting, offers an effective approach for the analysis of how the framing of a policy as a threat to human health might effect the outcome of a conflict over that policy. Risk to human health can expand the participation of new actors in a conflict like few other strategies of issue definition and this can open opportunities for venue shifting unavailable to actors advocating other policy frames. The strategy of venue shopping is

particularly important because of the characteristics of the institutions that structure these conflicts.

The framework for analysis described above includes the proposition that the deployment of a risk frame potentially drives expansion of a conflict because new actors 
participate, which opens opportunities for venue shopping. This is a clear causal relationship that requires testing. The next chapter proposes a research design for testing each of the proposed causal relationships. 


\section{Chapter 3 - Research Design and Methodology}

\section{Introduction}

Chapters 1 and 2 described some of the social science research around risk and outlined a conflict expansion approach that can help understand how conflicts over risk can be incorporated into policy theory. The varying perceptions of risk held by different actors will inevitably lead to conflict over which of these understandings of risk should be incorporated into policy decisions. This can be usefully conceptualized as a conflict over the framing of a policy. Policy research indicates that understandings of a policy problem are the central point of conflict in agenda setting disputes as actors opposed to an existing policy monopoly seek to change the problem definition to one that will expand the conflict to include new actors who can help them compete within the existing institutional venue or shop for one more amenable to their preferred problem definition. This research focuses on examining if a policy frame based on risk to human health risk can aid this by more effectively expanding the conflict to new actors. A risk frame is therefore more likely to lead to policy change than other policy frames. In fact, conceptualizing risk to human health as a potent type of policy frame suggests a causal link between the creation of a risk frame and the successful expansion of a conflict thereby contributing to potential policy change.

Causation is always difficult to isolate in any complex social event and agendasetting conflicts are no different. Disentangling potential causes of an event, the conditions within which those causes function, and linking cause to effect is difficult and often contentious in any social science. However, policy studies impose a specific burden on the researcher. Public policy is always an attempt to use state resources and collective 
action to 'solve' some public problem. This assumes, even if implicitly, a cause and effect relationship between the application of resources and a change in outcomes. Research about public policy thus has an explicit focus on causation but still must deal with the inherent limitations of research methodologies in revealing that causation.

The following chapter describes the application of a form of case study analysis to the hypotheses proposed in Chapter 1 and 2. Process tracing, a form of within-case analysis, seeks to explicitly reveal the underlying causal mechanisms that link events to the outcomes we observe. This is done through the careful description of a set of events in the case under study, and using this description to test for the presence of a causal mechanism that can explain why a particular outcome occurred. Causal mechanisms are the links between an event and an outcome. This link is not established through a regularity of association, as is the case in much social science research based on statistical associations. Instead, causal mechanisms focus on the precise process that occurs between two variables to understand exactly how a change in one elicited the change in the other. Process tracing can reveal the causal mechanism, in this case the relationship between a risk frame and the expansion of a conflict, and the outcomes we observe, in this case either the completion or defeat of a proposed project.

This chapter begins with a discussion of the case selection logic applied in this study and the usefulness of cross case comparison. Next is a brief introduction to process tracing including a proposed causal mechanism that explains the success or failure of a risk frame in eliciting policy change. The next section presents the research design and evidence used to test for the presence of the proposed causal mechanism and then discusses the usefulness of comparing results of each case study to identify the conditions 
under which that mechanism might function. Finally, the data collection methodologies used to test for this hypothesized causal mechanism are introduced.

\section{Research Design: Case Studies and Process Tracing}

Policy studies utilize a variety of research approaches, designs, and methodologies but case studies are particularly common. Case studies are a method of intensively studying a particular class of events in order to reveal variables that are theoretically important and that provide "some leverage for policymakers to enable them to influence outcomes" (George \& Bennett, 2005, p. 69). Case study methodology is most often qualitative but many researchers assert the value of case studies for theory testing, theory development, and the identification of causal processes (Gerring, 2007; George and Bennett, 2005; Poteete, Janssen, and Ostrom, 2010; Ragin, 1987; Yin, 1994). Case studies offer both empirical traction for identifying policy solutions as well as theoretically sophisticated explanations of events.

\section{Case Selection}

Case selection can be particularly challenging when applying qualitative methods to a research problem. Case study research, even comparative case studies that include multiple cases, generally trades reduced external validity for greater internal validity (Gerring, 2007; George and Bennett, 2005). Statistical research utilizes random selection of subjects in order to eliminate any systematic bias and ensure external validity. Due to the small number of cases under study, random selection of cases is not recommended and can create more problems for small- $n$ research than it solves (King, Keohane, \& Verba, 1994, p. 120). Instead, researchers using small- $n$ methods must carefully choose cases based on the needs of their study. Some advice about case selection in small- $n$ 
studies is based on quantitative inference and suggests that choosing cases on the basis of the value of the dependent variable can be problematic. ${ }^{2}$ However, many researchers that apply process tracing argue that selection of cases on the basis of outcomes is appropriate because the goal is to explain particular outcomes (Mahoney and Goertz, 2006). If explanation for a particular outcome is the goal, then the study must include cases that exhibit variation on that outcome.

Case selection in this dissertation was based on variation in both independent and dependent variables. One of the primary independent variables of interest in this study is the health risk frame advocated by opponents to each frame. How did that that frame contribute to the outcomes of each conflict? In each conflict the opposition framing initially focused on non-health risk opposition frames and the type of risk potentially posed by each facility was distinct (See Table 3-1 below). Opposition to the Site 41 landfill initially focused on nuisance effects to local residents and opposition to the Kincardine wind farm initially focused on the effects of industrial projects on rural landscapes. However, during the course of the conflict, each opposition group focused their strategies on the potential harm to human health posed by each facility. This shift in the opposition frame of each conflict affords the opportunity to view these conflicts before and after the public acceptance of the health risk frame and therefore identify the actual influence of the health risk frame.

\footnotetext{
${ }^{2}$ When cases are selected because of extreme values on the dependent variable, there is the potential that this truncated sample will underestimate the strength of the actual causal relationship. See Collier \& Mahoney (1996) for a detailed discussion of selection bias in small- $n$ studies.
} 
Table 3-1: Case Comparison Criteria

\begin{tabular}{|l|l|l|}
\hline Key Case Characteristics & Site 41 & Kincardine Wind Farm \\
\hline Initial Opposition Frame & Nuisance effects of landfill & $\begin{array}{l}\text { Landscape impacts of wind } \\
\text { turbines }\end{array}$ \\
\hline Type of Health Risk & $\begin{array}{l}\text { Risk from contaminated } \\
\text { water }\end{array}$ & $\begin{array}{l}\text { Risk from low level sound } \\
\text { and vibrations from } \\
\text { turbines }\end{array}$ \\
\hline Scale of that Risk & $\begin{array}{l}\text { Regional threat from } \\
\text { potentially polluted aquifer }\end{array}$ & $\begin{array}{l}\text { Localized to those near } \\
\text { turbines }\end{array}$ \\
\hline Key Institutions & $\begin{array}{l}\text { EA processes (tribunal), } \\
\text { Land use appeal tribunals } \\
\text { (OMB), County Councils }\end{array}$ & $\begin{array}{l}\text { EA processes Screening } \\
\text { Repibunals } \text { (OMB), County } \\
\text { Councils }\end{array}$ \\
\hline $\begin{array}{l}\text { Dependent Variable: } \\
\text { Outcome of conflict }\end{array}$ & Cancellation of facility & Completion of facility \\
\hline
\end{tabular}

In both cases the focus of opposition framing shifted during the conflict but the nature of the health risk posed by each facility was also distinct. Those opposed to Site 41 argued that it posed a threat of contamination to an important regional water source, the Alliston Aquifer. Site 41, according to opponents, therefore threatened the health and ability of Simcoe County residents to access safe drinking water. The scale of the threat was regional and, as will be argued in Chapter 4, this risk was particularly salient in Ontario after 2001. The Kincardine Wind Farm (and large wind turbines generally) poses a different type of health threat according to opponents. Large wind turbines generate low levels of noise and vibrations. Opponents suggest that this can have a negative impact, especially over the long term, on the health of people (and animals) living near wind turbines. This can manifest as problems such as anxiety and loss of sleep. Because it is relative proximity to a turbine that leads to potential health threats, wind farms pose a more localized scale of risk then source water contamination. This is somewhat mitigated because Bruce County was perceived to have an abundance of wind resources, even those 
who would not live near turbines in the Kincardine project feared that acceptance of this project might expose them to future projects. The different type of health risk posed by each facility allows for the testing of how this influences the outcome of each conflict. Chapter 6, the first empirical chapter to compare the cases, will also introduce two other elements important to understanding the differences in the role of framing between the two cases.

An alternative to the selection of two cases with different types of risk would have been a research design that compared a case in which opponents utilized a health frame to one that did not. This would set the variable of health risk frame to 1 and 0 . This strategy would be able to make assertions about the difference between conflicts that use this strategy and those that don't. In effect, it would answer the question of whether framing a policy as a health risk has an effect on the outcome of a conflict over that policy. However, that the framing of public policies influences conflicts over those policies is not really in doubt. Public policy theorists have long understood that the way a policy is understood has an influence on the policy process (Baumgartner and Jones, 1994; Cobb and Ross, 1997; Rochefort and Cobb, 1994; Stone, 1989). This study therefore seeks to understand how that influence actually occurs and compares two different types of risk frame (essentially setting that variable to between 0 and 1 for each case) in order to trace how different health risk frames influenced each case.

A second key independent variable in this study is the institutional context that structured these conflicts. Because these conflicts both occurred in Ontario the institutions that were key in each conflict are vey similar. The most significant difference was the different environmental assessment (EA) processes. In the Site 41 case the EA 
process was longer and far more involved then the assessment process used in the Kincardine Wind Farm case. Holding the institutional structures relatively constant should allow for a robust comparison between the roles of each health risk frame. These cases are also situated in similar rural regions, which should help hold cultural and economic factors relatively constant. ${ }^{3}$

The dependent variable in this study is the outcome of the two conflicts, either the cancellation or completion of each facility. The Site 41 facility was eventually cancelled and the Kincardine Wind Farm was completed and currently operating. Variation on dependent variable is essential for testing the role of the health risk frame in each case. It should be noted that this study does not suggest that the health risk frame is the only variable that contributed to the outcome of these conflicts. There are any number of factors that could, and probably did influence the outcome of each conflict. For instance, the relative resources available to different political actors is often suggested as a explanation for the success of political mobilization in social movements (Snow and Soule, 2010). Chapter 6 will make the argument that the framing of each facility as a health threat was an important source of resources by mobilizing new actors. However, organizational features such as leadership and learning undoubtedly played a role in each conflict and details about the central actors in each case are included in the empirical chapters but these potential variables are not central to the analysis. It is not argued here that health risk framing is the only explanation, only that it is an important part of the story that has been under examined.

\footnotetext{
${ }^{3}$ In no way does this constitute a controlled comparison or natural experiment.
} 


\section{Process Tracing}

Debates about the use of case studies, and qualitative methods generally, have received a resurgence of interest in the social sciences since King, Keohane, and Verba published Designing Social Inquiry (1994). In this seminal work they argued for more rigorous qualitative methodologies based on a logic of inference derived from quantitative methods. Response to this challenge has been diverse, but at the very least, it has sparked an interesting and vigorous debate about the use of qualitative methods for drawing causal inferences. ${ }^{4}$ Without wading too deeply into this methodological debate, it is important to briefly outline the epistemological basis of the research presented here.

The terrain between quantitative and qualitative methodologies has been well explored, yet fundamental disagreements between researchers in each tradition remain. King, Keohane, and Verba attempted to bridge this unstable terrain by building a theory of qualitative methods on the foundations of a logic of causal inference developed in quantitative methods (1994). However noble this attempt, many qualitative researchers maintain that their methodology is based on a different logic of causality and is not derivative of quantitative methodology (Bennett and Elman, 2006; Beach and Pedersen, 2013; Brady and Collier, 2004). Instead, qualitative methods have advantages and disadvantages, based solely on a different logic of causation. To subsume this logic within a logic of inference specific to quantitative methods would be to sacrifice those advantages that make quantitative methods distinctly useful. While it is impossible to identify a single dominant qualitative tradition, this dissertation adopts an approach based

\footnotetext{
${ }^{4}$ For a pointed response, see Brady and Collier, 2010
} 
on the identification of the underlying causal mechanisms of an event or phenomena we wish to explain.

Defining causal mechanisms can be difficult as researchers understand them differently, but there is a basic level of agreement. Beach and Pedersen define it as a mechanism that links an independent variable to an observed outcome (2010, p. 5). They contrast this with the traditional frequentist approach to causation that specifies if the independent variable is correlated and precedes the outcome, causation can be inferred (Beach and Pedersen, 2010, p. 6). The frequentist approach seeks no explanation of how the independent variable affected the change in the outcome. This is what the causal mechanism approach seeks to rectify by explaining exactly how the independent variable elicits change in the outcome of interest. George and Bennett suggest this linkage is made by explicitly identifying the intervening variables between the independent variable and the dependent variable (2005). Beach and Pederson suggest that this approach is insufficient and propose a mechanistic approach based on identifying the entities and activities that transmit causality from the independent to the dependent variable (2010). Entities are the nouns, often actors, and activities are the verbs, such as voting, that affect the change observed. Figure 1-1 from Chapter 1 outlines this mechanistic approach using the causal path proposed in this study. This approach focuses on what occurs between the variables, instead of introducing new variables between the independent and dependent variables. While this project adopts the approach suggested by Beach and Pederson, both approaches propose within-case process tracing as the most appropriate method for identifying causal mechanisms. 
Process tracing is the detailed review of each step of a causal path to reveal the total process involved in producing an outcome, including intervening variables and necessary conditions (George and Bennett, 2005). The goal is to identify the causal mechanism that can explain the outcome we observe. Causal mechanisms, like most social science concepts, are unseen and we, therefore, need to infer their existence. This is achieved by identifying possible observable implications of our theories, often called causal-process observations (CPOs), in the case we are studying (Collier, 2011; Collier, Brady, and Seawright, 2010). As causal mechanisms and most social science concepts are essentially unobservable, we instead look for CPOs that indicate their presence. Through descriptive and causal inference, we use CPOs as evidence of the existence of unseen mechanisms or concepts. If our proposed implications are observed, we can conclude that our theory adequately explains the causal mechanism connecting the independent variables of interest to the observed outcome (Beach and Pederson, 2013; Collier, 2011; George and Bennett, 2005). Process tracing therefore, relies on testing for these observable implications to explain a case of interest. The relevant CPOs are the evidence used to text each of the hypotheses introduced in Chapter 1.

\section{Tests of Evidence}

Testing for observable implications is the core of process tracing, and the evaluation of evidence of these observations is essential. Evaluation of evidence in process tracing is generally based on the type of tests described by Van Evra who measures the strength of a test on two dimensions: certainty and uniqueness (1997). These two dimensions lead to four types of tests (Table 3-1) that can be applied to the predictions of the observable implications we generate with theory, prior to commencing 
the case study. Doubly decisive tests are difficult to identify in practice and straw -in- the -wind -tests offer only weak support for a theory. In practice, most tests are of the smoking gun and hoop test variety (Mahoney, 2012). By identifying stringent tests that have the potential to eliminate or support a theory, we hope to build a base of evidence to test the theories we propose.

Table 3-2 Tests of Observable Implications of Theory in Process Tracing (Van Evra, p. 31)

\begin{tabular}{|l|l|l|l|}
\hline \multicolumn{2}{|c|}{} & \multicolumn{2}{c|}{ Certainty } \\
\cline { 3 - 4 } & \multirow{2}{*}{ High } & $\begin{array}{l}\text { High } \\
\text { Doubly decisive tests: can } \\
\text { both prove and disprove a } \\
\text { theory. Strongest test }\end{array}$ & $\begin{array}{l}\text { Smoking gun tests: can } \\
\text { only support a theory } \\
\text { but not eliminate it }\end{array}$ \\
\cline { 2 - 4 } & Low & $\begin{array}{l}\text { Hoop tests: can only } \\
\text { eliminate a theory, not } \\
\text { prove one }\end{array}$ & $\begin{array}{l}\text { Straw in the wind tests: } \\
\text { unable to decisively } \\
\text { prove or eliminate a } \\
\text { theory but can add } \\
\text { some weight. Weakest } \\
\text { test }\end{array}$ \\
\hline
\end{tabular}

\section{Conflict Expansion: Tracing Causes to Outcomes}

Studies that utilize process tracing proceed, at least implicitly, in two stages. The first involves a careful description of the events under study. As Collier makes clear, process tracing identifies the process of causation over time, as causation is transferred from independent to dependent variables (2011). However, to see a change over time we need a series of "snapshots" of the case at different points of time (Collier, 2011). Good description is therefore the first crucial stage in developing a case study to test the presence of causal mechanisms. Only after a careful description can the casual 
mechanisms be identified. The following section provides an outline of both the descriptive and causal inferences and the evidence used in each stage.

Figure 3-2 below elaborates on the basic causal path outlined in Chapter 1 (Figure 1-1) and illustrates the descriptive and causal stages of the dissertation. The descriptive stage establishes each step of the causal path (the large boxes). The evidence to test for each stage is presented below in the section on descriptive inferences. The causal mechanisms between each step are the entities and activities (the small boxes) that transmit causality from independent to dependent variables. The evidence (or CPOs) used to test for the proposed causal mechanisms follows in the section on causal inferences.

Figure 3-1 Proposed Causal Process Mechanisms

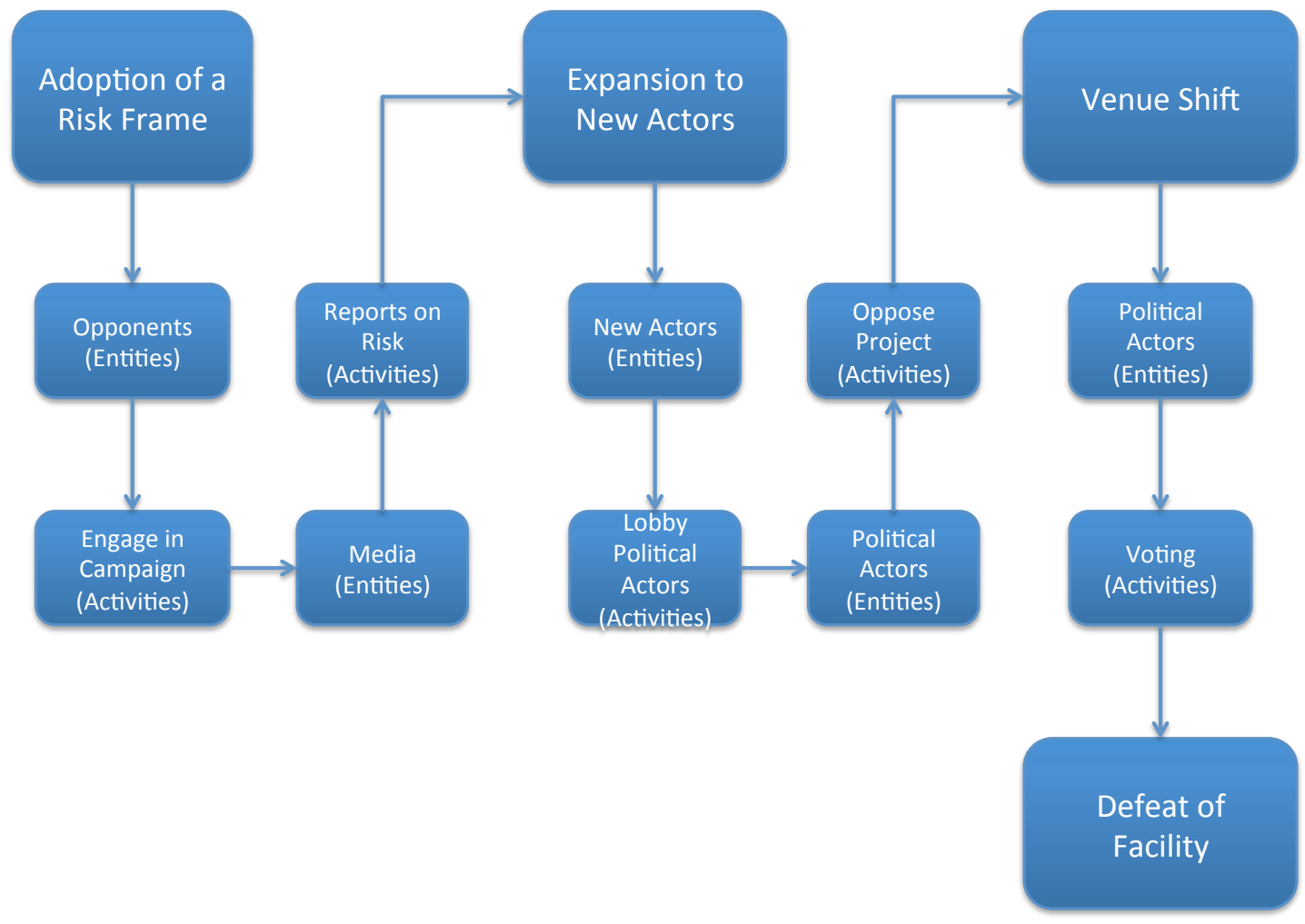




\section{Stage 1: Descriptive Inference}

The first stage in this research project is therefore a careful description of the unfolding of events in each case. Figure 3-2 above outlines the sequence of events in the proposed causal path for this study. Each step must be described as a discrete moment in time, prior to testing for the causal mechanisms that links each of these events (Collier, 2011; Mahoney, 2012). The first proposed step is the change from a non-risk frame to a risk frame. If no risk frame develops, then we cannot hope to identify what effect that development would have. A risk frame is primarily identified through media reports of the conflicts, interviews with participants, and surveys of the public. Media reports expose readers to these frames and framing theory suggests that the more people are exposed to a frame, the more influence that frame will have (Chong ad Druckman, 2007). The goal is to identify if a risk frame has become the dominant frame utilized by the opposition to each facility. The next step is the expansion of the conflict to new actors that is aided (in the theory proposed here) by the adoption of the risk frame. New actors join the conflict that would have been unlikely to participate without the advent of the risk frame. Once the opposition is expanded to include new actors that opposition will attempt to shift to new venues that are more amenable to a risk frame. Once the venue shifts, the defeat of the facility is possible. At the descriptive stage, no attempt is made to link these events through a causal mechanism but only to use descriptive inference to determine if these events actually occurred.

Because concepts such as a risk frame are essentially unobservable, descriptive inference is required to confirm their existence. Tests of the type outlined above can be applied to these expected inferences to confirm they actually exist in the cases examined. 
Table 2 outlines the tests, evidence, and data for each of the expected stages in the proposal causal path. These tests are not to establish causality between stages, but only to provide a descriptive snapshot at each stage. We cannot hope to establish that the change in the frame of the conflict to a risk-based frame caused (or at least allowed) the expansion of the conflict to new actors, if we cannot confirm that the frame did in fact change and that the expansion of the conflict actually occurred. Only then is it reasonable to try to reveal through causal inference that one caused the other.

Table 3-3 Descriptive Inferences of Proposed Causal Mechanism

\begin{tabular}{|c|l|l|}
\hline $\begin{array}{c}\text { Implication of } \\
\text { Theory }\end{array}$ & Evidence and Data Type & Type of test \\
\hline \multirow{5}{*}{$\begin{array}{c}\text { Adoption of risk } \\
\text { frame }\end{array}$} & $\begin{array}{l}\text { Interviews - focus on risk by } \\
\text { opponents/denial by proponents } \\
\text { (elite risk perception) }\end{array}$ & $\begin{array}{l}\text { Hoop test - failure indicates } \\
\text { risk not an elite factor, passing } \\
\text { does not mean it is the } \\
\text { dominant frame (not a } \\
\text { representative sample) }\end{array}$ \\
\cline { 2 - 3 } & $\begin{array}{l}\text { Media research - risk is dominant } \\
\text { frame (media risk frame) as } \\
\text { revealed through coding of stories } \\
\text { about conflict }\end{array}$ & $\begin{array}{l}\text { Doubly decisive - passing } \\
\text { proves it is the dominant } \\
\text { frame and eliminates anything } \\
\text { else as the dominant frame }\end{array}$ \\
\cline { 2 - 3 } $\begin{array}{l}\text { Survey - perception of risk as } \\
\text { dominant understanding (public } \\
\text { risk perception) }\end{array}$ & $\begin{array}{l}\text { Doubly decisive - passing } \\
\text { proves it is the dominant } \\
\text { frame and eliminates anything } \\
\text { else as the dominant frame }\end{array}$ \\
\hline \multirow{2}{*}{$\begin{array}{c}\text { New actors join } \\
\text { conflict (expansion } \\
\text { of conflict) }\end{array}$} & $\begin{array}{l}\text { Interviews - subjects reporting } \\
\text { role of new actors }\end{array}$ & $\begin{array}{l}\text { Smoking gun - passing means } \\
\text { there are new actors but } \\
\text { failing does not mean there is } \\
\text { not (could be unknown to } \\
\text { interview participants) }\end{array}$ \\
\cline { 2 - 3 } & $\begin{array}{l}\text { Media research - reports of } \\
\text { introduction of new actors from } \\
\text { outside region }\end{array}$ & $\begin{array}{l}\text { Smoking gun - passing means } \\
\text { there are new actors but } \\
\text { failing does not mean there is } \\
\text { not (could be unknown to } \\
\text { media) }\end{array}$ \\
\cline { 2 - 3 } & $\begin{array}{l}\text { Survey - actors (non-elite) outside } \\
\text { local actors participating in } \\
\text { conflict }\end{array}$ & $\begin{array}{l}\text { Smoking gun - passing means } \\
\text { there are new actors but } \\
\text { failing does not mean there is } \\
\text { not (could be elites that are }\end{array}$ \\
\hline
\end{tabular}




\begin{tabular}{|c|c|c|}
\hline & & joining unknown to public) \\
\hline & $\begin{array}{l}\text { Interviews - reports of strategies } \\
\text { of venue shopping to more open } \\
\text { venues }\end{array}$ & $\begin{array}{l}\text { Hoop test - failure means that } \\
\text { at least those interviewed did } \\
\text { not engage in venue shopping }\end{array}$ \\
\hline Venue Shopping & $\begin{array}{l}\text { Media research - reports on actors } \\
\text { seeking more open venues (i.e. } \\
\text { applications for appeals to EA } \\
\text { decisions, campaigns for } \\
\text { municipal elections, etc.) }\end{array}$ & $\begin{array}{l}\text { Smoking gun - passing means } \\
\text { there is venue shopping } \\
\text { occurring but failing does not } \\
\text { mean there is not (could be } \\
\text { unknown to media although } \\
\text { this seems unlikely) }\end{array}$ \\
\hline Outcome & $\begin{array}{l}\text { Secondary research - completion } \\
\text { of facilities }\end{array}$ & Doubly decisive \\
\hline
\end{tabular}

\section{Stage 2: Causal Inference}

The second stage of process tracing is the linkage of events and outcomes through testing for the proposed causal mechanism hypothesized to link an independent and dependent variable. In this study, three key linkages must be established to confirm that proposed causal mechanisms are present and function as expected. Figure 3-2 above outlines the entities and activities (the smaller boxes) that link each of the stages in the proposed causal path. Each step of this process are the hypotheses that were introduced in Chapters 1 and 2 and restated below. These hypotheses are based on expectations derived from the literature on agenda-setting conflicts, especially the literature on problem definition such as Rochefort and Cobb (1993) and Pralle's theory of conflict expansion (2006). The contribution of this research is the addition of a particular form of policy frame, the risk frame, to these theories.

\section{Hypothesis for Each Stage of Proposed Causal Path}

H1: That the greater the acceptance of a risk frame (by the public or elite actors), the greater degree to which a conflict will expand to new actors (public and elite). 
$\mathrm{H} 2$ : That the more actors that are drawn into the conflict, the more opportunity there will be to pursue venue shopping strategies.

H3: That the more opponents are able to engage in venue shopping, the greater the likelihood of altering the outcome of the conflict.

Figure 3-2 above describes the causal mechanism proposed to link the change in the risk frame and expansion of the conflict to include new actors that were established in the descriptive stage of the research project. The entities and actors are specified in the smaller boxes. In these cases, opponents of the project (entities) are hypothesized to engage in a campaign (activity) within the policy arena, such as protests and information dissemination that promote the risk-based frame. The media (entity), if these campaigns are successful, will then report on this frame (activity) and this may lead to the expansion of the conflict to include new actors outside of the original opponents of the facility. The risk frame is the key explanatory variable here as it is assumed that the risk frame is what attracts the interest of the media that then further disseminates the risk frame to a much larger public. That public is hypothesized to be far more receptive to that risk frame than an alternative frame. The causal mechanism is therefore the mechanism through which the risk frame is disseminated to the larger public, thereby engaging new actors in the conflict. This stage is compared across both cases in chapter 6 .

In the next step of the conflict, it is hypothesized that the new actors (entities) that have been drawn in will engage in pressure activities within the policy arena such as voting, lobbying, or protesting that will influence political actors (entities) to engage in the conflict within the municipal or provincial legislative body (activity). The 
engagement of political actors such as municipal councilors moves the conflict to an open institutional venue where, if there is enough political support, opponents of the facility can defeat the proposed facility. Participation in the new venue can include either the existing political actors changing their previous support for the facility (necessary to have approved the facility initially) or the election of new political actors based (at least partially) on their opposition to the facility. This stage of the conflict is compared across both cases in chapter 7 .

Testing for the causal mechanisms outlined above requires the same tests required for effective descriptive inference. Table 3-4 below outlines the data source, evidence, and the type of test for each of the proposed causal mechanisms. Each stage in the mechanism is tested using several data sources and the different form of test is largely determined by the data available. As the above discussion of evidence suggests, the evidence and the corresponding tests of that evidence proposed here are not necessarily comparable across each stage of the proposed causal mechanism. The tests used to establish that a risk frame has become the dominant opposition frame are not comparable to the evidence used to test the existence of new actors in the conflict. They are distinct events that are both essential to the proposed causal path but cannot be identified or tested using the same evidence. If the tests for the existence of these CPOs are positive, it indicates that the proposed causal mechanism, the deployment of a risk frame by opponents of each facility, contributed to the outcome of that conflict. 
Table 3-4 Causal Inferences of Proposed Causal Mechanism

\begin{tabular}{|c|c|c|c|}
\hline $\begin{array}{l}\text { Implication of } \\
\text { Theory }\end{array}$ & $\begin{array}{l}\text { Causal } \\
\text { Mechanism }\end{array}$ & $\begin{array}{l}\text { Evidence and Data } \\
\text { Type }\end{array}$ & Type of test \\
\hline \multirow{4}{*}{$\begin{array}{l}\text { Adoption of } \\
\text { Risk Frame - } \\
\text { New Actors } \\
\text { Join Conflict }\end{array}$} & \multirow{3}{*}{$\begin{array}{l}\text { Opponents (Entity) } \\
\text { engaging in } \\
\text { activities to } \\
\text { promote the risk } \\
\text { frame }\end{array}$} & $\begin{array}{l}\text { Interviews - subjects } \\
\text { reporting on activities of } \\
\text { opponents related to } \\
\text { promotion of risk frame } \\
\text { (protests, etc.) }\end{array}$ & $\begin{array}{l}\text { Smoking Gun - Passing } \\
\text { means that opponents } \\
\text { did engage in activities } \\
\text { to promote risk frame } \\
\text { but failing does not } \\
\text { mean there is not (could } \\
\text { be unknown to } \\
\text { interview participants) }\end{array}$ \\
\hline & & $\begin{array}{l}\text { Media Research - } \\
\text { media coverage of } \\
\text { opponents }\end{array}$ & $\begin{array}{l}\text { Smoking Gun - Passing } \\
\text { means that opponents } \\
\text { did engage in activities } \\
\text { to promote risk frame } \\
\text { but failing does not } \\
\text { mean there is not (may } \\
\text { not have been covered } \\
\text { by media) }\end{array}$ \\
\hline & & $\begin{array}{l}\text { Secondary Research - } \\
\text { documents outlining } \\
\text { activities of opponents } \\
\text { including publications } \\
\text { from opponents }\end{array}$ & $\begin{array}{l}\text { Smoking Gun - Passing } \\
\text { means that opponents } \\
\text { did engage in activities } \\
\text { to promote risk frame } \\
\text { but failing does not } \\
\text { mean there is not } \\
\text { (documents may not be } \\
\text { available or appropriate) }\end{array}$ \\
\hline & $\begin{array}{l}\text { Media (Entity) } \\
\text { reports on risk } \\
\text { frame (Activity) }\end{array}$ & $\begin{array}{l}\text { Media Research - } \\
\text { Media reports of } \\
\text { conflict focus on risk } \\
\text { frame }\end{array}$ & $\begin{array}{l}\text { Doubly Decisive - } \\
\text { passing proves the } \\
\text { media did report on the } \\
\text { risk frame and proves } \\
\text { no other frame received } \\
\text { as much coverage }\end{array}$ \\
\hline \multirow[t]{2}{*}{$\begin{array}{l}\text { New Actors - } \\
\text { Venue Shift }\end{array}$} & \multirow[t]{2}{*}{$\begin{array}{c}\text { New Actors } \\
\text { (Entities) engage } \\
\text { in activities to } \\
\text { influence political } \\
\text { actors }\end{array}$} & $\begin{array}{l}\text { Interviews - subjects } \\
\text { report participation of } \\
\text { new actors in conflict } \\
\text { (beyond original } \\
\text { opponents) }\end{array}$ & $\begin{array}{l}\text { Smoking gun - passing } \\
\text { means that new actors } \\
\text { engage in political } \\
\text { activities but failing } \\
\text { does not mean there is } \\
\text { not (could be unknown } \\
\text { to interview } \\
\text { participants) }\end{array}$ \\
\hline & & $\begin{array}{l}\text { Media Research - } \\
\text { reports of new actors }\end{array}$ & $\begin{array}{l}\text { Smoking gun - passing } \\
\text { means there are new }\end{array}$ \\
\hline
\end{tabular}




\begin{tabular}{|c|c|c|c|}
\hline & & participating & $\begin{array}{l}\text { actors engaging in } \\
\text { political activities but } \\
\text { failing does not mean } \\
\text { there is not (could be } \\
\text { unknown to media) }\end{array}$ \\
\hline & & $\begin{array}{l}\text { Survey Research-- } \\
\text { respondents outside of } \\
\text { immediate area of } \\
\text { facility reporting } \\
\text { engaging in activities } \\
\text { (voting or direct } \\
\text { participation) to } \\
\text { influence political } \\
\text { actors }\end{array}$ & $\begin{array}{l}\text { Smoking gun - passing } \\
\text { means that new actors } \\
\text { are participating but } \\
\text { failing does not mean } \\
\text { there is not (could be } \\
\text { elites that are engaging } \\
\text { in political activities } \\
\text { unknown to } \\
\text { respondents) }\end{array}$ \\
\hline & \multirow{2}{*}{$\begin{array}{l}\text { Political Actors } \\
\text { (Entities) engaging } \\
\text { in opposition } \\
\text { (activity) to } \\
\text { project }\end{array}$} & $\begin{array}{l}\text { Interviews - subjects } \\
\text { report engaging in or } \\
\text { observing other political } \\
\text { participants engaging in } \\
\text { political activities (for } \\
\text { example, running for } \\
\text { election) in opposition } \\
\text { to the project }\end{array}$ & $\begin{array}{l}\text { Smoking gun - passing } \\
\text { means that political } \\
\text { actors engage in } \\
\text { political activities but } \\
\text { failing does not mean } \\
\text { that political actors are } \\
\text { not engaging in political } \\
\text { activities (could be } \\
\text { unknown to interview } \\
\text { participants) }\end{array}$ \\
\hline & & $\begin{array}{l}\text { Media Research-- } \\
\text { reports of political } \\
\text { actors engaging in } \\
\text { political activities in } \\
\text { opposition }\end{array}$ & $\begin{array}{l}\text { Smoking gun - passing } \\
\text { means there is political } \\
\text { actors engaging on } \\
\text { political activities but } \\
\text { failing does not mean } \\
\text { there is not (could be } \\
\text { unknown to media) }\end{array}$ \\
\hline \multirow{3}{*}{$\begin{array}{l}\text { Venue Shift - } \\
\text { Defeat of } \\
\text { Facility }\end{array}$} & \multirow{3}{*}{$\begin{array}{l}\text { Political Actors } \\
\text { (Entities) vote to } \\
\text { defeat facility }\end{array}$} & $\begin{array}{l}\text { Interview - reports of } \\
\text { political actors voting or } \\
\text { influencing others to } \\
\text { vote to defeat facility }\end{array}$ & $\begin{array}{l}\text { Smoking gun - passing } \\
\text { means that political } \\
\text { actors vote or influence } \\
\text { but failing does not } \\
\text { mean there is not (could } \\
\text { be unknown to } \\
\text { interview participants) }\end{array}$ \\
\hline & & $\begin{array}{l}\text { Media Research-- } \\
\text { reports of political } \\
\text { actors voting or } \\
\text { influencing others to } \\
\text { vote to defeat facility }\end{array}$ & $\begin{array}{l}\text { Smoking Gun - passing } \\
\text { means that political } \\
\text { actors vote or influence } \\
\text { but failing does not } \\
\text { mean there is not (could } \\
\text { be unknown to media) }\end{array}$ \\
\hline & & $\begin{array}{l}\text { Secondary Research - } \\
\text { voting records }\end{array}$ & Doubly Decisive \\
\hline
\end{tabular}




\section{Comparison Between Cases}

Process tracing, which is the core analytical tool applied in this dissertation, is a research design primarily focused on within-case analysis. However, small- $n$ qualitative studies often use cross case comparisons to gain additional insight. This method is generally based on the idea of a controlled comparison: to compare a small number of cases that vary on only a single variable. This attempt to isolate a single variable mimics the experimental method and is most often associated with Mill's methods of comparison (George and Bennett, 2005). However, many methodologists point to the difficulty in identifying real world cases that are nearly identical except on one crucial variable (George and Bennett 2005). Controlled comparison is an ideal that is generally not achievable and this is certainly the reality of this project.

Controlled comparison is not possible but a comparison of the within-case analysis of two cases can be important to reveal the conditions required for a causal mechanism to operate. Within-case analysis, through process tracing can reveal the causal mechanisms linking the changes in the dependent and independent variable. However, as most causal mechanisms in the social world are highly contextual, the conditions, called scope conditions by Mahoney (2012) that are necessary for them to operate are crucial in understanding why and when those mechanisms operate. Comparing the within-case analysis of two cases where the independent variable is present but where the dependent variable is different can help reveal the conditions under which a causal mechanism may or may not operate. As Goertz and Mahoney make clear, cross-case comparison has limited leverage for establishing causation without the crucial step of within-case analysis (2012). But by comparing the results of the within-case 
analysis, researchers gain additional leverage by understanding, not just why a causal mechanism works in a particular case, but why it does not work in another. ${ }^{5}$ Comparing these cases can reveal the minimal necessary conditions for the hypothesized causal path to operate. This study focuses on the within-case analysis of each of the two studies but the results of this analysis in each are then compared. Comparison can then identify under which conditions the proposed causal mechanism can be expected to function.

\section{Methodology: Sources and Analysis of Data}

Case studies are one way data are organized and understood. The actual collection of data for a case study varies based on the question of interest. Case studies often involve interviews, historical research, secondary research, participatory observation, survey data, or even formal modeling (Poteete, Janssen, and Ostrom, 2010). The concepts of interest and the evidence to make the descriptive and causal inferences described above will require a mix of data gathering and analysis techniques. The application of mixed methods to a single research project provides an opportunity to apply the most appropriate method to the research question. Some of the variables described above can be measured using several distinct methodologies, often described as triangulation, which will strengthen the validity of these measures. The four primary methods applied in this research project are: extensive secondary research, an analysis of the media reports of each conflict, interviews with key participants of each case, and a survey of residents of Simcoe and Bruce Counties. The research project began with gathering and analyzing secondary sources for both cases, followed by the media analysis and interviews for

\footnotetext{
${ }^{5}$ It should be noted here that, like the comparison of evidence across different stages of the causal mechanism, the evidence in each case may be non-comparable between cases (Beach and Pederson, 2013). Only the presence or absence of each stage of the proposed causal path will be directly comparable.
} 
Simcoe County, and then these were completed for Bruce County. The surveys of both counties were completed simultaneously and were the final data gathering stage of the project.

\section{Secondary Sources}

Extensive documentary research was central to understanding the context, background, and history in each case study, which included scholarly publications relevant to these types of conflicts. Both case studies were recent, but essentially historical studies, which necessitates identifying the important written records of events. These included formal communications by municipal, provincial, and federal levels of government, the official records of the Ontario Municipal Board (OMB) and Environmental Assessment tribunals, records of meetings, and communications by various groups opposed and supportive of the proposed facilities. Again, the evidentiary value of a document or source must be weighed as many are at the least ambiguous and some are intentionally misleading (Beach and Pederson, 2013). Corroboration between different sources is the best defense against ambiguity and is always used when possible. Most of these documents were not formally coded but were used to provide the context and outcomes of each conflict as well as evidence of the causal mechanisms hypothesized to be active in each case.

\section{Content Analysis of Newspaper Reports}

Newspaper articles can be important sources for process tracing case studies and are especially important to studies of agenda setting. The media plays a crucial role in agenda-setting studies, as they are sources that can reveal the nature and intensity of interest around an issue (Baumgartner and Jones, 1993). This is a common approach in 
framing research and is used to identify the presence or absence of frames of interest to the researcher (Chong and Druckman, 2007). Media reports are used in this study to help identify the dominant policy frame used by proponents and opponents of the projects under study. The media transmits these frames to the public but is not just a neutral conduit for these messages but is of course also a filter. The formation of a risk frame is an essential phase of the proposed causal path and the media are an essential part of the proposed causal mechanism that link advocating of that risk frame by opponents to new actors who may join the conflict (Figure 3-2). Newspaper reports about each project and the conflict over those projects can reveal the different frames that are developed and the number of times a frame is reported.

Because of the controversial nature of each conflict, there was an extensive record of newspaper stories, letters, and editorials available for analysis. In the Site 41 case over $500(\mathrm{n}=507)$ newspaper articles were identified using the Canadian Newsstand article index using key words such as "Site 41 ". In the Bruce county case, most local papers were not indexed, so in addition to those from Canadian Newsstand, two local newspapers were searched using keywords such as "Turbine", "windfarm", and "Enbridge" (the project owner) and this produced 302 articles. These searches were conducted for the periods beginning when the facilities were first proposed (1990 for Site 41 and 2003 for the Kincardine wind farm) until the end of the conflicts (2010 when Site 41 was cancelled by Simcoe County ad 2009 when the Kincardine wind farm was completed).

Once identification of the reports was complete a directed content analysis on each newspaper report was completed using a coding instrument and the NVivio content 
analysis software. The initial coding instrument focused on the frames used to either oppose or support each facility based on predetermined definitions of the expected frames. For example, identification of the health risk frame was based on any mention of the possible consequences of the facility for human health. Articles were not themselves coded as either supportive or oppositional and many reports included mention of multiple frames. While the coding instrument was predetermined, the coder was open to potential previously unidentified frames and several, such as the opposition framing of the potentially inequitable leasing contracts offered by wind energy companies, were identified during the coding process. As the author was the only coder, inter-coder reliability was not a concern.

\section{Interviews}

Interviews with key actors are a central method of gathering essential data within process tracing case studies (Beach and Pederson, 2013; George and Bennett, 2005; Tansey, 2007). Semi-structured interviews with key informants provide crucial information and evidence related to each case. Much of the data can only be gathered by direct contact with the participants as interviews provide the opportunity to assess the motivations and perceptions of individual actors in the cases (Kvale, 1996; Tansey, 2007). While important, interviews must be carefully weighed as evidence as subjects may misremember, have imperfect understandings of events, or may intentionally mislead (Beach and Pederson, 2013; Tansey, 2007). In light of this, multiple sources are always used to corroborate the accounts of interview subjects. However, while there is extensive documentation surrounding each case, only interviews can provide context and insight beyond the official documents. 
Any social research involving human subjects requires close attention to ethics, but interviews can pose specific problems. Each of the cases under study occurred in mostly rural communities and involved conflicts that were often heated and bitter. The legacies of these conflicts remain in each community and any researcher must recognize the potential risk faced by participants if their identity or comments became public. Many of the interview subjects are still community or political actors and might suffer stigma from comments about these controversial facilities. With this in mind, all requests for interviews were confidential and interviews were conducted privately in locations where the participant was comfortable. No attribution of any participant's comments will be included in this dissertation. Each participant was provided with a consent form (Appendix A) that outlined the potential risks of the research, and the researcher prior to commencing the interview also explained these risks verbally. While informed consent is a contentious concept, the participants were all adults who participated publically in the conflicts under study and we are confident as possible that all participation was informed. ${ }^{6}$ Ryerson University's Research Ethics Board approved this research project. Selecting interview participants is always difficult, but if conducted based on a coherent criteria, a suitable mix of participants can be identified. ${ }^{7}$ In both cases, actors representing those opposed to the proposed facility, actors that were part of the municipal decision-making process, and proponents of the facilities were identified and invited to participate (see Table 3-5). Secondary sources and media research provided the first set of interview subjects and others were identified through early interviews. Twelve

\footnotetext{
${ }^{6}$ See Thorne (2005) for excellent discussion of potential issues of informed consent including problems such as language barriers or unequal social position.

${ }^{7}$ See Tansey (2007) for discussion of selection criteria for interview participants in process tracing studies.
} 
interviews were completed in Simcoe County and nine in Bruce County. The number of final interviews was based on the evaluation that further interviews were unlikely to yield substantial new evidence. The relatively low number of interviews reflects both the reluctance of some actors to participate and the need to only focus on key decisionmakers in what are relatively local conflicts.

Table 3-5: Number of Interview Subjects by Position

\begin{tabular}{|l|l|l|}
\hline & Site 49 & $\begin{array}{l}\text { Kincardine Wind } \\
\text { Farm }\end{array}$ \\
\hline County Councilors & 6 & 4 \\
\hline Activists (community or provincially based) & 6 & 4 \\
\hline Municipal Bureaucrats & 0 & 1 \\
\hline
\end{tabular}

The interview guide (Appendix A) for both cases provided some structure to each interview. Questions about risk perception and institutional trust were similar in each case to aid in comparisons across cases. However, other questions were highly specific to each case and often to the individual interviewed. These questions were aimed at revealing the context, sequence of events, and personal views of the participant about his or her role in the case.

\section{Surveys of Simcoe and Bruce County Residents}

The proposed causal path outlined above includes several steps that premises the adoption of a risk frame will lead to the expansion of these conflicts to new actors. While some of these actors will be new elite actors, such as environmental groups, the expansion of the conflict hypothesized here assumes the public will also become more engaged. An engaged public that accepts (or largely accepts) the risk frame are more likely to participate in the conflict, either directly through such activities as protests or attending public meetings, or through voting in support of political actors who oppose the 
project. Evidence about public perception of the risk posed by the conflict and of any political activity by the public is essential for testing for the existence of this causal mechanism. Therefore, a public opinion survey of residents in each region of the two case studies was conducted.

Qualitative case studies within the process tracing tradition do not generally include survey data. However, many methodologists who advocate for process tracing methods explicitly recognize that numeric data can provide important evidence for both descriptive and causal inference (Beach and Pederson, 2013; Collier, 2011). In this study, survey data can provide crucial evidence for testing some of the descriptive and causal inferences outlined in Tables 3-2 and 3-3. One key step in the proposed causal path is the expansion of the conflict to include actors who would not normally participate in a local land use dispute. Survey data of residents outside of the immediate area of each facility can indicate the extent of awareness of the conflict, concern over risk, and participation of actors far from the facility. If a significant number of actors outside the immediate area accept the risk frame (as measured by survey questions about the risk of the project) then we can claim the risk frame has become a dominant understanding of the issue. If those actors are also opposed to the project and participate in the conflict, either through direct participation or voting, this is strong evidence that the conflict has expanded to new actors. Survey data can provide a strong test for many of the essential descriptive and causal inferences in this study.

The survey was conducted in the summer of 2012 and 3000 questionnaires were mailed (hard copy) to residents of Simcoe and Bruce counties for a total of 6000 surveys. A total of 1159 completed surveys were returned for a response rate of $19.3 \%$,in Bruce 
County and $17 \%$ in Simcoe County. This response rate is lower than is often the case with mailed surveys and this is explained by the lack of the recommended regimen of follow up reminders because of the lack of resources necessary (Rea and Parker, 2005). The list of potential respondents was generated from a commercial address list, which was stratified into two regions in each county, based on location relative to the proposed facility. This was done to test the effects of proximity to the facility. The crucial issue of whether the conflict expanded to new actors can be tested with this variable. Actors living close to the facility are presumed to have higher levels of interest in the conflict based on simple concerns such as aesthetics. If the deployment of a risk frame by opponents is successful, we should see residents living far from the facility become engaged in the conflict because of concerns around risk. The conflict expands from a localized conflict around the nuisance of the facility to a regional conflict centered on the risk of that facility to the broader community. Within each of the four regions (two per county), a random number generator was used to generate the final sample frame.

The survey questionnaire (Appendix B) involves three different sections, each aimed at measuring different variables important to the study. The first section can be answered by anyone who received the survey whether he or she is familiar with the conflict at the center of each case. This section asks a variety of questions about the respondent's opinion about trust in various institutions of decision-making in the area including all three levels of government. The intent is to capture a more nuanced account of trust including perceptions of competence and fairness that are often suggested as important components of trust (Levy, 1997). Several questions in this section are specific to each region and ask general questions about respondents' opinions on issues related to, 
but not specific to, each conflict. For example, in Simcoe County, questions were asked about the respondent's willingness to live near a solid waste facility without referring to Site 41. In Bruce County, residents were asked about their willingness to live near a wind farm without specifically referring to the Enbridge facility. The next set of questions in the first section asked respondents to rate their relative perception of the risks associated with a number of technologies and issues including wind turbines, solid waste facilities, genetically modified organisms, and nuclear power. These questions were essential for gauging the acceptance of the risk frame by the broader public.

The second section was preceded by a screening question about the respondent's knowledge of the facility at the heart of the conflict in each region. Those unfamiliar were asked to proceed to the final section comprised of demographic questions. Those familiar with the facility were asked if they opposed the facility, if they participated in any events around the facility, and if the facility had any impact on their voting preferences at each level of government. These are the key questions for evaluating the degree to which the conflict expanded beyond the initial actors opposed to the facility. The final section of the survey is standard demographic questions such as sex, level of education, and level of income. No open-ended questions were included in the survey because of difficulty in coding the large number of responses.

Representativeness of the sample has several weaknesses. The problems faced by all self-completed surveys of education bias and of assuring that only adults answered the survey (as was requested in the letter) are of course present (Rea and Parker, 2005). Because both counties are prominent vacation areas, the survey likely underrepresents seasonal residents who may not have been present during the survey period. A question 
on the survey to indicate seasonal residence was designed to capture this problem. More problematic is the potential overrepresentation of respondents who felt strongly, either for or against, the proposed project. This may lead to the overestimation of the degree of engagement of residents as those with little interest in the conflict are less likely to respond to the survey. Caution is therefore important when making generalizations about the overall political engagement of citizens in these areas.

The surveys and return envelopes had no identification, so the anonymity of respondents was assured. Surveys sent to each of the four regions were distinct so that respondents from each region could be identified and coded. This anonymity prevented follow up reminders from being sent but it was believed that this might encourage more honest responses from residents concerned with their opinions about these very divisive conflicts becoming public. The Ryerson University Research Ethics University Board approved this element of the research project. Once the surveys were returned, the responses were coded into a statistical software package, which was used for analysis.

\section{Conclusion}

Chapters 1 and 2 outlined the agenda-setting approach and the framework of issues, actors, and institutions that can be used to understand the influence of risk frames in the outcome of policy conflict. This chapter has elaborated on the research questions, hypotheses and casual mechanism that are the focus of this research project and how those questions can be answered utilizing process tracing. By using process tracing, the research seeks to identify the causal mechanisms that lead from a risk frame, to the expansion of a conflict, to the capture of an open institutional venue, to the final outcome of the policy conflict. Process tracing was used in both cases to examine and compare the 
use of risk frames and contribute to our understanding of what conditions allow a risk frame to lead to conflict expansion, venue shopping and ultimately outcomes to policy conflicts. Each case tests for evidence that allows for descriptive and causal inferences that the causal mechanism is present and functions as hypothesized. The evidence, or causal process observations, will be subjected to tests that will verify that the observations conform to expectations. Data for these tests is gathered from a number of sources that will provide a rich understanding of the cases and allow for triangulation of findings.

The following four empirical chapters present findings from the two case studies in journal article format. Each chapter applies the process tracing method to understand how the deployment of a risk frame changed the nature of each conflict by expanding that conflict to new actors. Each chapter presents and analyzes the data gathered to provide crucial evidence for establishing the causal processes outlined in this chapter. Chapters 4 and 5 present each of the conflicts selected as stand-alone case studies that trace each of the conflicts from the introduction of the risk frame, to the expansion of new actors, to the search for institutions that are the most receptive to the risk frame. Chapters 6 and 7 present comparisons of the two cases, Chapter 6 focuses on the deployment of the risk frame and the expansion of the process to include new actors and Chapter 7 focuses on the evidence of venue shopping and its significance in terms of altering the policy process and outcomes. 


\section{Chapter 4 - Policy Conflicts and the Framing of Risk: Evidence from a Land Use Conflict ${ }^{8}$}

\section{Introduction}

In the early 1980s a small municipal solid waste landfill site in Simcoe County, Ontario was proposed. Simcoe County is a largely rural area north of Toronto, Ontario, Canada that is dominated by agriculture and tourism. The proposed landfill, referred to as Site 41 would have serviced four of the small communities within the county and was a conventional design. Local decision-makers had little initial reason to suspect that the proposed facility would create opposition beyond the expected opposition of those living near the proposed solid waste facility. However, after prolonged legal battles, significant media and Non-Governmental Organization (NGO) attention including national environmental leaders and First Nations, the occupation of the site and subsequent arrest of protestors, the conflict had become a regional conflict with provincial and national coverage. In 2009, the County government voted to halt construction of the facility.

One of the most interesting characteristics of this conflict was the framing of Site 41 as a threat to local drinking water by the opponents of the facility. What role did the framing of this land use conflict (Site 41) as a threat to human health (through the contamination of local drinking water) play in the outcome of this conflict? This land use case is like many other local land use conflicts in the growing area of public policy where decisions once made by experts, government officials and elected politics are increasingly challenged by citizens that seek to recast a policy as a threat to human health

\footnotetext{
${ }^{8}$ This chapter is in article format. The potential venues for publication include Policy Studies Journal, Journal of Environment and Planning C, or Local Environment
} 
The framing of a policy problem has long been recognized as a key element in conflicts over public policy. Framing a policy problem involves arguments about where a problem comes from, what are the acceptable solutions to that problem, its relative urgency, and its social significance (Rochefort and Cobb, 1994). Conflict over the definition of a problem occurs when different actors wish to see their preferred frame accepted by elites and the public. These conflicts are an important part of the policymaking process because once a definition is accepted it will have a profound influence on whether that issue reaches the policy agenda, what solutions to that problem will be seen as an acceptable, and ultimately the outcome of these policy conflicts.

However, we know from policy research to date that all policy frames are not created equal. For example, problems that can be defined as threatening vulnerable groups will be seen as more urgent problems and are therefore more likely to reach the policy agenda (Boothe and Harrison, 2009; Pralle, 2006b; Schneider and Ingram, 1993; Stone, 1989). These problems often appeal to fundamental values and are therefore more likely to engage the public in these problems (Boothe and Harrison, 2009; Stone, 1989). A central component of the conflict over the proposed landfill in Simcoe, Ontario was the very different frames advanced by both sides. Proponents of the facility advocated the facility as a cost effective and safe way to manage local solid waste. Opponents instead claimed the facility was a dangerous risk to regional drinking water, and through potential contamination, a threat to human health. What role did the framing of Site 41 as a threat to human health through the contamination of local drinking water play in the outcome of this conflict? 
In order to analyze this question, this paper focuses on analyzing this case as a case of policy conflict using an approach developed by Sarah Pralle. Policy conflicts are created when different actors and groups of actors attempt to influence or control the course of decision-making about a policy. These actors will engage in various strategies to advance their aims. Pralle, building on theories of agenda setting (Baumgartner ad Jones, 1993) and conflict expansion (Rochefort and Cobb, 1994; Schattschneider, 1960), has developed an approach that categorizes the strategies used by these groups into three categories: strategies of issue definition, strategies of actor participation, and institutional strategies (2006).

This paper focuses on the framing of the facility as a risk to human health as a strategy of issue definition. While Pralle recognizes the interdependence of the three categories of strategies this paper aims to build on this approach by specifying a causal relationship between framing of the facility as a risk to human health, the expansion of the conflict to include new actors, and the shifting of institutional venues to alter the outcome of the conflict. To test this relationship and the influence of a human health frame by opponents on the outcome of the conflict, three hypotheses are proposed:

1. That the greater the success at framing Site 41 as a threat to local drinking water, the more successful opponents will be at expanding the conflict to include new actors (strategies of actor expansion).

2. That the more actors that are drawn into the conflict, the more opportunity opponents will have to shift the conflict to new institutional venues (an institutional strategy). 
3. That the more successful opponents are at moving conflicts to new institutions, the greater the likelihood of defeating the facility and altering the policy outcome. The following paper uses a case study and process tracing method to test these hypotheses in a local land use conflict (the case of the conflict over Site 41 in a rural County in Ontario, Canada). Process tracing is a form of within case analysis that focuses on linking cause to effect and is particularly appropriate for testing the above hypotheses. The findings from this case study make clear the centrality of the contest over framing to understanding the outcome of this conflict and other policy conflicts involving health risk frames. The paper makes a contribution to the understanding of policy conflicts and the role of framing in the policy process. The first is to specify the nature of the interrelationship between one type of framing issue definition strategy, the framing of a policy as a threat to human health, and the subsequent opportunities available to both opponents and proponents of that policy. When actors make decisions to engage in different strategies, those strategies will inevitably open or close opportunities for other types of strategies. For instance the framing of Site 41 as a threat to human health opened the door to new actors and, in turn, new institutional strategies. This case study specifies the institutional characteristics that created the incentive to frame the proposed landfill as a threat to local drinking water and human health. This frame opened the door to new actors and institutional venues that ultimately resulted in a different policy outcome. This analysis reveals under what circumstances the framing of a policy as a threat to human is likely to be successful and how this ultimately contributes to the outcome of this type of policy conflict. 


\section{Theoretical Foundations}

Actors, whether elected officials, bureaucrats, members of non-governmental organizations, or citizens, engage in conflicts over policy in order to influence or control decision-making over that policy. In order to influence policy these actors engage in strategies to influence or change policy outcomes. The aim of these strategies will often depend on whether these actors are part of a policy monopoly that controls that policy issue or are seeking to overturn that policy monopoly in order to affect policy change. Policy monopolies, as defined by Baumgartner and Jones (1994), are groups of actors who are able to maintain control over a policy by keeping that policy off the political agenda. This accounts for periods of relative policy stability, or equilibrium where little change in that policy area occurs. However, when another set of actors wish to see policy change, they challenge that monopoly. Those seeking policy change can deploy various strategies to alter the balance of power that supports the policy monopoly thereby punctuating the existing equilibrium (Baumgartner and Jones, 1994; Pralle, 2006).

Agenda-setting theories have often focused on the interaction between the problem definition (or policy frame), actors and institutions (Baumgartner and Jones, 1994; Boothe and Harrison, 2009; Pralle, 2003; Rochefort and Cobb, 1994). Different institutions will be more or less amenable to various frames and these definitions will, therefore, be more successful at achieving policy change in different institutions. Pralle made a significant contribution to this approach by focusing on policy conflicts and identifying three key sets of strategies actors will use to challenge or support a policy monopoly (2006). 
Issue definition is the first set of strategies identified by Pralle (2006) and the most critical for this case study as it is hypothesized here to be the strategy that opens opportunity for the others. Issue definition is about how groups are "interpreting events and constructing them in such a way that makes sense to potential participants and decision-makers" (Pralle, 2006a, p. 17). Theories of framing are useful ways of organizing the analysis of the different issue definitions advanced by opponents and proponents of a policy. If strategies of issue definition are about how the central policy in a conflict is understood, frames are the competing conceptions of that policy (Pralle, 2006a). Framing can defined as "the process by which people develop a particular conceptualization of an issue or reorient their thinking about an issue" (Chong and Druckman, 2007a). Frames can be thought of as the different, often competing conceptualizations of the problem definition, or casual story of a given policy.

Issue definition strategies are the strategies that can be deployed in order to raise or lower the salience of an issue to the public. By raising the salience of an issue, advocates of policy change hope to place the issue on the public agenda thereby providing the opportunity to overturn the existing policy monopoly (Baumgartner and Jones, 1993; Rochefort and Cobb, 1994). Controlling the way in which a policy issue is framed can provide significant advantages by controlling the scope of the issue, by claiming ownership of an issue, or by linking a previously low salience issue to a more salient one (Pralle, 2006). In the conflict over Site 41 this strategy was key as framing the facility as a threat to local drinking water was what expanded the conflict well beyond the initial participants. 
Framing is important in all policy conflicts but not all frames are created equal. This is particularly the case in land use, nuisance facility siting, and other 'risky' policy conflict cases. Traditionally, conflicts over land use such as construction of a solid waste facility, often attributed to the so-called NIMBY syndrome, were about citizen concern over declining property values if an unwanted facility, be it a group home, a food processing plant, or waste management facility was located near to their property (Dear, 1992). Typically, these concerns were only of interest to those living nearest the facility. Alternatively, both the public policy and risk literatures indicate that frames that focus on the potential of a facility to threaten human health or quality of life can potentially garner significant attention. While all facilities go through extensive technical evaluations to assess their impacts, the public's perception of risk is often contrary to the beliefs of experts and risk management professionals who quantify the risk as minimal without recognizing that the perception of risk by the public is often rooted in "non-quantifiable factors" (Johnson, 2007; Kasperson, 2005; Leiss, 2001; Siegrist and Cvetkovich, 2000; McAvoy, 1998; Slovic, 1993). The policy conflict then becomes about the relative risk posed by a facility or technology and risk can be integrated with theories of framing in public policy.

Problem framing is an intentional strategy of conflict expansion and this raises questions of how exactly actors make the decisions to engage in this strategy (Pralle, $2003,2010)$. While policy framing is never an entirely rational process, the conflict over Site 41 can be understood as two sets of actors, opponents and proponents, each advancing their preferred policy frame: Site 41 as a threat to drinking water and therefore as a risk to human health (opponents) and Site 41 as a cost effective and safe way to deal 
with locally generated solid waste. Opponents advocated the health risk frame as way of expanding the conflict beyond those who resided near the actual facility. Proponents of the facility sought to contain the conflict to a small set of actors by downplaying the potential risk and framing opponents as local NIMBY activists. The goal of opponents of the facility was to frame the facility as one that threated local drinking water and human health with the hope of drawing in new participants to the conflict.

The second set of strategies for conflict expansion identified by Pralle are focused on the participation of actors (2006). When a policy is controlled by a policy monopoly, actors within that monopoly will seek to limit the participation of new actors in order to preserve their monopoly of the policy. Advocates of change will seek to draw in new actors in order to tip the balance and undermine the monopoly. Opponents of Site 41 hoped to draw in actors from outside the immediate area of the facility by framing the facility as a risk to human health. This could raise the salience of the issue and bring it on to the public agenda. By drawing in new actors they hoped to overcome the policy monopoly held by the proponents of the facility, Simcoe County. The County, by advancing an alternative frame hoped to contain the conflict to only local actors.

The third set of strategies for conflict expansion identified by Pralle are focused on the institutional context of the policy conflict (2006). Institutions, as the set of rules that structure decision-making, are a key element of any political conflict. Strategies around institutions focus on how institutions provide opportunities for conflict expansion or contraction by limiting participation or access to decision-making institutions. Pralle identifies a number of institutional strategies but the strategy of venue shopping is the key strategy used in this conflict (2006). Venue shopping is the strategic movement of an 
issue or conflict by some group (such as policy-makers or advocacy groups) from one decision-making venue to another for the purpose of achieving advantage in realizing that groups goals (Baumgartner and Jones, 1993; Pralle, 2006a).

Critical to the concept of venue shopping is the recognition that institutional venues are not all the same. Different institutional venues are governed by different rules and those rules are never strictly neutral. All institutional rules contain biases, such as the rules around participation that benefit a particular group of actors (Boothe and Harrison, 2009; Pralle, 2003, 2010). Venue shopping as a conflict expansion strategy presupposes that different institutions offer different advantages and disadvantages to actors operating within those institutions. This is what provides the incentive to try moving a conflict from one venue to another. If an environmental group has been unsuccessful in advocating for policy change within a legislature, that may reflect a failure to raise the issue to the public agenda. Pursuing policy change within a legislature often requires significant public interest in that policy area and groups that are unable to generate that public interest will face significant barriers to success within that institution. That legislative institution contains rules that are biased against groups without the ability to mobilize significant public interest in the issue. Conversely, launching a lawsuit to effect policy change through the courts does not require the same public attention. However, this venue may be unavailable to a group without significant financial resources. Each venue offers opportunity but also has barriers that must be surmounted.

Thus institutional biases are crucial for understanding policy conflicts in this and other cases. In this case the relationship between the framing of Site 41 and the expansion of actors and the institutions of decision-making are the focus of analysis. Initial approval 
of the facility occurred within the Environmental Assessment process necessitated by the province of Ontario for solid waste facilities. These panels restrict participation to approved actors (generally stakeholders) and have formalized or even quasi-judicial proceedings that, in this case privileged expert and technical understandings of the potential risk posed by Site 41 . This is not to say that the tribunal would inevitably approve the facility, but only that the decision was grounded in technical understandings of risk based on expert assessment and evidence.

Because the strategies of conflict expansion and containment are the key to understanding the influence of the health risk frame on the outcome of the conflict over Site 41 , this study also seeks to investigate how the actors in this conflict selected and used the strategies they did. It also investigates the degree to which framing, the expansion of the conflict to include new actors, and the process of venue shopping were rational strategies pursued by opponents of Site 41 . The approach of analyzing strategies of conflict expansion developed by Pralle (2006) recognizes and describes the interdependency of these strategies but this study seeks to advance theory and research by examining the causal links between these strategies using Site 41 as a case study. The framing of Site 41 as a risk to human health by opponents was a deliberate strategy that drew in new participants to the conflict, which opened the opportunity for venue shopping. This hypothesized relationship requires testing and the following section outlines the research design and methodologies used in this case study.

\section{Research Design and Methodology}

This paper employs a case study research design using process tracing as the primary tool for testing the above hypotheses. Process tracing, a form of within-case 
analysis, seeks to explicitly reveal the underlying causal mechanisms that link events to the outcomes we observe. Process tracing is a particularly appropriate approach for the study of policy change (Kay and Baker, 2014). The specific evidence used in this case study was gathered using a number of methodologies. First, extensive documentary evidence was collected including formal communications by municipal, provincial, and federal levels of government, the official records of Ontario Municipal Board (OMB) and Environmental assessment tribunals, records of meetings, and communications by various groups and individuals involved in the conflict. This evidence provided significant detail about the case under study.

Second, 507 media reports about the conflict were collected from digital archives for the years 1990 through 2010 and coded to identify the frames used by newspapers in each county in media coverage of the conflicts. This is a common approach in framing research and is used to identify the presence or absence of frames of interest to the researcher (Chong and Druckman, 2007). The first stage of this process utilized a search of Canadian Newsstand database using search terms such as "Site 41", and "Simcoe County waste". Because several of the local papers were not indexed in the database, a second stage involved using the same search terms in local papers such as the Barrie Examiner. These searches were conducted for the periods beginning when the facility was first proposed (1990) until the end of the conflict in 2010 when Site 41 was cancelled by Simcoe County.

Once identification of the reports was complete a directed content analysis on each newspaper report was completed using a coding instrument. The initial coding instrument focused on the frames used to either oppose or support the facility based on 
predetermined definitions of the expected frames. For example, identification of the health risk frame was based on any mention of the possible consequences of Site 41 for human health. Articles were not themselves coded as either supportive or oppositional and many reports included mention of multiple frames. As the author was the only coder, inter-coder reliability was not a concern.

Third, 12 semi-structured interviews with a variety of stakeholders from the Site 41 conflict were conducted. These interviews were invaluable for assessing the opinions and motivations of stakeholders, including: current and former political actors, members of groups opposed to each site, and municipal bureaucratic actors involved in the conflict. This is crucial for identifying the strategies of policy actors. Secondary sources and media research provided the first set of interview subjects and others were identified through early interviews.

Finally, a mail out survey of Simcoe County residents was conducted in the spring of 2012. Three thousand surveys were mailed to randomly selected residents and 510 completed surveys were returned for a response rate of $17 \%$. This response rate is lower than is often the case with mailed surveys and this is explained by the lack of the recommended regime of follow up reminders because of concerns around the anonymity of respondents (Rea and Parker, 2005). Nonetheless, the survey provided some important data about the opinions of residents and crucial evidence regarding the success of the problem framing efforts of opponents and, when combined with the media analysis and interviews, offers some data related to testing the hypotheses. 


\section{The Case Study: Site 41 in Simcoe County, Ontario, Canada}

Simcoe County is located in Southern Ontario, north of Toronto and has a population of approximately 440,000 people although only 279,000 are within the direct jurisdiction of the County government (Simcoe County, n.d.). The average income of $\$ 39,855$ is slightly below the provincial average of $\$ 42,264$ and the number of immigrants as a percentage of total population is $12.3 \%$ considerably less than the more urbanized areas of the province such as Toronto at $49.4 \%$ (Simcoe County, n.d.) The area within the jurisdiction of Simcoe County is predominantly rural and, while agriculture is important, manufacturing and especially tourism play important roles in the local economy (Simcoe County, n.d.). The County of Simcoe borders over 500 kilometers of shoreline, which leads to relatively high levels of tourists and seasonal residents. 


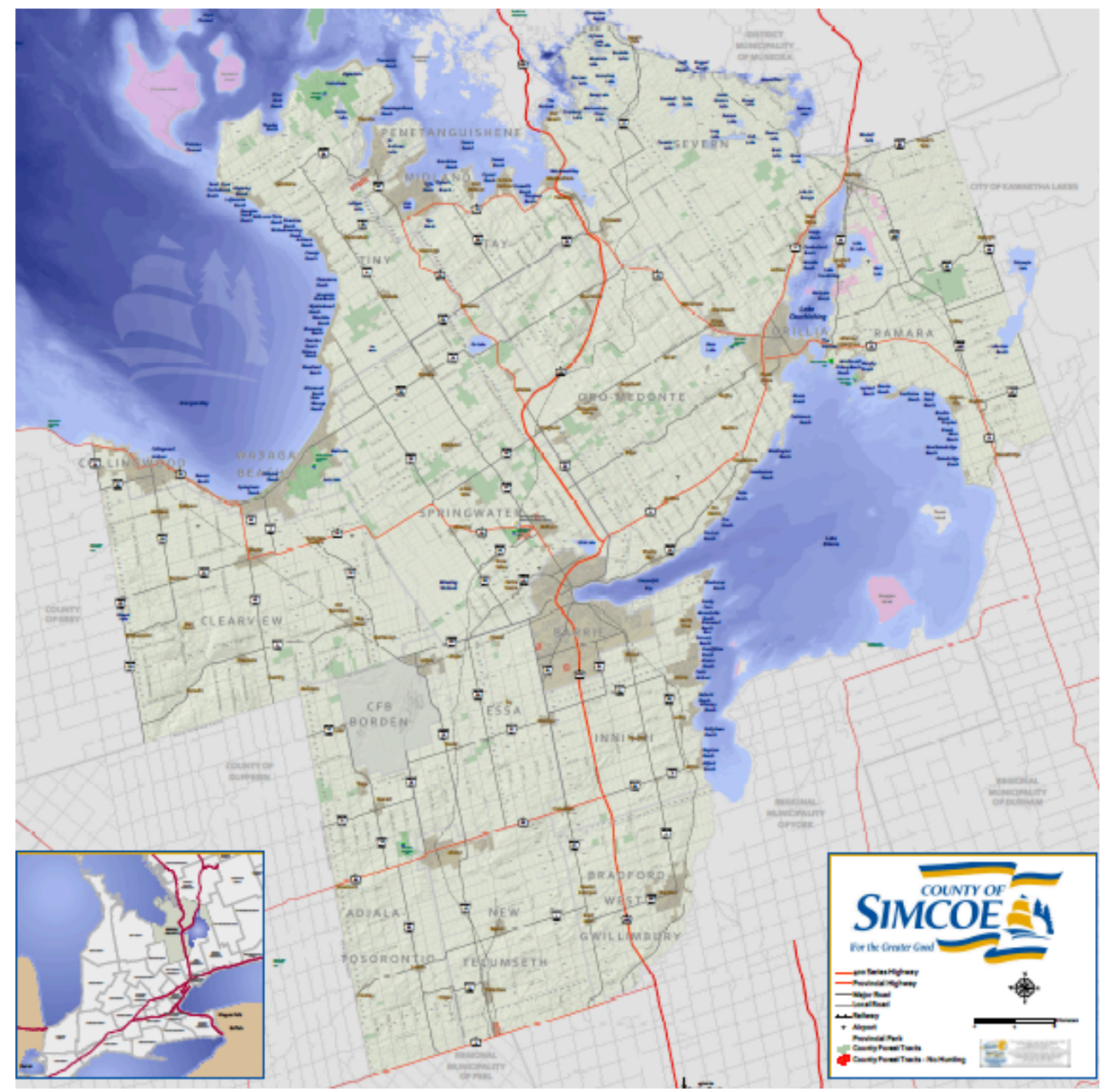

Figure 4-1 Map of Simcoe County (Simcoe County, n.d.)

In Canada's, provinces, local governments have limited autonomy from the provincial government so the many of the institutions important to decision-making at the local level are influenced or controlled by the province. Simcoe County is an upper tier municipality, which consists of sixteen towns and townships. Each of these lower tier governments consists of a mayor and council and is responsible for its own water and sewer services, local roads, recreation services, land use policies, and police and fire services. The County, or upper tier municipal government, consists of the mayor and 
deputy mayor of each of the sixteen towns and townships for a council of thirty-two. The council elects a Warden from amongst the mayors and deputy mayors to head the County Council. The County is responsible for services such as social housing, county roads, land use policy planning, and environmental services including solid waste management. Several First Nations exist within the geographic region of Simcoe County but do not participate in the County government.

The Site 41conflict began in the 1980's over a proposed location for a landfill site that would have accepted waste from two towns (Penetanguishene and Midland) and two townships (Tiny and Tay) within Simcoe County. The proposal was made by North Simcoe Waste Management Association, which was a cooperative body of a number of towns and townships in Simcoe formed to share resources for waste management but was later subsumed within Simcoe County, which then became the proponent. The proposed site was located in Tiny Township and local residents immediately resisted the proposal.

The proponents of Site 41 were the bureaucratic actors such as officials with the waste management department of Simcoe County that recommended Site 41 as the best alternative for dealing with local waste and the County Councilors who approved the site selection and design proposals in numerous County Council meetings. These actors initially recognized that there would be opposition from citizens living near the proposed site but based on the recommendations of experts and staff they supported Site 41: "The information we had on Site 41 — and we had a consultant - and my people at the county, your staff [County staff members]. They do their best to do things way honestly and upfront. We knew that Site 41 was the preferred site" (Interview with former County Councilor, 2012). Because most of the County, outside of Tiny where Site 41 was 
located, was relatively disengaged in the issue, council expected only local opposition that would largely be ignored.

Initially opposition was limited to a number of citizens who lived in relative proximity to Site 41 . The Wye Citizens Group was formed by local residents to oppose Site 41 but this group was small (several dozen members) and had few resources (Interviews, 2012). The Tiny municipal council (a lower tier body) was also opposed but this was expected. Opposition to Site 41 was initially pursued through opposition in the Environmental Assessment and deputations to the County Council. This opposition was localized and the County Council, with the support of the majority of Councilors from outside Tiny, repeatedly passed motions to continue the process of constructing Site 41 . At this point the proponents of Site 41 saw little need for compromise.

While the opponents to Site 41 continued to unsuccessfully lobby the County Council they also pursued their opposition to Site 41 through the Environmental Assessment process. In 1989, a Joint Assessment Board Tribunal (the environmental assessment tribunal) rejected the proposed site, based on a fundamentally flawed selection process (Environmental Assessment Board, 1989). Opponents to Site 41 were excited by the outcome it should be noted that the failure to approve was not based on assessment that the site posed a risk to drinking water but because of the failure of the County to conduct a thorough selection process. The tribunal ruled that the proponent had not sufficiently considered other potential sites before settling on Site 41 . The County then appealed to the Provincial Cabinet, which overturned the Joint Assessment Board's decision through an executive decision known as an Order in Council (OIC), and ordered a resumption of the hearings with stipulations that opponents of the site must prove actual 
harm and that the site selection process was sufficient (Executive Council of Ontario, 1990). After a failed judicial challenge to the OIC by opponents of the site in 1993 , the Joint board resumed, and based on the new criteria outlined in the OIC, approved Site 41. The Ontario Ministry of the Environment (MOE) issued a Certificate of Approval (CofA), which is required in Ontario to approve the actual design of the facility, in 1998.

Once the CofA was issued, the construction of the site could have followed with little further ability of opponents to stop it. Because opposition was mostly residents living near the facility and the Tiny municipal council it was easy to categorize them as NIMBY activists. Without expert based scientific evidence demonstrating a risk to local water those opponents were unsuccessful within the EA process. Because opposition was limited to the community of Tiny the County Council was under no real pressure to alter their decision to go forward with the construction of Site 41. At this point the opponents to Site 41 had been unsuccessful at expanding the conflict over Site 41 and the proponents of Site 41 largely enjoyed a policy monopoly around decision-making about Site 41 .

\section{Framing Site 41}

The failure of opponents to Site 41 to expand the conflict beyond local opposition was essentially a failure to reach the political agenda of the County outside the community of Tiny. Framing a policy problem (or issue definition) is often the key to reaching the political agenda (Baumgartner and Jones, 1993; Pralle, 2006) and the first hypothesis in the causal chain described above is that the greater the acceptance of the health risk frame, the greater the degree of expansion of the conflict is possible. The necessary evidence for the proposed causal process mechanism, that the framing of Site 
41 as a risk to health drives the expansion of the conflict to include new participants, is that opponents of Site 41 advanced the health risk frame and that the media then adopted this frame. It also needs to be demonstrated that this was a purposeful strategy by those opponents. The following section presents the two contending frames advanced by proponents and opponents of Site 41, evidence from interviews with participants about their perceptions of the risk posed by Site 41, and media reports of conflict. A key element is the role of a focusing event in the province of Ontario that pushed the protection of water on to the provincial policy agenda. The following analysis clearly demonstrates that the risk to local drinking water posed by Site 41 became the dominant frame and that this was a clear strategy of opponents to Site 41 made possible by a key focusing event.

Proposed land uses can pose a variety of potential risks to those living near them including nuisance risks such as increased traffic or noise, risks to property values, and risks to health such as potential radioactivity leaks from nuclear facilities. The proposed landfill at Site 41 was a clay-lined site with an additional artificial liner that would collect leachate for treatment in a local water treatment facility. The site was only approved for domestic, commercial, and non-hazardous solid industrial waste as well as dewatered sewage sludge (Ministry of the Environment, 1998). The proposal for Site 41was assessed as relatively low risk by the proponent: "the continued Provincial approval for this facility, particularly given the high level of scrutiny and study that has been part of this process, is undeniable evidence that this site can and will be developed to be protective of the environment" (Simcoe County, 2006, Para 3). Interviews with former members of the County council clearly indicate that decision makers believed that Site 41 
was a safe and responsible way to deal with local waste: "We were proactive in getting a site, no matter who was our county council. We were very proactive, making sure we were managing our own waste. And to me... with the liner and the quality of the liner, there's no darn way would ever anything ever leach out of there. I still believe that it would have been all right" (Interview with former County Councilor, 2011). The framing of Site 41 by proponents was clearly one based on the idea that Site 41 was a safe and cost effective method of solid waste disposal. This was the frame accepted by most members of the Simcoe County Council, as evidenced through their voting to continue the project, who initially approved construction of the facility.

Opponents of the site, however, deemed the site to be a fundamental threat to drinking water in the County through the possible contamination of the Alliston aquifer that lay beneath the site. This had always been one element of the opposition framing of Site 41 but this had gained little traction prior to 2000. In 2000 however, water, in particular the protection of drinking water, had become a powerful issue in Ontario after a tragedy in Walkerton, Ontario in which seven people died and 2300 became ill from e. coli contamination in a municipal water well. The tragedy led to a multi-year public inquiry that garnered significant attention and led to several regulatory responses including the Clean Water Act, 2006 aimed at comprehensive source water protection (Johns, 2008). The protection of the Alliston aquifer, which underlays most of the County and provides drinking water to many residents, quickly became the dominant frame of those opposed to the site analyzed in the media coverage of Site 41. "Water affects our family a lot - we need good water for dairy farming - but it could affect a lot of people. They're building this on top of the Alliston aquifer - it's huge. If (contaminants) get into 
the aquifer, it could be very dangerous for a large group of people" (Midland Free Press, 2003). Interviews with members of the opposition to Site 41 overwhelmingly reported the protection of water as the prime motive for involvement in the conflict over Site 41. Opponents used the example of the Walkerton tragedy to emphasize the risks from a poor waste facility or a problematic facility: "Well, I think here was great harm or there was a potential for great harm to the aquifer. It was an exposed aquifer. It's my view and it continues to be my view that Site 41 was selected, absent to any scientific or engineering specifics" (Interview with former Tiny councilor, 2011).

In relation to water policy in the province of Ontario, the Walkerton tragedy is an important focusing event. A focusing event is "an event that is sudden; relatively uncommon; can be reasonably defined as harmful or revealing the possibility of potentially greater future harms; has harms that are concentrated in a particular geographical area or community of interest; and that is known to policy makers and the public simultaneously (Birkland, 1998). These events attract more attention than is typical of other policy areas as they are often concentrated in a specific area and are hazards in which governments are expected to intervene (Birkland, 1998). Focusing events are important because they can provide windows for groups to advocate for policy change because of the increased attention paid to the issue. The intense media attention that follows these events eliminates the advantage governments or other powerful groups have when framing issues that received little public attention. This often allows actors seeking policy change to draw in new actors that can upset the policy monopoly that are resistant to policy change. They represent important opportunities for conflict expansion. The Walkerton tragedy is a classic example of a focusing event (Johns, 2014). 
The tragedy, in conjunction with the Inquiry that followed led to significant institutional and policy change in Ontario and resulted in a realignment of power within the policy community around water policy in the province (Johns, 2014). As result of the inquiry, provincial environmental groups formed coalitions that would prioritize the protection of source water in the province. The issue of water protection also became an important public issue with significant media attention (Johns, 2014). The primary focus of the Walkerton Inquiry was not on water protection as an environmental issue but on the human health dimension of drinking water. This focus remains "the dominant frame of water policy ideas in the province" (Johns, 2014, p. 223)

The Walkerton tragedy and the outcome of the Walkerton Inquiry provided an opportunity for opponents of Site 41 to link that facility to an issue that was already high on the political agenda in Ontario. Linkage to other, well-publicized or controversial policy issues are a strategy of issue expansion identified by Pralle (2006). Linking an isolated policy issue to another important or controversial issue can increase the significance of the isolated issue. This can aid the expansion of the conflict by drawing in new actors attracted by the linkage to an existing important issue (Pralle, 2006). This is precisely what happened in the conflict over Site 41. Opponents of the site, by focusing on water contamination, were able to link the conflict over Site 41 to the protection of drinking water in Ontario.

Media reports of Site 41 began to consistently identify this link after 2001: "we live in a far different world than that which existed in 1998 when Site 41 was approved. Walkerton changed everything and had this disaster occurred prior to the approval of Site 41, I believe considerably different guidelines would have been used in making the 
decision to place this high volume landfill facility atop a major fresh water supply" (Midland Free Press, 2002). Since the Walkerton tragedy and the inquiry that followed, drinking water protection has become an important and difficult to challenge policy priority in Ontario. Table 4-1 below clearly indicates that the health risk frame was the dominant frame reported by the media in Simcoe County with $86 \%$ of the analyzed newspaper reports mentioning the potential threat to Site 41 to local water. The analysis of media coverage of Site 41 and interviews with participants clearly indicate that the protection of water became the dominant frame of Site 41 .

Table 4-1 Percentage of Media Reports that Include at Least Single of Supportive or Oppositional Frames $(N=507)$

\begin{tabular}{|c|c|c|}
\hline Frames & Specific Frames & $\begin{array}{l}\text { Percentage of Newspaper } \\
\text { Reports with at Least one } \\
\text { mention of that Frame }\end{array}$ \\
\hline \multirow{4}{*}{$\begin{array}{l}\text { Opposition } \\
\text { Frames }\end{array}$} & Health risk & $86 \%$ \\
\hline & $\begin{array}{l}\text { Environmental (not related to } \\
\text { human health) }\end{array}$ & $32 \%$ \\
\hline & Agricultural loss & $28 \%$ \\
\hline & Other & $26 \%$ \\
\hline \multirow{4}{*}{$\begin{array}{l}\text { Support } \\
\text { Frames }\end{array}$} & Cost effective & $32 \%$ \\
\hline & Responsible for own waste & $22 \%$ \\
\hline & $\begin{array}{l}\text { Necessary because of low existing } \\
\text { capacity }\end{array}$ & \\
\hline & Other & $13 \%$ \\
\hline
\end{tabular}

\section{Expanding the Conflict: Actor Strategies, Site 41 and Participation}

Framing the issue as a human health risk was an important strategy of conflict expansion by actors but in this case it is not sufficient to explain the outcome. Framing of the problem drives the participation of new actors into the conflict. The evidence used to 
test for the expansion of the conflict is based on media reports, interviews, and survey data. The causal mechanism being tested is whether the framing of Site 41 helped opponents expand the conflict to include new elite actors and First Nations activists (identified through media reports and interviews) who further raised the profile of the issue in Simcoe County (confirmed through survey data). The evidence presented below confirms that new elite participants and First Nations activists were drawn in by concern over the protection of water and human health. The survey data confirms that the protection of water became the dominant concerns over Site 41 with an overwhelming percentage of survey respondents reporting that Site 41 represented a threat to local water and that this concern affected their participation in the conflict through their municipal voting decisions.

The success of framing the linkage between Site 41 and water protection can be seen in the new actors that were drawn into the conflict. As described above, the initial opposition to Site 41 had been largely restricted to those living within the community of Tiny. After 2001 this began to change, as those actors were able to create linkages to activists outside of the immediate region. Leaders within the opposition to Site 41 actively sought to draw in these participants by linking the fight over Site 41 to broader issues of water protection and the environment. This was a deliberate strategy and they actively invited outside elites to participate (Interviews with Site 41 Activists, 2011, 2012). New participants included high profile environmental activists and leaders such as David Suzuki, Elizabeth May, Maude Barlow, and Ralph Nader.

The Council of Canadians led by Maude Barlow in particular assisted the anti-Site 41 activists by providing experience in these types of campaigns (Interview with Site 41 
activist, 2011,2012). Their participation was clearly linked to the issue of water protection: "There are too many unanswered questions about Site 41 and we can't risk polluting the purest groundwater ever tested," said Barlow. "The solution to Site 41 is a one-year moratorium, not arresting grandmothers who are protecting the water" (Midland Free Press, 2006). Media reports of these actors in the Simcoe County media were extensive which further raised the profile of the issue:

I think the Council Canadians provided a great service to us. They brought it to the awareness to the national stage, international stage. Ralph Nader attended for example. Maude Barlow [From the Council of Canadians] whom I have great respect for, did a lot for us. And that helped us get it beyond that local level. And I think moving beyond the local level and bringing some media attention to it caused individual members of county council to reflect upon their earlier position (Interview with local activist, 2012).

In addition to environmental activists, a group of First Nations protestors from a local First Nations community also joined the conflict and participated in an occupation of an area near Site 41. Interviews revealed that their primary interest was the protection of local water resources. "And when they started taking the water-permit to take water, I didn't think that the ministry would allow—like I did never think the ministry would allow it to happen. And then when I've seen on Facebook that they had given permission to take water and it was going ahead, that's kind of when I jumped onboard" (Interview with First Nations Activist, 2011). Media reporting of the camp was extensive. The opponents that had once been a largely localized group of residents had now become a more extensive network of opponents that included experienced activists and First Nations that further raised the profile of the conflict over Site 41.

The new participation of First Nations activists and high profile actors from outside the region significantly raised the profile of the opposition to Site 41 . The 
expanded network of opponents to Site 41 built on the original opposition and helped the opposition to engage in a number of strategies to gain further public attention that Pralle labels "encouraging a conflict" (2006a). Encouraging a conflict generally involves various forms of protest activities and attention seeking by actors seeking to draw attention, and therefore new participants, to a conflict (Pralle, 2006a). While this network never coalesced into an institutionalized advocacy group, there were identifiable leaders who coordinated the campaigns to stop Site 41 and the opposition could claim several hundred committed supporters and donors including many from outside the County (Interview with activist, 2012). They led an opposition campaign that included a website, organized protests at Council meetings and the provincial legislature, letter writing and petition campaigns, and media relations. In 2009, protests and eventually an occupation of Site 41 by citizens and First Nations protestors occurred, which led to the arrest of some protesters and the County seeking court injunctions preventing protesters from interfering with construction of the site that began in 2007. The framing of a Site 41 as a risk to human through the potential contamination of water helped opponents of Site 41 create links to new actors that further raised the profile of the conflict and undermined attempts to contain the conflict.

The participation of new actors from outside the immediate vicinity of Site 41 also made characterizing opposition to Site 41 as a manifestation of NIMBY far more difficult. The identification of the initial local opponents to Site 41 as self-interested NIMBY activists was initially a powerful strategy of conflict containment utilized by the proponents of Site 41. Pralle identifies this strategy as a characterization contest which is an attempt to expand or contain a conflict through attacks on the character of the 
opposition instead of the issue itself (2006). New opposition actors from outside the region undermined attempts to label opponents of Site 41 as NIMBY activists.

The survey data collected as part of this study reveals the success of the linkage of Site 41 to water protection. Data presented in Table 1 demonstrates that $87 \%$ of respondents believed Site 41 posed a risk to local water. ${ }^{9}$ In order to control for distance to the facility, a stratified sample was created to contrast those within the immediate area of Site 41 and those outside that area. Those closest to Site 41 report slightly higher levels of opposition (91\%), but even those well outside the vicinity of the facility were still overwhelmingly (84.1\%) opposed (Table 4-2). This is distinct from some research about other types of land use conflict that suggests that those further away are less opposed than those living close to the proposed facility (Warren, Lumsden, O'Dowd, and Birnie, 2005; van der Horst, 2007). This is likely the result of the nature of the risk posed by this facility. Site 41 was not just opposed on the grounds of property values or nuisance effects, but on an issue that was likely to concern even actors far from the actual site. The linkage of Site 41 to the protection of a regional water source expanded the conflict by drawing in new actors well outside the immediate area of the proposed site.

Table 4-2 Relationship between Proximity to Site 41 and Opposition

\begin{tabular}{|l|c|c|c|}
\hline & \multicolumn{3}{|c|}{ "Site 41 posed a health risk by potentially contaminating local water" N= 375** } \\
\hline & Close to Site $\mathbf{4 1}$ & $\begin{array}{c}\text { Further from Site } \\
\mathbf{4 1}\end{array}$ & Total \\
\hline $\begin{array}{l}\text { Strongly or } \\
\text { somewhat agree }\end{array}$ & $91 \%$ & $84.1 \%$ & $87.7 \%$ \\
\hline $\begin{array}{l}\text { Strongly or } \\
\text { somewhat disagree }\end{array}$ & $8.8 \%$ & $15.9 \%$ & $10.4 \%$ \\
\hline
\end{tabular}

\footnotetext{
${ }^{9}$ The margin of error is $4.28 \%, 95 \%$ of the time. It should be noted that while these findings are statistically significant, it is likely that the survey slightly over-represents people who held strong beliefs, either positive or negative, about Site 41 . The relatively low response rate may exaggerate this problem.
} 
Opposition to Site 41 was significant and existed in parts of the County far from the facility. However, opposition does not necessary lead to political activity to further that opposition. People must be willing to transfer that opposition into a political act that contributes to their preferred policy outcome. The question is then to what degree did the perception that Site 41 posed a risk cause residents to oppose the facility and did they act on that opposition? Survey data reveals that respondents who believed Site 41 posed a threat to health through the contamination of water were more likely to oppose the construction of Site 41, and most importantly, were more likely to report that Site 41 was a strong influence on their voting preferences at the municipal level (Table 4-3). The survey data demonstrates that the perception of Site 41 as a threat to drinking water was held by a majority of respondents throughout the County and that those respondents were more likely to act on that perception through voting based on that issue. However, because of the potential response bias inherent in self-completed surveys, the survey may over represent those most engaged in the conflict. 
Table 4-3 Relationship between Risk, Opposition, and Influence on Voting Preferences

\begin{tabular}{|c|c|c|c|c|c|}
\hline \multicolumn{6}{|c|}{ "If you are familiar with Site 41 , were you opposed to the proposed landfill site?" $N=479$ " } \\
\hline & \multicolumn{5}{|c|}{ "Site 41 posed a health risk by contaminating local water" } \\
\hline $\begin{array}{l}\text { Opposition to } \\
\text { Site } 41\end{array}$ & $\begin{array}{l}\text { Strongly } \\
\text { Agree }\end{array}$ & $\begin{array}{l}\text { Somewhat } \\
\text { Agree }\end{array}$ & $\begin{array}{c}\text { Somewhat } \\
\text { Disagree }\end{array}$ & $\begin{array}{l}\text { Strongly } \\
\text { Disagree }\end{array}$ & Total \\
\hline Yes (opposed) & $98.2 \%$ & $56.1 \%$ & $0 \%$ & $0 \%$ & $79.4 \%$ \\
\hline No (not opposed) & $1.8 \%$ & $43.9 \%$ & $100 \%$ & $100 \%$ & $20.6 \%$ \\
\hline \multicolumn{6}{|c|}{$\begin{array}{l}\text { "If you are familiar with Site } 41 \text {, how much did this issue influence whom you } \\
\text { voted for at each of the following levels of government?" }\end{array}$} \\
\hline \multicolumn{6}{|c|}{ Municipal N=479** } \\
\hline & \multicolumn{4}{|c|}{ "Site 41 posed a health risk by contaminating local water" } & \\
\hline $\begin{array}{l}\text { Influence on } \\
\text { vote preference }\end{array}$ & $\begin{array}{l}\text { Strongly } \\
\text { Agree }\end{array}$ & $\begin{array}{c}\text { Somewhat } \\
\text { Agree }\end{array}$ & $\begin{array}{l}\text { Somewhat } \\
\text { Disagree }\end{array}$ & $\begin{array}{l}\text { Strongly } \\
\text { Disagree }\end{array}$ & Total \\
\hline $\begin{array}{l}\text { Strong or } \\
\text { moderate } \\
\text { Influence }\end{array}$ & $63.3 \%$ & $15.3 \%$ & $0 \%$ & $18.2 \%$ & $34 \%$ \\
\hline Some Influence & $12.6 \%$ & $15.3 \%$ & $30.3 \%$ & $0 \%$ & $14.5 \%$ \\
\hline $\begin{array}{l}\text { Not much or no } \\
\text { influence }\end{array}$ & $21.5 \%$ & $62.3 \%$ & $66.7 \%$ & $72.7 \%$ & $37.9 \%$ \\
\hline
\end{tabular}

The framing of Site 41 conflict quickly became one focused on protection of water. The Walkerton tragedy, as an example of the human costs of failure to protect source water was a persistent theme. The survey data demonstrates that this resonated with the public. Reassurances from County bureaucrats and County councilors who supported Site 41 and the expert assessments from the EA process and the MOE were unable to allay these fears, and the risk to water became the dominant frame of the Site 41 conflict. This frame moved the conflict from a local conflict involving only those closest to the facility and primarily concerned with nuisance affects or property values to the protection of a water resource central to the health of the entire County.

\section{Shopping for New Venues: Site 41 and Institutions}

The above outlines the success of opponents of Site 41 at linking their opposition to the risk of water contamination and the success of that linkage at drawing new elite 
and public actors. The conflict expanded far beyond localized opposition to an unwanted facility. However, this is not sufficient to explain the outcome of this conflict. This conflict, like most political conflicts, occurred within a set of institutions that structured the conflict. The strategies adopted by opponents and the success of those strategies is largely the product of the institutions that structure the available opportunities for action. The key institutional strategy used by opponents of Site 41 was venue shopping. The following demonstrates that venue shopping was a deliberate strategy that only became possible once the conflict had expanded to include new participants.

Venue shopping is a strategy used by actors seeking an institution of decisionmaking in which their success is more likely (Baumgartner and Jones, 1993; Pralle, 2003, 2006). When a policy area is dominated by a policy monopoly, that monopoly typically has control of the key decision-making institutions responsible for that policy area. Those who wish to challenge that monopoly will often seek to challenge that control or seek new institutions more amenable to their preferred policy preferences. They may look for institutions that are more likely to grant them access or where the rules of the institution are less biased in their opponent's favor (Pralle, 2003, 2006). The opponents of Site 41 sought to shift the focus of the conflict from the institutions that privileged technical understandings of risk and had very limited participation, such as the Environmental Assessment (EA) process, to institutions that privileged lay understandings of risk and open participation. Interviews reveal this as a clear strategy of opponents to Site 41 as opponents recognized the limitations of these institutions "For example, the county had unlimited reserves, spending the taxpayer's money to challenge the arguments. The Community Monitoring Committee [a stakeholder committee stipulated by the CofA] and 
those who opposes the development of the site had to hold spaghetti suppers to raise funds. We had to buy, beg, borrow whatever legal representation we could get (Interview with Anti-Site 41 Activist, 2011). Shifting to institutional venues that did not focus on technical or legal arguments become the focus of the opponents to Site 41 .

After the County Council approved the initial proposal for Site 41, the institutions of decision-making around Site 41 became ones that privileged technical conceptions of risk and are open to the participation of a small group of stakeholder and not subject to public debate. This was the protracted Environmental Assessment Tribunal that eventually approved Site 41 and the Certificate of Approval process that granted provincial approval, through the Ministry of the Environment, for the specific design of the facility. Both processes were quasi-judicial and relied on technical expertise for assessment of the relative risk posed by Site 41 . Claims that Site 41 was an unacceptable risk to regional drinking water made by participants in this process that were not supported by expert assessments were unlikely to be accepted. In both sets of institutional decision-making, site proponents were able to offer sufficient peer reviewed assessments of the proposed design to satisfy these tribunals.

The Certificate of Approval, which is a process required to approve the actual design of solid waste facility, issued by the MOE stipulated that the County must convene a Community Monitoring Committee (CMC). The $\mathrm{CMC}$ was meant to provide a community review of the "development, operation, ongoing monitoring, closure and post closure care related to the landfill site" (Ministry of the Environment, 1998). The committee consisted of one member from the County, two members from the Tiny Council, three members from the township of Tiny who live within three kilometers of 
Site 41, and one non-voting member from the Ministry of the Environment. The committee began meeting in 2000 and quickly became the site of significant conflict as opponents sought to use the CMC as a forum to demand the cancellation of Site 41. However, the CMC was intended to improve communication between the County and local community around Site 41 and did not have any actual power to influence decisionmaking. Interviews with participants and media reports confirmed that those who did participate perceived that their participation was minimal and that they felt they had little real impact on the outcome of the process.

Opponents of Site 41 soon recognized that the EA process and the CMC were not likely to lead to the defeat of Site 41: “The decision wasn't going to be made by the Province of Ontario. They were the approval authority. The decision was one that would be made at the county level. So I asked people to concentrate their efforts and their discussions with individual members of council" (Interview with former Tiny Councilor, 2011). Opponents to Site 41 initially pursued their opposition to Site 41 through the EA and CofA processes but eventually learned that these institutions were unlikely to accept their preferred frame. The focus of the opponents to Site 41 now moved from the circumscribed rules of tribunals to the much more open arena of electoral politics and protest. The goal was to either pressure existing County council members to alter their support for Site 41 or elect new members who would: "So, if the decision is going to be made by those 32 members of county council, you need to get out and get in their facefor lack of a better term — of every municipal councilors going to vote in it" (Interview with resident activist, 2011). The more open character of these venues allowed actors beyond direct stakeholders to participate. 
The opportunity for opponents of Site 41 to produce their goals through the electoral process was made possible by the changing nature of the perception of risk posed by the site. The County council consists of 32 members, 2 from each of the 16 towns and townships in Simcoe County. This would suggest that local opposition to a proposed landfill from one or even several towns or townships should be easily overcome by the majority of the council. If opposition is only local, the majority of councilors from outside the effected region should be immune from voter pressure from their largely indifferent constituents. However as the survey data in Table 2 indicates, $84.1 \%$ of all respondents who did not live in the adjoining municipalities to Site 41 reported believing Site 41 posed a risk to regional drinking water. Over $63 \%$ of respondents who believed Site 41 posed a risk to regional drinking water reported that Site 41 was a strong or moderate influence on their municipal voting decisions (Table 3). Residents well outside of the immediate area surrounding Site 41 were concerned about the safety of Site 41 and this concerns influenced their voting decisions.

The changing public perception of Site 41 influenced the decisions of the Simcoe County Council by pressuring councilors to change their vote or defeating those that would not. Interviews with several former councilors reveal they believe they lost their council seats because of their support to Site 41: "I guess the last election that I ran and lost, I know now, I lost it because of Site 41. All I had to do in that election was to say, "I'll reject Site 41," and would have won" (Interview with former Simcoe County councilor, 2011). The increased awareness and participation of the public in the Site 41 conflict created pressure for many Councilors to alter their support for Site 41 or led to the defeat of several who would not change their minds. In 2009, the County Council 
voted to impose a one-year moratorium on the construction of Site 41 , which had already begun and they voted to permanently withdraw the approval in 2010 . The County Council that had last voted to approve the start of construction on Site 41 in 2007 had clearly changed. Members that initially supported the construction of Site 41 had either changed their position or been defeated in municipal elections. The public perception that Site 41 posed a threat to water changed the scale of the conflict and overcame the institutional structure that should have enabled the County to overcome local opposition to the proposed site.

Opponents of Site 41 clearly achieved their goal by framing the issue as one about the protection of water and shifting the conflict to more open institutions but was this a deliberate strategy of framing, actor expansion and venue shopping? Pralle highlights the difficulties with assumptions around the instrumental rationality of actors and the ability of groups to shift venues with no regard to ideological or organizational preferences (2003). Pralle instead suggests that venue shopping is probably more ad-hoc and experimental that often assumed (2003). The evidence in this case clearly indicates that the opposition to Site 41 recognized new opportunities and shifted strategies accordingly but that this was a less rational process than is often assumed. The core opposition to Site 41 had begun long before the Walkerton tragedy occurred but these actors quickly recognized the linkage between Site 41 and the new focus on drinking water and human health in Ontario. "Ohhh, that whole water thing in Walkerton had a significant impact in this because every time somebody talked about Site 41, they use the Walkerton contamination as something that could happen here. And if we put waste into Site 41, we'd all be dead" (Interview with former County Councilor, 2011). The opposition to 
Site 41 was open to new opportunities and capable of adopting strategies to meet those opportunities. This is consistent with Pralle's observation that single issue groups that lack a firm ideology are more likely to engage in new venue shopping strategies (2010). These groups are far more focused on 'winning' then on maintaining an attachment to a particular strategy or venue.

The opposition actors to Site 41 were clearly engaged in strategic decisionmaking but the process was not a sequential movement from one venue to another based on purely instrumental considerations. Instead they engaged in a parallel strategy of pursuing their goals in all the available venues and only shifted resources to focus on the County Council once it became clear that they would not achieve their goals within the more constrained and biased venues. Several attempts at venue shopping were ultimately unsuccessful.

In 2003 the Tiny municipal council launched a challenge to Site 41 through the Ontario Municipal Board (OMB), which is an appeal tribunal for land use decisionmaking in Ontario. This was also unsuccessful because of the privileged nature of expertise in this format and some saw this is as the final proof that stopping Site 41 could not occur within these types of institutions: "We are out of legal opinions and there is no legal recourse available to this council to stop Site 41" (Tiny Councilor, Midland Free Press, 2003). Opponents to Site 41 also held a number of demonstrations in the provincial capital and the local provincial Member of Parliament proposed a private members bill removing provincial approval for Site 41 . The failure of this to pass through the legislature is unsurprising given that few private members bills are successful in the Canadian political system. However, the attempt to shift the conflict over Site 41 to the 
provincial legislature demonstrates the limits to venue shopping where a local land use dispute was unlikely to capture the provincial political agenda.

The pursuit of the above strategies, as well as the long opposition within the EA process, demonstrates that the opposition to Site 41 did not always make strategic decisions that were likely to succeed. Strategy formation in this case was not a purely rational process whereby all options were carefully considered and decisions were made with perfect information. Instead, the opposition to Site 41 engaged in a number of strategies, such as the OMB appeal and the attempt to stop Site 41 in the provincial legislature, that were unlikely to succeed. However, there is evidence that opponents learned lessons from these failures and focused their efforts on the strategies that were showing promise.

What allowed the opposition to Site 41 to participate in the formal processes such as the challenge in the OMB while simultaneously engaging in protests politics designed to pressure the County Council was the diffuse character of the opposition to Site 41 . They were not a hierarchical and specialized formal organization but instead a loose collection of citizens, local political actors, and environmental activists. This structure allowed the pursuit of multiple strategies at once. The Tiny municipal Council was able to pursue the OMB challenge while citizen activists, allied with environmental and First Nations activists, were able to engage in protests designed to win public attention. A more formally organized advocacy group that was committed to particular institutional venues would in all likelihood not have had the same flexibility. This is contrary to the assumption that groups with more resources (money) will be able to engage more successfully in venue shopping (Pralle, 2010). It was the flexibility and diffuse character 
of the opposition to Site 41 that allowed them to pursue multiple strategies simultaneously.

\section{Conclusion}

This chapter began with a simple research question: What role did the framing of this land use conflict (Site 41) as a threat to human health (through the contamination of local drinking water) play in the outcome of this conflict? In order to answer this question, an approach for understanding policy conflict that focuses on the strategies of conflict expansion developed by Pralle was adapted to produce three interrelated hypotheses: 1) That the greater the success at framing Site 41 as a threat to local drinking water and risk to human health (a strategy of issue definition), the more successful opponents will be at expanding the conflict to include new actors (strategies of actor expansion); 2) That the more actors that are drawn into the conflict, the more opportunity opponents will have to shift the conflict to new institutional venues (an institutional strategy); and, 3) That the more successful opponents are at moving conflicts to new institutions, the greater the likelihood of affecting the outcome of the conflict.

Using a process tracing methodology to evaluate the evidence for each of the hypotheses allows for some confidence in concluding that the framing of the facility as a risk to human health through the possibility of contamination of local water created the conditions for opponents to engage new participants in the conflict. This in turn opened opportunities for venue shopping by opponents of Site 41. In the conflict over Site 41, the framing of the facility as a threat to human health clearly influenced the outcome of that conflict. 
That the framing of a policy as a risk to human health can lead to more contentious policy conflicts is not a new or unexpected finding but exactly how this happens is still a crucial research question. This study helps answer this question by focusing on the causal mechanism that links the framing of a problem to the expansion of the conflict to include new actors. It is not the framing itself that leads to policy change, but the acceptance of the altered frame by people who then choose to participate in the conflict. New participants then opened new venue shifting strategies. Evaluating, or even predicting, the success of conflict expansion must therefore focus not on the frames deployed by actors, but instead on the success of that framing at engaging new participants in the conflict. This is a corrective to the over-analysis of policy discourses, or narratives without linking them to actual mechanisms that can drive policy change.

The agenda-setting literature has always recognized the linkage between institutions and the framing of policy issues (Baumgartner and Jones, 1994; Boothe and Harrison, 2009; Pralle, 2006a). This paper advances this understanding by specifying the relationship between a specific frame - policies understood as a risk to human health and specific institutional biases. Venue shopping was the key strategy as the EA and OMB processes were biased in favour of technical, evidence based assessments of risk. In order to reject Site 41, evidence of risk needed to be presented to counter any evidence in favor of the proposal. The risk conception of those who are not formally part of the proceedings played little role in decision-making. Whether or not the public in Simcoe County believed that Site 41 was a risk to drinking water was not formally considered in this process. Only the expert evidence of the relative risk of Site 41 was important. Framing Site 41 as a significant threat to water without sufficient technical evidence was 
unlikely to succeed in this type of institution. Opponents of the facility needed to shift the conflict to a venue of decision-making that did not privilege expert understandings of risk. It was the biases of this institution that created the incentive for venue shopping. Institutions that privilege technical and expert evaluations of a facility or technology will most often not be receptive to policy frames that lack expert confirmations of that frame. Because opponents of Site 41 could produce little expert support for their contention that Site 41 posed a serious threat to human health they were unlikely to be successful in these institutions.

Any time we consider the strategic actions of actors we must consider the degree of rationality driving that strategic decision-making. The three sets of strategies for conflict expansion described above all require some rational decision-making on the part of those actors pursuing these strategies. However, policy processes are not linear and rational. Opponents to Site 41 were for the most part not seasoned activists employed within highly institutionalized advocacy groups. Policy learning was therefore the key to the development of successful strategies. Opponents pursued many strategies at once including legal challenges to Site 41 and a public advocacy campaign aimed at framing Site 41 as a threat to local water resources. Once it became clear that they would ultimately be unsuccessful within the more constrained venues did they focus all resources on a public campaign that included protests and a site occupation. Policy actors may be rational but that rationality is tempered by inexperience and this confirms Pralle's findings that venue shopping is often more ad-hoc than the venue shopping literature suggests (2003). 
This paper advances our understanding of the role of policy frames centered on risk to human health but more research is required to confirm that these relationships hold in other circumstances. Different forms of risk to human health may be more or less successful at drawing in new participants to a conflict and the degree of scientific or expert consensus about the degree of risk posed will affect the potential incentives for venue shopping. As these types of conflicts, from pipelines to nuclear waste repositories, become more commonplace, understanding how and why they expand will only become more important. 


\section{Chapter 5 - Wind Power in Ontario: Risk, Trust, and the Role of Institutions ${ }^{10}$}

\section{Introduction}

Wind power deployment has grown significantly worldwide in the last decade and many predict that this will continue to grow as governments seek ways of reducing reliance on carbon intensive technologies (Ferguson-Martin and Hill, 2011). The deployment of wind power in Canada has varied significantly by province, but Ontario has the most installed capacity (Ferguson-Martin and Hill, 2011; Rowlands, 2009; Valentine, 2010). The province of Ontario has set an ambitious goal of increasing renewable energy to $15 \%$ of total installed capacity by 2030 (Stokes, 2014).

The success of wind energy deployment is dependent on a number of factors. The availability of transmission capacity, the success of various forms of market incentives, the local and environmental approvals process, and the political sustainability of the programs to encourage renewable energy development have all been identified as important variables for explaining the success of wind energy deployment (FergusonMartin and Hill, 2011; Yatchew and Baziliauskas, 2011). Each of these factors has been important in Ontario, but an increasing threat to wind power projects is the problem of social acceptance (Ferguson-Martin and Hill, 2011; Stokes, 2014; Wustenhagen, Wolsink, and Burer, 2007). Many large facilities face opposition by the public when first proposed, and land use conflicts are nothing new. While wind power is popular generally,

\footnotetext{
${ }^{10}$ This chapter is written in article format. Potential publication venues include Energy Policy and Renewable \& Sustainable Energy Reviews
} 
specific facilities are often opposed (Wolsink, 2007). Wind turbines have faced frequent opposition in Europe and opposition is predominantly based on objections to the industrialization of rural landscapes (Breukers and Wolsink, 2007; Wolsink 2007a, 2007b).

In Ontario, much of the focus of opposition to wind energy deployment has come to focus on the perceived risks to human health posed by wind turbines (Baxter, Morzaria, and Hirsch, 2013; Deignan, Harvey, and Hoffman-Goetz, 2013; Hill and Knot, 2010; Songsore and Buzzelli, 2014). Threats to human health from wind turbines are generally based on noise generated as the turbine blades spin. Problems attributed to noise include annoyance, sleeplessness, and anxiety. These claims are often highly contentious, as little medical evidence supporting many of these claims exists, but these claims have seemingly intensified the opposition to wind energy projects in Ontario. The central research question posed in this paper is how does the framing of wind energy as a threat to human health affect the outcome of conflicts over the deployment of specific wind energy projects? In order to answer this question this paper analyzes a conflict over the Kincardine Wind Farm in Bruce County, Ontario.

This paper utilizes the concept of conflict expansion drawn from policy literature and applies the specific approach to conflict expansion developed by Sarah Pralle (2006a). This approach focuses on the strategies policy actors use to advance their interests within conflicts over public policies and Pralle identifies three categories of strategies: strategies of issue definition, strategies of actor participation, and institutional strategies (2006a). The paper seeks to test the influence of the framing of the Kincardine Wind Farm as a risk to human health, a strategy of issue definition, on the outcome of the 
conflict. The framing of the Kincardine Wind Farm as a risk to human health is hypothesized to aid the opposition to the wind farm in drawing in new participants to the conflict (a strategy of actor participation) and in allowing the opposition to shift the institutional venue in which the conflict itself plays out (an institutional strategy).

The paper finds that attempts to frame wind energy as a threat to human health in Bruce County was successful in generating opposition but that was opposition was ultimately unsuccessful at shifting to the new venue. The paper contributes to the literature on wind energy deployment by integrating the literature on the social acceptance of wind energy, especially the recent research on the health concerns around wind farms in Ontario (Baxter, Morzaria, and Hirsch, 2013; Deignan, Harvey, and Hoffman-Goetz, 2013; Hill and Knot, 2010; Songsore and Buzzelli, 2014) with the institutional literature about wind energy deployment (Agterbosch, Meertens, and Vermeulen, 2009; Breukers and Wolsink, 2007; Ferguson-Martin and Hill, 2011; Valentine, 2010; Wolsink, 2000). The framing of a wind energy project as a risk to human health is potentially a strong frame for those opposing wind energy projects but this opposition can only be successful within the specific institutional constraints around wind energy decision-making.

\section{Theoretical Approach}

\section{Social Acceptance}

Social acceptance has been identified as a key problem potentially limiting the deployment of renewable energy projects (Wustenhagen, Wolsink, and Burer, 2007). This has often proven difficult to reconcile with the very high levels of support for renewable energy generally and wind power specifically reported in many national and 
regional surveys (Bell, Gray, Haggett, 2005; Devine Wright, 2005; Mills, 2014; Wolsink, 2000). A survey conducted in Ontario in 2010 found that $87 \%$ of respondents at least somewhat supported wind energy development in their community (Ipsos Reid, 2010). While a variety of explanations are identified for this disconnect, the focus is mostly on the difference between generalized national support and local opposition to a specific project (Agterbosch, Meertens, Vermeulen, 2009; Klick and Smith, 2010; Wolsink, 2007).

Community opposition to wind farms in Europe is most often attributed to the perceived threat to local quality of life in rural regions through the visual impact of wind turbines (Breukers and Wolsink, 2007; Devine-Wright, 2005; Wolsink 2000, 2006, 2007a, 2007b). This is supported by research that suggests wind farms that have fewer turbines lead to more acceptance and that the characteristics of the turbines, such as color, play a role in acceptance (Devine-Wright, 2005). Research also suggests that context is important; regions that are already considered industrial typically have less opposition (Devine-Wright, 2005; Wolsink, 2007; van der Horst, 2007). Wolsink (2007) has found that attitudes to wind turbines follow a u-shape pattern; attitudes are generally positive prior to specific project being proposed in the area, become negative when a facility is proposed, and generally become more positive once a facility is completed. This seems to suggest that once a facility is completed, those living nearby come to see the facility as acceptable because the feared negative consequences do not materialize (van der Horst, 2007). Research in Europe, where wind power projects are plentiful clearly suggests that landscape values accounts for most opposition to wind farms. 
Opposition to wind energy deployment in Ontario has taken on a distinctly different focus. Research about media reporting of wind energy development in Ontario shows that health concerns are a central issue and that the focus on them is growing (Deignan, Harvey, and Hodffman-Goetz , 2013; Hill and Knot. 2010; Songspore and Buzzelli, 2014). Deignan, Harvey, and Hodffman-Goetz found in a study of newspaper reporting of wind turbines in five Ontario community newspapers and in four national newspapers that 'dread', a factor about the health dangers of wind turbines, was the most commonly reported environmental or health concern (2013). They note that newspaper reporting can have a strong influence on the acceptance or resistance of wind development. Another analysis of newspaper reporting of wind energy in Ontario by Songsore and Buzzelli supports the findings about the centrality of health concerns in reporting about wind energy development and make the same link between media reports and opposition "health risk perceptions are playing a major role in fuelling resistance to wind energy development in Ontario" (2014, p. 291). Media coverage of wind energy deployment in Ontario is increasingly focused on the health effects of wind turbines.

Survey research has also shown that health concerns are a significant factor in opposition to wind energy development within many communities in Ontario. A study by Baxter, Morzaria, and Hirsch of two communities in Ontario highlights this issue (2013). The study conducted research in two communities, the case community that currently has wind turbines and control case with none. The study found that in the control community with no wind turbines, only $25 \%$ of respondents support wind energy development and found that even controlling for other factors such as aesthetics, concerns over health risks are a strong predictor of opposition to wind energy development (Baxter, Morzaria, and 
Hirsch, 2013). General support for wind energy in Ontario is generally high but in some communities in Ontario that face the prospect of hosting a wind energy project shows opposition is much higher and is based to a significant degree on fear of the health effects of turbines.

\section{Public Policy Theory}

Public policy literature and theories of policy change have long recognized that the way a policy is framed can have important effects on the acceptance and implementation of that policy (Baumgartner and Jones, 1994; Rochefort and Cobb, 1994; Stone, 1989). Framing a policy problem involves arguments about where a problem comes from, what are the acceptable solutions to that problem, its relative urgency, and its social significance (Rochefort and Cobb, 1994; Stone, 1989). Different actors will advance different understandings of a policy problem in order to see those understandings accepted by the public or policy elites. Proponents of wind energy argue that wind turbines are a safe form of electricity generation that reduce reliance on fossil fuels thereby reducing greenhouse gas emissions and improving air quality. Opponents of wind turbines often suggest they represent the industrialization of rural landscapes and are a threat to local health. Conflicts over wind turbines are therefore often about which policy frame will become dominant.

While the framing of a public policy can influence a conflict over that policy, the institutions that structure that conflict also play an important role in explaining the outcomes of those conflicts. There is a significant body of literature that focuses on the effects of institutions on the deployment of renewable energy projects (Agterbosch, Meertens, and Vermeulen, 2009; Breukers and Wolsink, 2007; Ferguson-Martin and Hill, 
2011; Valentine, 2010; Wolsink, 2000). What is required is the integration of the literature that focuses on the framing of wind energy (Baxter, Morzaria, and Hirsch, 2013; Deignan, Harvey, and Hoffman-Goetz, 2013; Hill and Knot, 2010; Songsore and Buzzelli, 2014) and the literature on the institutional context of the conflicts over wind energy. This paper uses an approach developed by Sarah Pralle (2006) that focuses on the strategies used by actors contesting a public policy in order to capture the role that the framing of wind turbines as a threat to human health plays in explaining the outcome of a specific conflict over a wind energy project.

\section{Conflict Expansion: Integrating Framing and Institutions}

The literature on conflict expansion and agenda-setting highlight the ways in which conflicts contract or expand (Baumgartner and Jones, 1994; Pralle, 2006; Rochefort and Cobb, 1994). When there is no conflict, the policy can be contained by a small group of policy actors who can create a monopoly on decision-making around that issue. Policy monopolies are groups of actors who are able to maintain control over a policy by keeping that policy off the political agenda (Baumgartner and Jones (1994). This accounts for periods of relative policy stability where little change in that policy area occurs. A conflict develops when the dominant policy frame describing that policy issue is challenged and new actors demand access to the policy process. Expansion of the scope of the conflict is the way challengers to the existing monopoly can open the process and achieve change (Baumgartner and Jones, 1994). Actors who control the policy monopoly seek to contain the policy conflict by excluding new actors thereby maintaining their monopoly. Conflict expansion or containment is therefore the key element in explaining change or stability in public policy. Pralle identifies three key sets 
of strategies actors will engage in to expand (those wishing policy change) or contain (those wising to maintain stability) a policy conflict.

Issue definition is the first set of strategies identified by Pralle (2006) and is the key element in this study as the degree to which the framing of wind power as a threat to human health is hypothesized to drive the choice and success of other strategies. Issue definition strategies are the strategies that can be deployed in order to raise or lower the salience of an issue to the public. By raising the salience of an issue, advocates of policy change hope to place the issue on the public agenda thereby providing the opportunity to overturn the existing policy monopoly (Baumgartner and Jones, 1994; Rochefort and Cobb, 1994). Controlling the way in which a policy issue is defined can provide significant advantages by controlling the scope of the issue, by claiming ownership of an issue, or by linking a previously low salience issue to a more salient one (Pralle, 2006).

Issue definition is important in all policy conflicts but not all policy frames are equal. Issues that can be defined as more urgent or significant problems will be more effective at drawing in new participants and therefore at expanding conflicts (Boothe and Harrison, 2009; Pralle, 2006b; Schneider and Ingram, 1993; Stone, 1989). These types of problems appeal to fundamental values and are more likely to engage the public (Boothe and Harrison, 2009; Stone, 1989). That policies that may pose a threat to human health are more contentious then some other types of policy conflict is certainly not new. However, understanding how and when these types of issue definitions actually contribute to conflict expansion is an important research question.

Theories of framing are useful ways of organizing the analysis of the different policy definitions advanced by opponents and proponents of a policy. Framing can 
defined as "the process by which people develop a particular conceptualization of an issue or reorient their thinking about an issue" (Chong and Druckman, 2007a). Frames are the different ways of understanding a given policy. Proponents of wind energy development in Ontario advocate wind energy as a clean source of electricity that can benefit local and provincial economies (CANWEA, n.d.). Opponents of wind energy development in many rural areas affected by wind energy deployment counter with a frame that highlights the potential health risk posed by turbines to those living near them (Wind Concerns Ontario, n.d.). While both opponents and proponents include other arguments in their opposition or support for wind energy development, they are largely subsumed within these two dominant frames. The contest over framing wind energy is a contest over which frame will be accepted by the public and decision-makers.

The second set of strategies for conflict expansion identified by Pralle are focused on the participation of actors (2006). Policy monopolies will seek to limit the participation of new actors in order to preserve their monopoly of the policy. Those opposed to the monopoly will seek new participants in order to tip the balance and undermine the monopoly. The struggle over framing is a key element in the potential to expand the conflict to new participants. Proponents of wind power, which includes the provincial government, the wind energy industry, and many environmental groups, seek to define wind energy as good for the environment and the economy, which contains the conflict by discouraging new participants. Opponents of wind energy development attempt to draw in new participants by framing wind energy as a threat to the health of those living near them. Drawing in new participants allows opponents to challenge new 
wind energy deployment. The question posed in this study is does the health risk frame draw in more participants than other potential opposition frames.

The third set of strategies for conflict expansion identified by Pralle are focused on the institutional context of the policy conflict (2006). Institutions, as the set of rules that structure decision-making, are a key element of any political conflict and have been identified as important for explaining renewable energy deployment (Agterbosch, Meertens, Vermeulen, 2009; Jobert, Laborgne, and Milmer, 2007; Wolsink, 2000). Strategies around institutions focus on how institutions provide opportunities for conflict expansion or contraction by limiting participation or access to decision-making institutions. Pralle identifies a number of institutional strategies but the strategy of venue shopping is central in this conflict (2006). Venue shopping occurs when a group of actors that have been frustrated in their ability to change a policy in one venue, for instance a provincial legislature, seek out a new venue, such as the courts, in which they believe they will be ore successful in realizing their goals (Baumgartner and Jones, 1993; Pralle, 2003).

Participants in policy conflicts seek out new venues because all institutional venues are different (Boothe and Harrison, 2009; Pralle, 2003, 2010). The rules of any given venue will always provide advantages and disadvantages to the actors participating within them. Actors with strong public support for their preferred policies will often have more success in legislative venues while actors able to construct their preferred policies in terms of rights may have more success in the courts. As will be made clear through the analysis of the case below, the inability of opponents of the Kincardine wind farm to shift 
the conflict to a venue more amenable to their preferred policy frame is the key to explaining the outcomes of the conflict.

Pralle's approach to studying policy conflicts focuses on the strategies that actors use to advance their preferred policy outcome and categorizes these strategies into three groups: strategies of issue definition, strategies of actor participation, and institutional strategies (2006). If reframing wind energy as a threat to human health is a strategy of issue definition the question then becomes how did the use of this strategy affect the choice and success of other strategies. Applying Pralle's approach to this case, three hypothesis are tested:

H1 That the greater the success at framing the wind energy as a threat to human health (a strategy of issue definition), the more successful opponents will be at expanding the conflict to include new actors (strategies of actor expansion).

$\mathrm{H} 2$ That the more actors that are drawn into the conflict (strategies of actor expansion), the more opportunity opponents will have to shift the conflict to new institutional venues (an institutional strategy).

H3 That the more successful opponents are at moving conflicts to new institutional venues, the greater the likelihood of halting the construction of a proposed facility. These hypotheses can capture both the effect of framing wind turbines as a threat to human health as well as the institutions that inhibit or facilitate the effects of that frame.

\section{Methodology}

The following paper utilizes a case study methodology to test these hypotheses in a specific conflict over wind turbine deployment. A form of within case analysis called 
process tracing is a methodology that focuses on linking cause to effect and is particularly appropriate for testing the above hypotheses, is applied to the case of a wind farm project in Bruce County, Ontario first proposed in 2003 and completed in 2009. The case was selected because it spans the period in which the health effects of wind turbines entered the debate in Ontario (Deignan, Harvey, and Hodffman-Goetz , 2013; Hill and Knot. 2010; Songspore and Buzzelli, 2014) so the opposition to the proposed facility initially focused on non-health related concerns and shifted during the conflict itself. This allows for the comparison of the effects of the different problem definition on the conflict.

The specific evidence used in this case study was gathered using a number of methodologies including extensive documentary evidence such as formal communications by municipal, provincial, and federal levels of government, records of meetings, and communications by various groups and individuals involved in the conflict.

Second, 305 media reports of the conflict over the Kincardine Wind Farm were collected and coded to identify the frames used by newspapers in media coverage of the conflict. This is a common approach in framing research and is used to identify the presence or absence of frames of interest to the researcher (Chong and Druckman, 2007). The first stage utilized the Canadian Newsstand database to identify newspaper reports using search terms such as "Kincardine wind farm" and "wind turbines". Because several local papers were not indexed in the database, a second stage involved using the same search terms in local papers in each county such as the Kincardine Times and Kincardine News. These searches were conducted for the period beginning when the facility was first 
proposed in 2003 until the end of the conflict in 2010 when the Kincardine wind farm was completed.

Once the articles were collected, a directed content analysis on each newspaper report was completed using a coding instrument that focused on the frames used to either oppose or support the wind farm. For example, identification of the health risk frame was based on any mention of the possible consequences of wind turbines for human health. Articles were not themselves coded as either supportive or oppositional and many reports included mention of multiple frames. While the coding instrument was predetermined, frames not initially part of the coding instrument were also identified during the coding process. As the author was the only coder, inter-coder reliability was not a concern.

Third, semi-structured interviews with a variety of stakeholders, ten interviews were conducted, and these were invaluable for assessing the opinions and motivations of stakeholders including: current and former municipal councilors, members of the opposition, and bureaucrats in Simcoe County. Potential interview subjects were identified through the secondary research and media reports.

Finally, a mail survey of Bruce County residents was conducted in the spring of 2012. Mailed questionnaires were sent to 3000 randomly selected residents and 657 completed surveys were returned for a response rate of $22 \%$. This response rate is lower than is often the case with mailed surveys and this is explained by the lack of the recommended regime of follow-up reminders because of limited resources (Rea and Parker, 2005). Nonetheless, the survey provided important and statistically significant data about the opinions of residents who may not have been direct stakeholders in the conflict. 


\section{Case Study: The Kincardine Wind Farm}

Bruce County is a largely rural region of Ontario, Northwest of Toronto and on the shores of Lake Huron and Georgian Bay. The population is just over 66,000 people (Bruce County, n.d.) and average income and education are slightly below the provincial average. The economy is largely driven by agriculture, manufacturing, and tourism although the Bruce Nuclear plant employs a substantial number of residents (Bruce County, n.d.).

\section{Figure 5-1: Map of Bruce County in Southern Ontario}

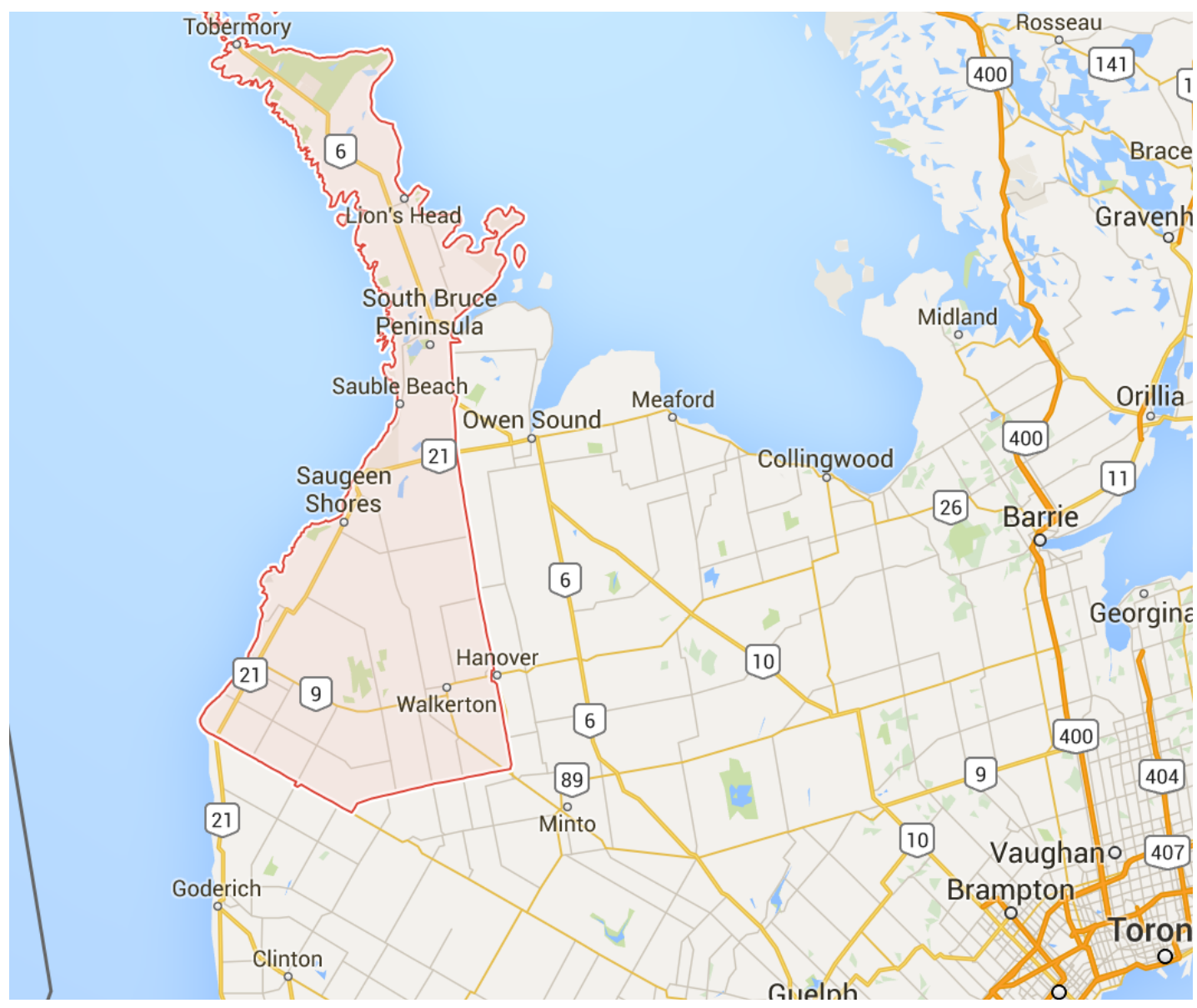

The governance structure in Bruce County consists of the upper tier County government, which is responsible for social housing, county roads, land use policy planning (County Plan), and environmental services including solid waste management. 
The County council is made up of the mayors of each of the eight local municipalities that make up the county, and they select a Warden to act as the head of the Council. The municipal councils are elected by ward and each has a mayor and deputy mayor. The lower tier municipalities are responsible for their own water and sewer services, local roads, recreation services, land use policies (local by-laws), and police and fire services.

The conflict over the Kincardine wind farm began in 2003 with a proposal by Leader Wind Corporation to construct a wind turbine farm in the municipalities of Kincardine and Saugeen Shores. The proposed farm would include 154 turbines with a rated capacity of 199.65 MWs of power (OMB, 2008). In 2006, citing the prolonged process approval, Leader wind passed the project to Enbridge Ontario Wind Power. In April of 2006, Enbridge submitted the Environmental Screening Report (ESR) required for energy projects and during the summer of 2006, public meetings were held to discuss the project which were well attended by the public (OMB, 2008).

The proponents of the Kincardine wind energy project included Enbridge Wind Energy, the Municipal Councilors in Kincardine and the Bruce County Council who were supportive of the project, many landowners who would directly benefit from the facility through hosting a turbine, and local and provincial environmental activists who were supportive of wind energy. The actors were not members of an organized group but instead formed a loose network that supported the construction of the proposed project for the economic and environmental benefits.

The opponents to the proposed project were landowners who lived near the project but who would not benefit economically and local and provincial anti-wind activists who are opposed to the construction of wind projects generally. These actors 
were initially poorly organized but as the conflict intensified they became better organized and created links with provincial anti-wind groups such as Wind Concerns Ontario. Local chapters of these provincial groups, such as Wind Concerns Bruce, were formed over the course of the conflict. These groups had several dozen members as active participants and claimed much broader support in the community. These organizations included formal leaders and communication strategies including formal media relations, websites, and lawn signs. While funding was limited, many of the members are highly committed.

The ESR process was the first institutional venue within which the Kincardine wind farm was contested. This process required consultation with the public, municipalities, and other government agencies but is driven by the proponent with no independent review of the information submitted as would occur in a full environmental assessment process. However, in Ontario, ESRs must be publicly posted for a 30-day comment period, which enables the public or other interested parties to make comments or request that the proposal be elevated to a full Environmental Assessment that requires review of all plans by external auditors. In the Kincardine project, 21 members of the public requested elevation, which was subsequently denied by the Ministry of the Environment (MOE, 2006). The requests were based on a number of concerns, including a substantial number noting concerns about potential noise. The MOE response made clear that the ministries guidelines on noise were based on international standards and that because "no receptors will be subjected to noise levels above ministry criteria and therefore no measures have been deemed necessary to mitigate noise level impacts" 
(MOE, 2007). Because there was little scientific acceptance of the potential health impacts of wind turbines internationally, they carried little weight in the ESR process.

Bruce County (through the planning department) also requested an elevation to a full EA when several of their concerns about siting distances to municipal roads were not addressed by Enbridge (MOE, 2007). By June of 2007, Enbridge responded to the Counties' concerns by extending the distance of several of the proposed turbines to municipal roads and the County subsequently withdrew its request for elevation in August (Interview, 2012). The MOE formally denied the remaining requests for elevation by the end of 2007 and that concluded the ESR phase of the conflict.

A second, important institution in this conflict was the Ontario Municipal Board (OMB). The OMB is constituted by the Ontario Planning Act 1990, and is an appeal tribunal for land use planning decisions. A second crucial set of institutions is constituted by the Ontario Planning Act 1990 which provide for the Ontario Municipal Board as an appeal tribunal for land use planning decisions. The OMB is open to almost any appellant with some interest in a land-use decision and can be used to appeal any decision made by a municipality under the Ontario Planning Act, 1990 (Moore, 2009). In 2006, the municipality of Kincardine issued 105 by-law amendments to permit the construction of the wind farm. In September, a number of Kincardine residents living near proposed turbines appealed 38 of the 105 by-law amendments. Again, the appeals focused on may aspects of the project but noise standards were central. However, the OMB refused to make a determination about noise and instead suggested that the MOE "and not the Board should make the final determination regarding compliance with the Ministry guidelines for noise, and that the Board has no jurisdiction to modify or change the guidelines or the 
interpretations that the Ministry may wish to impose" (OMB, 2007, p. 67). Neither the MOE, through the ESR process, or the OMB were willing to overturn the proposed project, as long as it met with the then accepted standards, posed a threat to health. The project at this point was free to proceed and the facility began commercial operation in February of 2009.

The opponents of the Kincardine wind energy project failed to stop the completion of the project through the ESR and OMB processes. The ESR and OMB processes, because they accepted that wind turbines were safe, were unlikely to halt the project. In fact, opponents of the facility believed that they would never be successful at stopping wind energy deployment through these processes: "the goddamned government [of Ontario] has rigged the game. They want to push the wind agenda so they've created an approval process that guarantees these things [wind energy projects] will pass" (Interview with anti-wind activist, 2011). These opponents recognized that they required new institutional venues if they were to successfully oppose this and potential future wind projects. Opponents recognized that the County Council, whose approval was required to complete the project, was the only opportunity to stop wind energy deployment. The goal was to either pressure existing County council members to alter their support for wind energy development or elect new members who would: "We knew that the county could stop the project so we encouraged people to talk to their local councilors and demand that they oppose it" (Interview with local anti-wind activist, 2012). Shifting to this new institutional venue however required a frame that would be more likely to engender public support. 


\section{Strategies of Issue Definition: The Framing of Wind Energy}

The inability of opponents of the Kincardine wind energy project to stop the project through the ESR and OMB processes created the incentive to look for institutions in which to contest this policy. This search for new institutions is the starting point of the analysis presented here as it creates the incentive for opposition groups to frame wind energy as a threat to human health. The first step hypothesis tested in this study is that the reframing of wind energy as a threat to human health raised the profile of the issue thereby drawing new participants into the conflict. This first requires establishing what were the dominant frames used to advocate for and against the proposed facility. The framing of the issue was primarily measured through the analysis of newspaper reports of the conflict. In addition, interviews with participants in the conflict and documents generated in the conflict were important for identifying both the frames and who was advocating those frames.

The key indicator of the growing success at framing wind turbines as a threat to health is newspaper reporting of that frame. As Figure 1 indicates, media reports about the health effects of wind turbines were increasing and by 2009 , there were 28 stories in Bruce County identifying the potential health risks of wind turbines. The findings in Bruce County are consistent with other studies of media reporting on wind turbines in Ontario. Figure 5-2 compares the results of the newspaper analysis conducted for this study compared to the findings by Hill and Knot (2010). The change over time in Bruce County is less dramatic than the national study by Hill and Knot (2010) but might be expected in a community that faced a proposed large wind facility much earlier than other 
regions. Figure 5-2 compares both media surveys, and the increase over time of media stories focusing on health risks is clear.

Figure 5-2 Comparison of National and Bruce County News Coverage of the Health Effects of Wind Turbines

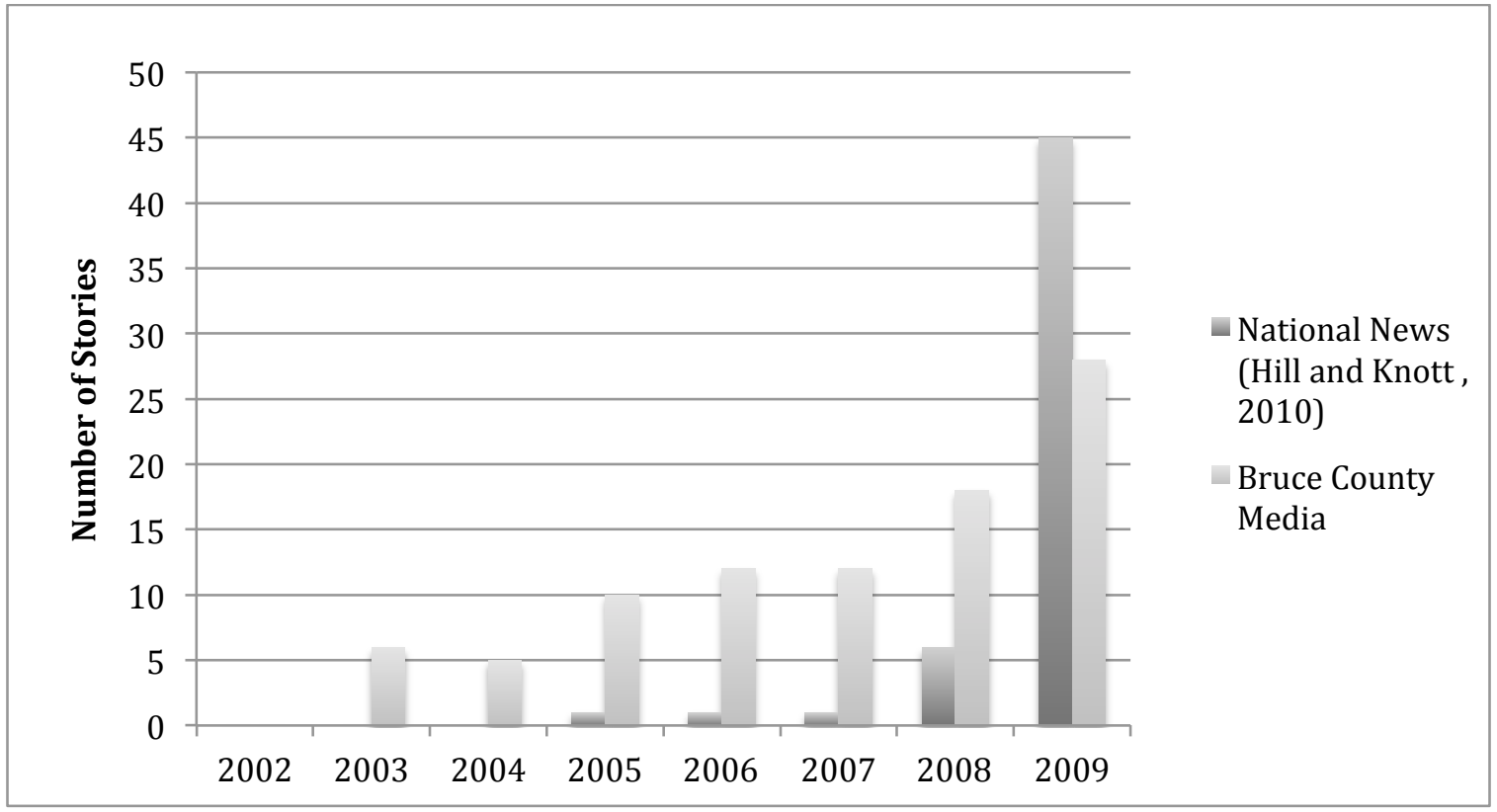

The increasing media coverage of the health effects of wind turbines is clear but also important is the coverage of heath effects relative to other opposition frames. Table 5-1 demonstrates the relative dominance of the health risk frame over other opposition frames across the total period of this study with $78 \%$ of newspaper reports mentioning the health risk claims of opponents while the next most mentioned opposition frame was the unfair decision-making process at $65 \%$. The shift in the framing of wind energy is confirmed through other media studies in Ontario (Deignan, Harvey, and HodffmanGoetz , 2013; Songspore and Buzzelli, 2014). It is clear that the focus on the health 
effects of wind turbines has grown substantially over time and it is therefore important to understand why this frame has increasingly become accepted.

Table 5-1 Percentage of Media Reports that Include at Least Single of Supportive or Oppositional Frames

\begin{tabular}{|l|l|l|}
\hline \multirow{4}{*}{ Frames } & Specific Frames & $\begin{array}{l}\text { Percentage of Newspaper } \\
\text { Reports with at Least one } \\
\text { mention of that Frame }\end{array}$ \\
\hline \multirow{5}{*}{ Opposition } & Health risk & $78 \%$ \\
\cline { 2 - 3 } & Unfair decision making & $65 \%$ \\
\cline { 2 - 3 } & $\begin{array}{l}\text { Environmental (not related to } \\
\text { human health) }\end{array}$ & $55 \%$ \\
\cline { 2 - 3 } & Other & $32 \%$ \\
\hline \multirow{3}{*}{ Supportive } & Good for local economy & $63 \%$ \\
\cline { 2 - 3 } & Good for the environment & $55 \%$ \\
\cline { 2 - 3 } & Other & $22 \%$ \\
\hline
\end{tabular}

That the reporting of the potential health effects of wind turbines was increasing over time is clear and research suggests two key reasons for the change in the relative success at reframing wind turbines as a threat to health are important: the increasing number of wind energy projects in Ontario and the strategic decision by opponents to focus on this issue. The study by Hill and Knot (2010) suggests that the increased number of proposed and completed wind turbine project explains the increase in media stories about health effects. The rise in number of national media stories about health risks from wind farms and the rise in opposition to wind farms directly correlate with the increase in installed wind capacity in Ontario (Ferguson-Martin and Hill, 2011; Hill and Knot, 2010). This is intuitive as we would expect that the more people that are exposed to wind turbines, the more interest in the effects of turbines would be generated. This is interesting as it contradicts some research that suggests that opposition to unwanted 
facilities often drops once the facility is created (Wolsink, 2007; Van der Horst, 2007). Once completed, residents realize that the facility does not cause many of the negative consequences they feared and are, therefore, more supportive of the facility. This does not seem to be the case in Bruce County. The dramatic increase in installed wind projects in Ontario had undoubtedly caused some of the concern over health and wind turbines.

A second crucial factor has been the mobilization of opponents to wind turbines and their strategic use of the health frame. There is a clear correlation between increasing wind turbine installation and creation of local affiliates of Wind Concerns Ontario, which is the largest and most effectively organized opposition group in the province (Hill and Knot, 2010; Stokes, 2014). Interviews with opposition members, opposition documents, and newspaper reports about opposition groups such as Wind Concerns Ontario all reveal the decision to focus on health risks: "We quickly realized that people pay more attention to the idea that people are getting sick than they do the idea that birds might be injured" (Interview with anti-wind activist, 2011). Interviews with leaders of the opposition organizations revealed that the decision to focus on health concerns was made as it became clear that these concerns resonated with the public. This is reflected in the increased use of the health risk frame in media campaigns and protests.

\section{Strategies of Actor Participation}

The strategy of framing wind energy as a threat to human health had begun to show some success prior to the completion of the Kincardine wind facility and there is also some evidence that this frame was successful at drawing in new participants to the conflict over the project. During the initial stages of planning and consultation for the project, the Pollara polling firm, on behalf of the proponent, conducted phone surveys of 
residents in Saugeen Shores and Kincardine (the municipalities for the proposed facility). They conducted phone surveys in 2006 of 402 respondents in each municipality with an overall accuracy of $3.5 \%, 19$ times out of 20 . In both regions, over $60 \%$ of respondents were supportive of the proposed project with only $19 \%$ somewhat or strongly opposed. Of those opposed to the facility, only $3 \%$ of respondents reported suggested health as the main reason for opposition while 43\% in Saugeen shores and 28\% in Kincardine reported the visual impact as most important. The majority of residents in 2006 were in favor of the facility and very few saw the facility as a potential health risk. In both the media and public opinion, health risks were not yet a significant concern and the public was generally supportive of the project.

However, as the health risk frame changed so did public opinion about wind energy development in Bruce County. Table 5-2 reports the values from the original Pollara survey and the survey conducted for this research in 2012, and the results are significantly different. ${ }^{11}$ While the populations and questions were somewhat different, the degree of change between the time periods is apparent. Respondents in 2012 were much more likely to view wind turbines generally, and the Enbridge facility specifically, as a potential health risk. Respondents were also more likely to support the original project than are willing to accept new projects. The belief of Bruce County residents about the safety and desirability of wind power projects has decreased since the original project was proposed. The importance of the perception of the health risk of turbines as a

\footnotetext{
${ }^{11}$ It should be noted that the survey methodologies were different as the Pollara study was a phone survey and that might explain some of the observed difference. A mail survey is likely to show a higher response bias with residents with strong views of the facility more likely to respond to the mail survey.
} 
predictor for wind energy development opposition is also supported by research in other communities in Ontario (Baxter, Morzaria, and Hirsch, 2013).

Table 5-2 Comparison Between 2006 and 2010 Surveys Reporting Support for Wind Farms in Bruce County

\begin{tabular}{|l|c|c|}
\hline $\begin{array}{l}\text { Question from 2006 } \\
\text { Survey/Question from 2012 } \\
\text { survey }\end{array}$ & $\begin{array}{c}\text { 2006 (only } \\
\text { Kincardine and } \\
\text { Saugeen Shores) }\end{array}$ & $\begin{array}{c}2012 \text { (All of Bruce } \\
\text { County) }\end{array}$ \\
\hline $\begin{array}{l}\text { Support for wind power in general/ } \\
\text { Support for construction of more } \\
\text { wind facilities in Bruce County }\end{array}$ & $\begin{array}{l}65.5 \% \text { (Strongly or } \\
\text { somewhat support) }\end{array}$ & $19.2 \%$ \\
\hline $\begin{array}{l}\text { Believe that wind turbines pose } \\
\text { health risks/Believe that wind } \\
\text { farms pose a medium or high risk } \\
\text { to health }\end{array}$ & $\begin{array}{c}3 \% \text { (of the 19\% } \\
\text { opposed to facility) }\end{array}$ & $72.1 \%$ \\
\hline
\end{tabular}

The change over time of both media coverage and Bruce County residents' perception of the risks of the Enbridge facility is clear. However, a change in risk perception in of itself does not necessarily change the outcomes of these conflicts. What is required for change is that heightened perceptions of risk lead to political action and this is clearly the case in Bruce County. Table 5-3 demonstrates that residents who perceive the risk of wind farms as higher were far more likely to be opposed to the construction of more wind farms in Bruce County. Of the residents who perceived the risk from wind turbines as low, only $17.9 \%$ are opposed to new wind farm development. Of those who see the risk is high, $87.3 \%$ are opposed to more development. 
Table 5-3 Effects of Risk on Opposition to Wind Farms, Participation, and Voting

\begin{tabular}{|l|c|c|c|c|}
\hline \multicolumn{5}{|c|}{ "Are you opposed to the construction of more wind farms in Bruce County?" N=396** } \\
\hline & Low & Medium & High & Total \\
\hline $\begin{array}{l}\text { Opposition to Wind } \\
\text { Turbines }\end{array}$ & $17.9 \%$ & $50.5 \%$ & $87.3 \%$ & $57.3 \%$ \\
\hline Yes (opposed) & $66.1 \%$ & $28.8 \%$ & $8.7 \%$ & $20.2 \%$ \\
\hline No (not opposed) & & & \\
\hline
\end{tabular}

"If you are familiar with the Enbridge wind farm, how much did this issue influence whom you voted for at each of the following levels of government?"

\begin{tabular}{|l|c|c|c|c|}
\hline \multicolumn{5}{|c|}{ Regional N=393** } \\
\hline $\begin{array}{l}\text { Influence on vote } \\
\text { preference }\end{array}$ & Low & Medium & High & Total \\
\hline $\begin{array}{l}\text { Strong or moderate } \\
\text { Influence }\end{array}$ & $17.3 \%$ & $48.6 \%$ & $69.3 \%$ & $43 \%$ \\
\hline Some Influence & $12.1 \%$ & $22 \%$ & $8.9 \%$ & $13.9 \%$ \\
\hline $\begin{array}{l}\text { Not much or no } \\
\text { influence }\end{array}$ & $64.7 \%$ & $33.9 \%$ & $18.5 \%$ & $38.2 \%$ \\
\hline Did not vote & $6 \%$ & $2.8 \%$ & $3 \%$ & $4.8 \%$ \\
\hline \multicolumn{4}{|c|}{ Provincial N=395** } \\
\hline $\begin{array}{l}\text { Influence on vote } \\
\text { preference }\end{array}$ & Low Perception of Risk & High & Total \\
\hline $\begin{array}{l}\text { Strong or moderate } \\
\text { Influence }\end{array}$ & $21 \%$ & Medium & $79.4 \%$ & $53.9 \%$ \\
\hline Some Influence & $13.2 \%$ & $29.7 \%$ & $11.9 \%$ \\
\hline $\begin{array}{l}\text { Not much or no } \\
\text { influence }\end{array}$ & $63.1 \%$ & $29.7 \%$ & $12.4 \%$ & $31.9 \%$ \\
\hline Did not vote & $2.6 \%$ & $0.9 \%$ & $2.9 \%$ & $4.5 \%$ \\
\hline$* *=p<0.01, *=\mathrm{p}<0.05$ & & \\
\hline
\end{tabular}

Table 5-3 also demonstrates the relationship between the perceived risk of wind farms and the importance of this issue when voting. Respondents were asked to what degree the issue of wind turbines affected their voting preferences at all three levels of government. People who perceived turbines as a high risk were far more likely to vote based on this issue at both the regional and provincial level of government. Of those that perceived the risk from wind farms as low, only $17.3 \%$ and $21 \%$ reported that the wind farm in Kincardine affected their voting decisions at the county and provincial levels of 
government respectively. Those that perceived the risk posed by wind turbines as high, $69.3 \%$ and $79.4 \%$ reported it influenced their voting decisions at the county and provincial levels of government respectively. Voting at the local municipal level had no significant relationship with perception of risk. Residents in Bruce County who perceive wind turbines as a threat to health are more likely to oppose the construction of wind farms, and are more likely to let these beliefs influence their political decision-making. New actors that would not have participated if the primary concern around wind turbines was one about property values or visual impacts have clearly become active participants in the conflict over wind power in Bruce County.

\section{Institutional Strategies: Venue Shopping}

The above story outlines the increasing success of opponents of wind energy development in Bruce County at framing wind turbines as a threat to health and the increasing acceptance of that frame by the public in Bruce County. Opposition to wind energy is no longer limited to those directly effected by a project but has spread to the community and the new frame has clearly contributed to that change. However, this is not sufficient to explain the outcome of these conflicts. These conflicts, like most political conflicts, occurred within a set of institutions that structured the conflict and actors will seek out, or shop, for venues that they believe will provide them advantages. Venue shopping is a strategy used by actors seeking an institution of decision-making in which their success is more likely (Baumgartner and Jones, 1993; Pralle, 2003, 2006). When a policy area is dominated by a policy monopoly, that monopoly typically has control of the key decision-making institutions responsible for that policy area. Those who wish to challenge that monopoly will often seek to challenge that control or seek new institutions 
more amenable to their preferred policy preferences. They may look for institutions that are more likely to grant them access or where the rules of the institution are less biased in their opponent's favor (Pralle, 2003, 2006). The institutional strategy that opponents of the Kincardine wind farm pursued was a venue shift away from the ESR and OMB processes and to the more open venue of the County Council. The strategy of framing wind turbines as a threat to human health was ant attempt to gain public support to stop the facility in that venue.

This strategy was not successful in stopping the construction of the Kincardine wind farm. In 2009, the County Council approved the construction of the facility and it was completed that year. While $57 \%$ of respondents to the survey were opposed to the facility (Table 5-3), this was not sufficient to pressure council to overturn earlier support for the project. "I believed, and still believe that the project would be great for farmers

and great for Kincardine (Interview with former County Councilor, 2012). The reframing of wind turbines as a threat to human health clearly had some effect on the growing opposition to the proposed facility, but it was not sufficiently accepted by the public in Bruce County to allow opponents to successfully shift venues and defeat the facility. The strategies adopted by opponents and the success of those strategies is largely the product of the institutions that structure the available opportunities for action. The successful completion of the proposed wind facility in Bruce County is due to the nature of the institutions within which decisions about that facility were made.

\section{PostScript: The Green Energy Act, 2009 and Framing Wind Energy}

The completion of the Kincardine wind farm should have signaled that future wind power projects in Bruce County could also expect success. However, this has not 
been the case. Interviews and media reports both indicate that completing new projects has become far more difficult. By 2009, the rise of the perception of risks posed by wind turbines contributed to the belief by many that local opponents of wind farms were slowing, or halting a number of wind farms in Ontario (Ferguson, 2009; Ferguson-Martin and Hill, 2011). Local opposition groups, and their provincial umbrella group Wind Concerns Ontario (WCO), had been successful in exerting pressure on local councils to oppose many projects. The provincial government, which was committed to implementing a green energy program, saw local opposition as the cause: "We're going to find a way through this new legislation to make it perfectly clear that NIMBYism will no longer prevail when it comes to putting up wind turbines, solar panels and bio-fuel plants" (Dalton McGuinty, former premier of Ontario in the Canadian Press, 2009). The success of opposition groups in slowing the local approvals process led to the introduction of the Green Energy Act (GEA), 2009, which among other changes meant to encourage renewable energy deployment, removed approval authority from the local to the provincial level. ${ }^{12}$ The province, through the MOE, would now have sole approval authority for renewable energy projects in Ontario and local governments would no longer be significant participants in the process.

The GEA has reinvigorated the debate about wind turbines as a potential health threat through its effect on trust in the communities facing wind energy development. Many researchers investigating the role conflicting perceptions of risk play in social conflict have identified trust as especially important in the public's assessment of the risk of a given facility or technology (Breakwell, 2007; Fischhoff, 1995; Hunter \& Leyden,

\footnotetext{
${ }^{12}$ The Kincardine wind farm was completed prior to the enactment of the GEEA and so was decided under the old rules.
} 
1995; Kasperson, 2005; McAvoy, 1998; Sjoberg and Drottz- Sjoberg, 2009; Siegrist and Cvetkovich, 2000). Trust affects the perception of risk because actors will evaluate the institutions, organizations, and individuals that are responsible for overseeing risks. When they trust those actors, they believe that those risks will be managed well (Baxter, Eyles, and Elliott, 1999; Jenkins-Smith and Kumreuther, 2001; Sjoberg and DrottzSjoberg, 2009; Slovic, 1993; Whitfield, Rosa, Dan, and Dietz, 2009). The GEA has significantly reduced the trust many members of these communities have in the institutions that make decisions about wind energy development.

The loss of trust is predominantly due to the loss of participation in decisionmaking. One of the most controversial components of this legislation, at least in rural areas affected by wind power development, was the removal of local decision-making power over the approval of wind farm projects. Power was instead vested in the provincial government through the Ministry of Environment. Research about land use conflicts suggests that opposition is largely due to the imposition of siting decisions on communities with little to no input in the process (Aitken, 2010; Breukers and Wolsink, 2007; Gross, 2007; Kuhn and Ballard, 1998; McAvoy, 1998; Puschak \& Rocha, 1998; Hunter \& Leyden, 1995; Gerrard, 1994; Rabe, 1994). Siting processes that focus only on the technical merits of a proposal and are perceived to exclude meaningful local participation are often unsuccessful because they proceed on the belief that experts and traditional political institutions possess sufficient legitimacy to make decisions (Besley, 2012; Kasperson, 2005; Fischhoff, 1995). This suggests that if citizens are excluded from a decision-making process, or judge that process to be unfair, their trust in the institutions that make those decisions will be undermined. 
The survey data gathered for this study amply demonstrates the relationship between trust and the perception of risk in Bruce County. Table 5-4 below outlines the trust relationships amongst different levels of government in Bruce County. Of those reporting low trust in the provincial government, $46.9 \%$ perceived the risk posed by wind farms as high. Of those reporting high levels of trust of the provincial government, only $8.5 \%$ perceived the health threat from wind farms as high. There is a significant relationship between the reported trust in the provincial government and the perception of risk in Bruce County residents. The distrust of the institution responsible for making wind energy decisions has a clear effect on the perception of the risk posed by wind turbines in Bruce County.

Table 5-4 Effects of Trust in Government on Perceptions of Risk

\begin{tabular}{|l|c|c|c|c|}
\hline \multicolumn{5}{|c|}{ Effect of Trust in Provincial Government on Perception of Risk N=604** } \\
\hline & \multicolumn{4}{|c|}{ Reported Trust } \\
\hline Perception of Risk & High & Medium & Low & Total \\
\hline Low & $51.1 \%$ & $27.3 \%$ & $24.6 \%$ & $27.3 \%$ \\
\hline Medium & $40.4 \%$ & $42 \%$ & $28.5 \%$ & $32.6 \%$ \\
\hline High & $8.5 \%$ & $30.8 \%$ & $46.9 \%$ & $40.1 \%$ \\
\hline$* *=\mathrm{p}<0.01, *=\mathrm{p}<0.05$ & & & \\
\hline
\end{tabular}

The GEA changed the rules of the game by removing local approval power for renewable energy projects. Changing the rules of the game is a powerful institutional strategy because it can "limit the set of players to those who share a common understanding of the nature of a policy problem and the solutions to it" (Pralle, 2006, p. 30). In this case decision-making authority was vested in the MOE who, as described above, was unlikely to be swayed by public, non-technical understandings of risk. This is 
not to say that the public would be excluded from the process but only that participation would occur within a much more circumscribed set of rules that privileged technical, and expert based assessments of risk. However, this strategy, while successful is what Cobb and Ross refer to as a high-cost conflict containment strategy (1997). These are strategies that often involve significant costs and in this instance the cost has been in declining support for the governing party in many rural areas affected by wind energy development (Spears, 2013).

\section{Conclusion}

This chapter and article has sought to integrate the literature on the social and policy responses to wind energy development and the institutional context within which those responses develop. An approach for understanding conflict expansion adapted from Pralle (2006a) was used to test the degree to which the framing of wind energy development as a threat to human health was more effective at conflict expansion. Three hypotheses were examined: H1: That the greater the acceptance of a the problem definition as one focused on the threat to human health posed by wind turbines, the greater degree to which a conflict will expand to new include new participants H2: That the more new participants that are drawn into the conflict, the more opportunity opponents will have to shift the conflict to institutional venues that provide them with advantages. H3: That the more successful opponents are at moving conflicts to new institutional venues, the greater the likelihood of halting the construction of a proposed facility. The analysis of the conflict in Bruce County confirms the first two hypotheses. As the health risk frame became accepted, new participants joined the conflict. However, 
the increased participation generated by the increasing acceptance of the health risk frame was not sufficient to overcome support for the facility in the county council.

That policy frames that focus on risks to human health often lead to more contentious policy conflicts is not a new or unexpected finding but exactly how this happens is still a crucial research question. This study contributes to answering this question by focusing on the mechanism that links the reframing of a policy to the expansion of the conflict to include new actors. It is not the redefinition itself that leads to policy change, but the acceptance of the altered frame by people who then choose to participate in the conflict. Those new participants open the door for opponents to engage in venue shopping for institutional venues that are do not privilege technical understandings of risk.

The findings from this analysis also contribute to the integration of the literature on social acceptance of renewable energy and the institutional literature around renewable energy deployment (Agterbosch, Meertens, Vermeulen, 2009; Deignan, Harvey, and Hodffman-Goetz , 2013; Hill and Knot. 2010; Jobert, Laborgne, and Milmer, 2007; Songspore and Buzzelli, 2014; Wolsink, 2000). What this study makes clear is that the framing of a policy as a threat to human health will create incentives for opponents to seek out institutions that privilege their preferred understanding of risk. The lack of scientific support for that belief will not eliminate conflict but only drive opponents of facilities believed to be a threat to seek out venues, such as municipal electoral politics, to contest these facilities. The degree to which they will be successful in these venues will depend entirely on the degree to which they can generate public belief in that risk and the degree to which that public belief pressures actors within those institutions. 
These findings have clear implications for public policy. Those seeking to develop renewable energy facilities need to develop strategies, such as improving the public's trust in crucial institutions, in order to attenuate perceptions of risk. Simply denying that there is a risk is unlikely to be successful as the research on risk perception demonstrates. The public does not only evaluate the risk posed by facilities through a technical risk assessment process but through a social process. The removal of local decision-making power over these facilities has circumvented this opposition by moving decision-making to a scale of decision-making in which the health risk frame is less salient. This has unfortunately only exacerbated opposition in Bruce County as there is little trust in the provincial government, which only amplifies perceptions of risk as demonstrated through the survey findings in this study. The development of renewable energy is an important policy goal and while these facilities will always generate opposition, recognizing and adapting to the form that opposition takes is essential for resolving conflicts over these facilities. 


\section{Chapter 6 - The Strategic Use of Risk in Public Policy Conflicts: Expanding Conflicts for Policy Change ${ }^{13}$}

\section{Introduction}

Conflicting perceptions of risk play a role in many conflicts over public policy. Conflicts over the construction of oil pipelines, the regulation of genetically modified food, and the mandating of vaccinations often hinge on the understanding of the risk these technologies pose to human health advanced by proponents and opponents. Risk has been a central issue in many public policy studies, particularly environmental policies studies (Caduff and Bernauer, 2006; Harrison, 1991; Harrison and Hoberg, 1991; Legge and Durant, 2010; Montpetit, 2011; Montpetit and Rouillard, 2008; Zerbe, 2007) but little attention has focused on how to systematically integrate risk into theories of the policy process. The recognition that these problems are more contentious than other types of policy conflicts is hardly new but how exactly this recognition should be incorporated into broader theories of public policy is less clear.

This chapter proposes a framework for integrating the role of risk into theories of the policy process by focusing on the role that competing policy frames play in the agenda-setting phase. The goal is to both explain when and why strategies of risk are successful in actual conflicts and to integrate this understanding into a framework for applying this understanding to a broader array of cases. This framework builds on the approach to conflict expansion developed by Sarah Pralle (2006a). Conflict expansion is a strategy to overturn an existing policy monopoly by drawing in new actors to the conflict, thereby bringing the issue on to the political agenda. Policy monopolies, as

\footnotetext{
${ }^{13}$ This chapter is written in article format. It is anticipated that this article will be submitted to Review of Policy Research, Policy Studies Journal, or Policy Sciences
} 
defined by Baumgartner and Jones (1994), are groups of actors who are able to maintain control over a policy by keeping that policy off the political agenda. This accounts for periods of relative policy stability, or equilibrium where little change in that policy area occurs. However when another set of actor's wish to see policy change they must challenge that monopoly by expanding the conflict. Those seeking expansion are hoping that raising the policy to the political agenda will draw in new participants and alter the balance of power that supports the policy monopoly thereby punctuating the existing equilibrium (Baumgartner and Jones, 1994; Pralle, 2006).

The analysis of conflict expansion developed by Pralle focuses on three categories of strategies utilized by actors seeking to expand or contract a policy conflict; issue definition strategies, actor participation strategies, and institutional strategies (2006a). This paper applies Pralle's approach to analyzing two case studies to test the degree to framing public policy as a threat to human health might be more effective at influencing the outcomes of conflicts over those policies. While Pralle emphasizes that the three categories of strategies are interdependent, this study seeks to specify a causal relationship between the type of issue definition and the subsequent success of other strategies of conflict expansion. Two hypotheses are tested: 1) that the stronger the risk frame is relative to other frames advanced in the conflict, the greater degree to which a conflict will expand to new actors (public and elite); and 2) that the more new participants are drawn into the conflict, the greater will be the success of opponents at effecting the outcomes of these conflicts. The goal is to reveal under what conditions the strategy of framing a policy as a risk to human health will be successful. 
The above hypotheses are tested here using two case studies of policy conflicts in which the definition of the policy was challenged by those seeking to define that policy as a threat to human health. The first conflict was over a proposed landfill in Simcoe County, Ontario referred to as Site 41 . Opponents to Site 41 sought to challenge the landfill by redefining it as a threat to local drinking water. The second case concerns the Kincardine wind farm in Bruce County, Ontario, which opponents sought to characterize as a threat to residents health. Site 41 was eventually defeated but the Kincardine wind farm was completed. These two conflicts were selected because they are situated in similar rural communities and both center on the potential risk posed by the facilities proposed in each case. $^{14}$

The research presented here indicates that the acceptance of the redefinition of these policies as a threat to human is more likely when there is a well-accepted scientific consensus about the risk posed and that no strong alternative frame is available. While both were true for the conflict over Site 41, the conflict over wind energy development lacked both these conditions. Once there is acceptance of the opposition policy definition, there is rapid expansion of the conflict to include new participants. Opponents of Site 41 were able to attract participants to the conflict well outside of the immediate stakeholders to the conflict raising the public profile of the conflict. Opponents of wind energy in Bruce County were far less successful at this initially and were unable to gain the broad public support enjoyed by the opposition to Site 41 . The degree of successful expansion then opened the door for venue shopping strategies.

\footnotetext{
${ }^{14}$ It should be noted that this does not equal a perfect most-similar case design.
} 
This study contributes to the literature on conflict expansion and agenda-setting by specifying under what conditions a specific types of issue definition - risk to human health - contributes to the expansion of policy conflicts. While framing has always been a key element in understanding conflict expansion, this paper seeks to specify the relationship between a specific type of frame and the expansion of a conflict. Further, the comparison of two similar cases of siting conflict, but where the character of risk differs, allows for an examination and illustration of the specific characteristics of the issue definition that contributes to successful opposition. To explore why the opponents of the Kincardine wind farm were less successful, lessons from the literature on framing is used to compare the framing of each facility. Chong and Druckman have explored the use of frames in competitive political contexts and have begun to identify the characteristics that make for a strong versus a weak frame $(2007 \mathrm{a}, 2007 \mathrm{~b}, 2011)$. While this research is generally developed in an experimental setting, this study seeks to test the characteristics, specifically the public acceptance of scientific evidence of risk (or its absence) and the

relative strength of the frames deployed by each side in a case study research design. This can suggest under what circumstances the deployment of a health risk frame might be expected to be successful.

\section{Theoretical Approach: Risk and Public Policy Theory}

\section{Risk Perception}

Early work on risk in the social sciences, often termed the psychometric paradigm, studied the expressed perceptions of risk by individuals, often through questionnaires, to reveal their subjective understanding of risk (Zinn and Taylor-Gooby, 2006). This research suggests that how risk is framed is important to risk assessment 
(Slovic, Fischhoff, \& Lichentstein, 1984), that social, political, and psychological factors play a role in risk assessments (Slovic, Fischhoff, and Lichentstein, 1982), and that there is often a disconnect between our emotive response to risk and a more balanced analysis of the same risk (Slovic, Peters, Finucane, \& MacGregor, 2005). A second influential approach to explaining risk perception in the social sciences is the anthropological approach called cultural theory. Initially developed by Mary Douglas and Aaron Wildavsky (1982), the cultural approach suggests that the values or worldviews, called cultural biases, of individuals fundamentally affect how they perceive risk (Rippl, 2002). Both of these approaches are important to understanding risk perception but perhaps the most important insight for the purpose of this study is the recognition that risk perceptions are highly individualized.

The definition of risk in most technical forms of risk assessment is the "probability of a particular adverse event occurring during a stated period of time" and can be conceptualized in terms of two related dimensions: probabilities, which is the likelihood of an event occurring, and effects, which is the magnitude of the damage of that event (Breakwell, 2007). Technical risk assessment is generally the multiplication of these two in order to quantitatively assess the relative risk of some technology or activity (Kasperson et al, 2005). However, the public's perception of risk is often contrary to the beliefs of technical risk management professionals who quantify the risk as minimal without recognizing that the perception of risk by the public is often rooted in "nonquantifiable factors" (Johnson, 2007; Kasperson, 2005; Siegrist and Cvetkovich, 2000; McAvoy, 1998). As the psychometric and cultural approaches to risk perception make clear, risk perception is always contextual. Resistance to a type of risk is not, therefore, 
based on a technical evaluation of risk but on the perception of risk that is as much a social product as one based on objective scientific quantitative criteria. This leads to inevitable political conflicts about the risk posed by a proposed facility or technology.

While the formation of risk perception is obviously important, this study is focused less on how individuals come to form perceptions of risk and instead focuses on how those perceptions inform political action. It is how the different understandings of the risk posed by a particular facility or technology that are deployed by opponents and proponents influence the outcome of the conflict over these facilities that is of interest in this study.

\section{Strategies of Issue Definition}

The brief discussion of risk perception above highlights the fact that different actors may have very different understandings of the risks posed by a given technology or facility. The importance of how different understandings of a public policy advanced by conflicting actors in a policy conflict can influence the outcome of that conflict is highlighted in theories of conflict expansion (Rochefort and Cobb, 1994). This approach to public policy conflict analyzes the role that different 'problem definitions' play in aiding the expansion; that is, how the problem definition draws in new actors to the conflict, or contains and limits new actors from joining the conflict. To expand conflict an issue will be defined in terms of "sweeping social themes, such as justice, democracy, or liberty" (Rochefort and Cobb, 1994, p. 5). Those seeking to contain a conflict will attempt to define the issue in "narrow technical terms" (Rochefort and Cobb, 1994, p. 5). Opponents of wind farm construction will attempt to characterize those turbines as a threat to human health, one of the most important social themes, to draw attention to the 
issue to expand the conflict. Proponents of wind turbines will try to define any negative effects as a technical problem that can be resolved through expert assessment and placement of turbines or outsight deny that any negative effects exist. This can contain the conflict to expert processes with little public input or interest.

Actors engaged in a conflict over a policy have many strategies they can deploy to expand or contain a policy conflict. In order to clarify the analysis of conflict expansion, Pralle organizes these strategies into three groups: strategies focused on issues, strategies focusing on actor participation, and institutional strategies (2006a). Issue definition strategies are the first set of strategies identified by Pralle (2006) and the most critical for this case study as it is hypothesized here to be the strategy that opens opportunity for the others. Issue definition strategies are the strategies that can be deployed in order to raise or lower the salience of an issue to the public. By raising the salience of an issue, advocates of policy change hope to place the issue on the public agenda thereby providing the opportunity to overturn the existing policy monopoly (Baumgartner and Jones, 1994; Rochefort and Cobb, 1994). Controlling the way in which a policy issue is defined can provide significant advantages by controlling the scope of the issue, by claiming ownership of an issue, or by linking a previously low salience issue to a more salient one (Pralle, 2006). Issue definition becomes a point of conflict between those seeking to contain and those seeking to expand a conflict with each attempting to define the issue in way that advantages them relative to their opponents.

Scholars of policy theory have long recognized the importance of how a policy is defined to the policy process. Deborah Stone's seminal work describes the role that causal stories play in policy conflicts (1988). Causal stories explain who has been 
affected by a problem and who is responsible for the problem; it is about identifying who are the oppressors and who are the victims (Stone, 1988, p. 207). Conflicts over causal stories are about the struggle to control which story will become the prevailing narrative and therefore which story will inform policy decisions. Conflicts over risk are very much about conflicts over the 'correct' causal story of that risk. A wind turbine facility can be a low impact method for generating clean electricity or an industrial blight that poses substantial health risks to those living near them. In the former case, those opposing wind turbines are resisting a safe technology for their own individual concerns. In the latter, wind turbines are being imposed on communities regardless of the real risk they pose to members of those communities. Creating the most compelling causal story can provide the opportunity to affect public opinion around a particular policy.

Understanding the role that issue definition plays in these conflicts can be aided by applying theories of framing. Framing is "the process by which people develop a particular conceptualization of an issue or reorient their thinking about an issue" (Chong and Druckman, 2007). Frames are the different and often competing conceptualizations of the issue definition, or casual story of a given policy. Frames generally contain three important elements: "a problem, a protagonist, and a solution (Levin, 2005, p. 84). Frames affect an individual's opinion of an issue by focusing attention on a particular aspect of that issue (Druckman, 2001). For example, framing wind turbines as an advantage to rural economies emphasizes that economic considerations are the most important way of evaluating wind energy development.

In political conflicts, framing occurs in what Chong and Druckman refer to as a competitive framing environment (2007a, 2007b). This occurs when actors are exposed 
to multiple, competing frames about a single issue. Frames in this context are the weapons used by competing sides to advance support for their preferred policy. This of course leads to questions about why some frames are more effective than others. Chong and Druckman identify the relative strength of a frame as an important element in explaining their success in shaping public opinion. A strong frame can "strike opinion leaders and audiences as being more compelling than alternative arguments" (Chong and Druckman, 2007b, p. 116). They do so by connecting to an idea or value that is widely shared. Chong and Druckman identify the relative paucity of research about what makes a frame stronger but research has suggested some characteristics such as a credible source and that a frame does not contradict existing beliefs (Chong and Druckman, 2007a). The research presented here seeks to test the hypothesis that the stronger the health risk frame, the greater the potential for conflict expansion to include new participants and to identify what characteristics of those frames may make that expansion more or less successful.

Frames that focus on human health risks connect to one of the most basic human values and should therefore be expected to be potentially strong frames. In both cases studied here, those proposing the facilities in question advanced the initial frames that described those facilities. In each case, opponents sought alternative or counter-frames with which to oppose the facility. A counter-frame is defined as "a frame that opposes an earlier effective frame" and is characterized by three components: it comes after another frame, it offers a conflicting position to the first frame, and that the first frame affected opinion and this sparks the need to create the counter-frame (Chong and Druckman, 2011). Counter-framing is an effective strategy when a strong frame can be presented and is capable of undermining the existing frame (Chong and Druckman, 2011). 
The research presented here investigates two different forms of the health risk frame: risk to health through the potential contamination of water and the risk to human health from wind turbine noise. Comparing the success of each frame at mobilizing participation can reveal the characteristics of each frame that contributed to that success. Two characteristics revealed in this study prove to be particularly important in strengthening a frame: the degree of the public acceptance of the scientific consensus around the potential risk and the relative strength of the opposing frame.

\section{Strategies of Actor Participation and Conflict Expansion}

Strategies around encouraging or discouraging participation are the second set of strategies Pralle identifies (2006). When a policy is controlled by a policy monopoly, actors within that monopoly will seek to limit the participation in a conflict in order to preserve that monopoly. They will seek to have participation in the conflict as contained as possible. Advocates of change will seek to draw in new actors in order to change the balance of power and overturn the monopoly. Encouraging or discouraging participation therefore become key strategies. Pralle identifies a number of strategies that opponents or supporters of a policy will deploy in order to expand or contain the conflict (2006a). Each of these strategies can be used in any policy conflict but the contention in this research is that the strategy of framing a policy as a potential health to human health (a strategy of issue definition) is so effective because it opens the opportunity for strategies of participation expansion.

The first strategy of participation expansion Pralle identifies is a characterization contest (2006a). This is the strategy of attacking opponents by labeling them negatively in an effort to dissuade the public from supporting the stigmatized group. This is a very 
common strategy for proponents of new facilities to vilify opponents by labeling them as 'Not In My Backyard '(NIMBY) activists. NIMBY activism is generally associated with local and self-interested opposition to facilities that are a benefit to the larger community. NIMBY activists are assumed to oppose facilities because of unreasonable fears of property value loss or the general nuisance of a proposed facility. NIMBY activists are accused of putting their own selfish interests above the interests of their community. The framing of a facility as a threat to human health is a powerful counter to claims of NIMBYism. Opposition to a facility that threatens the health of community members, or even the entire community, cannot be characterized as a purely self-interest. The framing of a facility as a threat to human health therefore counters one of the most effective strategies deployed by proponents of those facilities to contain these conflicts.

The second strategy of participation expansion Pralle identifies is encouraging or minimizing a conflict (2006). Conflict encouragement involves highlighting the disagreements at the center of the conflict through protest and media campaigns. The point is draw attention to the conflict in order to draw in new participants. Those seeking to contain the conflict will attempt to minimize disagreements (Pralle, 2006). These strategies are again possible in any conflict but the deployment of a health risk frame strengthens this strategy. Protests focused on the potential nuisance of a facility or the potential loss of property value for a handful of citizens are unlikely to draw significant attention. Protests that claim a facility is threat to human health are far more likely to attract attention. The imposition of a facility that harms the health of the people around it strikes at fundamental values of justice and fairness and is far more likely to engage the interest of the public. 
Framing a public policy as a potential threat to human health is an issue definition strategy but it also has the potential to draw new actors in these conflicts. It is the relationship between the framing of the facility as a threat to human health (an issue definition strategy) and the success of subsequent strategies aimed at increasing the participation of actors that is the focus of Hypothesis 1: that the stronger the risk frame is relative to opposition frames, the greater degree to which a conflict will expand to new actors (public and elite).

\section{Institutional Strategies}

The final set of strategies categorized by Pralle are institutional strategies (2006a). Institutions, as the set of rules that structure decision-making, are a key element of any political conflict and have become central to the study of public policy (Booth and Harrison, 2009; Montpetit, 2005). Institutional strategies of conflict expansion focus on how institutions can limit participation or access to decision-making institutions. Pralle identifies a number of institutional strategies but the strategy of venue shopping is the key strategy used in this conflict (2006). Venue shopping is the strategic movement of an issue or conflict by some group (such as policy-makers or advocacy groups) from one decision-making venue to another for the purpose of achieving advantage in realizing that groups goals (Baumagartner and Jones, 1993; Pralle, 2003).

Venue shopping is an important strategy because all institutions contain biases, such as the rules around participation that can provide advantages to groups or individuals (Boothe and Harrison, 2009; Pralle, 2003, 2010). Shifting venues is therefore about seeking out institutional venues where the biases of that institution provide some benefit. The crucial question in this research project is how and why does framing a 
policy as a threat to human health aid in venue shopping? The key to answering this question is in the relationship between the framing of the policy image and the institutional biases of the venues in which that policy is contested.

The institutional biases that are crucial for understanding this conflict are the relationship between the policy frame and the institutions of decision-making necessary for approval of the facility. These conflicts are focused on the very different framing of the risk posed by each facility advocated by proponents and opponents of that facility. Initial approval of the facility in each case occurred within a set of institutions such as Environmental Assessment panels and land use panning tribunals. These types of institutions tend to restrict participation to approved actors (generally stakeholders) and have formalized or even quasi-judicial proceedings that will almost universally privilege expert and technical understandings of risk. This is not to say that they are more likely to approve facilities or technologies, but only that their decision will be grounded in technical understandings of risk based on expert assessment and evidence. In order to reject a proposed facility or technology, evidence of risk needs to be presented to counter any evidence in favor of the proposal. The risk conception of those who are not formally part of the proceedings will play little role in decision-making. Framing the facilities as a threat to human health without sufficient technical evidence would be unlikely to succeed in this type of institution. Opponents quickly recognized that they needed to shift the conflict to a venue of decision-making that did not privilege expert understandings of risk. It is the ability to shift venues made possible by the framing of the facility as a threat to human health and the increased participation of actors in the conflict that is captured in 
Hypothesis 2: that the more new participants are drawn into the conflict, the greater will be the success of opponents at effecting the outcomes of these conflicts.

The above section began with a brief review of the vast literature on risk perception and focused on the finding that the risk perception of individuals is both highly personal and at least partially socially constructed. Disputes about risk are therefore essentially clashes between the different understandings of the risk posed by a technology held by different actors. The question therefore becomes does the different understandings of that risk presented by opposing actors aid them in influencing the outcome of policy conflicts over that risk? The literature on conflict expansion, and in particular the approach to analyzing policy conflict strategies developed by Pralle, are an ideal approach to analyzing these conflicts over risk because they explicitly recognize the interplay between how a policy is framed, the participation of actors in that conflict, and the central role that institutions play in structuring these conflicts (2006a). The following section outlines the research design and data used to test the two hypotheses outlined in the introduction.

\section{Research Design and Methodology}

This research employs a within case process tracing method as the primary tool for testing the above hypotheses. Process tracing seeks to explicitly reveal the underlying causal mechanisms that link events to the outcomes we observe. Those advocating process tracing methods define causal mechanisms in different ways (see Collier, Brady, and Seawright, 2010; George and Bennett, 2005; Mahoney, 2012) but Beach and Pedersen offer a broadly typical definition as a process or series of processes that links an independent variable to an observed outcome (2010, p. 5). The goal of identifying causal 
mechanisms is to reveal the process through which causation is transferred from cause to effect to reveal the true cause of a given outcome. Process tracing offers a number of advantages that make it particularly appropriate for policy studies including its inherent strength in disentangling complex causal relationships and the transparency it builds into the research process (Kay and Baker, 2014).

A number of medthodolgies were employed to conduct the analyses of the two case studies. First, extensive documentary evidence was collected including formal communications by municipal, provincial, and federal levels of government, the official records of Ontario Municipal Board (OMB) and Environmental assessment tribunals, records of meetings, and communications of the opposition groups and individuals involved in the conflict. This evidence provided significant detail about the case under study.

Second, media reports (Site $41 n=507$, Wind Turbine $n=305$ ) about each conflict were coded to identify the frames used by newspapers in media coverage of the conflicts. This is an approach that is often used to identify the presence or absence of frames of interest to the researcher in studies of framing (Chong and Druckman, 2007). The first step was a search of the Canadian Newsstand database using search terms such as "Kincardine wind farm" and "Site 41". Because several of the local papers in each county were not indexed in the database, a second stage involved using the same search terms in local papers in each county such as the Kincardine Times and the Barrie Examiner. These searches were conducted for the periods beginning when the facilities were first proposed (1990 for Site 41 and 2003 for the Kincardine wind farm) until the end of the conflicts 
(2010 when Site 41 was cancelled by Simcoe County ad 2009 when the Kincardine wind farm was completed).

Once the newspaper reports were identified, a content analysis was completed using a coding instrument that focused on the frames used to either oppose or support each facility. For example, identification of the health risk frame was based on any mention of the possible consequences of the facility for human health. Many reports included mention of multiple frames. While the coding instrument was predetermined, some new frames were identified through the coding process. For example the potentially inequitable leasing contracts offered by wind energy companies were identified during the coding process. As the author was the only coder, inter-coder reliability was not a concern.

Third, semi-structured interviews with a variety of stakeholders from both cases, 12 in the Site 41 conflict and 10 in the Kincardine wind farm case, were conducted. These interviews were invaluable for assessing the opinions and motivations of stakeholders including: current and former political actors, members of groups opposed to each site, and bureaucratic actors involved in the conflict. Secondary sources and media research provided the first set of interview subjects and others were identified through early interviews.

Finally, a mail out survey to Simcoe and Bruce County residents was conducted in the spring of 2012. Six thousand surveys were mailed to randomly selected residents and 1159 completed surveys were returned for a combined response rate of $19.3 \%$ with $22 \%$ in Bruce County and $17 \%$ in Simcoe County. This response rate is lower than is often the case with mailed surveys and this is explained by the lack of the recommended 
regime of follow up reminders because of limited resources (Rea and Parker, 2005). The surveys provided important data about the opinions of residents who may not have been direct stakeholders in the conflict. This was used to measure the success of the contending frames at increasing the participation of the public in the conflict.

\section{Cases: Simcoe and Bruce Counties}

Case selection for this study is based on variation on the key independent variable and the dependent variable (Table 6-1). The key independent variable of interest is the health risk frame used by opponents in each case. Variation on this variable is based on the different type of health risk posed by each. This should allow for the identification of the role the health risk frame played in each case and to compare the effects of the different types of risk. Because opponents in each case initially focused on a non-health risk frame, the success of opponents at expanding the conflict before and after the introduction (or at least the decision to focus almost exclusively) of the health risk frame can be identified. This is not to suggest that this is the only important factor in explaining the outcomes of these conflicts. Factors such as the organization and leadership of the different opposition groups in each case certainly played a role. The dependent variable is the outcome of the conflict, the completion or cancellation of the respective facilities.

\section{Table 6-1: Case Selection}

\begin{tabular}{|l|l|l|}
\hline Key Case Characteristics & Site 41 & Kincardine Wind Farm \\
\hline Initial Opposition Frame & Nuisance effects of landfill & $\begin{array}{l}\text { Landscape impacts of wind } \\
\text { turbines }\end{array}$ \\
\hline $\begin{array}{l}\text { Type of Health Risk } \\
\text { (Independent variable) }\end{array}$ & $\begin{array}{l}\text { Risk from contaminated } \\
\text { water }\end{array}$ & $\begin{array}{l}\text { Risk from low level sound } \\
\text { and vibrations from } \\
\text { turbines }\end{array}$ \\
\hline $\begin{array}{l}\text { Dependent Variable: } \\
\text { Outcome of conflict }\end{array}$ & Cancellation of facility & Completion of facility \\
\hline
\end{tabular}


Simcoe and Bruce Counties are located in Southern Ontario. Each County has a population of approximately 440,000 and 66,000 people respectively (Bruce County, n.d.; Simcoe County, n.d). The average income and education of both is slightly below the provincial average and the number of immigrants as a percentage of total population is considerably less than the more urbanized areas of the province such as Toronto (Bruce County, n.d.; Simcoe County, n.d.) Both areas are predominantly rural and, while agriculture is important, tourism plays an important role in the local economies as they both have extensive shorelines on the Great Lakes (Bruce County, n.d.; Simcoe County, n.d.).

Both Simcoe and Bruce are upper tier municipalities, which are made up of smaller towns and townships. Each of these lower tier governments consists of a mayor and council and is responsible for its own water and sewer services, local roads, recreation services, land use policies, and police and fire services. The County, or upper tier municipal government, consists of the mayor and deputy mayor of each of the sixteen towns and townships for a council of thirty-two which elects a Warden to head the County Council. The County is responsible for services such as social housing, county roads, land use policy planning, and environmental services including solid waste management.

\section{Results and Discussion}

\section{Issue Definition: Risk to Human Health}

The Site 41 conflict began in the 1980 's over a proposed location for a land fill site that would have accepted waste from four towns and townships within the County. The proposed site was located in Tiny Township and local residents were opposed to the 
proposal. In 1989, an Environmental Assessment Tribunal rejected the proposed site based on a flawed process (Environmental Assessment Board, 1989). The tribunal ruled that the proponent had not considered all other potential sites before deciding on Site 41 . The County then appealed to the Provincial Cabinet, which overturned the Joint Assessment Board's decision through an executive decision known as an Order in Council (OIC), and ordered a resumption of the hearings with stipulations that opponents of the site must prove actual harm and that the site selection process was sufficient (Executive Council of Ontario, 1990). After a failed judicial challenge to the OIC by opponents of the site in 1993, the Joint board resumed, and based on the new criteria outlined in the OIC, approved Site 41. A Certificate of Approval (CofA) was issued by the Ontario Ministry of the Environment (MOE) in 1998.

Site 41 was proposed as a clay-lined site with an additional liner that would collect leachate for treatment in a local water treatment facility. The site was only approved for domestic, commercial, and non-hazardous solid industrial waste as well as dewatered sewage sludge (Ontario Ministry of the Environment, 1998). The proponents of Site 41 were the County bureaucrats who initially recommended the site and continued to advocate of it as the best option and the County Councils who approved the proposal and supported it through subsequent Council meetings. The proposal for Site 41was assessed as low risk by proponents: "the continued Provincial approval for this facility, particularly given the high level of scrutiny and study that has been part of this process, is undeniable evidence that this site can and will be developed to be protective of the environment" (Simcoe County, 2006, Para 3). Proponents of Site 41 framed the proposed facility as a low risk facility that would safely dispose of local sold waste. 
The opponents to Site 41 were initially limited to citizens and municipal councils living near the proposed site in the municipality of Tiny. These opponents did create an opposition group to mobilize support, the Wye Citizens Group, but it initially had only several dozen members and few resources (Interviews, 2012). These opponents deemed the site to be a fundamental threat to local drinking water because of potential contamination from the proposed facility: "Water affects our family a lot - we need good water for dairy farming - but it could affect a lot of people," she said. "They're building this on top of the Alliston aquifer - it's huge. If (contaminants) get into the aquifer, it could be very dangerous for a large group of people" (Midland Free Press, 2003).

Table 1 below displays the percentage of newspaper reports analyzed for this study that make at least a single mention of each of the identified supportive or oppositional frames. The data demonstrates that the health risk frame was the frame most identified by newspaper reports about Site 41 , appearing in $86 \%$ of reports. While other opposition frames were used, for example the potential loss of prime agricultural land if Site 41 was completed (Table 6-2), by 2010 the health risk frame had become the dominant opposition frame appearing in over $95 \%$ of the media reports about Site 41 analyzed for this study (Table 6-3). No other opposition frame had nearly that significant coverage, the next most popular frame of loss of agricultural land because of Site 41, appeared in only $32 \%$ of newspaper reports (Table $6-2$ ). Only $32 \%$ of newspaper articles mention the cost effectiveness of Site 41 and $22 \%$ of articles mention the County's responsibility to manage their own waste. The most dominant single frame used in newspaper reports about Site 41 was the health risk frame. 
Table 6-2 Percentage of Media Reports that Include at Least Single of Supportive or Oppositional Frames

\begin{tabular}{|c|c|c|c|}
\hline County & Frames & Specific Frames & $\begin{array}{l}\text { Percentage of Newspaper } \\
\text { Reports with at Least one } \\
\text { mention of that Frame }\end{array}$ \\
\hline \multirow{7}{*}{$\begin{array}{l}\text { Simcoe } \\
(\mathrm{N}=507)\end{array}$} & \multirow{4}{*}{$\begin{array}{c}\text { Opposition } \\
\text { Frames }\end{array}$} & Health risk & $86 \%$ \\
\hline & & Agricultural loss & $32 \%$ \\
\hline & & $\begin{array}{l}\text { Environmental (not related to } \\
\text { human health) }\end{array}$ & $28 \%$ \\
\hline & & Other & $26 \%$ \\
\hline & \multirow{3}{*}{$\begin{array}{l}\text { Support } \\
\text { Frames }\end{array}$} & Cost effective & $32 \%$ \\
\hline & & Responsible for own waste & $22 \%$ \\
\hline & & Other & $13 \%$ \\
\hline \multirow{7}{*}{$\begin{array}{c}\text { Bruce } \\
(\mathrm{N}=305)\end{array}$} & \multirow{4}{*}{ Opposition } & Health risk & $78 \%$ \\
\hline & & Unfair decision making & $65 \%$ \\
\hline & & $\begin{array}{l}\text { Environmental (not related to } \\
\text { human health) }\end{array}$ & $55 \%$ \\
\hline & & Other & $32 \%$ \\
\hline & \multirow{3}{*}{ Supportive } & Good for local economy & $63 \%$ \\
\hline & & Good for the environment & $55 \%$ \\
\hline & & Other & $22 \%$ \\
\hline
\end{tabular}

Table 6-2 Change over Time of Media Reports that Include at Least Single Mention of Health Risk Frame

\begin{tabular}{|l|l|l|}
\hline & $\begin{array}{l}\text { First Year of } \\
\text { Sample }(\text { Simcoe }= \\
1990, \text { Bruce }= \\
2003)\end{array}$ & $\begin{array}{l}\text { Last Year of Sample } \\
(\text { Simcoe }=2010, \text { Bruce } \\
=2009)\end{array}$ \\
\hline Simcoe County: Site 41 $(\mathrm{N}=507)$ & $22 \%$ & $96 \%$ \\
\hline Bruce County: Wind Energy $(\mathrm{N}=305)$ & $11 \%$ & $84 \%$ \\
\hline
\end{tabular}

The conflict around the Kincardine Wind Farm began in 2003 with a proposal by Leader Wind Corporation to construct a wind turbine farm in Bruce County. The proposed farm would include 154 turbines with a rated capacity of 199.65 MWs of power (OMB, 2008). In 2006, citing a problematic approval process, Leader wind passed the 
project to Enbridge Ontario Wind Power. In April of 2006, Enbridge submitted the Environmental Screening Report (ESR) required for energy projects and during the summer of 2006, public meetings were held to discuss the projects which were well attended by the public (OMB). The ESR process is an environmental review process with little or no review of the information submitted by the proponent. However, ESR reports must be publicly posted for a 30-day comment period, which enables the public or stakeholders to request that the proposal be elevated to a full Environmental Assessment that requires independent review of the proposal. Twenty-one members of the public did make that request as did the County when several of their concerns were not addressed by Enbridge (MOE, 2007). By June of 2007, Enbridge responded to the Counties' concerns and the County subsequently withdrew its request for elevation in August (Interviews, 2012). The MOE formally denied the remaining requests for elevation in March of 2007 and that concluded the ESR phase of the conflict.

In addition to the ESR process, opponents of the proposed project filed an appeal to the Ontario Municipal Board (OMB), which is an appeal tribunal for land use planning decisions in Ontario. In 2006, the municipality of Kincardine had issued 105 by-law amendments to permit the construction of the turbines. In September, 38 of the by-law amendments were appealed to the OMB by 37 appellants who were landowners located near proposed turbines. While some changes were made by the proponent including the reduction of turbines noted above, the OMB ruled in favor of the proponent in July of 2007. The project at this point was free to proceed and the facility began commercial operation in February of 2009. 
The proponents of the Kincardine Wind Farm included Enbridge Wind Energy, the majority of Bruce County councilors that supported the facility, the landowners who might benefit directly from leasing land for a wind turbine, and local and provincial environmental activists supportive of wind energy. These actors did not comprise an organized group but were a loose network of actors that supported the project for economic and environmental reasons. The opponents of the facility were initially made up of local landowners who lived near but would not benefit from the project and local and provincial anti-wind activists. At the start of the conflict these actors were loosely organized but as the conflict progressed they became better organized as they developed formal memberships, began media campaigns and websites, and formed alliances with provincial anti-wind groups such as Wind Concerns Ontario. Local chapters of these provincial groups, such as Wind Concerns Bruce, were formed over the course of the conflict. Like the proponents and opponents of Site 41, these groups initially did not constitute an organized advocacy group. However, because these groups shared a clear set of shared goals and engaged in cooperation around strategies, for the purpose of analysis they are treated here as collective actors. Table 6-4 below summarizes the initial proponents and opponents in each case.

Table 6-4: Initial Proponents and Opponents

\begin{tabular}{|l|l|l|}
\hline & Site 41 & Kincardine Wind Farm \\
\hline Proponents & $\begin{array}{l}\text { Simcoe Waste } \\
\text { Management, Simcoe } \\
\text { County Council }\end{array}$ & $\begin{array}{l}\text { Leader Wind (later } \\
\text { Enbridge), Bruce County } \\
\text { Council, Local Municipal } \\
\text { Councils, Land owners, } \\
\text { Local and provincial } \\
\text { environmental groups }\end{array}$ \\
\hline Opponents & $\begin{array}{l}\text { Tiny Municipal Council, } \\
\text { Local land owners }\end{array}$ & $\begin{array}{l}\text { Local land owners (not } \\
\text { those leasing land for } \\
\text { turbines), Local and } \\
\text { provincial anti-wind groups }\end{array}$ \\
\hline
\end{tabular}


The framing of wind turbines has proven more balanced then the framing around Site 41. Two central competing frames developed around the Kincardine wind farm. The first is the environmental and economic benefits of wind turbines. These represent wind power as a clean power source without the environmental consequences of fossil fuel based electricity generation: "Unlike thermal sources of electricity production, such as coal or nuclear power, wind turbines generate electricity without consuming or contaminating fresh water" (CANWEA, N.D.) In addition, wind power is presented as a new technology in which Ontario can gain a competitive advantage and recapture lost manufacturing jobs: "Wind energy developments are delivering local benefits and making positive and lasting economic contributions across Canada" (CANWEA, N.D). These frames appeared in at least $63 \%$ and $55 \%$ of newspaper reports analyzed for this case (Table 6-1).

The dominant opposition frame in Bruce County was the belief that wind turbines pose a substantial health risk to those living close to turbines and the consequent exposure to audible and inaudible noise and vibration. This concern manifests itself in the centrality of setback distance (the allowable distance between a turbine and a potential receptor); setback distance is a central point of contention in many of the conflicts over wind turbine facilities and regulations. By 2009 the health risk frame appeared in $84 \%$ of all media reports about wind turbines in the Bruce County newspapers analyzed for this study (Table 6-2). This is consistent with research conducted by Deigman, Harvey, and Hoffman-Goetz that showed the health effect frame appeared in over $90 \%$ of local newspaper reports in a number of communities hosting wind turbines in Ontario (2013). 
Unlike the Site 41 conflict, the second most popular opposition frame was related to the unfairness of the decision-making process surrounding the facility. This frame was present in $65 \%$ of analyzed reports (Table 6-2). The health risk frame was the dominant opposition frame in newspaper reports about the Kincardine wind farm but was not as dominant as it was in newspaper reports about Site 41 and the newspaper reports that included frames supportive of the wind farm were far more numerous than supportive frames around Site 41.

\section{Participation: Expanding the Conflict}

There is ample evidence in the framing literature that the way a policy is framed can affect public opinion about that policy (Chong, 1996; Chong and Druckman, 2007; Druckman, 2001; Jacoby, 2000). This effect is clearly evident in both cases analyzed here. Table 2 reports the responses from the survey conducted in 2012 to a question asking if the facility in question poses a threat to local human health. Respondents in Simcoe County clearly accepted the health risk frame with $61.6 \%$ strongly agreeing that the proposed Site 41 posed a health risk from the potential contamination of water (Table $6-5$ ). Only $12.2 \%$ of respondents either strongly or somewhat disagreed with the same statement. Further, in answer to a question about their opposition to the facility, $68.8 \%$ of respondents in Simcoe County responded they were opposed to the facility while only 17.9\% were in favour (Table 6-6). The relationship between belief that Site 41

represented a threat to health and opposition is also clear: $98.2 \%$ of respondents that said they strongly believe that Site 41 was a threat to health reported being opposed to the facility (Table 6-7). At the time of the survey, respondents in Simcoe County clearly 
accepted the health risk frame and a convincing majority were opposed to Site 41 because of this belief.

Table 6-5 Does facility X (Site 41 or Kincardine Wind Farm) pose a health risk? $(\mathrm{N}=772)^{* * *}$

\begin{tabular}{|l|l|l|}
\hline & Simcoe County & Bruce County \\
\hline Strongly agree & $61.6 \%$ & $16.9 \%$ \\
\hline Somewhat agree & $26.1 \%$ & $33.5 \%$ \\
\hline Somewhat disagree & $9.3 \%$ & $23.7 \%$ \\
\hline Strongly disagree & $2.9 \%$ & $25.7 \%$ \\
\hline$* *=\mathrm{p}<0.01, *=\mathrm{p}<0.05$ & \multicolumn{2}{|l|}{} \\
\hline
\end{tabular}

Table 6-6 Answer to Question: If you are familiar with facility X (Site 41 or Kincardine Wind Farm), were you opposed to the facility? ( $N=776)$ **

\begin{tabular}{|l|l|l|}
\hline & Simcoe County & Bruce County \\
\hline Opposed & $68.8 \%$ & $57.4 \%$ \\
\hline Not opposed & $17.9 \%$ & $28.4 \%$ \\
\hline Don't know & $13.3 \%$ & $14.2 \%$ \\
\hline$* *=p<0.01, *=\mathrm{p}<0.05$ & \multicolumn{2}{|l|}{} \\
\hline
\end{tabular}

Table 6-7 Answer to Question: Are you opposed to the facility?**

\begin{tabular}{|l|l|l|l|l|l|}
\hline & & \multicolumn{4}{|c|}{ Facility is a threat to local health? } \\
\hline & Opposed? & $\begin{array}{l}\text { Strongly } \\
\text { Agree }\end{array}$ & $\begin{array}{l}\text { Somewhat } \\
\text { Agree }\end{array}$ & $\begin{array}{l}\text { Somewhat } \\
\text { Disagree }\end{array}$ & $\begin{array}{l}\text { Strongly } \\
\text { Disagree }\end{array}$ \\
\hline \multirow{2}{*}{$\begin{array}{l}\text { Simcoe County } \\
(\mathrm{N}=321\end{array}$} & Yes & $98.2 \%$ & $56.1 \%$ & $0 \%$ & $0 \%$ \\
\cline { 2 - 6 } & No & $1.8 \%$ & $43.9 \%$ & $100 \%$ & $100 \%$ \\
\hline $\begin{array}{l}\text { Bruce County (N } \\
=383)\end{array}$ & Yes & 96.9 & $93.8 \%$ & $49.2 \%$ & $17.8 \%$ \\
\cline { 2 - 6 } & No & $3.1 \%$ & $6.1 \% \%$ & $50.7 \%$ & $82.1 \%$ \\
\hline & $* *=\mathrm{p}<0.01, *=\mathrm{p}<0.05$ & & \\
\hline
\end{tabular}

The focus on framing Site 41 as a threat to human health not only engaged the public but assisted opponents in drawing in new active participants to the opposition. As the conflict grew and shifted to focus on the protection of water the number of active 
participants grew into a loose network of activists. This network never coalesced into an institutionalized advocacy group but their were identifiable leaders who coordinated the campaigns to stop Site 41 including protests, letter writing and petition campaigns, and media relations. . In 2009, protests and eventually an occupation of Site 41 by citizens and First Nations protestors occurred, which led to arrests of protesters and the County seeking court injunctions preventing protesters from interfering with construction of the site that began in 2007. A vigil by a group of First Nations protestors near Site 41 garnered significant media attention.

It was the actions of these opponents of Site 41, most of who lived near the facility that garnered the attention that shifted the conflict from a local to regional one. In addition, a private members bill halting the construction at Site was twice tabled by the local Member of the Provincial Parliament (a member of the official opposition) but was defeated. The conflict over Site 41 was an intense conflict that generated both local passion and interest by actors well outside of the region directly affected by the landfill itself.

The case in Bruce County is somewhat different. While the health risk frame is the dominant opposition frame in the Bruce County conflict, the acceptance of that frame is not as clear as in the conflict over Site 41 . Only $16.9 \%$ of respondents reported that they strongly agree with the statement that the Kincardine Wind Farm is a threat to local health while $33.5 \%$ somewhat agree (Table $6-5$ ). $49.4 \%$ of respondents either strongly or somewhat disagreed with the same statement. Not surprisingly, only $57.4 \%$ of respondents were opposed to the facility (Table 6-6). The health risk, while the most 
mentioned frame in the newspaper reports analyzed for this study, was not as accepted by the public nor was opposition to the facility as overwhelming as it was in the Site 41 case.

The relationship between the health risk frame and opposition to the facility is also less clear. $96.9 \%$ of respondents that strongly agreed with the statement that the facility posed a threat to local health also opposed the facility much like in the Site 41 case (Table 6-5). In the Site 41 case no respondents that disagreed with the statement that Site 41 posed a threat to health were opposed to the facility. However, in the Kincardine case $49.2 \%$ of respondents that disagreed with the statement that the Kincardine Wind Farm posed a threat to health were still opposed to the facility and $17.8 \%$ of respondents that strongly disagreed with the statement were still opposed to the facility. While health risk was the dominant opposition frame in the Bruce County case, this frame was not as accepted by the public nor does it explain all opposition to the facility as it does the opposition to Site 41.

The above analysis clearly demonstrates the importance of the health risk frame to these two conflicts but the difference in the level of acceptance and influence of the health risk frame in each requires explanation. In the Site 41 case, the dominance of the health risk frame is clear as is the acceptance of that frame by the public in Simcoe County and the influence of that acceptance on opposition to the proposed facility. The framing of Site 41 as a threat to health clearly expanded the conflict to include new participants who would never have participated if the conflict had remained about local property values. In Bruce County, while the health risk frame was the dominant opposition frame in local newspaper reports of the conflict, fewer residents accepted that frame and fewer people who were opposed to the facility reported the potential health 
risk as the reason. What accounts for the difference in the acceptance of the opposition's framing of the two facilities? Three key elements (Table 6-7) contribute to explaining the outcomes in these cases: the scale of the risk potentially posed by the facility, the public's acceptance of the relative scientific consensus concerning the risks of each facility and the presence or absence of a strong alternative frame.

Table 6-3: Comparison of the Health Risk Frames

\begin{tabular}{|l|l|l|}
\hline Key Case Characteristics & Site $\mathbf{4 1}$ & Kincardine Wind Farm \\
\hline Type of Health Risk & $\begin{array}{l}\text { Risk from contaminated } \\
\text { water }\end{array}$ & $\begin{array}{l}\text { Risk from low level sound } \\
\text { and vibrations from } \\
\text { turbines }\end{array}$ \\
\hline Scale of Risk & $\begin{array}{l}\text { Regional threat from } \\
\text { potentially polluted aquifer }\end{array}$ & $\begin{array}{l}\text { Localized to those near } \\
\text { turbines }\end{array}$ \\
\hline $\begin{array}{l}\text { Public Acceptance of } \\
\text { Scientific Evidence of Risk }\end{array}$ & $\begin{array}{l}\text { Low degree of public } \\
\text { acceptance of expert } \\
\text { assessments }\end{array}$ & $\begin{array}{l}\text { High degree of public } \\
\text { acceptance of expert } \\
\text { assessments }\end{array}$ \\
\hline Alternative Frame & $\begin{array}{l}\text { Cost effective and safe } \\
\text { management of local solid } \\
\text { waste }\end{array}$ & $\begin{array}{l}\text { Low carbon energy and } \\
\text { local and provincial } \\
\text { economic opportunity }\end{array}$ \\
\hline
\end{tabular}

Perhaps the most obvious difference between the two different health risk frames is the relative scale of risk opponents argued each posed. Site 41, according to opponents, could poison regional water resources, which could have affected many citizens well outside the immediate vicinity of the facility. This made the facility of direct interest to a large group of citizens. The risk potentially posed by the Kincardine Wind Farm is different. The health threat from wind turbines, according to opponents, is only felt by those living close enough to an actual turbine to be affected by the noise and vibration generated by that turbine. Actors not in proximity to that turbine will bear no risk. Because the facility included over one hundred turbines, those potentially affected is a considerable number of people but nowhere near the percentage of the citizens of the County that could have been potentially affected by Site 41 . Citizens that may be directly 
affected by a health risk have a greater direct stake in decisions about that risk and therefore can be expected to participate at greater rates than those not directly affected. However, even when not directly affected themselves, it is likely that actors that perceive others in their community are threatened by a potential health risk will be more likely to be engaged in decisions about that risk than they would be if the issue was one of annoyance. The protection of human health is a fundamental value even when protecting others. That of course is only true if actors, whether or not they are directly affected, actually accept that the risk to health is real.

The consensus of the expert reviews of the design of Site 41 facility assessed the proposed facility as low risk (MOE, 2003) but the majority of the pubic in Simcoe County eventually refused to accept this conclusion. The primary explanation for this is the role of a focusing event in raising public awareness of the risk to drinking water in Ontario. In 2001, in Walkerton, Ontario seven people died and 2300 became ill from E. coli contamination in a municipal water well. The tragedy led to a multi-year public inquiry that garnered significant attention and has acted as a classic focusing event (Johns, 2014). A focusing event is "an event that is sudden; relatively uncommon; can be reasonably defined as harmful or revealing the possibility of potentially greater future harms; has harms that are concentrated in a particular geographical area or community of interest; and that is known to policy makers and the public simultaneously (Birkland, 1998). Focusing events are important because they can provide windows for groups to advocate for policy change because of the increased attention paid to the issue.

The Walkerton tragedy allowed opponents to link Site 41 to an issue already high on the public agenda. Linkage to other, well-publicized or controversial policy issues are 
a strategy of issue expansion identified by Pralle (2006). Linking an isolated policy issue to another important or controversial issue can increase the significance of the isolated issue. This can aid the expansion of the conflict by drawing in new actors attracted by the linkage to an existing important issue (Pralle, 2006). This is precisely what happened in the conflict over Site 41. Opponents of the site, by focusing on water contamination, were able to link the conflict over Site 41 to the protection of drinking water in Ontario. The linkage to Walkerton raised the stakes of a potential leak at Site 41 which meant that expert assurances that the site was properly designed were largely ignored: "we live in a far different world than that which existed in 1998 when Site 41 was approved. Walkerton changed everything and had this disaster occurred prior to the approval of Site 41, I believe considerably different guidelines would have been used in making the decision to place this high volume landfill facility atop a major fresh water supply" (Midland Free Press, 2002). Interviews with municipal political actors in Simcoe confirmed the impact of Walkerton on the Site 41 conflict: "Ohhh, that whole water thing in Walkerton had a significant impact in this because every time somebody talked about Site 41, they use the Walkerton contamination as something that could happen here. And if we put waste into Site 41, we'd all be dead. The contaminated water in Walkerton really just drove the last nail in the coffin" (Interview with Former County Councilor, 2011). The Walkerton tragedy acted as a focusing event that opened the opportunity for the opposition to link Site 41 to issue already high on the provincial agenda.

The success of framing the linkage between Site 41 and water protection can be seen in the new actors that were drawn into the conflict. New participants included elite actors such as high profile environmental activists and leaders such as David Suzuki, 
Elizabeth May, Maude Barlow, and Ralph Nader. Their participation was clearly linked to the issue of water protection: "There are too many unanswered questions about Site 41 and we can't risk polluting the purest groundwater ever tested. The solution to Site 41 is a one-year moratorium, not arresting grandmothers who are protecting the water" (Maude Barlow in the Midland Free Press, 2006). A group of First Nations protestors from a local First Nations community also joined the conflict and participated in an occupation of the area around Site 41, and interviews revealed that their primary interest was the protection of local water resources. "And when they started taking the water-permit to take water, I didn't think that the ministry would allow—like I did never think the ministry would allow it to happen. And then when I've seen on Facebook that they had given permission to take water and it was going ahead, that's kind of when I jumped onboard" (Interview with First Nations Activist, 2011). This activist subsequently organized an occupation adjacent to Site 41 and participated in many of the subsequent protests. The new participation of First Nations activists and high profile actors from outside the region significantly raised the profile of the opposition to Site 41 . These actors represent the expansion of the conflict and made characterizing opposition to Site 41 as a manifestation of NIMBY far more difficult.

Unlike the case of Site 41, the conflict over the Kincardine Wind Farm revolved around debates about the existence of a health threat. Because of the linkage to the Walkerton tragedy, most residents in Simcoe County accepted that Site 41 posed a threat to health. No such clear consensus existed over the risk posed by wind turbines. The evidence for potential health risks from wind turbines is limited and much of the opposition's claims about the risk were based on the lack of scientific evidence that they 
do not cause harm. Many of the claims by local activists are based on unscientific or anecdotal evidence: "Gillis, a member of Wind Concerns Ontario, is serving as the lead for a self-reporting health survey of people who live within two kilometers of a wind turbine. She said about 100 people have responded and reported adverse health effects. The most common, Gillis said, is sleep deprivation, caused by the sound of the turbines and blades and a "humming that seems to come up through the pillow." (Gillis quoted in Langlois, 2009).

Opponents therefore demanded more studies and a moratorium on wind energy development until those studies were completed while supporters denied any health effects: "It has been further confirmed by the Chief Medical Officer of Health that, based on all scientific evidence gathered to date, there exists nothing that would demonstrate a (causal) association between wind turbine noise and adverse health affects" (Mitchell quoted in Henry, 2008). Over half of the media reports about wind turbines analyzed for this study acknowledged the unconfirmed nature of the claims. Unlike the conflict over Site 41 , the acceptance of the health risk claim by the public was undermined by the lack of clear evidence of harm.

In addition to the more mixed acceptance of the evidence for potential health risk hazards from wind turbines, the strength of the health risk frame was undermined by the presence of a strong alternative frame. In both cases, the proponents of the proposed facilities were able to offer the initial frame used to describe the facility. In the case of Site 41 , the facility was framed as a safe and cost effective way to responsibly manage locally generated solid waste. This was sufficient when opposition to the facility was limited to those living nearby and who could easily be characterized as NIMBY activists. 
However, after the opposition's successful linkage of Site 41 to the issue of drinking water protection, the initial frame became far less effective. The majority of citizens in Simcoe County viewed the proposed facility through the health risk frame and was therefore opposed to the facility (see Table 6-3). As the experimental framing literature predicts, in a competitive framing environment, a strong frame will dominate a weak one (Chong and Druckman, 2007). Because of the nature of the Site 41 facility, there was no frame available to the proponents of Site 41 that would engage the public and help produce a 'pro-dump' movement. The best strategy available to proponents was therefore one of containment where the participants were limited to actors that accepted the efficiency frame such as municipal bureaucrats and Councilors.

The conflict over wind turbines in Bruce County also represents a competitive framing environment but one in which the two competing frames are more evenly balanced. While Site 41's proponents did not offer a frame that was an effective counter to the health risk frame, proponents of wind power could offer an alternative frame that was initially very successful at driving support for the project. Proponents advocated for the facility as both a boon to the local economy and an environmentally sound way to generate electricity. Evidence for the effectiveness of this frame is data from a survey conducted during the initial stages of planning and consultation for the Kincardine wind project. In June of 2006, a phone survey of 402 respondents in each of the municipalities of Kincardine and Suageen Shores was conducted by Pollara Research on behalf of the proponent (2006). ${ }^{15}$ In both regions, over $60 \%$ of respondents reported strongly or somewhat supporting the proposed project. Of those supportive of the project, $40 \%$ suggested the environment was an important consideration (the most reported reason) and

\footnotetext{
${ }^{15}$ The surveys had an overall accuracy of 3.5\%, 19 times out of 20
} 
$26 \%$ reported the boost to the local economy as the most important consideration (the second most reported reason). Of those opposed to the facility, only $13 \%$ ( $3 \%$ of total respondents) reported potential health concerns as the main reason for opposing the proposed facility. In 2006, most residents reported supporting the proposed facility and the frame of economic and environmental benefits clearly resonated with many. Only a small percentage of residents were opposed to the project because of the potential health risk.

By 2009, as the above data indicates this had changed. In $200950 \%$ of respondents reported strongly or somewhat agreeing that the Kincardine Wind Farm is a threat to health and almost $58 \%$ or respondents reported opposing the project (Table 6-5). While the framing of the Kincardine project as a threat to human health had some success at mobilizing local opposition, it was far less successful than the opposition to Site 41 . The project mobilized several local groups of actors such as the Bruce County Wind Action Group but these groups were not yet well organized and were primarily composed of residents directly affected by the proposed facility (Interviews, 2012, 2013). These groups had little success in creating linkages to outside actors, except links with the growing anti-wind opposition in Ontario, as was so successfully done by the opposition to Site 41. Environmentalists, which are often allied with local opposition to controversial facilities, have in fact actively campaigned for wind energy development and denied the linkage between wind turbines and health risk:

Concerns about the health effects of wind turbines have been grossly exaggerated by those who have other agendas involved," said John Bennett, the executive director of Sierra Club Canada, during a presentation to Bruce County council on Thursday. "I've talked to hundreds of people who oppose wind turbines and it comes down to that they just don't want them and then they go looking for reasons. . I think what happens is that people have aesthetic 
responses to this and then they go looking for arguments (Bennett quoted in Crosby, 2010)

The strong frame available to supporters of the Kincardine wind farm greatly reduced the effectiveness of the health risk frame.

The conflict over Site 41 and Kincardine reveal both the strength and weakness of health risk frames in expanding conflicts. Opponents of Site 41 were able to link the issue of local water protection to broader concerns over water protection in the province and expand support to actors who would have been unlikely to participate if the conflict had remained about local opposition to an unpleasant facility. In this case, the first hypothesis is confirmed, a strong health risk frame will expand the conflict to include new participants. In the second case, hypothesis is not confirmed. Opponents of wind turbines had more difficulty in expanding the conflict to include new actors. While they are gaining significant support in communities affected by wind turbine projects, the wellfinanced and organized pro-wind movement has a strong set of competing frames to counter the health risk frame. Until research about the health effects of wind turbines is less ambiguous, the anti-wind movement may have difficulty in expanding these conflicts.

\section{Institutions: Strategies of Expansion and Containment}

The above demonstrates the relative success of the opposition to each facility at reframing the policy conflict in each case as one about public health and the success of that reframing at drawing in new participants to each conflict. However, this is not sufficient to explain the outcomes of these conflicts. These conflicts, like most political conflicts, occurred within sets of institutions that structured the conflicts. The reframing

of the facilities in question as threats to human health can only be a successful strategy of 
opposition if they allowed opponents to pursue their goal in the institutions that structured each conflict. For example, mobilizing public opinion may have little influence if the crucial decision-making venue is the courts. The key institutional strategy pursued by opponents of both facilities was venue shopping.

The initial set of institutions of decision-making responsible for decision-making in both conflicts was institutions that privilege conceptions of risk that are supported by technical evidence and are relatively closed to public participation. This was the protracted Environmental Assessment Tribunal that eventually approved Site 41 and the Environmental Screening process necessary for the approval of the Kincardine wind farm. Both processes were quasi-judicial processes that privileged technical expertise. In both sets of institutions, site proponents were able to offer sufficient peer reviewed assessments of the proposed design to satisfy these tribunals. In both cases, an initial, and ultimately unsuccessful, attempt at venue shopping saw opponents launch an appeal to each facility through the Ontario Municipal Board (OMB), which is an appeal tribunal for land use decision-making in Ontario. Interviews with opponents of each facility confirm that the frustration experienced in these institutions pushed them to seek out new venues that did not privilege expert assessment of risk: "For example, the county had unlimited reserves, spending the taxpayer's money to challenge the arguments. The Community Monitoring Committee [a stakeholder committee stipulated by the CofA] and those who opposes the development of the site had to hold spaghetti suppers to raise funds. We had to buy, beg, borrow whatever legal representation we could get (Interview with Anti-Site 41 Activist, 2011). Opponents of Site 41 clearly felt they lacked the resources to pursue their opposition within more formal settings and began to recognize that opposition to the 
facility could only be successfully pursued politically.

After failure to stop each facility in the Environmental assessment processes and the OMB, opponents of both facilities recognized that successful opposition would require extensive public support. The goal for both sets of opponents was to either pressure existing County council members to alter their support for each facility or elect new members who would: “The decision wasn't going to be made by the Province of Ontario. They were the approval authority. The decision was one that would be made at the county level. So I asked people to concentrate their efforts and their discussions with individual members of council (Interview with Anti-Site 41 Activist, 2011).

The opposition to Site 41 was able to pursue this strategy successfully. Opponents to Site 41 were able to eventually stop the construction of the facility by changing the frame to one of water protection, which drew in actors throughout the County and beyond and changed the scale of the conflict in order to contest the facility at the County Council. This is particularly interesting as the structure of the County council should have provided the opportunity to defeat any local resistance. The Simcoe County council consists of 2 members from each of the 16 towns and townships in Simcoe County. This would suggest that local opposition to a proposed landfill from a few towns or townships should be easily overcome by the majority of the council. If opposition is present in only the immediate area around the site, the majority of councilors from outside the affected region should be immune from voter pressure from their largely indifferent constituents. However, once that conflict became about a potential risk to a regional resource, councilors from all 16 municipalities began to feel pressure to oppose Site 41. Interviews confirm that pressure was felt by councilors well outside the 
immediate area of Site 41. "I guess the last election that I ran and lost, I know now, I lost it because of Site 41. All I had to do in that election was to say, "I'll reject Site 41," and would have won" (Interview with Former Simcoe County Councilor, 2011). The public perception that Site 41 posed a threat to water changed the scale of the conflict, which allowed opponents to move the conflict from the EA and OMB tribunals to the County Council and overcome the institutional structure that should have enabled the County to defeat local opposition to the proposed site. The reframing of Site 41 as a threat to health opened the door for a successful strategy of venue shopping confirming the second hypothesis.

Opponents of the Kincardine wind farm had much less success at shifting venues. Because of the support for the project by most members of the Bruce County council, opposition to the project needed significant public pressure to overcome that support. As the above data indicates, this was not forthcoming. While a small majority of respondents to the survey were opposed to the facility (Table 6-7), this was not sufficient to pressure council to overturn earlier support for the project. "I believed that the project would be great for farmers and great for Kincardine (Interview with Former County Councilor, 2012). The reframing of wind turbines as a threat to human health clearly had some effect on the growing opposition to the proposed facility, but it was not sufficiently accepted by the public in Bruce County to allow opponents to successfully shift venues and defeat the facility.

In both cases, opponents of each facility had significant incentives to shift the site of the conflict from the formal EA and OMB processes to the more open electoral institutions of the County Council. The proponents in both cases essentially constituted a 
policy monopoly in that by containing the conflicts in the EA and OMB processes they were almost certain of success because they had the resources, the scientific and expert assessments of each facility that classified the facilities as safe, necessary to 'win' in those institutions. Both sets of opponents therefore sought to expand the conflicts to include new participants (elite and the public) that would help them shift the conflict to the County Councils. Initially, both sets of opponents had been excluded from the Councils because they lacked the public support for their opposition that would pressure Council members (or elect new ones) into opposing the facilities. Without that public support, proponents in both cases could maintain their support in the County Council thereby maintaining their monopoly. Both sets of proponents therefore had every incentive to contain the conflict and minimize public opposition. In the Site 41 case this failed as opponents were able to vastly increase the public participation in the conflict thereby breaking that monopoly. In the Kincardine Wind Farm case containment was successful. Expanding the conflict to include new participants was the strategy dictated by the available institutional venues.

\section{Conclusion}

In theories of conflict expansion and containment, drawing in new actors is often the key to policy change (Baumgartner and Jones, 1993; Cobb and Ross, 1997; Pralle, 2006a; Rochefort and Cobb, 1993). This can be achieved through a number of strategies but redefining the issue is often the most effective (Pralle, 2006a). But not all issues are equal as the analysis of the two conflicts presented here amply demonstrates. Theories of conflict expansion must account for the relative strength of different policy frames at driving the participation of actors in conflicts over policy. 
This chapter proposed two hypotheses for testing: 1) that the stronger the risk frame is relative to opposition frames, the greater degree to which a conflict will expand to new actors (public and elite): 2) that the more new participants are drawn into the conflict, the greater will be the success of opponents at defeating the facility. The data presented confirms both hypotheses. The clearly dominant frame presented by opponents to Site 41 drew in new participants, both elite and public, to the conflict. The participation of these actors allowed opponents to shift venues and to defeat the facility in the County Council. The less dominant frame offered by opponents of the Kincardine wind farm was less successful at drawing citizens into the conflict and at creating linkages to elite participants. The failure to expand participation made contesting the facility in the County Council ineffective and the facility was ultimately completed.

These findings contribute to the body of research about conflict expansion by testing the effectiveness of a particular form of policy frame, risk to human health, at conflict expansion. If opponents in either of the conflicts in question had framed the issue as one of property values, neither would have had the success at expanding the conflicts that they did. Framing issue as a threat to human health clearly contributes to conflict expansion. That policy frames that focus on risks to human health often lead to more contentious policy conflicts is not a new or unexpected finding. But not all health risk frames are equal. Under what conditions that definition may be successful is essential to understanding when and why this strategy may be successful.

Three conditions are revealed as essential here: the scale of the risk, the relative public acceptance of the scientific evidence for the frame, and the relative strength of alternative frames. This finding advances the literature on framing by specifying specific 
characteristics that contribute to a strong frame based on the risk to human health. These findings could be further specified through experimental research designs.

Further, this study contributes to the literature on conflict expansion and venue shopping (Pralle, 2006a). The framing of each facility as a threat to human health opened the opportunity for the opposition in both cases to contest these facilities in the arena of local politics, an opportunity that the opponents of Site 41 were able to capitalize on. This is a particularly important observation for these types of policy conflicts as the focus of analysis is often on the formal institutional processes of decision-making such as the EA process. However, this study reveals that it is the relationship between those processes, the political opportunities available, and the ability of opposition groups to capitalize on those opportunities that determine the outcome of these conflicts.

The relative success of a health risk frame is not a surprise. Stone (1989) recognized the importance of issues that strike at basic values, or what Green-Pederson and Wilkerson (2006) call valence issues. This paper builds on the work of Pralle and others who work within the agenda-setting tradition by beginning to integrate an understanding of risk conflicts as a particular type of policy frame. The protection of human health is undoubtedly a fundamental value. What this study reveals is how these issues actually translate into the outcomes we can observe, while revealing both the power and limitations of framing of issues as risk to human health in the agenda setting process. Risks to the health of individuals and the public can provide a strong frame with which to overturn existing policy monopolies. However, the institutions that structure these conflicts and the public's acceptance of a policy frame can limit the utility of even the strongest frame. 


\section{Chapter 7 - Risk, Venue Shopping and Institutions: Exploring the Relationship Between Problem Definition and Venue Shopping in Two Land Use Conflicts ${ }^{16}$}

\section{Introduction}

From the early 1980s to 2010 an intense conflict in Simcoe County, Ontario divided the community. The conflict focused on the potential contamination of local water by a proposed solid municipal waste landfill. Simcoe County, which was the proponent, characterized the risk of contamination as low and approved the project as a low cost means of meeting the need for local waste disposal. Opponents of the project characterized the risk of water contamination as high and organized a campaign of opposition to the project. The conflict continued, even after construction had begun, and it saw protests, sit-ins, the arrest of protestors and it garnered the attention of activists from outside the region, which generated intense animosity that still remains today. In 2010, after significant expenditure of resources the project was halted and approval was withdrawn by the Simcoe County council.

In 2003, a large wind turbine facility was proposed by a private energy company for the municipalities of Kincardine and Saugeen shores in Bruce County, Ontario. While opponents of the facility engaged in advocacy against the project, it was eventually completed in 2009. However, during and after that conflict, opposition to large wind projects has grown and has become focused on the health risks believed to be associated with these facilities. Opposition to these projects has become so effective that projects

\footnotetext{
${ }^{16}$ This chapter is written in article format for potential submission to one of the following journals: Review of Policy Research, Policy Studies Journal or Journal of Public Policy
} 
were slowed and the provincial government passed legislation aimed at removing approval power from local levels of government.

The two conflicts described above share a crucial common characteristic. In both conflicts, the groups seeking policy change framed the issue as one about the protection of human health. In the case of solid waste landfill, the threat to human health was the potential contamination of drinking water. In the conflict over wind turbines, it was about the potential threat to local residents posed by the noise generated by the turbines. In both cases, this framing of the issue as one about human health risk was a deliberate strategy used by opponents of each facility. Threats to human health are a powerful frame for contesting public policy (Boothe and Harrison, 2009; Stone, 1989).

Agenda-setting literature has long recognized the importance of issue definition to policy change (Baumgartner and Jones, 1993). The problem definition is the basic understanding of the causes and consequences of the problem that a policy is designed to address. A key reason actors seek to redefine a policy problem is to facilitate a shift to a new institutional venue (Baumgartner and Jones, 1993; Pralle, 2003). Baumgartner and Jones explicitly recognized this link: "Where rhetoric begins to change, venue changes become more likely. Where venue changes occur, rhetorical changes are facilitated" (1993, p. 37). Venue shopping is a strategy for seeking new venues of decision-making that will provide some advantage. Advantages occur because all institutions contain biases, such as the rules around participation that benefit a particular group of actors (Boothe and Harrison, 2009; Pralle, 2003).

Institutional rules create biases that are more or less amenable to particular policy images. Boothe and Harrison, in their analysis of the development of a children's health 
frame (policy image), have identified the characteristics of US and Canadian institutions that contributed to the emergence of a children's health frame in environmental policymaking in the US but not in Canada (2009). The nature of the Canadian parliamentary system created disincentives for actors within that system to advocate for a children's health based frame for environmental policy making. The nature of the institutional biases in that case created incentives and disincentives for policy actors to adopt different frames for understanding the policy issue.

This research project instead focuses on two cases in which the adoption of a health risk frame drove the selection of institutional venues by opponents of the two facilities. As Pralle has demonstrated in relation to venue shopping by advocacy groups, advocacy groups do not make decisions in a strictly rational manner $(2003,2010)$. They also choose venues because of "ideological values or cultural norms" (Pralle, 2003, p.241). This also seems to be the case when some groups select a particular frame with which to characterize a policy that they support or oppose. The analysis below demonstrates that opposition groups, while clearly recognizing the potential strategic value of the health risk frame, also adopted this frame because it matched their own preferred conception of the risk posed by these facilities. Given the preferred frame of these opposition groups and the fixed number of available institutions and the relatively fixed nature of their rules: what venue shopping strategies were available?

This paper applies venue-shopping theory to two case studies. The purpose is to evaluate how the opposition framing of these conflicts interacted with the institutional biases in these conflicts to influence the venue shopping strategy of the opposition in each case. Two hypothesis are tested: 1) That the framing of these facilities as a threat to 
human health will lead to actors to pursue venue shopping strategies that seek venues more open to non-expert perceptions of that risk; 2) that the internal characteristics of the opposition organizations involved in these conflicts will facilitate or constrain the ability of these groups to successfully capitalize on venue shopping opportunities.

The second hypothesis acknowledges that venue shopping is constrained not only by the institutional biases that structure the incentives for venue shopping but by the characteristics of the actors and organizations that engage in venue shopping. Pralle (2010) identifies three potential characteristics of organizations that might limit their ability or willingness to engage in venue shopping regardless of institutional opportunities. First, policy actors have preferences in regard to their preferred policy solutions and those solutions may be only available in particular venues. Second, Pralle identifies groups' resources as a key factor in venue choice. Third, the goal orientation of an advocacy group may affect its willingness to engage in venue shopping. Pralle suggests that groups that are focused on a single issue and are more focused on 'winning' that issue, are more likely to show flexibility in shopping for new venues (2013). Each of these is tested in the following analysis.

The findings below suggest that the institutional biases of the venues in these conflicts interact with the problem definition of risk to human health create similar incentives for venue shopping by the groups opposed to the facilities in both cases. Opponents in both conflicts recognized the biases within the venues of these conflicts and sought to shift the conflicts to venues that were more open to their preferred understanding of the risk posed by each of the facilities. Similar sets of institutional biases created similar incentives for venue shopping once the problem definition had 
shifted to one focused on the risk to human health. In each case the characteristics of these organizations did influence their ability to successfully complete a venue shift.

This paper contributes to the literature on venue shopping by specifying the relationship between a particular form of policy frame and the institutional biases of the institutional venues in which that policy image is applied. As Boothe and Harrison suggest, this relationship produces consistent venue shopping opportunities (2009). Further, the framework of external and internal constraints on venue shopping developed by Pralle $(2003,2010)$ is further specified by applying it to a novel contexts in which the opposition policy frame is relatively stable but groups still engage in venue shopping. It finds that the loosely organized character of these opposition groups and their focus on a single goal aids their ability to engage in strategic venue shopping.

\section{Theoretical Background: Venue Shopping and Framing}

Venue shopping has been recognized as an important strategy for groups competing to influence policy by a number of theoretical approaches to policy studies (Baumagartner and Jones, 1993; Boothe and Harrison, 2009; Pralle, 2003; Sabatier and Weible, 2003). An institutional venue is "location where authoritative decisions are made concerning a given issue" (Baumgartner and Jones 1993, p. 31). Venues therefore have significant influence over the opportunity for success offered to any actor pursuing a particular policy goal. Venue shopping is the strategic movement of an issue or conflict by some group (such as policy-makers or advocacy groups) from one decision-making venue to another for the purpose of achieving advantage in realizing that groups goals (Baumagartner and Jones, 1993; Pralle, 2003). Of course, simply shopping for a new venue does not guarantee that a group can successfully shift to that new venue or 
compete successfully within it. The institutional rules and the resources available to that group will determine success. The punctuated equilibrium literature specifies that venue shopping is one of the key explanations for rapid policy change. Within this literature, groups seeking policy change generally utilize this strategy (Baumagartner and Jones, 1993; Pralle, 2003a, 2003b). These groups are unable to achieve change in the current venue because of the monopoly of the issue by another group. New venues can provide new opportunities by changing the balance of power between these groups.

One of the central strategies used by groups to affect a venue change is the manipulation of the image of a policy. A policy image is the understanding of a given policy (Baumagartner and Jones, 1993). Because policies and the problems they are designed to solve can be understood in different ways, not everyone will hold the same set of policy images. Policy images are the key to maintaining control of a policy because controlling how a policy is defined confers tremendous power. Therefore, those seeking to overcome a policy monopoly in order to affect policy change most often will seek to change the accepted image of that policy. This is particularly true when advocates of change seek to move venues. Changing the preferred understanding of a policy can open opportunities for venue shopping because different venues will be more or less accepting of different policy images (Baumagartner and Jones, 1993; Boothe and Harrison, 2009; Pralle, 2003). For instance, policy problems that can be understood as rights based, such as same sex marriage, may be more likely to find success within judicial institutions.

That different policy images are more accepted in some venues than others is clear, but as Boothe and Harrison state, less attention has been focused on the specific nature of those biases (2009). This research seeks to contribute to this focus by specifying 
the relationship between a specific type of policy image, risk to human health, and its interaction with institutional biases. Conflicts over risk are essentially what Stone calls conflicts over causal stories (2012). These stories can challenge or protect the existing social order, assign blame and responsibility for solving the problem, legitimize actors as "fixers of the problem", or create new groups of victims (Stone, 2012, p. 224). A solid waste landfill can be a low impact and cost effective way of dealing with inevitable municipal waste or can be an irresponsible refusal to deal with overconsumption that will inevitably contaminate the local environment. In the former case, those opposing a landfill are NIMBY activists selfishly concerned with their property values. In the latter, the facility is being imposed on a community despite the serious risk to human health.

Theories of framing can be a useful way of understanding the alternative policy images offered by competing actors. Framing can defined as "the process by which people develop a particular conceptualization of an issue or reorient their thinking about an issue" (Chong and Druckman, 2007). Frames in this context are therefore the competing conceptualizations of the policy image, or casual story of a given policy. Frames affect an individual's opinion of an issue by focusing attention on a particular aspect of that issue (Druckman, 2001). For instance, framing a landfill as a cost effective way of dealing with inevitable solid waste suggests to individuals viewing that frame (for instance in a newspaper report) that economic considerations are most important when evaluating that issue.

Frames are the way in which advocacy groups, in this case the groups opposed to each facility will contest the accepted policy image of those facilities. The research question of interest here is to what degree the opposition framing of those facilities as a 
threat to human health drove the venue shopping strategies of those opposition groups. Identifying the frames used by opposition groups through analysis of media reports, documents from those groups, and through interviews with participants can reveal the preferred frame offered by those opposition groups, when they were deployed, and the relative success of that frame in mobilizing support. Once the preferred frame is established, the interaction between that frame, or policy image and the institutional biases that structured these conflicts can be explored.

In order to overturn a policy monopoly, in the cases studied here that would be the set of policy actors that proposed and approved the two facilities, those seeking policy change must often seek new institutional venues. They do because all institutional venues contain biases that advantage one group of actors. Those supporting a policy monopoly will attempt to support that monopoly by keeping decision-making within a venue in which they have advantages. Those seeking policy change will seek to move to a venue that may advantage them relative to their opponents (Baumagartner and Jones, 1993; Boothe and Harrison, 2009; Pralle, 2003). Therefore, in order to understand why the opponents of these facilities sought new institutional venues, the relationship between their preferred frame of opposition and the institutional biases that characterized the available venues is essential.

The institutional biases that are crucial for understanding these conflicts is the relationship between the problem definition, the framing of these facilities as a threat to human health, and the institutions of decision-making. These conflicts are predominantly about the very different framing of the risk posed by each facility advocated by proponents and opponents. The initial venue of conflict between opponents and 
proponents of each facility were the municipal councils that first approved each facility. Because there was initially little public interest in these facilities outside of local stakeholders, the proponents were able to gain approval for each facility. The next venue was Environmental Assessment process necessitated by the province of Ontario for solid waste and energy facilities. These processes restrict participation to approved actors (generally stakeholders) and have formalized or even quasi-judicial proceedings that will almost generally privilege expert and technical understandings of risk. In order to reject a proposed facility or technology, evidence of risk needs to be presented to counter any evidence in favor of the proposal. Without significant expert generated evidence of the harms claimed by opponents, these processes were unlikely to find for opponents of the facilities. The risk conception of those who are not formally part of the proceedings played little role in decision-making. Because of the framing of these facilities as a threat to human health, opponents of the facility needed to shift the conflict to a venue of decision-making that did not privilege expert understandings of risk. The preferred frame of the opposition groups' involved combine with the institutional biases of the venues relevant to these conflicts to produce incentives for opponents to seek out new venues.

The decision to engage in venue shopping by a policy actor requires not only that institutions contain biases that incentivize venue-shifting strategies, but also that actors recognize those biases and adapt their strategies as a result. Policy theorists have long recognized that the purely rational decision-maker is a myth and Pralle suggests that venue shopping is probably more ad-hoc and experimental that often assumed (2003). While the policy literature identifies numerous cognitive and practical limits to rational 
decision-making Pralle, identifies a number of specific limitations to the deployment of purely rational venue shopping strategies.

Pralle identifies two potential models of advocacy group behavior in regards to venue shopping: the static and the dynamic (2010). The static model suggests that advocacy groups rarely seek new venues because these groups develop expertise in regards to particular venue, or might attempt to maintain their public identity through their association with particular venue, or because of ideological commitments to a particular venue. The dynamic model, largely based on the model of venue shopping developed by Baumagartner and Jones (1993), instead suggests that there are few constraints on the venue choice by policy actors other than the constraints of the venue itself (Pralle, 2010). In order to identify under what conditions advocacy groups will act as static or dynamic venue shoppers, Pralle identifies three sets of factors that play a role: internal organizational factors, external opportunities and constraints, and the policy subsystem context (2010).

The external opportunities and constraints are largely the institutional opportunities that shape policy actor behavior and the opportunities important to this study are identified above. The policy subsystem factors are related to the number of interest groups operating within that policy area and how they interact. In a context where there are many interest groups attempting to influence a single policy area, Pralle suggests that they will develop niches to differentiate themselves from the other groups operating in that context (2010). This may limit their willingness to engage in venue shopping outside of their 'turf'. Because of the opponents in these cases are essentially act as a single interest group, the sub-system has less relevant to this study. It is the 
internal characteristics of the groups opposing these facilities that are of primary interest in explaining the development of their venue shopping strategies and Pralle identifies three possible internal constraints (2010).

First, policy actors have preferences in regard to their preferred policy solutions and those solutions may be only available in particular venues (Pralle, 2010). These preferences may stem from ideological or value preferences and Pralle suggests that often these choices are made to appeal to the constituency of that group (2010). Groups that are specialized and have long term interests can be expected to shift venues rarely. This would suggest that because the groups involved in the conflicts studied here share little ideological beliefs other than their goal and had little institutional history; they will show significant flexibility in venue choice.

Second, Pralle identifies a group's resources as a key factor in venue choice (2010). The more resources a group possesses, the more likely they are to venue shop. Ley and Weber identify three types of resources that aid groups in venue shopping: political, legal, and technical (2015). Because different institutional venues are more or less amenable to access by these resources, the relative mix of resources is as relevant to venue shopping activities as the total availability of those resources. For example, groups with significant legal resources will have more success at accessing judicial venues while those groups with technical resources may have more success at influencing bureaucratic actors (Ley and Weber, 2015). Given the relatively low level of resources such as money and expertise possessed by the opponents of the facilities in this study, this might limit their ability to engage in venue shopping strategies. However, as will be demonstrated below, the opportunity to deploy a health risk frame can be a significant resource for 
conflict expansion but places limits on the type of institutional venues in which success can be expected.

Finally, the goal orientation of an advocacy group may affect its willingness to engage in venue shopping. Pralle suggests that groups that are focused on a single issue and are more focused on 'winning' that issue, are more likely to show flexibility in shopping for new venues (2013). Conversely, groups that are focused on broader concerns and not on winning a single issue are less likely to engage in venue shopping, at least in the short term (Pralle, 2010). Given the single-issue focus of the opposition groups in this study and their singular focus on winning (defeating the facility in question), it should be expected that they would have little reluctance in shifting venues. The characteristics of the groups engaged in venue shopping clearly play a role in explaining when groups might engage in venue shopping. When groups engage in venue shopping they are choosing a new strategy with which to pursue their goals

The discussion above outlines two important considerations for analyzing venue shopping in the two conflicts at the center of this conflict. The first centers on the relationship between the policy image, or frame, advocated by opposition to the two facilities and the institutional biases within which that opposition contended. Given the preferred frame of risk to human health adopted by the opposition, what institutional opportunities were available to them? The second set revolves around the ability of those opposition groups to take advantage of those opportunities. The insights into the internal constraints faced by groups considering venue shopping and policy learning above help suggest a number of potential hypotheses about how the organizational characteristics of groups might influence how and when they engage in venue shopping. That the lack of 
institutional history and a firm identity possessed by the groups opposing each facility and their single issue focus should increase the likelihood of their engaging in venue shopping. However, their relative lack of resources may undermine those advantages. Finally, the diffuse nature of the opposition groups, that is their almost network as opposed to organizational character, should aid policy learning as should the significant trust between members. Because the opposition in each of the cases discussed below varies on these characteristics, comparisons between them allow for the testing of these hypotheses.

\section{Research Design and Methodology}

This analysis of risk conflicts as agenda-setting conflicts is based on two in-depth case studies. Case studies have been identified within a variety of disciplines as an effective research methodology for disentangling complex causality as well as dealing with a limited set of potential cases (Beach and Pedersen, 2013; Gerring, 2007; George \& Bennett, 2005; Yin, 1994). The with-in case analysis utilized a process tracing method followed by a comparison across the cases. Process tracing is the detailed tracing of each step of a causal path to reveal the total process involved in producing an outcome and is an effective methodology for studies of public policy (George and Bennett, 2005; Kay and Baker, 2014).

The cases were selected based on the values of the dependent and a key independent variables (Table 7-1) The dependent variable in this case is the completion or cancellation of the facility at the center of each case. These are the goals pursued by the proponents and opponents of each facility respectively and is therefore the key measure of their 'success'. Variation in the dependent variable is essential for identifying 
under what circumstances venue shopping may be a successful strategy. The important independent variables are the health risk frame advocated by opponents of each facility and institutional venues available to those opponents. The health risk frame advocated by opponents in each case is distinctly different which allows for testing the relative effectiveness of each. The institutions show slight variation in the EA phase but are largely similar sets of institutional venues.

\section{Table 7-1: Case Selection}

\begin{tabular}{|l|l|l|}
\hline Key Case Characteristics & Site 41 & Kincardine Wind Farm \\
\hline $\begin{array}{l}\text { Type of Health Risk Frame } \\
\text { (Independent variable) }\end{array}$ & $\begin{array}{l}\text { Risk from contaminated } \\
\text { water }\end{array}$ & $\begin{array}{l}\text { Risk from low level sound } \\
\text { and vibrations from } \\
\text { turbines }\end{array}$ \\
\hline Key Institutions & $\begin{array}{l}\text { EA processes (tribunal), } \\
\text { Land use appeal tribunals } \\
\text { (OMB), County Councils }\end{array}$ & $\begin{array}{l}\text { EA processes Screening } \\
\text { Report), Land use appeal } \\
\text { tribunals }(\text { OMB), County } \\
\text { Councils }\end{array}$ \\
\hline $\begin{array}{l}\text { Dependent Variable: } \\
\text { Outcome of conflict }\end{array}$ & Cancellation of facility & Completion of facility \\
\hline
\end{tabular}

The evidence used for the analyses of each case study was gathered using several methodologies. First, documentary evidence was collected including formal communications by municipal, provincial, and federal levels of government, the official records of Ontario Municipal Board (OMB) and Environmental assessment tribunals, records of meetings, and communications by various groups and individuals involved in the conflict.

Second, media reports (Site $41 n=507$, Wind Turbine $n=305$ ) about each conflict were identified coded to identify the frames used by newspapers in each county in media coverage of the conflicts. This is a common approach in framing research and is used to identify the presence or absence of frames of interest to the researcher (Chong and Druckman, 2007). The first stage of this process utilized a search of Canadian 
Newsstand database using search terms such as "Kincardine wind farm", "Site 41", and "wind turbines". Because several of the local papers in each county were not indexed in the database, a second stage involved using the same search terms in local papers in each county such as the Kincardine Times, Kincardine News, the and the Barrie Examiner. These searches were conducted for the periods beginning when the facilities were first proposed (1990 for Site 41 and 2003 for the Kincardine wind farm) until the end of the conflicts ( 2010 when Site 41 was cancelled by Simcoe County ad 2009 when the Kincardine wind farm was completed).

Once identification of the reports was complete a directed content analysis on each newspaper report was completed. The initial coding instrument focused on the frames used to either oppose of support each facility based on predetermined definitions of the expected frames. For example, identification of the health risk frame was based on any mention of the possible consequences of the facility for human health. Articles were not themselves coded as either supportive or oppositional and many reports included mention of multiple frames. While the coding instrument was predetermined, the coder was open to potential previously unidentified frames and several, such as the opposition framing of the potentially inequitable leasing contracts offered by wind energy companies, were identified during the coding process. As the author was the only coder, inter-coder reliability was not a concern.

Third, semi-structured interviews with a variety of stakeholders from both cases, 12 in the Site 41 conflict and 10 in the Kincardine wind farm case, were conducted. These interviews were invaluable for assessing the opinions and motivations of stakeholders including: current and former political actors, members of groups opposed 
to each site, and bureaucratic actors involved in the conflict. Secondary sources and media research provided the first set of interview subjects and others were identified through early interviews.

\section{Cases}

The cases selected for this study were identified because they are similar rural counties that were both home to conflicts in which risk was central. Simcoe County is located in Southern Ontario north of Toronto and has a population of approximately 440,000 people although only 279,000 are within the direct jurisdiction of the County government (Simcoe County, n.d.). Bruce County, a largely rural region of Ontario, is on the shores of Lake Huron and Georgian Bay, northwest of Toronto. The population is just over 66,000 people (2011). In both counties, the average household income is slightly below the provincial average and the number of immigrants as a percentage of total population is considerably less than the provincial average (Simcoe County, n.d.; Bruce County, n.d.). Both counties are predominantly rural and while agriculture is important, manufacturing and especially tourism play important roles in the local economy. In Bruce County the Bruce Nuclear plant also employs a substantial number of residents. These two counties are similar in demographics, geography, and history.

\section{Venue Shopping and Risk: Windmills and Landfills}

\section{Policy Framing and Institutional Biases}

The conflict over Site 41 began in the 1980's over a proposed location for a landfill site located in Tiny Township that would have accepted waste from two towns and two townships in Simcoe County. The proposed site was located in Tiny Township 
and local residents immediately resisted the proposal. In 1986, the County Council accepted the proposed site and this began the EA process. In 1989, an EA review rejected the proposed site based on a fundamentally flawed selection process (Environmental Assessment Board, 1989). The County then appealed to the Provincial Cabinet, which overturned the decision through an Order in Council (OIC) and ordered a resumption of the hearings with a more circumscribed mandate (Executive Council of Ontario, 1990). After a failed judicial challenge to the OIC by opponents of the site in 1993, the Joint board resumed and, based on new criteria outlined in the OIC, Site 41 was approved in 1995 and a Certificate of Approval (CofA) was issued by the Ontario Ministry of the Environment in 1998.

The proponents of Site 41 were the County bureaucrats who recommended Site 41 and the County Councilors who approved the facility. They initially constituted a policy monopoly in that they were able to control the crucial institutional venues and at first controlled the framing of Site 41. The opposition to the proposed landfill at this point of the conflict was mostly limited to local residents of Tiny Township, including informal groups such as the Wye (a local community) Citizens Group, and Tiny Residents Against Pollution (TRAP). In addition several members of the Tiny municipal council were opposed to the selection of Site 41. Neither the proponents nor opponents of Site 41 were well organized advocacy groups but were instead loose networks of actors that supported or opposed the construction of Site 41.

The framing of Site 41 by proponent of Site 41 emphasized the safety of the proposed facility: "the continued Provincial approval for this facility, particularly given the high level of scrutiny and study that has been part of this process, is undeniable 
evidence that this site can and will be developed to be protective of the environment" (Simcoe County, 2006, Para 3). However, opponents of Site 41 asserted that the proposed landfill would be a threat to local drinking water: "They're building this on top of the Alliston aquifer - it's huge. If (contaminants) get into the aquifer, it could be very dangerous for a large group of people" (Midland Free Press, 2003). Interviews with AntiSite 41 activists clearly demonstrate that the focus of their opposition was the potential harm to local drinking water posed by the facility: "Well, I think there was great harm or there was a potential for great harm to the aquifer. It was an exposed aquifer. It's my view and it continues to be my view that Site 41 was selected, absent to any scientific or engineering specifics" (Interview with former Tiny Councilor, 2011).

Table 7-2 reports the findings of the analysis of newspaper reports of the conflict around each facility the focus on the health risk frame is clear. The table reports the percentage of newspaper reports about each conflict that mentioned each opposition frame at least once and clearly demonstrates that the health risk frame was the most mentioned in each conflict. The data demonstrates that the health risk frame was the frame most identified by newspaper reports about Site 41 , appearing in $86 \%$ of reports. 
Table 7-2 Percentage of Media Reports that Include at Least Single Mention of Oppositional Frames

\begin{tabular}{|c|c|c|c|}
\hline County & Frames & Opposition Frames & $\begin{array}{l}\text { Percentage of Newspaper } \\
\text { Reports with at Least one } \\
\text { mention of that Frame }\end{array}$ \\
\hline \multirow{4}{*}{$\begin{array}{l}\text { Simcoe } \\
(\mathrm{N}=507)\end{array}$} & \multirow{4}{*}{$\begin{array}{l}\text { Opposition } \\
\text { Frames }\end{array}$} & Health risk & $86 \%$ \\
\hline & & $\begin{array}{l}\text { Environmental (not related to } \\
\text { human health) }\end{array}$ & $32 \%$ \\
\hline & & Agricultural loss & $28 \%$ \\
\hline & & Other & $26 \%$ \\
\hline \multirow{4}{*}{$\begin{array}{c}\text { Bruce } \\
(\mathrm{N}=305)\end{array}$} & \multirow{4}{*}{ Opposition } & Health risk & $78 \%$ \\
\hline & & Unfair decision making & $65 \%$ \\
\hline & & $\begin{array}{l}\text { Environmental (not related to } \\
\text { human health) }\end{array}$ & $55 \%$ \\
\hline & & Other & $32 \%$ \\
\hline
\end{tabular}

The conflict over a wind turbine installation in Bruce County began in 2003 with a proposal by Leader Wind Corporation to construct a wind turbine farm in the municipalities of Kincardine and Saugeen Shores. The proposed farm would include 154 turbines with a rated capacity of 199.65 MWs of power (OMB). In 2006, citing the prolonged process approval as problematic, Leader wind passed the project Enbridge Ontario Wind Power. In April of 2006 Enbridge submitted the Environmental Screening Report (ESR) required for energy projects and during the summer of 2006 public meetings were held to discuss the project (OMB, 2006). The ESR process is a proponent driven process with little or no review of the information provided by the proponent. However, the ESRs must be publicly posted and a 30 day comment period is required in which the public or other interested parties to make comments or request that the proposal be elevated to a full Environmental Assessment. Elevation to a full EA invokes a tribunal procedure where the full project must pass through a public hearing. Twentyone member of the public made that request, as did Bruce County when Enbridge did 
address their concerns (MOE document). By June 2007, Enbridge responded to the Counties' concerns and Bruce County subsequently withdrew its request for elevation in August. The MOE formally denied the remaining requests for elevation in March of 2007 and that concluded the ESR phase of the conflict.

Like the conflict over Site 41, neither the proponents nor opponents of the Kincardine Wind Farm were organized into a single, formal advocacy organization but were a loose network of diverse actors. Proponents of the facility were Enbridge Wind Energy, the municipal and county Councilors that approved the facility, landowners that stood to benefit from leasing their land to the project, and local and provincial environmental activists supportive of wind energy. Opponents of the project were local landowners who were close to the project but would not benefit directly and local and provincial anti-wind farm activists. These actors were initially poorly organized but as the conflict intensified they became better organized and created links with provincial anti-wind groups such as Wind Concerns Ontario. Local chapters of these provincial groups, such as Wind Concerns Bruce, were formed over the course of the conflict.

Opponents of the Kincardine Wind Farm believed that wind turbines pose a substantial health risk to those living close to turbines and the consequent exposure to audible and inaudible noise and vibration. Opponents recognized that the health risk frame could be more effective than other frames at gaining public support: "We quickly realized that people pay more attention to the idea that people are getting sick than they do the idea that birds might be injured" (Interview with anti-wind activist, 2011). The newspaper analysis of the media in Bruce County confirms that the health risk frame was the most important opposition frame. Over $78 \%$ of media reports about the Kincardine 
Wind Farm mentioned the health risk at least once which was the most mentioned opposition frame. Both interview and newspaper data demonstrate that the health risk frame was the preferred opposition frame in each case. Given that the opposition to each of the proposed facilities preferred the opposition frame, or policy image, of the facility as a threat to human health, how did this interact with the institutional biases of venues of each conflict to produce incentives for venue shopping?

Once the facility in each case was proposed and passed an initial vote in the municipal councils, the central venue of decision-making became the environmental assessment processes. The EA and ESR venues described above exhibit two institutional biases that strongly favored the proponent. The first was the technical consideration of risk utilized by these processes. The consideration of the risk to the health of residents and the environment was a central concern of the processes. However, the consideration of that risk was based on a technocratic consideration of risk based on scientific evidence where the opinions and research of experts was the focus of the decision. In the EA process around Site 41, and in the subsequent consideration of the design of the site for the Certificate of Approval, focus was on the technical merits of the proposal. Without sufficient evidence of harm provided by experts, opponents were unsuccessful in this venue. While the expert reports generated for this process recognized the potential for harm, each concluded that the design of Site 41 could largely eliminate that risk (MOE, 2003). This institutional venue privileged expert risk assessment with little consideration of the broader public's perception of risk.

The ESR process around the Bruce County wind farm, as a proponent driven process, focuses almost exclusively on technical concerns of technical risk posed by a 
proposed project. The Bruce County Wind farm proposal therefore focused almost exclusively on the technical considerations such as shadow flicker (MOE, 2007; Interviews 2012, 2013). Almost no discussion focused on the potential health effects of wind turbines on those living nearby as those had not been recognized by experts as likely. Health concerns around turbines had not been widely recognized by the scientific or medical community and what concerns did exist were considered to be easily avoided by the existing setback restrictions: "no receptors will be subjected to noise levels above ministry criteria and therefore no measures have been deemed necessary to mitigate noise level impacts" (MOE, 2007). The potential risk to residents was entirely considered within the framework of an expert driven risk assessment process.

The second characteristic of both the EA and ESR processes was the restricted participation in these venues. These were highly circumscribed sites of conflict, which limited the actors to direct stakeholders, and the available actions of those participants were exclusively passive such as testifying or presenting information. The literature pointing to the failure of these types of processes to garner consent is significant and the inability of these processes to satisfy opponents of each facility is not surprising (Aitken, 2010; Breukers and Wolsink, 2007; Gross, 2007; Kuhn and Ballard, 1998; McAvoy, 1998; Hunter \& Leyden, 1995; Gerrard, 1994; Rabe, 1994). The failure of both these processes to include any participation beyond direct stakeholders virtually guaranteed that the decisions of these bodies would not be satisfactory to opponents. A central actor in the Site 41 conflict evaluated the opportunity to participate in these processes as poor:

The real decision, I think, had been made long before the public became involved. So that was problematic. And then everybody that - everybody that came on board afterwards, from the public, didn't really have a role to play in decision making. They were just challenging the decisions that had already 
been made. So, essentially, in my view, the public participation amounted to a little more than window dressing at the time (Interview with Former Tiny Councilor, 2011)

Evaluations of participants in the ESR process (prior to the passage of the Green Energy and Economy Act, 2008 that removed local decision-making) around the Kincardine project were similar: "the goddamned government [of Ontario] has rigged the game. They want to push the wind agenda so they've created an approval process that guarantees these things [wind energy projects] will pass" (Interview with anti-wind activist, 2011). The focus of the EA and ESR processes in these conflicts on technical evaluations of risk meant that the opposition's preferred frame, the health risk posed by each facility, would not prove effective in these institutions. Because of the nature of these institutions, the opponents to each facility had little hope at challenging those facilities in the above EA and ESR processes. ${ }^{17}$

Once each of the projects were approved through the respective EA processes, opponents of each facility then attempted to shift the venue by launching challenges to these facilities before the Ontario Municipal Board (OMB). The OMB is an independent, quasi-judicial tribunal that hears appeals to zoning by-law and planning decisions throughout Ontario. In both cases studied here, appeals to overturn by-laws that would allow the facility in question to proceed were presented to the board. The OMB is characterized as a powerful administrative tribunal that nonetheless allows significant participation by anyone with interest in the issue at hand (Moore, 2013). However the focus on expert testimony and the relative commitment necessary to appeal a decision greatly reduce the participatory element of the OMB.

${ }^{17}$ It should be noted this is not a conclusion aimed at all environmental assessment processes. Some may in fact be very effective at community consultation. It is a conclusion about the processes around these two specific facilities. 
The OMB appeal had little effect in the case of Site 41. In Site 41, the appeal by the township of Tiny, which sought to have the planning approval for Site 41 overturned, failed and several participants interviewed felt the OMB was unsuited to make decisions about important environmental issues (Interviews, 2011). After the failure of the OMB process, opponents recognized that stopping Site 41 would not occur within these types of processes: "We are out of legal opinions and there is no legal recourse available to this council [the municipality of Tiny Council] to stop Site 41" (Midland Free Press, 2003).

The appeal launched in Kincardine by a number of citizens living near proposed turbines involved the appeal of 38 specific by-laws. Again, the appeals focused on many aspects of the project but noise standards were central. However, the OMB refused to make a determination about noise and instead suggested that the MOE "and not the Board should make the final determination regarding compliance with the Ministry guidelines for noise, and that the Board has no jurisdiction to modify or change the guidelines or the interpretations that the Ministry may wish to impose" (OMB, 2007, p. 67). The process made clear to many the OMB's inability (or unwillingness) to become involved in adjudicating disputes about setbacks or noise limits that are the central issue when addressing concerns over health risks and wind turbines.

The institutions described above were constrained venues that largely limited participation to stakeholders and focused almost exclusively on technocratic discussions of risk. Media reports and interviews with participants reveal wide dissatisfaction with the institutions and processes of decision-making in both cases. In both conflicts, because of this dissatisfaction and the perception held by many actors that both facilities represented genuine threats to the health of local residents, it was unlikely that those 
opposed to the projects would be willing to accept the outcome of these processes. EAs or ESRs are mandatory processes that are required when a project is proposed and occur within independent and non-political processes as do OMB appeals. Because the proponents of each facility could produce significant evidence of the relative safety of each facility, within these venues they constituted a policy monopoly that opponents had little chance of overturning.

However, both proposed projects also required political consent: both required municipal council approval. Participation is of course very different in open political arenas such as municipal elections than in the closed institutions such as administrative tribunals. If the conflicts could reach the political agenda, opponents believed that public pressure could defeat the facilities. Once these conflicts were in the political arena, consideration of the risk posed by these facilities was no longer limited to expert assessments but became about the public's perception of that risk. As research about risk perception makes clear, the public perception of risk is not based solely on technical assessments by experts but is socially constructed through a myriad of influences (Kasperson et al., 2005; Huijts, Midden, and Meijnders, 2007; Slovic, 1987; Slovic, Fischhoff, and Lichentstein, 1982). Shifting the venue to political institutions became the key strategy of opponents to each facility.

\section{Shopping for New Venues: From EA Processes to Municipal Politics}

In the case of Site 41, once the CofA was issued in 1998, the construction of the site could have followed with little further controversy. However, this was not the case. To begin construction, the County required approval of the specific design of the landfill at Site 41 that required a series of technical submissions and peer reviews of those 
submissions to the Ministry of the Environment. These became a source of significant conflict, especially within the meetings of the Community Monitoring Committee (CMC), over the potential risk the landfill posed to local water. The CofA stipulated that the County must convene the CMC, which would provide community review of the "development, operation, ongoing monitoring, closure and post closure care related to the landfill site" (Ministry of the Environment, 1998, page). The committee consisted of one member from the County, two members from the Tiny Council, three members from the township of Tiny who live within three kilometers of Site 41, and one non-voting member from the Ministry of the Environment. The CMC could make information available to the public and convey public concerns to the public, but had no authority or power to affect change. This process allowed opponents of Site 41 to maintain public attention around the conflict after the CofA was issued, as the CMC meetings were well attended and covered by the local media.

Outside of this more formal process, there was also significant conflict within the community. Once the CofA was issued public protests and eventually an occupation of Site 41 occurred, which led to arrests of protesters and the County seeking court injunctions preventing protesters from interfering with construction of the site that began in 2007. A vigil by a group of First Nations protestors, members of the Beausoleil First Nation who believed that the threat to local water would have significant impacts on the environment, garnered significant media attention. A number of prominent actors from outside the region including: David Suzuki, a prominent environmental activist, Elizabeth May, the leader of the federal Green Party, and Maude Barlow, a water activist and 
member of the Council of Canadians also made public statements or appearances in opposition to Site 41.

The goal of opponents to Site 41 in the CMC meetings and the public protests was to either pressure existing County council members to alter their support for Site 41 or elect new members who would: "The decision wasn't going to be made by the Province of Ontario. They were the approval authority. The decision was one that would be made at the county level. So I asked people to concentrate their efforts and their discussions with individual members of council" (Interview with Former Anti-Site 41 Activist, 2011). The more open character of these venues allowed actors beyond direct stakeholders to participate and many, such as First Nations protestors and elite actors from outside the County, had significant influences on the media coverage of the conflict.

The opportunity for opponents of Site 41 to produce their goals through the electoral process was made possible by the changing nature of the perception of risk posed by the site. This occurred as the dominant public understanding of the conflict changed from a local conflict over local risks to a regional conflict over the risk posed by potential leakage of the landfill into the Alliston aquifer. The success of this process is seen in the 2009 council vote to cancel construction of the landfill. Interviews with sitting and former council members confirm that councilors were receiving significant public pressure to oppose the project: "I guess the last election that I ran and lost, I know now, I lost it because of Site 41. All I had to do in that election was to say, 'I'll reject Site 41', and would have won" (Interview, 2011). The intense and prolonged conflict over the construction of a landfill at Site 41 eventually led to the halt of the project by the Simcoe County Council. In 2009, the Council voted for a one-year moratorium on the 
construction at the site and then voted to halt construction permanently the same year. The Council vote was 72-50 in favour of the moratorium (the voting is weighted). The CofA was revoked in 2010 and the County dropped all lawsuits and charges against protestors. The strategy of focusing opposition on the Simcoe County council was clearly a winning strategy.

Opponents of the Kincardine wind farm had much less success at shifting venues. Because of the support for the project by most members of the Bruce County council, opposition to the project needed significant public pressure to overcome that support. While councilors who were interviewed reported feeling some public pressure to not support the project, this was not sufficient to pressure council to overturn earlier support for the project: "I believed, and still believe that the project would be great for farmers and great for Kincardine (Interview, 2012). The local and County councils voted to continue the project and it was completed in 2009. The reframing of wind turbines as a threat to human health clearly had some effect on the growing opposition to the proposed facility, but it was not sufficient to pressure Bruce County Councilors to oppose the project. The attempt to shift to a new venue was ultimately unsuccessful.

These cases clearly demonstrate that the institutional biases contained within the crucial venues of decision-making interrelated with the risk to human health frames, produce consistent strategies of venue shopping by opponents to each facility. This supports the contention by Booth and Harrison that a consistent relationship between institutions and policy agendas should be observable across different institutional contexts (2009). The health risk frame advocated by both sets of opposition actors interacted with the institutional biases of the EA and ESR venues to produce incentives 
for those actors to engage in venue shopping. The success of the opponents of Site 41 and the failure of opponents of the Kincardine Wind Farms lies in their respective ability to successfully shift venues. The opponents to Site 41 were able to gain significant public support for their preferred framing of Site 41 as a risk to resident's health. This public support is the key resource needed to compete within the elected County Council. Opponents of the Kincardine Wind Farm were unable to gain similar public support for their preferred frame and therefore could not successfully shift venues to the County Council. Proponents of the facility were able to maintain their dominance of that venue through public support (or at least public indifference) for the proposed facility. Success at venue shopping requires mobilizing the appropriate resources to compete within a new venue.

\section{Limits to Venue Shopping}

The two cases studies presented here clearly demonstrate the incentive for venue shopping created by the institutional biases of the venues and the relative success of opposition groups at shifting their respective conflicts to new institutions. However, both cases also reveal the limits of venue shopping strategies. In the conflict over Site 41, opponents were successful at moving the conflict into the political arena at the municipal level but were unsuccessful at raising the issue to the political agenda at the provincial level. Opponents had long called for the province to intervene in the conflict and stop the proposed project. They routinely identified the seeming contraction between provincial policies enacted after the Walkerton tragedy to protect source water and the provinces refusal to intervene to protect drinking water in Simcoe County (Interviews, 2011, 2012). A number of protests against Site 41 occurred at the provincial capital and the local 
member of the Provincial Parliament (MPP) introduced a private members bill that removed provincial approval for Site 41 but was unsuccessful. The lack of success is not surprising as most private member bills fail but the issue clearly did not resonate with the wider public in the province. The Ontario government, through the Ministry of Environment, regularly signaled that the province merely adjudicated the EA process and the ultimate decision about the construction of Site 41 rested with Simcoe County. Opponents of Site 41 failed to shift the venue to the provincial legislature.

The conflict over wind farms in Bruce County was different because as long as approval power rested with municipalities the opponents of wind-power were content to oppose wind projects at that level. However, in 2009 (after the completion of the Kincardine Wind Farm) the Ontario government passed the Green Energy and Economy Act (GEEA), 2009, which removed local approval power for renewable energy projects. This had little effect on the conflict over the Kincardine Wind Farm but was a response to the success of many groups in opposing wind projects in the province. The GEEA was clearly a strategy used by the Ontario government to overcome local opposition and encourage the development of renewable energy projects. Pralle identifies this type of move as an institutional strategy aimed at "changing the rules of the game" in order to gain advantage (2006, p. 29). In this case, the strategy was used by the province to contain these conflicts within institutions in which approval was more likely. This was a clear attempt to prevent the venue shopping strategy that was increasingly being used by opposition groups throughout the province (Ferguson, 2009). Opposition groups have reacted to this change by attempting to compete at the provincial level by mobilizing campaigns aimed at provincial voters and especially by opposing local MPP candidates 
from the governing party (Spears, 2013). Opposition groups have had little success in mobilizing provincial public opinion against wind power, as renewable energy is still popular but have had more success at influencing provincial elections within rural regions (Spears, 2013).

\section{Venue Shopping and Strategic Decision-Making}

The above discussion of the two cases illustrates the successes and failures of the opposition to each facility to engage in venue shopping but also provides insight into the processes by which these actors made strategic decisions. Pralle offers a number of hypotheses about the internal constraints different groups face when venue-shopping opportunities occur (2010). The first is that groups that are specialized, or have a specific ideological preferences, or have long-term interests in a specific institution can be expected to shift venues rarely. This is clearly not the case here. The opposition in each case carried little institutional or ideological history that might prevent them from considering new venues. Pralle's expectation seems confirmed here (2010). However, each group had a strong preference for their preferred frame, the risk to human health. It seems at least possible that a strong commitment to a particular frame could limit a groups willingness to shift venues or that the commitment to that frame might reduce the opportunity to affect the outcome in a current venue. If the preferred frame is perceived to be less effective in a specific venue, groups might be less willing to select that venue. It may be that a commitment to a specific frame could be as limiting as commitment to a specific ideology when it comes to venue shopping strategies.

The second hypothesis that low resources inhibit venue-shopping strategies is partially confirmed by the evidence in this case. Both sets of opposition groups were new 
(formed only for these conflicts) and lacked significant resources. However, the opponents to Site 41 were able to create linkages to external actors such as David Suzuki, a prominent environmental activist, Elizabeth May, the leader of the federal Green Party, and Maude Barlow, a water activist and member of the Council of Canadians, in addition to First Nation activists. This linkage with prominent advocates for the environment, while providing little tangible resources such as money, did provide significant expertise and exposure to the opponents of Site 41:

I think the Council Canadians provided a great service to us. They brought the awareness to the national stage, international stage. Ralph Nader attended for example. Maude Barlow [head of the Council of Canadians] whom I have great respect for, did a lot for us. And that helped us get it beyond that local level. And I think moving beyond the local level and bringing some media attention to it and caused individual members of the county council to reflect upon their earlier position" (Interview with Former Anti-Site 41 Activist, 2011)

This clearly aided their attempts to shift venues. The opponents to the Kincardine Wind Farm lacked this advantage. A strong provincial anti-wind movement has subsequently developed and is assisting with anti-wind activities by sharing resources and expertise (Ferguson-Martin and Hill, 2011), but this was not a substantial factor in the period of this conflict.

The final hypothesis is that groups that are focused on a single issue are more likely to show flexibility in shopping for new venues (Pralle, 2010). This is clearly the case in both these conflicts. The singular focus on 'winning' these conflicts, especially the belief that these facilities posed a threat to the health of local citizens, meant both groups were entirely willing to consider new venues. There is no evidence that either opposition failed to consider moving venues because of long-term concerns over a 
broader set of goals. In fact, the zero sum nature of the framing of these facilities virtually required opponents to seize any and all opportunities to defeat these facilities.

Venue shopping is often described as a sequential process where a group that is unsuccessful in one venue then seeks to access a new venue in order to pursue their policy goal. However, the process is often messier than this conception would suggest. As Pralle suggests: "venue-shopping can involve a lot of trial and error, particularly when an advocacy group is new to politics" (2003, p. 238). In both conflicts, opponents were unsuccessful within the environmental assessment processes for each facility because of the way risk was treated in each process. The decision to engage in legal challenges through the OMB, which were subject to similar rules of participation and evidence as the environmental assessment processes, therefore seems less rational. However the process of venue shopping in these cases was not a sequential process of trying a venue, failing in that venue, and then trying a new venue. Instead the opposition was pursing multiple venues simultaneously and only shifting resources once a venue began to show promise. In both cases, opponents were opposing the facilities within the environmental assessment processes and the $\mathrm{OMB}$ challenges while also still raising public awareness of the potential health risk of each facility in the public. This was possible because of the diffuse structure of the opposition. Direct stakeholders with access to the closed processes were opposing the facilities within the EA processes while activists engaged in protests and elite actors sought to influence political leaders.

\section{Conclusion}

Policy scholars have long recognized both the importance of venue shopping and the relationship between the institutional biases of the available venues and the problem 
definition of a particular issue (Baumgartner and Jones, 1993; Boothe and Harrison, 2009; Pralle, 2003). This paper has sought to make the relationship between a specific type of problem definition, that of risk to human health, and the institutional biases of specific venues explicit in order to understand how they create the incentives and opportunities for venue shopping. Several key findings are relevant to future studies of venue shopping.

First, policy venues contain institutional biases that make them more or less receptive to specific policy frames (Baumgartner and Jones, 1993). Institutional rules that privilege expert and technical considerations of risk will provide significant advantages to those that wish to advocate a technical understanding of risk from a given technology. This is most likely to be the proponent of that technology who will seek to limit conflict over that technology to venues that privilege their preferred understanding. Opponents will therefore seek out venues that privilege a public, non-technical perception of that risk. This will most likely be achieved through seeking venues that does not privilege the participation of experts. The relationship between the risk to human health frame and the institutional biases of these cases consistently leads to this strategy of venue shopping. This confirms the predictability of relationships between institutional biases and problem definitions suggested by Boothe and Harrison (2009).

Second, venue-shopping strategies that seek to shift to more open venues will only be successful if the opposition frame is widely accepted. In both cases studied here, the move to a new venue was only successful once the public accepted the problem frame advocated by opponents. This of course seems axiomatic; shifting venues to a political venue must mean that success in that venue requires political support. However, it is 
important to recognize this as an institutional biases and not a general rule. Acceptance of the health risk frame does not need to be universal but need only match the scale of the venue. The health risk of wind turbines did not need to be accepted provincially, and certainly not nationally, but only needed to be accepted by some of the public in Bruce County. These were the voters that would influence the decision-making at the Bruce County council. Acceptance by the provincial public only became important once the provincial government changed the rules of the game and shifted the venue to the provincial level. Defining which public needs to accept the risk frame is entirely dependent on the scale of the venue within which the policy is contended. Public support for the health risk frame becomes the crucial resource needed to compete within these institutions. Different institutional venues may of course require different resources but the contribution of this study is to specify the relationship between a specific policy frame and the institutional biases that are most receptive to that frame.

Finally, this study builds on the theoretical understanding of how institutional biases incentivize the strategic decision-making of advocacy groups. This study supports Pralle's qualification of decision-making around venue shopping as often "ad-hoc experimentation" (2003, p. 248). Opponents in both cases were faced with new events, such as the Walkerton tragedy, and changing institutional realities, such as the removal of approval authority for renewable energy projects from local hands, that forced them to learn and adapt as the conflicts unfolded. Instead of strategic decisions to focus on a single venue and then a shift when that was unsuccessful, both groups of opponents engaged in multiple strategies simultaneously and focused on one only when that strategy started to show results. This was aided by the diffuse character of the opposition in each 
case as their lack of a formal and hierarchical structure made the pursuit of multiple strategies at once possible. This counter-intuitively suggests that informally organized, often under-resourced, groups may sometimes have significant advantages in these types of conflicts.

In addition to the findings relevant to the theory of venue shopping, this study has lessons for both opponents and proponents of these types of technologies and facilities. The first lesson is that even small and relatively under-resourced opponents can have substantial impacts on public policy, when they are able to effectively deploy a problem frame as powerful as risk to human health. This is of course not sufficient for success, but is a powerful tool for capturing public attention. Proponents of these types of facilities should recognize that limiting these conflicts to institutions that privilege technical understandings of risk is not always a recipe for success. Ignoring public perceptions of risk will only force opponents to seek out public venues where the outcome is far from certain. Given that conflicts over risk will only become more common, understanding how they influence the strategies and actions of proponents and opponents will only become more important. 


\section{Chapter 8 - Conclusion}

\section{Introduction}

This dissertation began with the question: how does the framing of a policy as a threat to human health risk influence the outcome of a conflict about that policy? The answer, as is always the case in the social sciences, is that it depends. The framing of a facility as a threat to human was successful when a number of specific conditions were met including the strength of the frame and the ability of actors to shit to a venue appropriate to the policy frame they were advocating. That framing a facility as a threat to human health might expand a policy conflict is not surprising as many of the most visible and controversial policy conflicts involve some form of risk. But it is how this occurs that should be of interest to policy scholars. How this happens opens the door to understanding and even predicting under what circumstances this strategy might be most effective.

The following chapter begins with a summary of the main theoretical and policy insights drawn from the empirical chapters. Because these chapters are in a journal format, they each present the complete findings from that portion of the case study. These insights are therefore presented only briefly here to draw them together. Following that are some insights about the methodology applied in this dissertation and its application to policy studies generally. After summarizing the theoretical, policy, and methodological insights from the dissertation, the chapter proceeds with a brief discussion of the limitations to the findings in this dissertation. Next are some potential future directions for research about risk and policy studies. Finally, some brief concluding thoughts to the dissertation as a whole are offered. 


\section{Theoretical Insights}

\section{Core Research Questions}

The primary research question proposed at the beginning of this study was: how does the framing of a policy as a risk to human health influence the outcome of a conflict about that policy? In order to answer this question, Pralle's (2006a) approach to conflict expansion strategies was used to develop a theory about how one issue definition strategy, framing a policy as a risk to human health, might drive the participation of new actors and therefore open opportunities for venue shopping. Three hypotheses were tested. Each of the hypotheses and the conclusions drawn from the two case studies about those hypotheses are explained below.

Hypothesis 1: That the greater the acceptance of a risk frame, the greater degree to which a conflict will expand to new actors (public and elite).

This hypothesis was confirmed in the first case (Site 41) but not in the second case study (Kincardine Wind Farm). What accounts for this difference? The Site 41 case demonstrates that the clear dominance of the health risk frame leads to the participation of new actors. Two key conditions for this were revealed: the relative public acceptance of the scientific evidence for the frame and the relative strength of alternative frames. Because of the Walkerton tragedy in Ontario, which acted as focusing event drawing widespread public attention to the problem of drinking water protection, the public in Simcoe County was unwilling to accept the assurances of experts that the risk of water contamination from Site 41 was low. In the Site 41 case, policy-makers also lacked strong alternative frame with which to counter the health risk frame. The broad public acceptance of the health risk frame drove public participation in that conflict. The strong frame led a number of actors from outside the immediate vicinity of the proposed facility 
to join the conflict. This included provincial and national environmental activists and organizations, First Nations activists, and the general public throughout Simcoe County.

The Kincardine wind farm lacked both those conditions. Because of the uncertainty around the health effects of wind farms, the public in Bruce County never accepted the frame to the degree the public accepted the health risk frame in the Site 41 case. Proponents of wind turbines were also able to offer a powerful alternative frame. The public and outside elite actors did not engage in the Kincardine conflict to the extent that occurred in the conflict over Site 41. The comparison between the two conflicts clearly demonstrates that the more the public accepts the health risk frame, the more likely they are to engage in the conflict. The relative strength of the health risk frame drives conflict expansion.

Hypothesis 2: That the more actors that are drawn into the conflict, the greater will be the success of opponents at pursuing venues shopping strategies.

This hypothesis was also confirmed in the first case study but not the second. The opponents of Site 41 were able to shift the conflict from the EA process to the County Council because they had overwhelming public support. That support translated into significant pressure on councilors to oppose the facility, which led to many reversing their initial support for the facility or led to the defeat in municipal elections of those who would not. The framing of Site 41 as a risk to human health allowed opponents to draw in new participants to the conflict which opened the door to strategies of venue shopping.

In the case of the Kincardine Wind Farm, opponents were not successful in shifting the venue to the County Council. Because they lacked the overwhelming support enjoyed by the opponents of Site 41, the opponents of the Kincardine Wind Farm were not able to apply significant pressure on either the municipal or County Councils. 
Without significant public pressure, the County Councilors who had initially supported the facility were able to continue that support.

Hypothesis 3: That the more successful opponents are at venue shopping, the greater the likelihood of defeating the facility.

The final hypothesis is the link between venue shopping and the ability to influence the outcome of the conflict over each facility. It is possible that successful venue shopping might only lead to a partial victory for the opposition. For example, the opposition might have been able to force a significant alteration to the project, such as a smaller or differently designed landfill or fewer wind turbines. This initially occurred in the conflict over Site 41 when opponents were able to win a moratorium on the construction of Site 41 without actually having the County withdrawing approval. However, the opposition to Site 41 was able to subsequently pressure the County to cancel the proposed landfill entirely. In the case of the Kincardine Wind Farm, the failure to successfully shift venues of course provided little opportunity to influence the outcome of the conflict through the County Council.

\section{Risk to Human Health and Policy Studies}

The results of the analysis above demonstrate the role that the health risk frame played in each conflict. But is a health risk frame different in kind from other forms of frames available to policy actors contesting a public policy? The research design of this dissertation does not include a comparison between the use of a health risk frame in one case and a non-health risk frame in another. This was intentional as isolating all the potential variables that could influence the outcome of a conflict in two different cases to reveal the influence of the frame would be difficult. Instead two conflicts that each involved a change in the framing of the facility in question were analyzed. This allows 
for the comparison within each case between the conflict before and after the health risk frame was prominent. This does not equal a controlled experiment but through careful process tracing it does reveal the link between the introduction of the health risk frame, the expansion of the conflict to include new actors, and successful venue shopping by opponents. The comparison of two different types of risk frames also reveals the characteristics of a risk frame that contributes to the successful use of that frame to expand a conflict.

The answer to the question whether the framing of a policy as a risk to human health influences the outcome of a conflict about that policy is therefore a resounding maybe. Other frames, in certain circumstances, may be just as effective at expanding a conflict. However, the analysis of the two conflicts studied clearly reveals that that the health frame offered strategic opportunities to the opponents of these facilities unavailable to other potential frames within the studied conflicts. This study revealed that some venues, because of the way in which the treat the evaluation of health risks, are biased towards scientific and expert based assessments of risk. Actors that wish to oppose these policies therefore need to shop for new venues without these biases. The type of resources needed to compete within these new venues are determined by the rules of those venues. In the cases studied here, the key resource was public support for the health risk frame. This applied pressure to elected actors. A health risk frame, when it has the characteristics identified in Chapter 6, can therefore be best understood as a frame that opens opportunities for strategies not available to policy actors advocating other frames.

Integrating the findings from this study into theories of the policy process should occur in two ways: the recognition of the strategic incentives created by the institutions 
that structure policy making and the relationship between health risk frames and those incentives. This is the recognition of the relationship between institutional biases and a specific type of policy frame (policy image, issue definition, etc.) that is likely to become only more prevalent, especially in struggles over environmental policy-making. An approach to analyzing this therefore needs to identify the institutional venues available to actors and how those venues evaluate risk. In a conflict over policy in which the potential risk to health is important, the institutional venues that are available to various actors contesting that policy are relatively stable. ${ }^{18}$ Analysis therefore starts with the institutional venues available and how they make decisions about risk. In venues that prioritize expert (for example legal understandings of risk) or scientific evidence, those wishing to advocate a health risk frame will need to present evidence that meets those standards. In venues open to public pressure, those wishing to advocate a health risk frame will need to gain public support in order to apply that pressure to decision makers. The institutions then determine the resources, such as scientific or expert evidence of health risk versus public acceptance of that health risk, which actors require to be successful in those institutions.

It should be noted that the above is not to suggest that actors will always start with an institutional preference and then choose an appropriate health frame to match that institution. Actors may have various preferences for institutional venues or frames. Actors may choose the frame that best suits their preferred institution or may choose an

\footnotetext{
${ }^{18}$ This is not to say that institutions are not dynamic or unchanging but only that actors within those institutions have limited opportunity to change them in the short term. For instance, the actors in each of the environmental assessment processes studied here had little opportunity to change the rules of these processes. That would require changing the legislation that created those processes, which can only occur within the provincial legislature. Institutions at one level of operation can generally only be changed by actors within a set of institutions operating at a higher level (Ostrom, 2005).
} 
institutional venue that best suits their preferred frame. Some of the opponents of each facility interviewed for this study clearly believed that the facility in question posed a genuine threat to health. Others likely chose to focus on the health risk frame as a strategy to gain legitimacy for their opposition to the facility. In the former case it is likely those actors would focus on the health frame and then choose an institutional venue they thought was the most receptive to that frame. Their belief in the danger posed by a policy precedes their choice of venue. In the latter case it is likely that actors will choose the frame based on their understandings of the institutional venue they thought most likely to advance their preferences. This is complicated by the fact that actors choose institutions for many reasons. Actors will choose institutions based on available resources such as expertise or because of an ideological affinity for a particular venue (Pralle, 2010). Evaluating the strategies of these actors therefore may require the analysis of which comes first, the choice of venue or frame. One hypothesis for future research suggested by these findings is whether actors with deep held beliefs about the health risk posed by a policy are more likely to shift venues to match those beliefs.

A potential framework for evaluating how health risk frames effect policy outcomes need to focus on the above two elements: the institutional decision-making rules about risk and the opportunities afforded to actors by the health risk frame. A third variable of course is the nature of the groups advancing these frames. For instance, are they large groups with significant resources? The opposition groups in the cases presented here both began as small relatively disorganized groups and both opposition groups, initially at least had far less resources than the proponents in terms of money and expertise (the County governments and Enbridge). Both groups became better organized 
and funded over the course or the conflicts and some of this is certainly due to effective leadership. However, it is the health risk frame that enabled these groups to grow. The health risk frame is an essential resource because it can help draw in new participants which is a key resource. It is the new participants that raise and contribute money, raise awareness through protests and campaigns, and pressure members of the County Councils to oppose the facilities. The health risk frame is therefore a key independent variable in this framework.

Figure 8-1 below outlines this framework. The actors and frames are separate independent variables. ${ }^{19}$ Within each are a number of characteristics such as available resources and the strength of the frame. They of course interact as actors choose frames and frames can influence the resources available to those actors. The institutional venues available in a specific policy conflict are relatively stable over time but the key characteristic of interest is how each venue makes decisions about risk. These three sets of variables then interact in order to produce an outcome. Any analysis should of course recognize that these variables represent dynamic concepts and that the values will inevitably change over the course of a policy conflict.

\footnotetext{
${ }^{19}$ The term variable is used here in a general sense to indicate elements of the framework that need to be captured for analysis and not as a single measurement of a specific concept. Assigning values to each of these will depend on the specific context in which the framework is applied.
} 
Figure 8-1: Framework for Analyzing Health Risk Policy Conflicts

Available Institutions:

risk decision rules
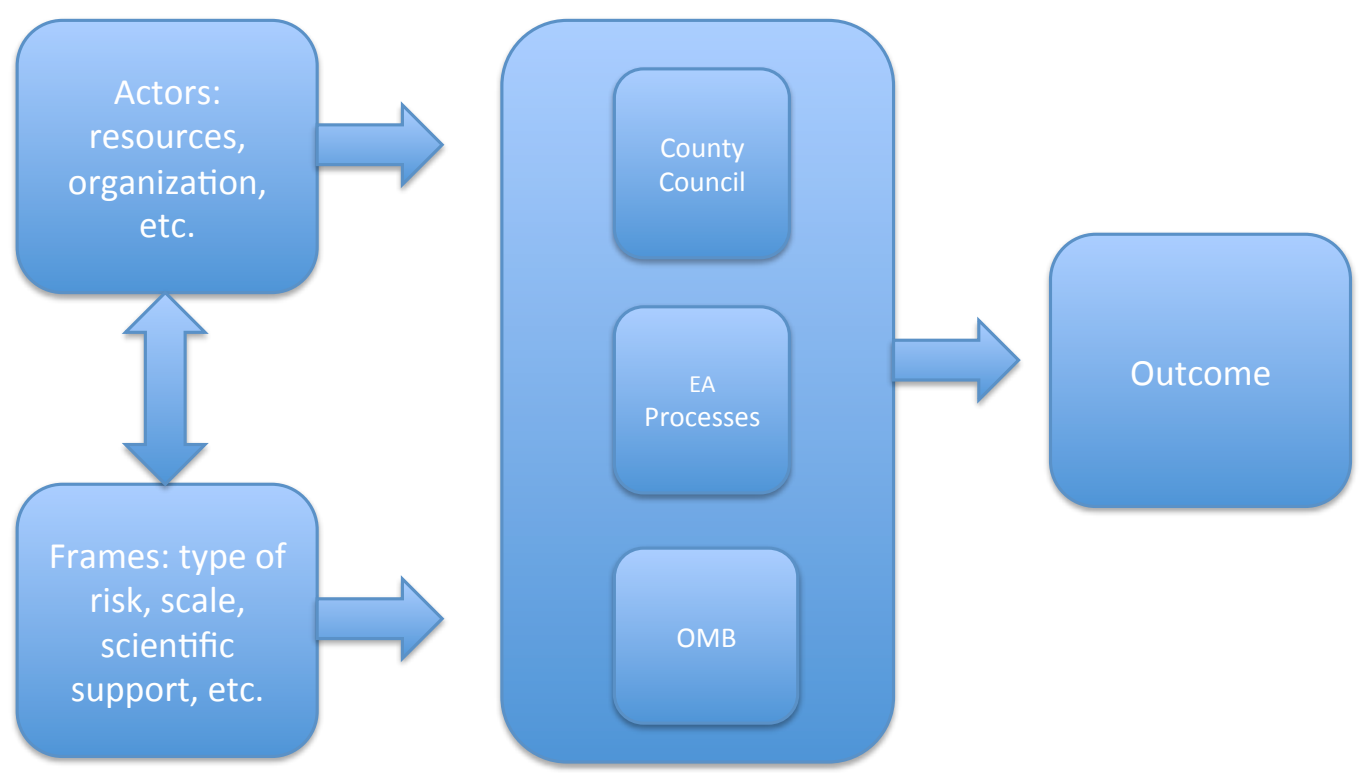

The above can be classified as a framework as opposed to a more general approach because it specifies the variables of interest. It is not a model because it does not specify the relationship between those variables. For instance, the framework does not specify the relationship between the frame and the resources available to actors and therefore does not allow for predicting their values. This framework is essentially the classic focus on actors, institutions, and ideas but is applied to a specific type of political conflict. The more general focus on ideas is narrowed to identify the central role of one specific idea: the perceived risk to human health of a given policy. This focus then narrows the analysis of the institutions to how different venues make decisions about risk 
and the opportunities and resources that set of ideas about risk affords the actors in these conflicts. This framework should aid analysis of these types of conflicts and integrate the consideration of health risk frames into more general theories of public policy.

\section{Policy Insights}

Each of the empirical chapters offers some insights to those participating in the types of conflicts analyzed in this dissertation. However, the most important is probably that no matter how participatory a process was used to engage stakeholders around these facilities, it is unlikely that opponents would have been satisfied by the outcome. Once opponents had adopted the health risk frame the conflict for them became a zero sum game. There is likely no compromise short of cancellation of the project that would have satisfied these opponents. Any meaningful participatory process (one that would allow stakeholders a legitimate say in the outcome) would therefore have led either to the cancellation of the facility or failing that, opponents would have inevitably sought to oppose the facility in other institutional venues. It is possible that a meaningful participatory process would have provided an effective counter-frame for proponents of a facility. Whether this would be sufficient to overcome a strong health risk frame such as the one used in Site 41 is questionable. In the future, both participants in these conflicts as well as those analyzing them must focus not only on the degree of participation allowed in formal processes for decision-making in these conflicts but on the relationship between those processes, the decision-making of actors within these conflicts, and the other institutional venues available to those actors. 


\section{Methodological Insights}

\section{Process Tracing}

The results of this dissertation support the contention that process tracing can be a powerful tool for policy studies (Kay and Baker, 2014). Focusing analysis on the causal mechanisms that link the dependent and independent variables of interest reveals the crucial processes that explain the outcomes of complex social interactions. Another approach to this research project could have been a quantitative study of the results of the content analysis of newspaper framing of each conflict with the results of the survey of each County and controlling for other variables such as the length of the conflict. A model could then test the influence of the framing on the perceptions of risk around each facility by residents of each County. This research design could answer the question of whether the framing of each facility influenced the perceptions of risk by the public and therefore whether it influenced the outcome of each conflict. However, that research design would answer the 'if' question without addressing the 'how'. It could evaluate if framing influences the outcome but not the processes by which that influence is transmitted from the frame to the outcome. That research design would miss entirely the role of venue shopping in this story as well as the strategic decision-making processes that undoubtedly influenced the outcome of each conflict.

Process tracing was a powerful tool for identifying the causal mechanisms in this study but like all research methodologies, it comes with challenges. Two challenges in particular were important in this study. The first challenge was the selection and evaluation of evidence. Process tracing requires the researcher to select evidence and then 
weigh its relative value. Evidence, whether from interviews or secondary sources that is generated by political actors is always subject to the biases and manipulation of those actors (Beach and Pederson, 2013; Kay and Baker, 2014). This dissertation dealt with this challenge through the triangulation of evidence from multiple sources including secondary sources, interviews, newspaper reports, and the survey. Nonetheless, some data were only obtainable from a single source and evaluating the perspective and credibility of those sources is a significant challenge. For instance, some of the data gathered in this dissertation from interviews about the motivations and strategic decisions made by the opponents was only available through a single interview. Careful attention had to be paid to how much weight was given to these statements. Future studies that propose process tracing as a method of analysis must carefully consider what evidence will be available and how to evaluate that evidence.

The second challenge posed by process tracing is practical. The evidence required for good process tracing is significant and the imperative of reporting that evidence places a significant burden when publishing results. This may be less problematic when publishing in a monograph format but the detail required might stretch the length of a paper well beyond what most journals will publish. The detailed tracing of each step of the proposed causal mechanism and the tables listing the proposed evidence in Chapter 3 gives some idea about the amount of detail required. Including this level of detail in an already long case study paper may be impossible. This may ultimately require a set of standards similar to what is becoming accepted when publishing quantitative data where the availability of the dataset used in analysis is made a condition of publication in a journal (Moravcsik, 2014). While universal standards are difficult to create for 
quantitative studies given the diversity of approaches, process-tracing offers a form of analysis that makes explicit the process by which inferences are made. This should ultimately be a strength as more value is placed on the openness of the research process.

\section{Limitations}

The core limitation of this study, as in almost all case studies, is the external validity of the findings (George and Bennett, 2005). Case studies are always embedded within a context and the degree to which the findings of a given case study can be applied in other contexts must always be carefully considered. Causal mechanisms in particular must be specified as to the context in which they might be expected to operate. Beach and Pedersen (2013) ask the crucial question: "Is it theorized to be a causal mechanisms that is broadly applicable across space and time, or applicable within a narrow context, or is it case specific (p. 54)? The case studies presented here are set within similar cultural, economic, and institutional contexts. The most significant variation between the two is the nature of the facility and therefore the nature of the risk at the center of each conflict. ${ }^{20}$ The similarity makes comparison more straightforward but also reduces its applicability in contexts that do not share those similar characteristics. Many of the more specific findings presented in this thesis will be limited to specific contexts but it is the relationship between the health risk frame and institutions, and the incentives for action that relationship produces, that are the most universally applicable findings of this study.

Institutions and the frames used to understand public policies are closely interrelated (Boothe and Harrison, 2009). Both cases examined in this study highlight this

\footnotetext{
${ }^{20}$ It should be noted that this does not equal a perfect most-similar case design. Real world cases with all of their attendant complexity makes the control of all variables impossible (George and Bennett, 2005). The causal claims in this study are not based on the comparative method but on the within-case analysis of process tracing.
} 
relationship and in particular reveal the relationship between how risk is considered within a specific institution and the incentives that creates for those advocating a health risk frame. Those who are advancing a health risk frame (whether from genuine belief or strategic motives) will seek new institutional venues if they believe the existing venue privileges technical conceptions of risk that do not support the health risk frame. This is hardly an earth-shattering finding; those who lose in one venue will often seek out others. However, it is the incentive to seek out an institution that does not privilege risk that is important. This finding is limited to democracies with enough institutional diversity to allow for venue shopping but within those it should be broadly applicable.

The findings about the expansion of risk conflicts to include new actors explored in Chapter 6 are less universally applicable then the relationship between risk frames and institutions. This study proposed a causal mechanism in which use of a health risk frame expanded these conflicts beyond the limited set of actors that would have participated if the conflicts had focused exclusively on issues such as local property values. The success of the conflict expansion determined the success of opponents at moving the two conflicts to more open institutions. Where that is possible, policy change may occur. That expansion is dependent on a number of conditions that have been important contributions of this study. However, those conditions are far more specific to a time and a place then the more general findings about the relationship between the risk frame and institutions. What types of risk will resonate with the public, the relationship between that type of risk and the current political agenda, and the willingness of proponents of change to engage in advocating that risk frame are all likely specific to a particular to a time and a place. The degree to which they apply to any given context will need to be empirically tested. 


\section{Future Directions}

The conclusion of each empirical chapter offers some possible future directions for research about the relationships between risk and the outcomes of policy conflicts and this section briefly outlines three more general observations. The first is that the distinction between the success of venue-shopping by policy actors and the outcome of a policy conflict reveals some ambiguity around the concept of venue shopping. Is venue shopping an attempt to access a new venue by a policy actor? Is it the successful access of a new venue? Or is venue shopping the ability to influence a policy outcome in that new venue? The cases studied here reveals the potential need to disaggregate the concept of venue shopping into discrete stages. For instance, venue shopping as the process of seeking out new venues and venue shifting as the successful move from one venue to the next. This is an opportunity to further specify what is a complex and dynamic process.

Second, while the research design of this dissertation focused on two different types of health risk frames, research comparing this type of frame to others would advance the understanding of the precise ways in which the health risk frame is distinct, if at all. This research design was not adopted here for good reasons but could answer a number of important questions such as why some policy actors may choose not to adopt a health risk frame.

Finally, the introduction to Chapter 1 noted that there has been little research that integrates risk into theories of the policy process. This dissertation analyzed risk in terms of the strategic use of a health risk frame by actors attempting to expand a policy conflict. This built on the approach to conflict expansion developed by Pralle (2006a). Studies that attempt to integrate risk into different theories of the policy process offer interesting 
opportunities for future research. The Advocacy Coalition Framework (ACF) developed by Sabatier and Jenkins-Smith would be ideal because of the focus on the beliefs of policy actors and how those beliefs inform their policy preferences $(1988 ; 1993)$.

Research that tests the applicability of several theoretical approaches at once would also significantly advance the understanding of the relationship between risk and public policy.

\section{Concluding Thoughts}

When the types of conflicts studied here are discussed it is often in the terms of the Not In My Backyard (NIMBY) syndrome. These discussions paint those opposed to a proposed facility as opposed to progress or only focused on their own narrow interest. There is another way to view these conflicts. Given the seeming apathy of many people around large-scale environmental problems, the commitment of the actors involved in these conflicts to protect their local environment and communities is cause for optimism. While the direction of that opposition may not always be desirable, for example the opposition to renewable energy facilities, the impulse to protect the local environment is a net positive. This dissertation was intended to open these conflicts for analysis to reveal how they occur and what drives them and to hopefully contribute to the knowledge required to resolve the conflicts in constructive ways. However, sometimes a good fight is required. Local environmental conflicts can mobilize a community more than equally urgent but more distant environmental problems. Engaged and motivated citizens are the best hope for real and sustained change around environmental decision-making. 


\section{Appendices}

\section{Appendix A: Interview Documents}

Interview Request Letter

\section{RYERSONUNIVERSITY}

Adam Thorn

Ryerson University, Politics and Public Administration 350 Victoria Street, Toronto, Ontario, Canada, M5B 2K3

Dear

My name is Adam Thorn and I am a doctoral student in Ryerson University's Policy Studies Program. I am currently conducting research for my dissertation about land use conflict in Ontario.

I am writing to request an in-person interview with you about your experience with the construction of commercial wind turbines in Bruce County. Your knowledge and experience in this subject area will add an invaluable contribution to my research. This interview should take roughly one hour to complete and can be at a location of your choice or by telephone. The interview will be confidential and nothing you say in the interview will be attributed to you. Upon your agreement to participate in an interview, a consent form and sample of interview questions will be provided for your review. To gain further knowledge about the focus of my research project, a brief description is provided below:

The dissertation is the final component necessary for the completion of a doctoral program and this interview will be part of the research needed to complete my $\mathrm{PhD}$. The research project consists of several case studies focusing on land use conflicts over waste and energy projects. In Canada, these conflicts occur within provincial and municipal institutions (rules) that structure how people are able to participate in these conflicts and ultimately how these conflicts are resolved. The central question of interest is why do 
some land use proposal conflicts related to siting of energy and waste facilities result in the completion of the facility and others do not? Interviews with key participants in each conflict are especially important as they may reveal the role of institutions in creating trust between actors within the conflict and the perceptions of risk posed by the facility. The hope is that this research may reveal which institutions contribute to outcomes that respect the right of local communities to participate in decision-making while providing important public goods.

Thank you for taking time to consider my request. If you wish to participate please contact me at the above address or the phone number or email address below.

Sincerely,

Adam Thorn PhD (Candidate)

Policy Studies

Ryerson University

(647) 2981442

adam.thorn@ryerson.ca 


\title{
Appendix B: Survey Documents
}

\author{
Survey Invitation Letter
}

\section{RYERSONUNIVERSITY}

\section{Dear Simcoe/Bruce County Resident:}

My name is Adam Thorn and I am a doctoral student in Ryerson University's Policy Studies Program. I am currently doing research on conflicts around where governments put facilities like garbage dumps and nuclear power plants. You can help me by completing and returning this short survey.

\section{What is the purpose of this research?}

My research project uses several case studies to understand how local communities influence land use conflicts around waste and energy projects. I hope that my research will show how organizations can help solve disputes over these facilities that respect the rights of local communities to participate in decision-making The benefits to you of participating in this study are primarily the opportunity to share opinions about an important local issue.

\section{Will my identity be protected if I participate?}

Your household was randomly selected and your survey answers will be entirely anonymous. The survey you return will not identify you and your name or address will never be connected with your answers. My research supervisor and myself are the only people who will have access to the collected data. Once the project is complete the completed surveys will be destroyed. Participation in this research is voluntary and you will not be paid for your participation. Your decision about whether or not to participate in this research will have no influence on your future relations with Ryerson University. The Ryerson University Ethics Board has approved this study. If you have questions regarding your rights as a participant in this study, you may contact the Ryerson University Research Ethics Board for information.

\author{
Research Ethics Board \\ rebchair@ryerson.ca \\ Ryerson University, 350 Victoria Street, Toronto, ON M5B 2K3
}

\section{Who can participate in the survey?}

Any adult member of your household may complete the survey. It should take approximately fifteen minutes to complete. 


\section{How do I complete the survey?}

To participate in this study simply complete the enclosed survey by checking your response to each of the questions. Once complete, please use the enclosed and anonymous, postage paid envelope to return the survey at any Canada Post mailbox. Please do not sign or print your name on the survey or return envelope.

Thank you in advance for your time. If you have any questions about this research, you may contact my supervisor or myself at the addresses below.

Sincerely,

Adam Thorn, PhD (Candidate)

adam.thorn@ryerson.ca

Policy Studies

Ryerson University

350 Victoria St., Toronto, Ontario, M5B 2K3
Dr. Carolyn Johns, Research Supervisor cjohns@politics.ryerson.ca

Department of Politics and Public Administration Ryerson University

350 Victoria St., Toronto, Ontario, M5B 2K3 


\section{Bruce County Survey}

Survey of Opinions on Government and Land Use

Please check the most appropriate response to each of the following questions. There is no right or wrong answer to these questions; I am only interested in your opinions. Your responses are anonymous and your identity will never be connected to your answers.

\section{Section A: These questions ask about your residency in Bruce County}

1. Are you a full time resident of Bruce County? Yes No

2. How long have you lived (even part time) in Bruce County?

years

\section{Section B: These questions ask about your opinion of different levels of government}

3. How impartial do you think each of the following organizations is when it performs its duties?

\begin{tabular}{|c|c|c|c|c|}
\hline $\begin{array}{l}\text { Completely } \\
\text { Impartial }\end{array}$ & $\begin{array}{c}\text { Mostly } \\
\text { Impartial }\end{array}$ & $\begin{array}{c}\text { Somewhat } \\
\text { Impartial }\end{array}$ & $\begin{array}{l}\text { Not Very } \\
\text { Impartial }\end{array}$ & $\begin{array}{l}\text { Not at all } \\
\text { Impartial }\end{array}$ \\
\hline
\end{tabular}

The Federal Government

The Ontario Government

The Ontario Municipal

Board

The Ontario Ministry of

the Environment

Bruce County

Your Local Township

4. How well do you think each of the following organizations enforces regulations?

\begin{tabular}{|c|c|c|c|c|}
\hline Completely & Mostly & Somewhat & Not Very & Do Not \\
\hline Enforced & Enforced & Enforced & Enforced & Enforce \\
\hline
\end{tabular}

The Federal Government

The Ontario Government

The Ontario Municipal

Board

The Ontario Ministry of

the Environment

Bruce County

Your Local Township 
5. How much do each of the following organizations allows the public to participate in decision making?

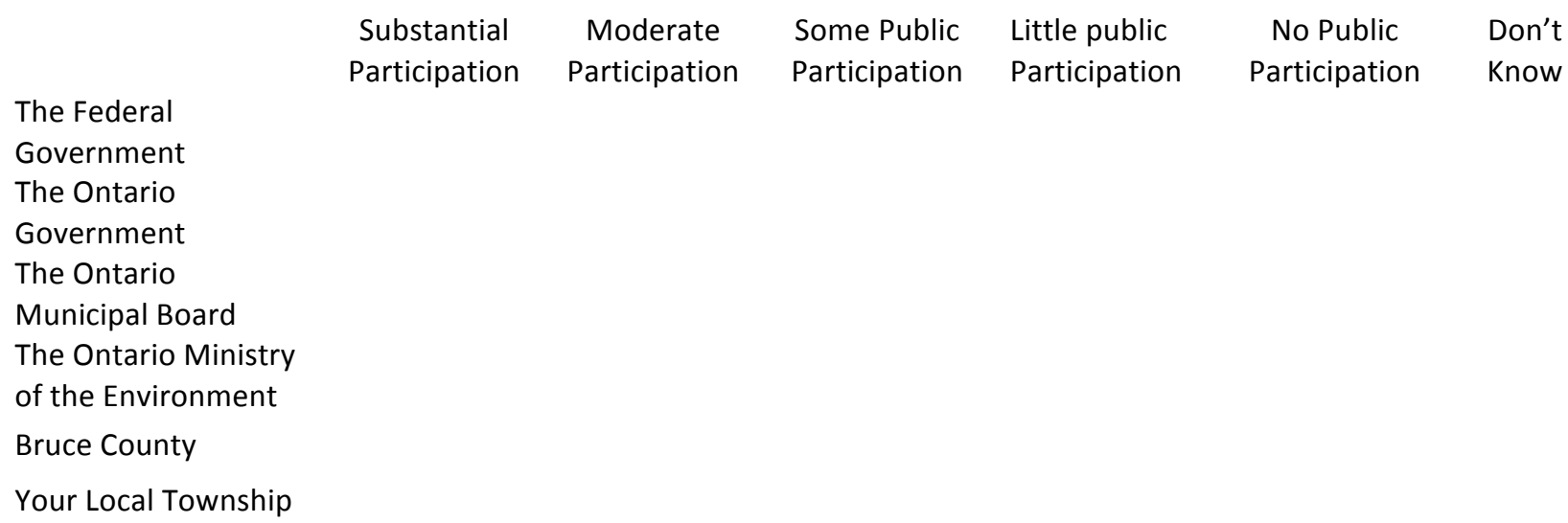

The Federal

Government

The Ontario

Government

The Ontario

Municipal Board

The Ontario Ministry

of the Environment

Bruce County

Your Local Township

6. Overall, how would rate the quality of the services provided by each of the following organizations?

\begin{tabular}{|c|c|c|c|c|}
\hline $\begin{array}{c}\text { Very High } \\
\text { Quality }\end{array}$ & $\begin{array}{l}\text { High } \\
\text { Quality }\end{array}$ & $\begin{array}{c}\text { Moderate } \\
\text { Quality }\end{array}$ & Low Quality & $\begin{array}{c}\text { Very Low } \\
\text { Quality }\end{array}$ \\
\hline
\end{tabular}

The Federal Government

The Ontario Government

The Ontario Municipal

Board

The Ontario Ministry of the

Environment

Bruce County

Your Local Township

7. How much do you trust each of the following organizations?

\begin{tabular}{|c|}
\hline $\begin{array}{c}\text { Completely } \\
\text { Trust }\end{array}$ \\
\hline
\end{tabular}

The Federal Government

The Ontario Government

The Ontario Municipal Board

The Ontario Ministry of the

Environment

Bruce County

Your Local Township

8. How much do you agree or disagree with each of the following statements?

$\begin{array}{cccc}\text { Completely } & \text { Mostly } & \text { Somewhat } & \text { Do } \\ \text { Agree } & \text { agree } & \text { Agree } & \text { Not }\end{array}$


Other people in Ontario are willing to live near wind farms.

Municipalities have the responsibility to contribute to the production of power by accepting wind farms.

I would be willing to live near a wind farm if I was financially

compensated.

Municipalities should have more power to manage wind farm

development.

I support the construction of more wind farms in Bruce County.

\section{Section C: These questions are about your opinions of the risks posed by various types of technologies and facilities}

9. How much risk do you think each of the following presents to you and your immediate family?

\begin{tabular}{lrllllllll} 
Low Risk & \multicolumn{4}{c}{ Medium Risk } & \multicolumn{3}{c}{ High Risk } \\
1 & 2 & 3 & 4 & 5 & 6 & 7 & 8 & 9 & 10
\end{tabular}

Nuclear Power

Genetically Modified Food

Climate Change

Commercial Windmill Farms

Water Pollution

Commercial Gravel Pits

Municipal Landfills

\section{Section D: These questions are about the Enbridge wind farm in your area}

10. Are you familiar with the Enbridge wind farm in Kincardine?

Yes, please proceed to question 11 below.

No, please skip to question 15 on page 4.

11. If you are familiar the Enbridge wind farm, did you participate in any of the following activities surrounding the decision to construct the site?

Attended Council Meetings

Yes

Attended Protest Events 
Attended Fund Raising Events

Attended Community Monitoring Committee Meetings

Participated on the Internet (Facebook, online petitions,

etc.)

Other, Please specify:

12. If you are familiar with the Enbridge wind farm, how much did this issue influence whom you voted for at each of the following levels of government?

\begin{tabular}{|c|c|c|c|c|}
\hline $\begin{array}{c}\text { Strong } \\
\text { Influence }\end{array}$ & $\begin{array}{l}\text { Moderate } \\
\text { Influence }\end{array}$ & $\begin{array}{c}\text { Some } \\
\text { Influence }\end{array}$ & $\begin{array}{l}\text { Not Much } \\
\text { Influence }\end{array}$ & No Influence \\
\hline
\end{tabular}

Municipal Elections

Provincial Elections

Federal Elections

13. If you are familiar with Enbridge wind farm, were you opposed to the site?

Yes No Don't Know

14. If you are familiar with the Enbridge wind farm, please indicate how much you agree with the following:

$\begin{array}{cccc}\text { Strongly } & \text { Somewhat } & \text { Somewhat } & \text { Strongly } \\ \text { Agree } & \text { Agree } & \text { Disagree } & \text { Disagree }\end{array}$

The Enbridge wind farm poses a health risk to myself or my family.

The decision-making process surrounding the wind farm was

fair.

I had sufficient opportunities to participate in decisions about

the Enbridge wind farm.

I had sufficient information about the Enbridge wind farm.

My opinion of my local government improved because of my knowledge of wind farm development.

\section{Section E: Finally, I'd like to know a bit about you}

15. In what year were you born?

16. What is your sex? Female Male

17. What is the highest level of education that you have completed?

Less than High School

High School Diploma/GED

Some College or College Diploma

Some University or University Degree 
Graduate Degree

18. Which category does your household's total income fall within?

Under $\$ 10,000$

$\$ 10,000$ to under $\$ 25,000$

$\$ 25,000$ to under $\$ 35,000$

$\$ 35,000$ to under $\$ 45,000$

$\$ 45,000$ to under $\$ 55,000$

$\$ 55,000$ to under $\$ 75,000$

$\$ 75,000$ to under $\$ 100,000$

$\$ 100,000$ and over

Prefer not to answer

Thank you for completing this survey. Please return this survey using the provided anonymous, postage paid envelope. Please do not sign or print your name on this survey or the return envelope. 


\section{Simcoe County Survey}

\section{Survey of Opinions on Government and Land Use}

Please check the most appropriate response to each of the following questions. There is no right or wrong answer to these questions; I am only interested in your opinions. Your responses are anonymous and your identity will never be connected to your answers.

\section{Section A: These questions ask about your residency in Simcoe County}

1. Are you a full time resident of Simcoe County? Yes No

2. How many years have you lived (even part time) in Simcoe County? years

\section{Section B: These questions ask about your opinion of different levels of government}

3. How impartial do you think each of the following organizations is when it performs its duties?

$\begin{array}{cccccc}\text { Completely } & \text { Mostly } & \text { Somewhat } & \text { Not Very } & \text { Not at all } & \text { Don't } \\ \text { Impartial } & \text { Impartial } & \text { Impartial } & \text { Impartial } & \text { Impartial } & \text { Know }\end{array}$

The Federal Government

The Ontario Government

The Ontario Municipal

Board

The Ontario Ministry of

the Environment

Simcoe County

Your Local Township

4. How well do you think each of the following organizations enforces regulations?

\begin{tabular}{|c|c|c|c|c|}
\hline $\begin{array}{c}\text { Completely } \\
\text { Enforced }\end{array}$ & $\begin{array}{l}\text { Mostly } \\
\text { Enforced }\end{array}$ & $\begin{array}{c}\text { Somewhat } \\
\text { Enforced }\end{array}$ & $\begin{array}{l}\text { Not Very } \\
\text { Enforced }\end{array}$ & $\begin{array}{l}\text { Do Not } \\
\text { Enforce }\end{array}$ \\
\hline
\end{tabular}

The Federal Government

The Ontario Government

The Ontario Municipal

Board

The Ontario Ministry of

the Environment

Simcoe County 
Your Local Township

5. How much do each of the following organizations allows the public to participate in decision making?

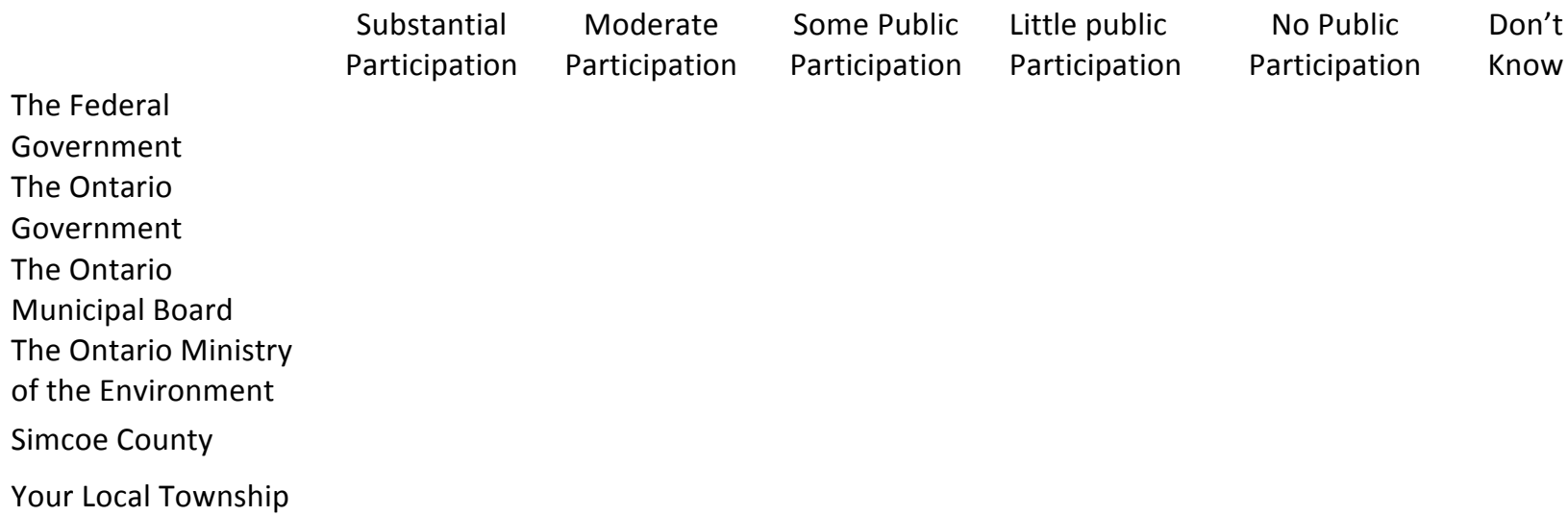

6. Overall, how would rate the quality of the services provided by each of the following organizations?

\begin{tabular}{|c|c|c|c|c|}
\hline $\begin{array}{c}\text { Very High } \\
\text { Quality }\end{array}$ & $\begin{array}{l}\text { High } \\
\text { Quality }\end{array}$ & $\begin{array}{c}\text { Moderate } \\
\text { Quality }\end{array}$ & Low Quality & $\begin{array}{c}\text { Very Low } \\
\text { Quality }\end{array}$ \\
\hline
\end{tabular}

The Federal Government

The Ontario Government

The Ontario Municipal

Board

The Ontario Ministry of the

Environment

Simcoe County

Your Local Township

7. How much do you trust each of the following organizations?

\begin{tabular}{|c|c|c|c|c|}
\hline $\begin{array}{c}\text { Completely } \\
\text { Trust }\end{array}$ & $\begin{array}{c}\text { Mostly } \\
\text { Trust }\end{array}$ & $\begin{array}{c}\text { Somewhat } \\
\text { Trust }\end{array}$ & Little Trust & $\begin{array}{c}\text { Do Not } \\
\text { Trust }\end{array}$ \\
\hline
\end{tabular}

The Federal Government

The Ontario Government

The Ontario Municipal Board

The Ontario Ministry of the

Environment

Simcoe County

Your Local Township 
8. How much do you agree or disagree with each of the following statements?

$\begin{array}{cccc}\text { Strongly } & \text { Somewhat } & \text { Somewhat } & \text { Strongly } \\ \text { Agree } & \text { Agree } & \text { Disagree } & \text { Disagree }\end{array}$

Other residents of Simcoe County are doing their part to manage waste responsibly.

Municipalities should be allowed to export waste to other areas for disposal.

I would be willing to live near a landfill site if I was

financially compensated.

The provincial government should make decisions

about municipal waste instead of local municipalities.

\section{Section C: These questions are about your opinions of the risks posed by various types of technologies and facilities}

9. How much risk do you think each of the following presents to you and your immediate family?

\begin{tabular}{llllllllll} 
Low Risk & \multicolumn{4}{c}{ Medium Risk } & \multicolumn{2}{c}{ High Risk } \\
1 & 2 & 3 & 4 & 5 & 6 & 7 & 8 & 9 & 10
\end{tabular}

Nuclear Power

Genetically Modified Food

Climate Change

Commercial Windmill Farms

Water Pollution

Commercial Gravel Pits

Municipal Landfills

\section{Section D: These questions are about a proposed landfill in your area}

10. Are you familiar with the conflict over a proposed landfill site in Tiny Township called Site 41?

Yes, please proceed to question 11 below.

No, please skip to question 15 on page 4.

11. If you are familiar with Site 41, did you participate in any of the following activities surrounding Site 41? 
Attended Council Meetings

Attended Protest Events

Attended Fund Raising Events

Attended Open Houses

Participated on the Internet (Facebook, online petitions,

etc.)

Other, Please specify:

12. If you are familiar with Site 41 , how much did this issue influence whom you voted for at each of the following levels of government?

$\begin{array}{ccccc}\text { Strong } & \text { Moderate } & \text { Some } & \text { Not Much } \\ \text { Influence } & \text { Influence } & \text { Influence } & \text { Influence }\end{array} \quad$ No Influence $\quad \begin{gathered}\text { Did Not } \\ \text { Vote }\end{gathered}$

Municipal Elections

Provincial Elections

Federal Elections

13. If you are familiar with the Site 41 , were you opposed to the proposed landfill site?

Yes No Don't Know

14. If you are familiar with Site 41, please indicate how much you agree with the following:

Site 41 posed a health risk by potentially contaminating

$\begin{array}{cccc}\text { Strongly } & \text { Somewhat } & \text { Somewhat } & \text { Strongly } \\ \text { Agree } & \text { Agree } & \text { Disagree } & \text { Disagree }\end{array}$
local water.

The decision-making process surrounding Site 41 was

fair.

I had sufficient opportunities to participate in decisions

about Site 41.

I had sufficient information about Site 41.

My opinion of my local government improved because

of my knowledge of Site 41 .

\section{Section E: Finally, I'd like to know a bit about you}

15. In what year were you born?

16. What is your sex? Female Male

17. What is the highest level of education that you have completed?

Less than High School

High School Diploma/GED 
Some College or College Diploma

Some University or University Degree

Graduate Degree

18. Which category does your household's total income fall within?

Under $\$ 10,000$

$\$ 10,000$ to under $\$ 25,000$

$\$ 25,000$ to under $\$ 35,000$

$\$ 35,000$ to under $\$ 45,000$

$\$ 45,000$ to under $\$ 55,000$

$\$ 55,000$ to under $\$ 75,000$

$\$ 75,000$ to under $\$ 100,000$

$\$ 100,000$ and over

Prefer not to answer

Thank you for completing this survey. Please return this survey using the provided anonymous, postage paid envelope. Please do not sign or print your name on this survey or the return envelope. 


\section{References}

Agterbosch, S., Meertens, R., \& Vermeulen, W. (2009). The relative importance of social and institutional conditions in the planning of wind power projects. Renewable and Sustainable Energy Reviews 13, 393-405.

Aitken, M. (2010). Why we still don't understand the social aspects of wind power: A critique of key assumptions within the literature. Energy Policy 38, 1834-1841.

Baumgartner, F., \& Jones, B. (1993). Agendas and instability in American politics. Chicago: University of Chicago Press.

Baumgartner, F., Green-Pedersen, C., \& Jones, B. (2006). Comparative studies of policy agendas. Journal of European Public Policy 13 (7), 959-974.

Baxter, J., Eyles, J., and Elliott, S. (1999). From siting principles to siting practices. Journal of Environmental Planning and Management 42 (4), 501-525.

Baxter, K., Morzaria, R., \& Hirsch, R. (2013). A case-control study of support/opposition to wind turbines: Perceptions of health risk, economic benefits, and community conflict. Energy Policy 61, 931-943.

Beach, D., \& Pederson, R. (2010). Process tracing methods: Foundations and guidelines. Ann Arbor: University of Michigan Press.

Bedford, T., Clark, J., \& Harrison, C. (2002). Limits to new public participation practices in local land use planning. Town Planning Review, 73 (3), 311-331.

Bell, D., Gray, T., \& Haggett, C. (2005). The 'social gap' in wind farm siting decisions: Explanations

Bennett, A., \& Elman, C. (2006). Qualitative Research: Recent developments in case study methods. Annual Review of Political Science 9, 455-476.

Besley, J. (2012). Does fairness matter in the context of anger about nuclear energy decision making? Risk Analysis 32 (1), 25-38.

Bierle, T., \& D. Konisky. (2000). Values, conflict, and trust in participatory planning. Journal of Policy Analysis and Management 19 (4), 587-602.

Birkland, T. (1998). Focusing events, mobilization, and agenda setting. Journal of Public Policy 18 (1), 53-74.

Booth, K., and Harrison, K. (2009). The influence of institutions on issue definition: Children's environmental health policy in the United States and Canada. Journal of Comparative Policy Analysis 11 (3), 287-307. 
Brady H., \& Collier, D. (2004). Rethinking Social Inquiry: Diverse Tools, Shared Standards. Lanham, MD: Rowman Littlefield.

Breakwell, G. (2007). The psychology of risk. Cambridge: Cambridge University Press.

Breukers, S, \& M. Wolsink. (2007). Wind Power implementation in changing institutional landscapes: An international comparison. Energy Policy 35, 2737-2750.

Bruce County (n.d.). Retrieved from http://www.investingreybruce.com/en/introductionto-grey-bruce.html.

Bulkeley, H. (2001). Governing climate change: the politics of the risk society?

Transactions of the Institute of British Geographers, 430-447.

Caduff, L. \& T. Bernauer. (2006). Managing Risk and Regulation in European Food Safety Governance. Review of Policy Research 23 (1), 153-168.

Chong, D., \& J. Druckman. (2007a). Framing Theory. Annu. Rev. Polit. Sci. 10, 103-126.

Chong, D., \& J. Druckman. (2007b). Framing Public Opinion in Competitive Democracies. American Political Science Review 101 (4), 637-655.

Chong, D., \& J. Druckman. (2013). Counterframing effects. The Journal of Politics 75 (1), $1-16$.

Cobb, Roger and Marc Howard Ross, eds. (1997). Cultural Strategies of Agenda Denial. Lawrence, KS: University Press of Kansas.

Collier D, Mahoney J. (1996). Insights and pitfalls: selection bias in qualitative research. World Politics 49 (1), 56-91.

Collier, D. (2011). Understanding processing tracing. PS: Political Science and Politics $44(4), 823-830$.

Collier, D., H. Brady, \& J. Seawright (2010). Sources of leverage in causal inference: Toward an alternative view of methodology. In H. Brady and D. Collier (Eds.), Rethinking Social Inquiry. Plymouth: Rowman \& Littlefield

Dear, M. (1992). Understanding and overcoming the NIMBY Syndrome. Journal of American Planning Association 58(3), 288-300.

Deignan, B., Harvey, E., Hoffman-Goetz, L. (2013). Fright factors about wind turbines and health in Ontario newspapers before and after the Green Energy Act. Health, Risk, \& Society 15 (3), 243-250. 
Deitz, T., \& Stern, P. (2008). Public participation in environmental assessment decision making. Washington: The National Academies Press.

Deitz, T., \& Stern, P. (2008). Public participation in environmental assessment decision making. Washington: The National Academies Press.

Devine-Wright, P. (2011). Renewable energy and the public. London: Earthscan.

Devine-Wright, P., (2005). Beyond NIMBYism: towards an integrated framework for understanding public perceptions of wind energy. Wind Energy 8, 125-139.

Douglas, M. \& Wildavsky, A. (1982). Risk and Culture. Berkeley; Los Angeles; London: University of California Press.

Druckman, J. (2001). The Implications of Framing Effects for Citizen Competence. Political Behavior 23 (3), 225-256.

Dunn, S. (2010). Grey explores charter challenge to wind farms. Owen Sound Times. Retrieved from: http://www.owensoundsuntimes.com/2010/05/05/grey-explores-charterchallenge-to-wind-farms-2.

Executive Council of Ontario. (1990). Order in Council CH-87-03.

Ferguson-Martin, C., \& Hill, S. (2011). Accounting for variation in wind deployment between Canadian provinces. Energy Policy 39, 1647-1658.

Ferguson, R. (2009). McGuinty vows to stop wind-farm NIMBYs. The Toronto Star. Retrieved from:

http://www.thestar.com/news/ontario/2009/02/11/mcguinty_vows_to_stop_windfarm_ni mbys.html

George, A., \& Bennett, A. (2005). Case studies and theory development in the social sciences. Cambridge: MIT Press.

Gerber, B., \& G. Neeley. (2005). Perceived Risk and Citizen Preferences for Governmental Management of Routine Hazards. Policy Studies Journal 33 (3), 395-419.

Gerrard, M. (1994). Whose backyard, whose risk: Fear and fairness in toxic and nuclear waste siting. Cambridge: MIT Press.

Gerring, J. (2007). Case study research: principles and practices. Cambridge: Cambridge University Press.

Goertz G. (2006). Social Science Concepts: A User's Guide. Princeton, NJ: Princeton Univ. Press. 
Goertz, G., \& J. Mahoney. (2012). A Tale of Two Cultures. Princeton: Princeton University Press.

Government of Ontario. (1989). Environmental Assessment Board Decision CH87-03.

Green-Pedersen, C., \& Wilkerson, J. (2006). How agenda-setting attributes shape politics: Basic dilemmas, problem attention, and health politics developments in Denmark and the US. Journal of European Public Policy 13 (7), 959-974.

Gross, C. (2007). Community perspectives of wind energy in Australia: The application of a justice and community fairness framework to increase social acceptance. Energy Policy 35, 2727-2736.

Hall, P. (1986). Governing the economy: The politics of the state intervention in Britain and France. New York: Oxford University Press.

Hall, P. (1992). The movement from Keynesianism to monetarism: Institutional analysis and British economic policy in the 1970s. In S. Steinmo, K. Thelen, \& F. Longstreth (Eds.), Structuring politics: Historical institutional in comparative analysis (pp. 90-113). Cambridge: Cambridge University Press.

Hall, P. A., \& Taylor, R. (1996). Political science and the three institutionalisms. Political Studies 44, 936-957.

Hardin, R. (1998). Trust in government. In V. Braithwaite \& M. Levi (Eds.), Trust and Governance (pp. 197-217). New York: Russell Sage Foundation.

Hardin, R. (2006). Trust. Cambridge: Polity Press.

Harrison, K. (1991). Between science and politics: assessing the risks of dioxins in Canada and the United States. Policy Sciences 24 (4), 367-388.

Harrison, K, \& Hoberg, G. (1991). Setting the environmental agenda in Canada and the United States: The case of dioxin and radon. Canadian Journal of Political Science 24 (1), 3-27.

Heikkila, T., \& A. Gerlak. (2013). Building a Conceptual Approach to Collective Learning: Lessons for Public Policy Scholars. Policy Studies Journal 41 (3), 484-512.

Hermansson, H. (2007). The ethics of NIMBY conflicts. Ethic Theory and Moral Practice, 10, 23-34.

Hill, S., \& Knott, J. (2010). Too close for comfort: Social controversies surrounding wind farm noise setback policies in Ontario. Renewable Energy Law and Policy Review 153168. 
Horst, D. (2007). NIMBY or not? Exploring the relevance of location and the politics of voiced opinions

Hunter, S., \& Leyden, K. (1995). Beyond NIMBY: Explaining opposition to hazardous waste facilities. Policy Studies Journal, 23 (4), 601-619.

Jenkins-Smith, H., \& Kunreuther, H. (2001). Mitigation and benefits as policy tools for siting potentially hazardous facilities: Determinants of effectiveness and appropriateness. Risk Analysis 21 (2), 371-382.

Jobert, A., Laborgne, P., \& Mimler, S. (2007). Local acceptance of wind energy: Factors of success identified in French and German case studies. Energy Policy 35, 2751-2760.

Johns, C. (2008). Non-point source water pollution institutions in Ontario before and after Walkerton. In M. Sproule-Jones, C. Johns, \& B. T. Heinmiller (Eds.), Canadian Water Politics: Conflicts and Institutions (pp. 203-241). Montreal \& Kingston: McGillQueens University Press.

Johns, C. (2014). The Walkerton inquiry: Anatomy of success for an inquiry. In G. Inwood and C. Johns (Eds.) Commission of Inquiry and Policy Change (pp. 214-243). Toronto: University of Toronto Press.

Johnson, G. F. (2007). The discourse of democracy in Canadian nuclear waste management policy. Political Science 40, 79-99.

Kasperson, R. (2005). Siting hazardous facilities: Searching for effective institutions and processes. In J. Kasperson \& R. Kasperson (Eds.), The social contours of risk, Volume 1 (pp. 29-50). London: Earthscan.

Kasperson, R., Golding, D., \& Tuler, S. (2005). Social distrust as a factor in siting hazardous facilities and communicating risks. In J. Kasperson \& R. Kasperson (Eds.), The Social Contours of Risk, Volume 1 (pp. 29-50). London: Earthscan.

Kay, A. and P. Baker. (2014). What Can Causal Process Tracing Offer to Policy Studies? A Review of the Literature. Policy Studies Journal 43 (1), 1-21.

King, G., Keohane, R., \& Verba, S. (1994). Designing social inquiry. New Jersey: Princeton University Press.

Kingdon, J. (1995). Agendas, Alternatives, and Public Policies. New York: Harper Collins.

Klick, H., \& Smith, E. (2010). Public understanding of and support for wind power in the United States. Renewable Energy 35, 1585-1591. 
Kraft, M. \& Scheberle, D. (1995). Environmental justice ad the allocation of risk. Policy Studies Journal 23 (1), 113-122.

Kuhn, R. (1998). Social and political issues in siting a nuclear-fuel waste disposal facility in Ontario, Canada. Canadian Geographer 42 (1), 14-28.

Kuhn, R.G., Ballard, K.R., 1998. Canadian innovations in siting hazardous waste management facilities. Environmental Management 22, 533-545.

Kvale, S. (1996). Interviews: An introduction to qualitative research interviewing. London: Sage Publications.

Lecours, A. (2005). New institutionalism: Issues and questions. In A. Lecours (Ed.), New institutionalism: Theory and analysis (pp. 3-26). Toronto: University of Toronto Press.

Legge, J., \& Durant, R. (2010). Public opinion, risk assessment, and biotechnology:

Lessons from attitudes toward genetically modified foods in the European Union. Review of Policy Research 27 (1), 59-76.

Leiss, W. (2001). In the chamber of risks: Understanding risk controversies. Montreal: McGill-Queen's University Press.

Levi, M. (1997). Consent, dissent, and patriotism. Cambridge: Cambridge University Press.

Levi, M. (1998). A state of trust. In V. Braithwaite \& M. Levi (Eds.), Trust and governance (pp. 197-217). New York: Russell Sage Foundation.

Levi, M., A. Sacks. (2009). Legitimating beliefs: Sources and indicators. Regulation and Governance 3,

Ley, A., \& E. Weber. (2015). The Adaptive Venue Shopping Framework: How Emergent Groups Choose Environmental Policymaking Venues. Environmental Politics 24 (5), 703-722.

Li, Q., Fuhrman, M., Early, B., \& Vedlitz, A. (2012). Preferences, knowledge, and citizen probability assessments of the terrorism risk of nuclear power. Review of Policy Research 29 (2), 207-227.

Mahoney, J. (2012). The logic of process tracing tests in the social sciences. Sociological Methods and Research 41 (4), 570-597.

Mahoney, J., \& G. Goertz. (2006). A Tale of Two Cultures: Contrasting Quantitative and Qualitative Research. Political Analysis 14 (3), 227-249. 
Maney, A., \& Plutzer, E. (1996). Scientific information, elite attitudes, and the public debate over food safety. Policy Studies Journal 24 (1), 42-56.

March, J. G., \& Olsen, J. P. (1984). The new institutionalism: Organizational factors in political life. American Political Science Review, 78(3), 734-749.

McAvoy, G. (1998). Partisan probing and democratic decision-making: Rethinking the NIMBY syndrome. Policy Studies Journal, 26(2), 274-292.

McConnell, A. (2010). Understanding policy success: rethinking public policy. New York: Palgrave MacMillan.

McKinney, M., \& Harmon, W. (2002). Public Participation in environmental decision making: Is it working? National Civic Review, 91 (2), 149-170.

Miller, W., \& B. Crabtree. (2004). Depth Interviewing. In S. Hesse-Biber and P. Leavy (Eds.), Approaches to Qualitative Research (pp. 185-202). Oxford: Oxford University Press.

Mills, S., Borick, C., Gore, C., \& Rabe, B. (2014). Wind energy development in the Great Lakes regions: Current issues and public opinion. Energy ad Environmental Initiative.

Ministry of Environment (1998). Provisional Certificate of Approval No. 253106.

Mitchell, B. (2005). Participatory partnerships: engaging and empowering to enhance environmental management and quality of life? Social Indicators Research, 71, 123-144.

Montpetit, E. (2005). Westminster parliamentary, policy networks, and the behavior of political actors. In A. Lecours (Ed.), New institutionalism: Theory and analysis (pp. 225244). Toronto: University of Toronto Press.

Montpetit, E., \& Rouillard. (2008). Culture and democratization of risk management: The widening biotechnology gap between Canada and France. Administration and Society 39 (8), 907-930.

Moore, A. (2009). Passing the buck: The Ontario Municipal Board and local politicians in Toronto, 2000-2006. Paper presented at the Canadian Political Science Association meeting in Ottawa, Ontario.

Moore, A. (2013). Planning Politics in Toronto. Toronto: University of Toronto Press.

Moravcsik, A. (2014). Transparency: The Revolution in Qualitative Research. PS:

Political Science and Politics 47 (1), 48-53.

North, D. C. (1990). Institutions, institutional change and economic performance. New York: Cambridge University Press. 
Olson, M. (1965). The logic of collective action. Harvard University Press.

Ontario Municipal Board (2007). Decision 1989: PL060986.

Ontario. (2009). Bill 150 green energy and green economy act 2009. Toronto: Government of Ontario.

Ostrom, E. (1990). Governing the commons. Cambridge: Cambridge University Press.

Ostrom, E. (2005). Understanding institutional diversity. New Jersey: Princeton University Press.

Palfreman, J. (2006). A tale of two fears: Exploring media depictions of nuclear power and global warming. Review of Policy Research 23 (1), 23-43.

Peters, B. G. (1999). Institutional theory in political science. London: Continuum.

Peters, B. G. (2008). Institutional theory: problems and prospects. In J. Pierre, B. G. Peters, \& G. Stoker (Ed.), Debating Institutionalism (pp. 1-21). Manchester: Manchester University Press.

Pierson, P. (2000). Increasing returns, path dependence, and the study of politics.

American Political Science Review, 94 (2), 251-267.

Pollara (2006). Report submitted to Bruce County Planning.

Poteete, A., Janssen, M., \& Ostrom, E. (2010). Working together: Collective action, the commons, and multiple methods in practice. Princeton: Princeton University Press.

Pralle, S. (2003). Venue shopping, political strategy, and policy change: The internationalization of Canadian forest advocacy. Journal of Public Policy 23 (3), 233 260.

Pralle, S. (2006a). Branching out, digging in: Environmental advocacy and agenda setting. Washington: Georgetown University Press.

Pralle, S. (2006b). Timing and sequence in agenda setting and policy change: a comparative study of lawn care pesticides politics in Canada and the United States. Journal of European Public Policy 13, 987-1005.

Pralle, S. (2006c). The "mouse that roared": Agenda setting in Canadian pesticides politics. The Policy Studies Journal 34 (2), 171-194. 
Pralle, S. (2010). Shopping around: environmental organizations and the search for policy venues. In A. Prakash \& M. Gugerty (Eds), Advocacy Organizations and Collective Action. Cambridge: Cambridge University Press.

Pralle, S. \& Boscarinno, J. (2011). Framing trade-offs: The politics of nuclear power and wind energy in the age of global climate change. Review of Policy Review 28 (4), 323346.

Princen, S. (2007). Agenda setting in the European Union: A theoretical exploration and agenda for research. Journal of European Public Policy 14 (1), 21-38.

Puschak, R., \& Rocha, C. (1998). Failing to site hazardous waste facilities voluntarily: Implications for the production of sustainable goods. Journal of Environmental Planning and Management 41(1), 25-43.

Rabe, B. (1994). Beyond NIMBY: hazardous waste siting in Canada and the United States. Washington D.C: The Brookings Institution.

Ragin, C. (1987). The comparative method: Moving beyond qualitative and quantitative strategies. Berkley: University of California Press.

Rea, L., \& Parker, R. (2005). Designing and conducting survey research. San Francisco: John Wiley \& Sons.

Renn, O., \& Schweizer, P. (2009). Inclusive risk governance: Concepts and applications to environmental policy making. Environmental Policy and Governance 19 (3), 174-185.

Rippl, S. (2002). Cultural theory and risk perception: a proposal for a better measurement, Journal of Risk Research 5, 147-165.

Rochefort, D. A., \& Cobb, R.W. (1994). The politics of problem definition. Lawrence, KS: University Press of Kansas.

Roe E. (1994). Narrative Policy Analysis: Theory and Practice. Durham, NC: Duke Univ. Press.

Rothstein, B. (2005). Social traps and the problem of trust. Cambridge: Cambridge University Press.

Rowlands, I. (2007). The development of renewable electricity policy in the province of Ontario: The influence of ideas and timing. Review of Policy Research 24 (3), 185-207.

Rowlands, I. (2009). Renewable electricity: The prospects for innovations and integration in provincial policies. In D. VanNijnatten and R. Boardman (Eds.) Canadian Environmental Policy and Politics, 167-182. 
Rubin, J. (1994). Models of conflict management. Journal of Social Issues 50 (1), 33-45.

Sabatier, P., \& Jenkins-Smith. (1988). An advocacy coalition model of policy change and the role of policy orientated learning therein. Policy Sciences 21, 129-168.

Sabatier, P., \& Jenkins-Smith. (1993). Policy Change and Learning: An Advocacy

Coalition Approach. Colorado: Westview Press.

Schattschneider, E. (1960). The Semisovereign People. Boston: Wadsworth.

Scharpf, F. (1997). Games real actors play. Cambridge: Westview Press.

Scheberle, D. (1994). Radon and Asbestos: A study of agenda setting and causal stories. Policy Studies Journal 22 (1), 74-86.

Schively, C. (2007). Understanding the NIMBY and LULU phenomena: Reassessing our knowledge base and informing future research. Journal of Planning Literature 21(3), $255-266$

Schmidt, Vivien. 2008. "Discursive Institutionalism: The Explanatory Power of Ideas and Discourse." Annual Review of Political Science 11 (2008): 303-26.

Schneider, A., \& Ingram, H. (1993). Social construction of target populations:

Implications for politics and policy. American Political Science Review 87 (2), 334-346.

Scholz, J. (1998). Trust, taxes, and compliance. In V. Braithwaite \& M. Levi (Eds.), Trust and governance (pp. 197-217). New York: Russell Sage Foundation.

Scholz, J., \& Lubell. (1998). Trust and taxpaying: Testing the heuristic approach to collective action. American Journal of Political Science 42(2), 398-417.

Siegrist, M., \& Cvetkovich, G. (2000). Perceptions of hazards: The role of social trust and knowledge. Risk Analysis 20 (5), 713-719.

Simcoe County (n.d.). http://edo.simcoe.ca/stats/index.htm.

Sjoberg, L., \& Drotz-Sjoberg, B. (2009). Public perceptions of nuclear waste. International Journal of Risk Assessment and Management 11 (3/4), 264-296.

Slovic, P. (1987). Perceptions of Risk. Science, 236 (4799), 280-285.

Slovic, P. (1993). Perceived risk, trust, and democracy. Risk Analysis, 13(6), 675-682.

Slovic, P., Fischhoff, B. \& Lichtenstein, S. (1982). Why study risk perception? Risk Analysis 2 (2), 83-93. 
Slovic, P., Peters, E., Finucane, M., \& MacGregor. R. (2005). Affect, risk, and decision making. Health

Smith, G. (2005). Democratic deliberation and environmental policy; Opportunities and barriers in Britain. In R. Paehlke \& D. Torgerson (Eds.), Managing leviathan:

Environmental politics and the administrative state (pp. 81-96). Peterborough:

Broadview Press.

Smith, K., \& Larimer, C. (2013). The Public Policy Theory Primer. Colorado: Westview Press.

Smith, M. (2005). Institutionalism in the study of Canadian politics: The EnglishCanadian tradition. In A. Lecours (Ed.), New institutionalism: Theory and analysis (pp. 101-127). Toronto: University of Toronto Press.

Songsore, E. \& Buzzelli, M. (2014). Social responses to wind energy development in Ontario: The influence of health risk perceptions and associated concerns. Energy Policy 69, 285-296.

Spears, J. (2013). Ontario cabinet ministers told to smooth out wind turbine conflict. The Toronto Star. May 15. Retrieved from:

http://www.thestar.com/business/2013/05/15/ontario_cabinet_ministers_told_to_smo oth_out_wind_turbine_conflict.html

Sproule-Jones, M. (1993). Governments at work: Canadian parliamentary federalism and its public policy effects. Toronto: University of Toronto Press.

Sproule-Jones, M., Johns, C., \& Heinmiller, T. (2008). Canadian water politics: Conflicts and institutions. Montreal: McGill-Queen's University Press.

Stewart, P., \& McLean, W. (2008). Public perceptions of benefits and worries over plantmade industrial products and plant-made pharmaceuticals: The influence of institutional trust. Review of Policy Research 25 (4), 333-348.

Stokes, L. (2014). The politics of renewable energy policies: The case of feed-in tariffs in Ontario, Canada. Energy Policy 68,

Stone, D. (1989). Policy Paradox $3^{\text {rd }}$ Edition. New York: Norton and Company.

Tansey, O. (2007). Process tracing and elite interviewing: A case for non-probability sampling. PS: Political Science and Politics 40 (4), 765-772.

Taylor-Gooby, \& Zinn. (2006). Current Directions in Risk Research: New Developments in Psychology and Sociology. Risk Analysis 26 (2), 397-411. 
Thelen, K. (1999). Historical institutionalism in comparative politics. Annual Review of Political Science, 2, 369-404.

Timmermans, A (2001). Arenas as institutional sites for policymaking: Patterns and effects in comparative perspective. Journal of Comparative Policy Analysis 3, 311-337.

Tsebelis, G. (2002) Veto Players. How Political Institutions Work, New York: Russell Sage Foundation.

Upreti, B., \& van der Horst, D. (2004). National renewable energy policy and local opposition in the UK: the failed development of a biomass electricity plant. Biomass and Bioenergy 26, 61-69.

Valentine, S. (2010). Canada's constitutional separation of (wind) power. Energy Policy 38, 1918-1930.

Van der Horst, D. (2007). NIMBY or not? Exploring the relevance of location and the politics of voiced opinions in renewable energy siting controversies. Energy Policy 35, 2705-2714.

Van Evera, Stephen (1997) Guide to Methods for Students of Political Science. Ithaca: Cornell.

Wakefield, S., \& Elliott, S. (2000). Environmental risk perception and well being; Effects of the landfill siting process in two Southern Ontario communities. Social Science and Medicine 50, 1139-1154.

Warren, C., Lumsden, C., O’Dowd, S., \& Birnoe, R. (2005). Green on green: Public perceptions of wind power in Scotland and Ireland. Journal of Planning and Management 48 (6), 853-875.

Watson, I., Betts, S., \& Rapaport, E. (2012). Determining appropriate wind turbine setback distances: Perspectives from municipal planners in the Canadian provinces of Nova Scotia, Ontario, and Quebec. Energy Policy 41, 782-789.

Whitfield, S., Rosa, E., Dan, A., \& Dietz, T. (2009). The future of nuclear power: Value orientations and risk perception. Risk Analysis 29 (3), 425-437.

Wolsink, M. (2000). Wind power and the NIMBY-myth: Institutional capacity and the limited significance of public support. Renewable Energy 21, 49-64.

Wolsink, M. (2007). Planning of renewable schemes: Deliberative and fair decisionmaking on landscape issues instead of reproachful accusations of non-cooperation. Energy Policy 25, 2692-2704. 
Wolsink, M. (2007a). Wind power implementation: The nature of public attitudes: Equity and fairness instead of 'backyard motives'. Renewable \& Sustainable Energy Reviews 11, 1188-1207.

Wolsink, M. (2007b). Planning of renewables schemes: Deliberative and fair decisionmaking issues instead of reproachful accusations of non-cooperation. Energy Policy 35, 2692-2704.

Wustenhagen, R., Wolsink, M., \& Burer, M. (2007). Social acceptance of renewable energy innovation: An introduction to the concept. Energy Policy 35, 2683-2691.

Yatchew, A., \& Baziliauskas, A. (2011). Ontario feed-in-tariff programs. Energy Policy 39, 3885-3893.

Yin, R. (1994). Case study research: design and methods. London: Sage Publications.

Zerbe, N. (2007). Risking regulation, regulating risk: Lessons from the Transatlantic biotech dispute. Review of Policy Research 24 (5), 407-423. 